\title{
Evidence-based pathway for solid waste modernisation and sustainability in Ghana
}

Citation for published version (APA):

Oduro-Appiah, K. (2020). Evidence-based pathway for solid waste modernisation and sustainability in Ghana. [Doctoral Thesis, Maastricht University]. ProefschriftMaken. https://doi.org/10.26481/dis.20200902ko

Document status and date:

Published: 01/01/2020

DOI:

10.26481/dis.20200902ko

Document Version:

Publisher's PDF, also known as Version of record

\section{Please check the document version of this publication:}

- A submitted manuscript is the version of the article upon submission and before peer-review. There can be important differences between the submitted version and the official published version of record.

People interested in the research are advised to contact the author for the final version of the publication, or visit the DOI to the publisher's website.

- The final author version and the galley proof are versions of the publication after peer review.

- The final published version features the final layout of the paper including the volume, issue and page numbers.

Link to publication

\footnotetext{
General rights rights.

- You may freely distribute the URL identifying the publication in the public portal. please follow below link for the End User Agreement:

www.umlib.nl/taverne-license

Take down policy

If you believe that this document breaches copyright please contact us at:

repository@maastrichtuniversity.nl

providing details and we will investigate your claim.
}

Copyright and moral rights for the publications made accessible in the public portal are retained by the authors and/or other copyright owners and it is a condition of accessing publications that users recognise and abide by the legal requirements associated with these

- Users may download and print one copy of any publication from the public portal for the purpose of private study or research.

- You may not further distribute the material or use it for any profit-making activity or commercial gain

If the publication is distributed under the terms of Article $25 \mathrm{fa}$ of the Dutch Copyright Act, indicated by the "Taverne" license above, 


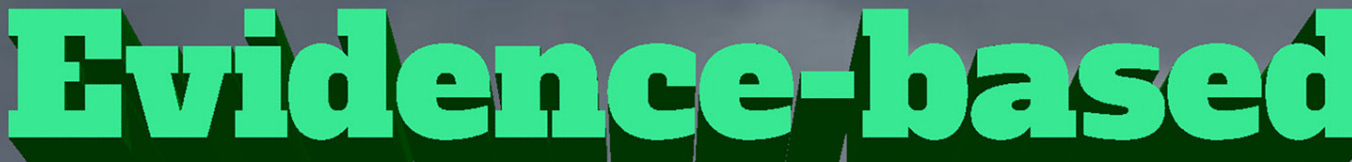 \\ pathway or sold waste-}

moderniseton and-sustaintbility

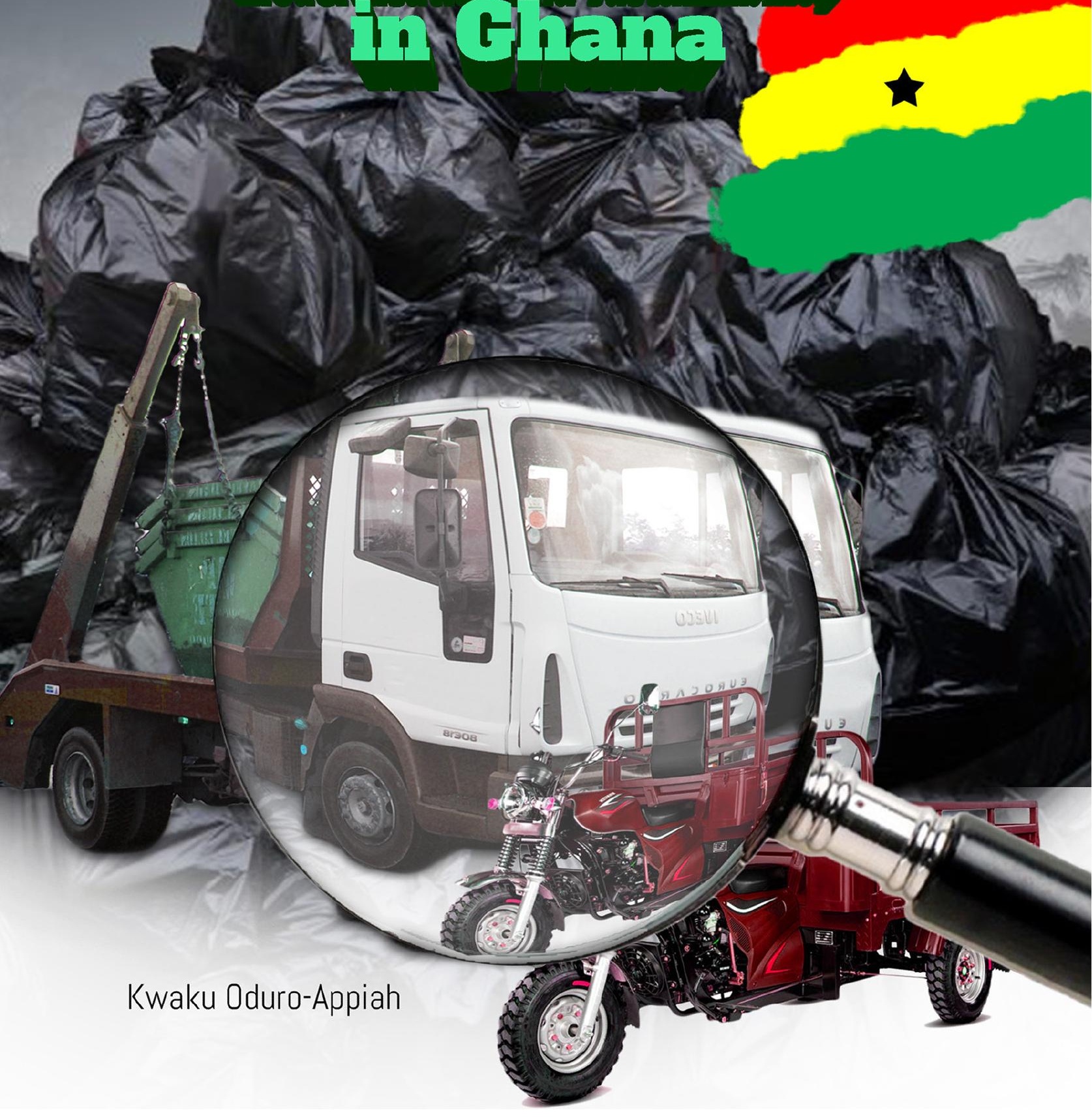





\section{Evidence-based pathway for solid waste modernisation and sustainability in Ghana}


Evidence-based pathway for solid waste modernisation and sustainability in Ghana

(C) copyright Kwaku Oduro-Appiah, Maastricht 2020

Printing: ProefschriftMaken II www.proefschriftmaken.nl

Publisher: Global Academic Press

NUR: 973

ISBN: 978-94-6380-884-2

All rights reserved. No part of this publication may be reproduced, stored in a retrieval system, in any form or by any means, electronic, mechanical, photocopying, recording or otherwise, without prior permission of the author for the copyright-owning journals for previous published chapters. 


\section{Evidence-based pathway for solid waste modernisation and sustainability in Ghana}

\section{DISSERTATION}

to obtain the degree of Doctor at the Maastricht University,

on the authority of the Rector Magnificus Prof. Dr. Rianne M. Letschert in accordance with the decision of the Board of Deans,

to be defended in public

on Wednesday 2 September 2020

by

Kwaku Oduro-Appiah 
Supervisor:

Prof. Dr. N.K. de Vries

Co-supervisor:

Dr. A. Scheinberg (Springloop Cooperatie U.A. Zwolle)

Assessment Committee

Prof. Dr. R. Crutzen (Chair)

Prof. Dr. S. Kremers

Prof. Dr. S. Ramani

Dr. Ir. B.J.M. van Vliet (Wageningen University)

Dr. L. Oyake-Ombis (ALISE Consulting Group Nairobi, Kenya) 
To my wife, Gifty Oduro-Appiah and children;

Frimpomaah, Konamah and Kofi.

Thank you for the time, energy and sacrifices you made along this journey.

To my parents Samuel Oduro-Brobbey and

Comfort Abena Frimpomaah

Your efforts have not been in vain. 
"Two roads diverged in a wood, and I- I took the one less traveled by, and that has made all the difference". Robert Frost 


\section{Table of Contents}

Chapter 1 General Introduction

Chapter 2 Assessment of the municipal solid waste management system in Accra, Ghana: A 'WasteAware' benchmark indicator approach

Chapter 3 Locally responsive intervention to improve municipal solid waste collection coverage in Accra, Ghana

Chapter 4 Working with the informal service chain as a locally appropriate strategy for sustainable modernisation of municipal solid waste management systems in lower-middle income cities: Lesson from Accra, Ghana

Chapter 5 The contribution of participatory engagement strategies to reliable data gathering and inclusive policies in developing countries: Municipal solid waste management data in the greater Accra metropolitan area of Ghana

Chapter 6 Existing realities and sustainable pathways for solid waste management in Ghana

Chapter 7 General Discussion

References

Valorisation Addendum

Summary

Acknowledgements

Curriculum Vitae

Publication List

Abbreviations 


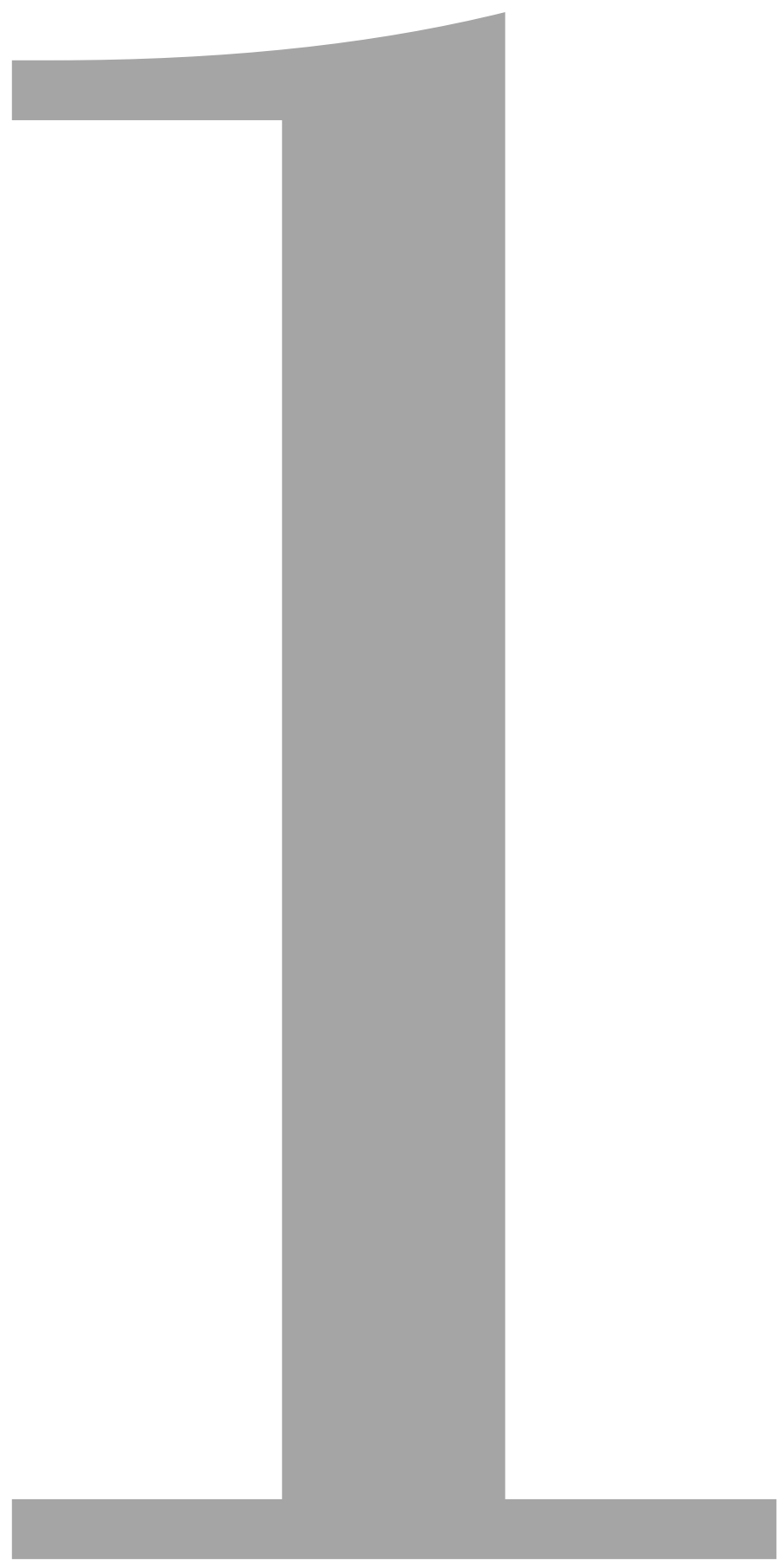




\section{Chapter 1}

\section{General Introduction}




\section{Introduction}

Solid waste management (SWM) has been considered, since early experiences with urbanisation, as one of the essential public services for human development. Although it is comparable to improved sanitation services, potable water and stable electricity supply, it seldom receives comparable attention or financing (Wilson et al., 2015b; Wilson et al., 2017; Scheinberg, 2011).

In the developed global North, the "public good" of the value of public health, environmental protection, resource management, and service user awareness and participation has for decades driven the solid waste management system towards modernisation and effectiveness (Wilson, 2007; Marshall and Farahbakhsh, 2013). The end of the $20^{\text {th }}$ century witnessed two new drivers: resource scarcity and climate change, which with facilitation from technological innovations has further driven the system towards efficiency and sustainability. In North America, Europe, high-income Asia, and some Oceania countries, continuous but stringent legislation and regulation based on these triggers ("drivers") has shifted the focus from collection and removal of solid waste, to environmentally sensitive disposal and resource management. Changing policy landscapes such as the solid waste hierarchy, extended producer responsibility, sustainable consumption and production, the circular economy and the green economy have both resulted from and driven the shifting solid waste policy frame.

This has not been the case for cities in most developing countries. The solid waste management of cities like Accra, Ghana, has more often than not been triggered by disaster management, exacerbated over time by issues of urbanisation, inequality, socioeconomic challenges, weak technical capacities, international influences, and poor governance systems (Marshall and Farahbakhsh, 2013; Cossu et al., 2019). Despite the fact that, the scholarly literature projects a more than $300 \%$ increase in solid waste generation rates in cities like Accra by the year 2050 (Kaza et al., 2018), the real-life waste system (ironically) is characterised by low collection coverage, uncontrolled forms of disposal, relatively low recycling rates, dissatisfied users, and limited infrastructure (UNEP, 2018; Bundhoo, 2018).

The wisdom and much of the literature ascribes low performance of the physical systems of waste management in cities to weak governance characterised by limited financial resources; low technical and human resource capacities; absence of national solid waste strategic plans and/or regulatory frameworks; and the lack (or absence) of data and research-based decision-making (UNEP, 2018; Leal Filho et al., 2016; Mmereki et al., 2016; Asase et al., 2009; Guerrero et al., 2013). 
Persistent attempts of the Ghana national government and professional staff at city level, to find lasting solutions to these challenges, creates a continuous stream of environmentaland public health crises. Such crises open up a window of opportunity for development partners and international financial institutions to intervene, in the assumption that globalised ideas will contribute to beneficial and sustainable improvements in the waste system (Achankeng, 2003). In the process, investment financing, complex technology transfer and market-oriented approaches (e.g. private sector participation, deregulation etc.) dominate, because they are familiar and are credited with having contributed to the SWM modernisation in the global North. The promise of technology transfer appears to be "quick fix" to stimulate the transition. Yet increasingly, there are questions as to whether "technology transfer" can offer sustained progress or even solve specific problems (Wilson et al., 2017; Cossu et al., 2019).

A review of the literature confirms that such approaches have - for more than four decades- structurally failed to contribute to processes that sustainably modernise solid waste management systems in Accra and comparable cities in developing countries (Marshall and Farahbakhsh, 2013; Oteng-Ababio et al., 2013). The country and especially the capital city Accra, has been at the receiving end of a confusing overlap of short-term donor-financed projects. And so after more than 60 years of independence from British colonial rule, it has become more of a challenge to find practical and locally appropriate strategies for the country to organise sustainable solid waste management finance, modernise policies, and promote inclusive governance.

Political expediency, complexity of technology transfer, limited skilled and technical education, lack of appraisal of the local situation and dynamics, and the refusal of both development partners and the national government to undertake the necessary stakeholder engagement in producing participatory baseline studies to inform change and guide intervention patterns are reported to be among the factors contributing to the SWM system failure in Ghanaian and other developing countries cities (Awortwi, 2004; Cossu et al., 2019; Guerrero et al., 2013; Obirih-Opareh and Post, 2002; Oteng-Ababio et al., 2013; Marshall and Farahbakhsh, 2013; Wilson et al., 2017; Ali, 2010).

Despite these recurring challenges, decision-makers and practitioners in the solid waste are still without any globally endorsed instructions or blueprints that give them practical guidance on how to improve the existing situation and reach better outcomes. Specifically, such leaders in Ghana do not have any coherent solid waste strategy, nor do policy-makers and managers of waste in Ghanaian cities have access to realistic strategies that would lead to a continuous and systematic improvement of the system. 
Those charged with solid waste management lack the technical capacity and financial resources to collect reliable data for planning purposes, neither do they make any significant effort to collaborate with research and academic institutions to close these gaps. Where some form of data exists, it generally is more than two decades old, has been on assumptions that are not transparent, and thus are neither reliable nor applicable to the current system. More often than not, such data has been produced by consultants using international reference data, in a project without active participation of the system managers and service providers and; creating problems of data recognisability, ownership and usage. Such structural information gaps hinder professional staff from assessing their solid waste systems. Rather than helping, the system of donors and consultants fails the direct managers the opportunity of identifying what works well within the system and what needs fixing; and so they own neither the problem nor the proposed solutions.

Franchise agreements for solid waste service delivery in Ghana are mostly signed with formal companies who consistently fail to deliver system improvements. Ironically, in most urban cities of Ghana and other developing countries, the reality is often better than the reports, due to the presence of a large variety of informal actors (both in the service- and value-chains) who are contributing to system improvement through collection, recovery and recycling at no cost to city authorities. Paradoxically, the system hardly recognises their efforts and do not involve them in decision-making and planning processes (Ezeah et al., 2013; Wilson et al., 2006; Oteng-Ababio, 2012; Oteng-Ababio et al., 2017).

As a result, the entire solid waste management system runs on ad hoc policies and on donor-financed projects which mostly do not have the option to be operated to scale, and usually lack sustainability plans. This denies professional staff and city authorities the institutional space to develop holistic and integrated intervention programs for implementation and evaluation.

Addressing these challenges and problems is necessary and urgent but moving away from earlier technologically-oriented and conventional top-down approaches (which has proven a failure for four decades) to locally appropriate, participatory action researchoriented and inclusive alternatives is critical, especially if the physical components and the governance aspects of the solid waste management system, and the demands of the sustainable development goals are to be met in Ghana and its sister Sub-Saharan African countries. 


\section{Human civilisations, settlements, history and drivers of solid waste management}

\section{The highly industrialised and developed worlds}

Despite the fact that solid waste has existed in some form since the earliest days of human history, institutionalised solid waste management as practised today commenced only in the middle of the $20^{\text {th }}$ century (Worrell and Vesilind, 2011). Although the literature reports the existence of possible solid waste collection and disposal systems and laws in cities in India, Greece and China between 2000 BC and 200 BC (Worrell and Vesilind, 2011; Marshall and Farahbakhsh, 2013), most reports of urbanisation in 'pre-modern' civilisations show they were dumping solid waste just within and the outskirts of their cities. The cities of Europe are reported to have been living in filth from the beginning of the Common Era through to the middle ages resulting in the periodic cataclysmic pandemics such as the Plague of Justinian (541-542 AD) and the Black Death (1347$1351 \mathrm{AD})$, which killed tens of millions of people especially within the cities and had a major impact on the societies as a whole.

The industrial revolution and accompanying waves of urbanisation in Europe and North America in the middle of the $19^{\text {th }}$ century brought an intensification of overpopulation and overcrowding in urban areas to earlier unknown levels, fostering new and overwhelming challenges in solid waste management and sanitation. This, coupled with poverty, drove some of the urban poor in European and American cities to separate and pick the valuable items within the heaps of waste in the cities to sell for a living (Wilson et al., 2015b; Louis, 2004; Velis et al., 2009); a practice which still occurs in cities of developing and lesser developed countries to this day (Meyer, 2019; Velis, 2017; Scheinberg et al., 2010b).

Perhaps the first major driver (public health) for collection of solid waste from doorsteps, streets, residential and commercial centres has its origins in the cholera outbreaks of Europe and North America in the middle of the $19^{\text {th }}$ century; after a causal link was made between disease and filth (Worrell and Vesilind, 2011; Wilson et al., 2015b). The collected solid waste was burned openly or disposed of in uncontrolled dumps with related direct and indirect environmental impacts on air quality, water and the soil. Reuse and recycling which arose in the $19^{\text {th }}$ century as a by-product of industrialisation, was until the 1970s, still largely a private sector activity with the resource value of the waste as the main driver (Scheinberg, 2011; Velis et al., 2009).

The ideas of both environmental control and resource management as policy impulses for the modernisation of solid waste management were absent until the emergence of environmental regulations protecting groundwater in the last third of the $20^{\text {th }}$ century. 
Growing scientific proof of the connections between land disposal and contaminated drinking water compelled politicians to commence the formation of environmental protection agencies and the subsequent development of policies, legislative instruments and regulations to protect the environment (Scheinberg et al., 2010b; Scheinberg, 2003). Since then, a combination of technical know-how, institutional development, and economic and governance innovations has fuelled continuous development of stringent environmental regulations and strengthened the role of the environmental control in solid waste management. The immediate and dramatic result was the introduction of tipping fees and the consequent rapid increase in the costs of waste management.

In addition to the drive to divert recyclable materials from using expensive and scarce space in sanitary landfills, concerns of climate change due to the emission of methane gas related to the anaerobic decomposition of organic waste, has rekindled interest in the diversion of organic and recyclable waste from municipal landfills. These two (mutually dependent) factors, cost and pollution control have combined to contribute to significant investment in recycling which has led to high diversion rates in most industrialised countries (Scheinberg et al., 2010b). This climate change driver in addition to concerns of resource scarcity has promoted the development of many policy initiatives ranging from the solid waste hierarchy to the current circular and green economies.

\section{The developing and lesser developed worlds}

Developing countries, especially those of the global South, have a very different history and their solid waste management systems are driven by different factors. Perhaps a mix of the lack of an industrial revolution, the socio-political consequences of colonisation and independence, and the seeming absence of systematic effort on the part of these countries towards modernisation has contributed to the shape and characteristics of the current solid waste management systems. The reality in most cities of the developing and the lesser developed world is that public health remains the major driver of solid waste management, even after almost two centuries since the first attempt to clean and collect solid waste away from communities commenced in the developed world (Scheinberg et al., 2010b; Scheinberg, 2011).

In recent years globalisation has been replacing industrialisation as the driver of urban growth, increased flow of goods and services, changing lifestyles and consumption patterns and their attendant solid waste management challenges; the impulses from outside have the effect of further denying these cities a $100 \%$ coverage for street cleaning, removal and collection service (Achankeng, 2003). Globalisation has virtually transformed the economies of developing countries, (especially those in Sub-Saharan Africa) into informal ones and further stimulated the unsustainable transfer of solid waste management technologies from the developed world which have been failing for 
almost four decades. The dependence on the developed world for ideas and technology has proved unsustainable in developing countries; creating downward spirals of dependency and greatly diminishing the institutional space for public and private sector professionals to map an autonomous path for modernisation.

Into the service void left by unsatisfactory performance of solid waste systems based on imported and inappropriate technologies, a large and vital informal waste and recycling sector has grown up, based on individual and family livelihood models to provide removal services and valorise recyclables picked from uncontrolled landfills. Small individual and family enterprises operating in the spaces left by overcapitalised formal systems contribute consistently to providing clean streets and directing recyclables diverted from disposal to the value chains, thereby increasing recycling rates. Their effectiveness is proven, albeit at a documented huge social and environmental cost (Wilson et al., 2015b). The environmental protection driver has simply not been a priority in lowand middle-income country cities, and neither is user participation in decision-making promoted. Despite the role and contribution of the informal waste sector towards increased collection and recycling rates across these cities (Linzner and Lange, 2013; Wilson et al., 2013), authorities have failed to recognise them as useful service- and value-chain actors towards the solid waste management system modernisation.

\section{An overview and chronology of solid waste management in Ghana}

Ghana is a lower-middle income republic along the West African Coast with a gross national income (GNI) per capita of US $\$ 1880.00$ (World Bank, 2019). It is bordered by Ivory Coast to the West, Togo to the East, Burkina Faso to the North and the Gulf of Guinea to the South (Figure 1.1). Ghana was the first country in Sub-Saharan Africa to gain independence from British colonial rule in 1957. It consists of 16 administrative regions, 260 Metropolitan, Municipal and District Assemblies (MMDAs), and covers an area of $238,539 \mathrm{~km}^{2}$. The country is home to an estimated $30,280,811$ inhabitants (Ghana Statistical Services, 2019). The average municipal solid waste (MSW) generation rate is estimated to be 5,389, 984 tons per year and the four largest household waste composition categories in Ghana are biodegradable waste (61\%), plastic (14\%), paper (5\%) and metals (2\%) (Miezah et al., 2015).

\section{Pre-colonial and colonial times}

Solid waste management in Ghana ("the Gold Coast", as it was previously called) before colonisation was similar to the circumstances that prevailed in industrialised Europe and North America in the first half of the $19^{\text {th }}$ century. The indigenous people lived in unplanned settlements and had public health challenges with solid waste management and sanitation. Chiefs and kings ruled and solid waste management was neither organised 
nor was it provided as a discrete service of its own. In fact, solid waste management in the Gold Coast had always been confused with general sanitation services; with the removal of faecal matter being considered more urgent and of higher priority in comparison to solid waste collection and disposal services.

In those times, most of the solid waste generated was from municipal sources with the largest proportion consisting of household waste; which was partly fed back to livestock or dumped in backyard gardens to support the growth of cultivated crops. The rest were dumped on community dumps, burned or buried. That is, each household and community managed their solid waste as they deemed fit, using their own resource base as both "market" and "sink" (Asomani-Boateng and Haight, 1998; Obirih-Opareh and Post, 2002). As the towns grew, waste leaked out of private compounds and exceeded the capacity of households to manage it, creating unsanitary conditions. This contributed (in addition to security concerns) to the practice of colonial expatriates choosing to live in coastal forts constructed on hills overlooking the native settlements and with easy access to the sea as receiver of their waste and offal (Mills-Tettey, 2013).

Solid waste management received a boost during the early years of colonisation, especially with the movement of the British colonial administrative capital from Cape Coast to Accra in 1877. The first Public Health Act: the Towns, Police and Public Health Ordinance, was enacted in 1878 , mandating town councils to provide urban services related to refuse collection and disposal, sanitation, potable drinking water, street lighting, markets and slaughterhouses (Asomani-Boateng and Haight, 1998; Mills-Tettey, 2013). Despite the existence of the law, enforcement was weak and this in addition to the huge cost of sanitation to the colony led to the outbreak of plague in 1908 (Addae, 1996).

The plague was perhaps a turning point in solid waste management and sanitation for the country: environmental sanitation and the health impacts of poor management caught the attention of the medical establishment for the first time. In 1910, a sanitary branch of that department was established to basically oversee the proper disposal of sewage (Mills-Tettey, 2013). Almost a decade prior to independence, there was the establishment of town councils to provide general public toilet services and infrastructure for the cities, and sanitary inspectors were trained to ensure the compliance of communities to sanitary practices; but these in themselves did not lead to any significant improvement in the sanitary conditions of the cities.

\section{Post-independence times}

Ghana was the first Sub-saharan country to gain independence from British colonial rule in 1957. But even after independence, up to the late 1980's there was still no 


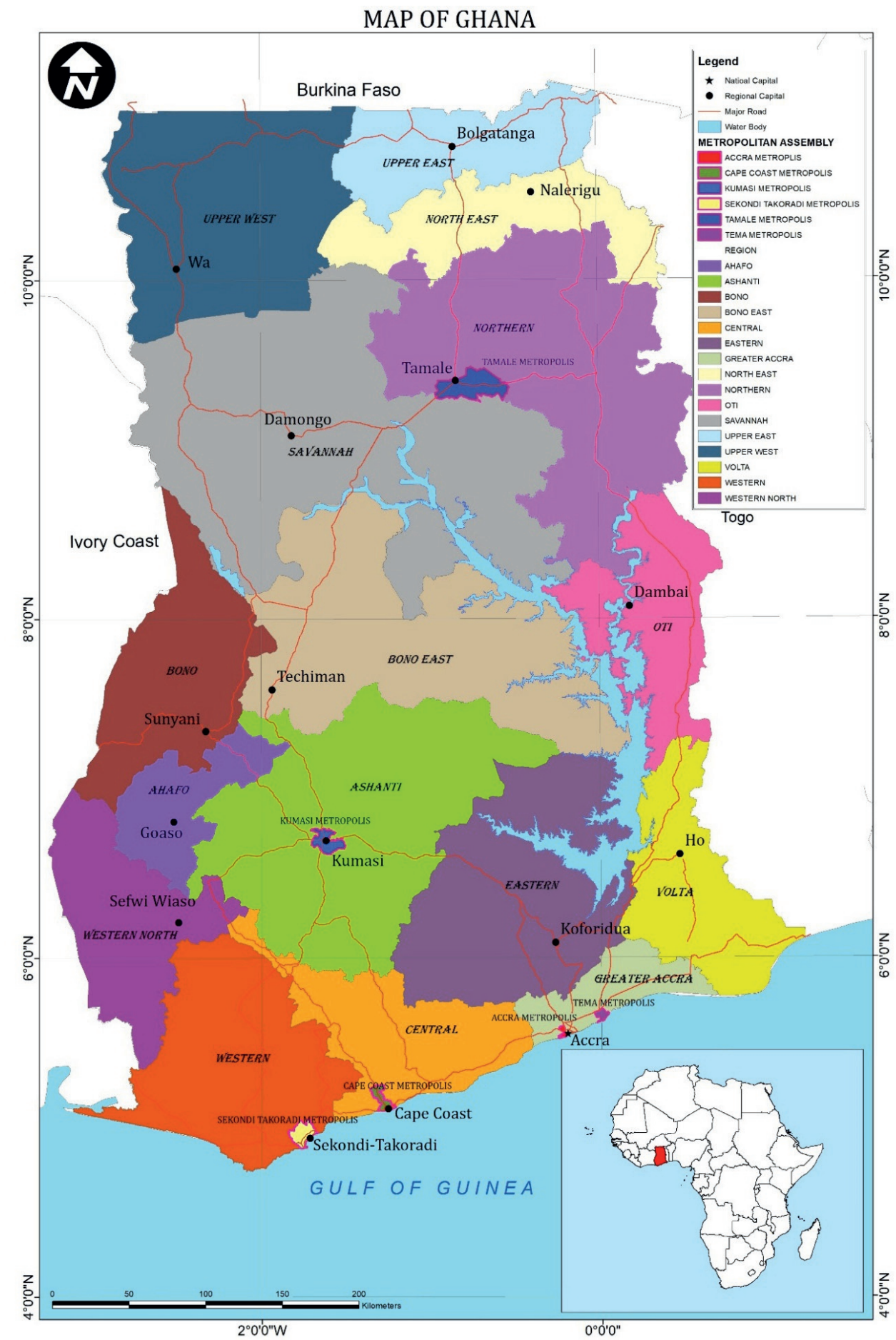

Figure I.I: Map of Ghana showing the regions and boundaries to neighbouring countries. Source: The author, 2019. 
organisation properly constituted nor charged to manage solid waste generated within its cities. Residents deposited their solid waste on nearby low-value lands (frequently wetlands), creating small uncontrolled dumping areas that accumulated more waste as time went by. These dumps also served as grazing sites for livestock, with residents having being ignorant of the deleterious effect of such practices. Moreover, in the mid 60's and 70's open burning turned the dumps into open air furnaces dotted around the cities without any form of site management (see Figure 1.2).
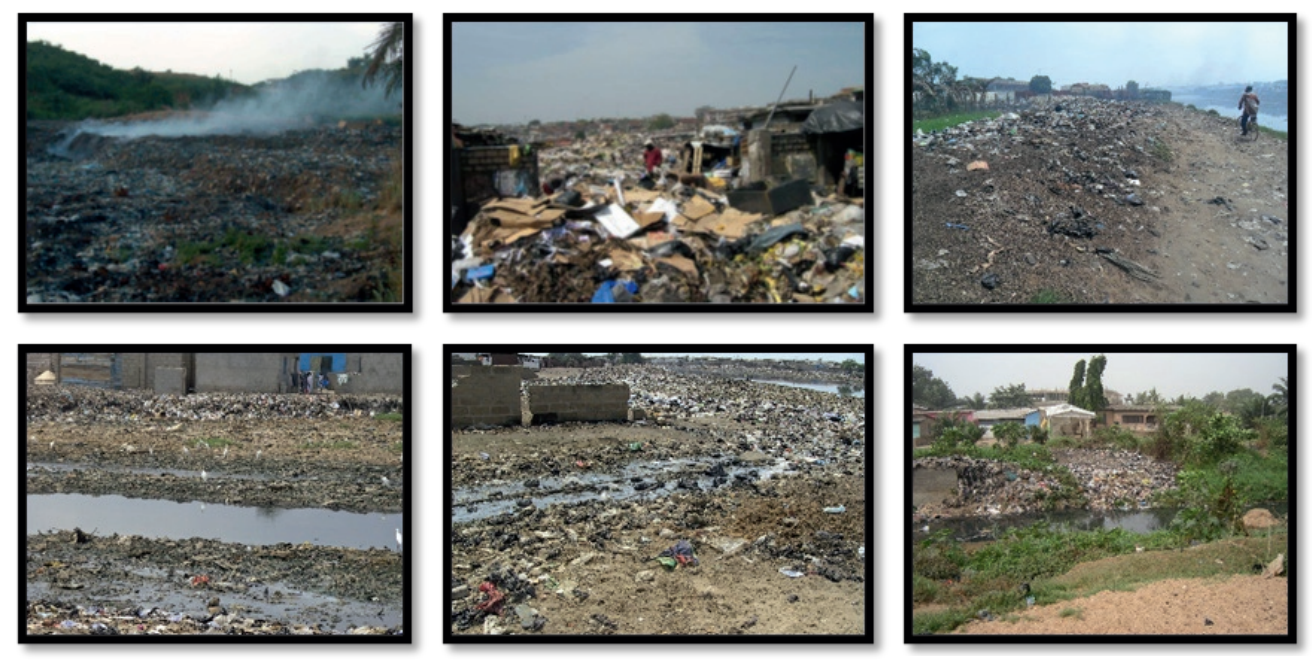

Figure I.2: Solid waste management practices in Ghanaian cities between I968 and I987. Photos: AMA Archives.

In 1962, most towns achieved the official status of city and with this came the creation of the City Councils. The City Councils, like their predecessor institution, the Town Councils, provided public toilet services as well as infrastructure. In 1985, the status of some cities were elevated to that of "metropolises"; thus transitioning the city councils, to the status of Metropolitan Assemblies (MA's). An example is the Accra Metropolitan Assembly (AMA), the site and host community for most of the studies in this dissertation.

The decentralised Metropolitan and Municipal Assemblies, operating under the political jurisdiction of the then Ministry of Local Government and Rural Development (MLGRD) were the institutions bearing ultimate responsibility for sanitation and solid waste management in the country. They were also responsible for:

- the overall development of the metropolis and the preparation of development and budgetary plans

- the initiation of programs for the development of basic infrastructure and the responsibility for provision of municipal infrastructure services 
- the development, improvement and management of human settlements and the environment, ensuring secured and sound conditions for development in the metropolis.

To carry out these tasks, the MA's in 1985 created "so called independent" Waste Management Departments (WMDs) with financial support from the German and the British governments (Asomani-Boateng and Haight, 1998; Boadi and Kuitunen, 2003). The WMD was an institution created with the goal to harmonise the operations of the various departments and to establish a department dedicated to waste management problems. For example, the creation of the WMD of the AMA was undertaken through the annexation of the then Mechanical Engineers Department and the Environmental Health Division of the Medical Officer of the Health Department. It served all offices of the Assembly and had the responsibility to:

- fine-tune and periodically update a strategic sanitation plan

- mobilise resources to implement components of the plan

- manage the tendering process for construction and service contracts

- supervise the design and construction of sanitation facilities and

- monitor the waste discharges

Thus the WMD has since its establishment been responsible for municipal solid waste management in the various metropolitan areas of the country. At present most WMDs consists of five divisions, all of which have their own tasks and responsibilities: Administration, Liquid Waste, Solid Waste, Landfill and Maintenance. Limited human resource capacity, frequent mismanagement and the political difficulties involved in improving public sector operations in cities of developing countries has continuously resulted in poor service delivery and huge financial cost at the WMDs. This in addition to the structural adjustment programmes of the International Monetary Fund (IMF) and the demands of external support agencies and development partners in the late 1980 's and early 1990's compelled authorities to go for private sector participation (PSP) in solid waste management (Obirih-Opareh and Post, 2002). Thus starting in 1997, solid waste collection and haulage have been privatised in the metropolitan and municipal areas of the country.

Disposal of solid waste in Ghana continued to depend on uncontrolled dumpsgenerally sited in mined-out quarries without any form of organised site management until 2003. In the 10 years following up to 2013, four out of the six metropolitan cities, (Kumasi, Tamale, Sekondi-Takoradi and Tema), sited and started operating sanitary landfills under the erstwhile Ghana Government Environmental Action Plan (EAP) and the World Bank's Urban Environmental Sanitation Project (UESP). The planned 
construction of a sanitary landfill in the capital city Accra has not been realised unto this day, largely due to limited land availability and public opposition.

In the years preceding 2013, there had been only one large scale mechanised composting plant in Ghana: the Teshie-Nungua composting plant which was constructed in 1979 (Oteng-Ababio, 2011b). The plant failed due to challenges in technical capacity, operating cost, energy and water, in addition to the absence of an institutionalised source separation or pre-processing system (Boadi and Kuitunen, 2003; Mensah et al., 2003). Up until 2009, the site of the plant was functioning as a dumping site for solid waste.

Starting in 2013, a privately managed state-of-the-art composting and recycled materials sorting plant, the Accra Composting and Recycling Plant (ACARP) has been operating under a public-private partnership agreement. A mechanical biological treatment plant, the Integrated Recycling and Composting Plant (IRECOP) has been constructed and it is in operation since the middle of 2019. There has also been some limited small scale composting and co-composting (some for biogas production) initiated and operated by other private solid waste management and sanitation entities.

Since the early part of 1990, the informal waste sector has been the main facilitators of recovery and recycling. They sell their materials to recycling companies within the industrial hub of Tema to recycle or process for sale to international recycling companies. Ghana has never operated a waste-to-energy plant as part of its municipal solid waste management system. A new Ministry of Sanitation and Water Resources, established since the beginning of 2017 is perceived to be another turning point in the history of waste management in the country.

\section{Research objectives}

The overall objective of the research work described in this dissertation is to identify and test methods to engage key public-sector stakeholders in finding real solutions and mobilising local resources and ideas, which will be sustainable over the long term. A related objective is to use evidence-based research approaches to break the vicious circle of donor dependency and wasted investments, and to substitute virtuous circles of continuous improvements to real problems experienced by system users and providers.

The strategy deployed has been to work in a participatory, evidence-based frame with responsible politicians and public managers, so they themselves can understand the SWM system of the country, find out for themselves - and in consultation with system users - what works and what is broken, and experiment with locally appropriate methods 
and approaches that had the potential to significantly improve inclusive governance and further contribute to modernise and upgrade the system.

The aforementioned overall objective of the thesis research has been achieved through:

- collection and validation of reliable evidence-based data using participatory action research approaches

- assessment of the physical components and governance aspects of the countries solid waste management system, using internationally recognised assessment methods which are suitable for use by direct system managers

- formulation of interventions that promote inclusive governance, strengthen successes and address challenges in a locally appropriate manner

- identification and elaboration of interventions to evaluate their effectiveness towards system modernisation, and promotion of their adoption as formal policies and practices

- sharing of lessons learnt to the scientific community, solid waste practitioners and decision-makers in cities of Ghana and other lower-middle-income economies in Sub-Saharan Africa and elsewhere, and

- systematisation of this evidence-based approach to make it accessible to solid waste managers, policy-makers, and donors active in the solid waste management system modernisation in developing countries

\section{Research questions}

In order to achieve the main research objective, the research questions for this dissertation consist of:

1. What solid waste data gaps exists within municipalities in Ghana? How can reliable and inclusive data collection processes be developed and promoted within the solid waste management sector of Ghana?

2. What is working and what is failing in the solid waste management system of metropolitan cities of Ghana?

3. What locally appropriate interventions can be implemented and sustained to strengthen successes and fix failures in the solid waste management system of cities of Ghana? Who should be involved and how should interventions be developed, implemented and evaluated? 
4. What experiences gained, lessons learnt and evidence-based pathway to system modernisation in the solid waste management system of Ghana can be recommended and shared with other developing countries?

\section{The research method and approach}

The work in this dissertation is based on the participatory action research (PAR) method. The PAR is considered suitable for research work that is committed to codevelop interventions and programs with people rather than the conventional research approaches that (engage consultants and experts) to develop solutions for people (McIntyre, 2007; Chambers, 1994; Chambers, 1992; Van de Klundert et al., 2001). According to McIntyre, 2007, PAR has four main underlying tenets: "(a) the collective commitment to investigate an issue or a problem, (b) a desire to engage in self- and collective reflection to gain clarity about the issue under investigation, (c) a joint decision to engage in individual and/or collective action that leads to a useful solution that benefits the people involved, and (d) the building of alliances between researchers and participants in the planning, implementation, and dissemination of the research process."

The research for this dissertation adopted the PAR approach based on four main reasons:

1. the experience of the author and his colleagues with the SWM system of the Accra Metropolitan Assembly and the resulting realisation that the conventional systems for data collection, system assessment and intervention development have for too long failed to provide validated and reliable data to support planning and decisionmaking

2. the availability and "open source" framework of the integrated sustainable waste management (ISWM) concept for the various studies within this dissertation; to which participatory processes are considered central to allow managing authorities to open governance and planning to both professionals and non-professionals

3. the systematisation of ISWM approaches into a globally available "shareware" system of benchmarking city performance under the name of the "WasteAware Benchmark Indicators," with the implication that those involved in the research can continue to use this frame without further guidance from the author and also with a higher level of ownership of problems and solutions

4. the unique desire and understanding of the author and his collaborators (some of whom are academicians and researchers) to collaborate with municipalities to: build 
capacities, promote inclusive governance and close existing gaps between research and industry as a potential path for solid waste improvement in Ghana

A mixed method approach was adopted for the various studies within this dissertation. Quantitative data were collected through structured surveys, field observations and laboratory measurements to: map waste flows, establish stakeholder contributions, assess system performance and evaluate interventions. Qualitative data were collected mainly through focus-group discussions to establish the factors and nexus between success and failure; in addition to assessing the quality of system performance.

The first step in the research approach was to review the scientific literature of the solid waste management practices in cities of Ghana and other similar developing lowerincome economies. The work of Ijgosse et al, 2004, Van de Klundert et al., 2001 Scheinberg et al., 2010 and Wilson et al., 2015, all based on the ISWM framework, served as an entry point to the studies since they provided an in-depth analysis of the potential of the framework and participatory action research processes to improving the solid waste governance and systems of low and lower-middle income cities. The research to this dissertation followed the methodological recommendations of Ijgosse et al., 2004 .

The lead research arranged meetings with the solid waste managers and municipal authorities to discuss processes to support them with data collection for effective planning purposes and improvement of their solid waste management systems. These meetings did not only provide the opportunity for protocol establishment but also for clarifications, nature and scope of work and the roles and responsibilities of stakeholders. The municipality of Accra (the capital city) hosted the research and provided support and access to stakeholders and solid waste infrastructure. The research team together with the municipality identified 24 relevant stakeholders for the research for this dissertation (see Table 1.1). These stakeholders were carefully divided into working groups based on their experience, classification, nature and level of education, and the position at work.

Structured surveys, semi-structured interviews, field observations, mapping, laboratory and field measurements and working group discussions formed the main approach to data collection, intervention development and implementation. The 'Wasteaware' benchmark indicator Excel tool (Wilson et. al 2015), the IBM statistical package for social sciences (SPSS), versions 20 to 25 and the substance flow Analysis (STAN) software, versions 2.5 and 2.6 were used for data analysis, evaluations and drawing of waste flow diagrams. Detailed methodological approaches have been provided in the published outputs of the dissertation in the succeeding chapters. 


\section{Chapter I}

Table I.I: Stakeholders used to form working groups for the various research studies within this dissertation.

\begin{tabular}{|c|c|c|}
\hline No. & Stakeholders (Number of representatives) & Designation of representatives \\
\hline 1 & Waste management department, Accra (6) & Waste managers, public health engineers \\
\hline 2 & University of Cape Coast (3) & Lead research and research assistants \\
\hline 3 & Ministry of sanitation and water resources* (1) & Environmental analyst \\
\hline 4 & Ministry of finance and economic planning (1) & Finance officer \\
\hline 5 & $\begin{array}{l}\text { Ministry of gender, children and social protection } \\
\text { (1) }\end{array}$ & Environmental representative \\
\hline 6 & Metropolitan planning and coordinating unit (2) & Development and physical planners. \\
\hline 7 & Municipal environmental select committee (1) & Head of Assembly members \\
\hline 8 & Environmental protection agency (1) & Built environment audit officer \\
\hline 9 & Local government service secretariat (1) & $\begin{array}{l}\text { Deputy head of management \& informa- } \\
\text { tion systems }\end{array}$ \\
\hline 10 & $\begin{array}{l}\text { Municipal town and country planning department } \\
\text { (1). }\end{array}$ & Physical planner and regional geographer \\
\hline 11 & Environmental service providers association (2) & Innovations manager and head of research \\
\hline 12 & Municipal budget and rating department (2) & Municipal budget and rating officers \\
\hline 13 & Municipal public health departments (2) & Environmental Health Officers \\
\hline 14 & Accra technical university (1) & Lecturer, Civil Engineering Department. \\
\hline 15 & $\begin{array}{l}\text { Africa institute of sanitation and waste manage- } \\
\text { ment (1) }\end{array}$ & Programme coordinator \\
\hline 16 & Informal waste collectors (2) & Deputy Head and Secretary. \\
\hline 17 & Informal waste pickers association (2) & Head and Organiser \\
\hline 18 & Association of Market Women (1) & Chairperson and President \\
\hline 19 & $\begin{array}{l}\text { Ghana Plastic Waste Manufacturers Association } \\
\text { (1) }\end{array}$ & Head \\
\hline 20 & Plastic Waste Management Program (1) & Head. \\
\hline 21 & Coalition of NGO's in Waste Management (1) & Deputy Head \\
\hline 22 & Coalition of NGO's in Water and Sanitation (1) & Head \\
\hline 23 & Disability Fund Management Committee (1) & Head \\
\hline 24 & Residential Associations (1) & Representative \\
\hline
\end{tabular}

* The ministry of sanitation and water resources was an environmental health and sanitation directorate under the ministry of local government and rural development at the start of the research to this dissertation in 2015. 


\section{The integrated sustainable waste management (ISWM) analytical framework}

The research for this dissertation is imbedded in the integrated sustainable waste management (ISWM) analytical framework. The ISWM framework was first developed in 1996 by the CWG, that is, the Collaborative Working Group on solid waste management in low- and middle-income countries, a European-based community of practice convened in the 1990s by the World Bank's Carl Bartone, with its secretariat at SKAT in Switzerland.

ISWM is basically a lens through which a city's solid waste management system can be viewed. ISWM assumes that there is always a system, a set of stakeholders, and a number of aspects associated with the system, and that any attempt to modernise the system must precede first with an understanding of what works well and what needs repair; who does the repair benefit (harm) and in which aspect? Thus, ISWM allows for a comprehensive appraisal of the system elements, the stakeholders, and the governance aspects required to self-correct and also deliver a well-functioning solid waste and recycling system in a city or country (Scheinberg et al., 2010b; Schübeler et al., 1996; Wilson et al., 2013).

In 2010, the ISWM framework was used to create a baseline methodology of indicators to capture data, assess and compare the municipal solid waste management system of 20 cities across the globe (Wilson et al., 2012). These indicators, first presented in the award winning UN-Habitat publication "Solid waste management in the World's Cities" (Scheinberg et al., 2010b), later became known as the WasteAware benchmark indicators (Wilson et al., 2013) as shown in Figure 1.3. The absolute claim of the WasteAware benchmark indicators is that, if any MSWM system is secured within the overlapping physical components and governance aspects triangles of Figure 1.3, it will produce a well-functioning system and also experience continuous modernisation. The WasteAware indicators represent an open system "shareware which is continuously available to system managers in any country, but their focus is on supporting sustainable modernisation in low-and lower-middle-income countries".

The WasteAware benchmark indicators have become one of the most adaptive sets of indicators ever developed to assess the performance of a city's MSWM, and has since 2010 been used to benchmark the MSWM system of more than 50 cities across all continents (Kabera et al., 2019; Wilson et al., 2015a; Ali et al., 2019; Wilson et al., 2012).

We selected the ISWM framework after a review of the available solid waste management frameworks (McDougall et al., 2008; Schübeler et al., 1996) and the realisation that it 


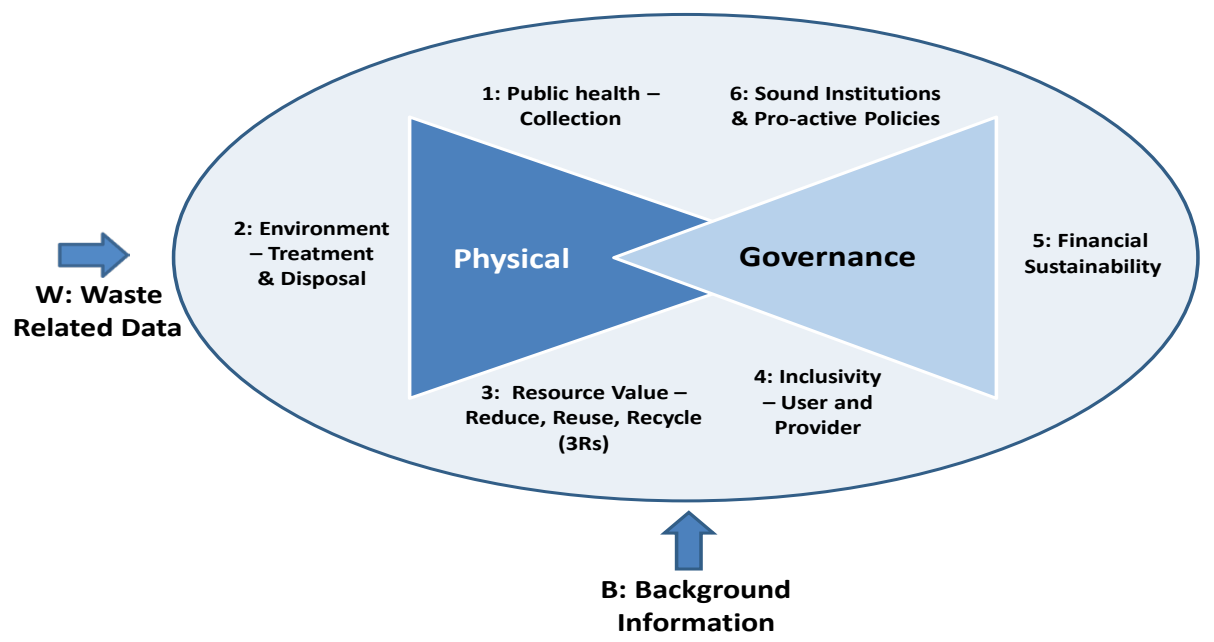

Figure I.3: The simplified version of the ISWM framework (Wilson et al., 20I5a).

Reproduced with permission from authors.

had a global applicability across all gross national income (GNI) levels, broad usage and coverage, the free availability of a detailed user manual and an automated Microsoft Excel sheet to guide benchmarking agents on its usage and implementation (Cervantes et al., 2018; Wilson et al., 2015), and the proven record and potential to support the overall objective of this dissertation. The ISWM framework seem the most relevant approach to allow us address the continuous failure of expensive and technologicallyoriented solutions that has been transferred from the global North into the solid waste management system of low- and middle-income countries (Schübeler et al., 1996).

The ISWM analytical framework also embraces the use of participatory action research tools such as participatory rapid appraisal (PRA) (Van de Klundert et al., 2001); an approach which has been used in all the studies within this thesis. We envisaged that bringing researchers, municipal officials, solid waste managers, the informal solid waste sector, private solid waste organisations and other relevant stakeholders together in a working group to assess the system and develop, prioritise, implement and evaluate locally appropriate interventions in a participatory manner was the most probable way to win decision-makers' commitment in addressing the numerous challenges of the SWM system of the greater Accra region of Ghana.

The choice of participatory action research was and remains a practical and resultoriented one; the conventional top-down approach of information gathering and system assessment has proven inadequate throughout the years to support such a cooperative process. Participatory action research methods empower stakeholders and creates ownership to facilitate the implementation of interventions (IJgosse et al., 2004). 
Last but not least, we had at our disposal, best practices and challenges from the implementation of the ISWM methodology in seven countries (Bulgaria, Costa Rica, Egypt, India, Mali, Peru and the Philippines) within four continents as part of the Urban Waste Expertise Program (IJgosse et al., 2004), to support planning and organisation of the research studies for this dissertation and also to strengthen governance and improve upon SWM service delivery in Ghana.

\section{Outline and narrative to the various chapters of this dissertation}

The current thesis provides an overview of how structural and coordinated cooperation between academicians, researchers and municipalities can provide an enabling platform to address recurring and complex problems in the solid waste management service delivery in cities of Ghana. The collaboration of researchers and the professional staff of the 25 municipalities within the greater Accra Metropolitan Area (GAMA) has led to the strengthening of human resource capacities, the closing of chronic data gaps, the development of interventions to improve the physical aspects (collection coverage, disposal, recycling rates) and some of the governance aspects (inclusivity and policy) of municipal solid waste management (MSWM) in the greater Accra region.

Five studies were conducted within the period of this dissertation. The studies and their outputs have been published independently and form the subject matter of Chapter 2 through to Chapter 6 of the dissertation. These chapters have been arranged to provide a linkage with the overall and specific objectives of the work. Basically there was an initial comprehensive assessment of the physical components and governance aspects of municipal solid waste management (MSW) system of the city of Accra (Chapter 2). The purpose of the assessment was to create a baseline and identify what was working and what was failing. Chapters 3 and 4 describes the attempts that were made to develop, prioritise and implement locally appropriate interventions to strengthen what was working already and improve upon what was failing. Chapter 5 expanded the scope of the research from Accra to the 25 municipalities to further support the closing of data gaps, especially related to informal sector actors and also improve inclusive MSW governance. Chapter 6 builds on the collaborative and participatory experiences of the previous chapters to appraise the country's SWM system with an objective to create an entry point for academia, research institutions, development partners, and not-forprofit organisations to intervene and contribute sustainably towards the modernisation of the SWM system of the country. A comprehensive outline of each of the chapters of this dissertation is explained further in the following paragraphs.

Chapter 2 is a baseline study that assesses the performance of the city of Accra in municipal solid waste management as of 2016, using the integrated sustainable waste 
management analytical framework as a lens. This study was conducted to enable the working groups to understand what was working in the system and what was failing that required fixing. The study brought together 24 relevant stakeholders to assess the physical components and the governance aspects of the system using the ISWM WasteAware benchmark indicators. It collected background and waste related data, mapped the process flow of solid waste for nine months and computed scores and corresponding traffic light colour symbolism for the city's performance in each of the six indicators of Figure 1.3. Finally the study explained the reasons behind each indicator score and provided recommendations for system improvement.

1. The question for the chapter was: How is the city of Accra performing in the physical and governance indicators of municipal solid waste management, and what is working and what requires fixing?

Chapter 3 discusses the development of an intervention by the working group to address the municipal solid waste collection system. The intervention was based in part on the outcome and recommendations of chapter two, partly on the performance assessment results of an existing fee- and performance-based municipal solid collection franchise agreement between the municipality of Accra and the formal service providers, and partly on the outcome of a service user satisfaction survey. The study focused on an intervention to improve the physical indicator of collection coverage and the governance indicator of provider inclusivity. The objective was to create a path of cooperation and understanding between the officially recognised formal MSW companies and the informal waste collectors (also referred to as informal service providers) to shore up collection coverage.

2. The research question was: How can the informal waste collectors (informal service providers) have the institutional and financial support of formal authorities to contribute to an increase in solid waste collection coverage in Accra, against the backdrop that their activities are not sanctioned by law and considered illegal?

The study hypothesised that if recognition, support and some measure of administrative and legal freedom were granted the informal service providers (ISPs), it might potentially empower them to contribute significantly to an improvement in collection coverage. The study further describes how an unusual agreement in which the formal service providers agreed to work with their informal counterparts as subcontractors and also support them with equipments on hire purchase was brought about.

Chapter 4 benchmarks the performance of the city using the indicators and shares lessons learnt, two and half years after the recognition and involvement of the 
informal service providers in service provision. The study further discusses locally appropriate interventions that were developed to close illegal dumps, improve disposal infrastructure, and promote provider inclusivity in system management. The study maps the improvements in the physical and governance indicators on a year by year basis as a potential tool to advocate for the integration of the informal service providers into the formal solid waste management system. The objective was to find out if interventions developed in a participatory frame, and leading to locally appropriate choices, could lead to significant system improvement.

3. The research question was: Will evidence-based indicators of municipal solid waste management (MSWM), demonstrate significant improvement in the physical and governance aspects, at the close of a process where stakeholders have deliberately developed and implemented together locally appropriate interventions focused on the informal solid waste sector for a period of two and half years?

Chapter $\mathbf{5}$ shifts the scope and focus of the research from Accra and the informal service providers to the 25 municipalities within the greater Accra area (GAMA) and also brings on board the informal levels of the value chains (the waste pickers, the waste buyers, the junk dealers and the recyclers) who pick, buy and process all sorts of recyclable material from the regions landfills to sell to recycling industries. The study assesses the roles and socio-economic contribution of the informal waste sector to the system, and maps the intricate flows of different waste materials collected and recovered by the informal waste sector. The objective was twofold, (1) to project the benefits of action research to inclusive governance and the closing of reliable data gaps in informal sector operations, and (2) to use the socio-economic contribution and possible livelihood creation as a means to justify the need for integration of the informal sector into the formal waste management system. The widening of the research scope and area was a necessary condition for the working group to win the commitment of the local government towards the integration process. The chapter finally ends by mapping a pathway to support the local government in the integration process.

4. The research question for this study was: How can the informal service- and valuechain actors within the 25 municipalities of the greater Accra metropolitan area be stimulated to collect reliable evidence-based socio-economic data from their activities, and how can such data be legitimised and used to influence decisionmaking towards informal waste sector integration into the formal waste management system?

Chapter $\mathbf{6}$ discusses the realities of solid waste management in Ghana and attempts to recommend the most probable evidence-based pathway with the potential to holistically 
address the numerous solid waste management challenges of the country. The scope here is nation-wide and all forms of solid waste (e-waste, industrial waste, agricultural waste, construction and demolition waste, biomedical waste, and municipal solid waste) are considered. The study maps a comprehensive process flow diagram of all forms of waste to assist stakeholders to identify points of entry for support to the system. The objective is to show how participatory and coordinated cooperation of researchers and the 25 municipalities of Ghana has led to the closing of data gaps, the building of human resource capacities, and the improvement in the municipal solid waste (MSW) service delivery and inclusive governance, and how such a path might be feasible with other forms of waste management modernisation and also in similar cities of developing economies.

5. The research question was: What are the points of intersection between system failure and success in solid waste management in Ghana, and how can lessons learnt and evidence gathered in the previous studies be used to map a potential pathway to stimulate solid waste modernisation in Ghana?

Finally, Chapter 7 discusses and summarises the findings of the studies conducted in this dissertation. It outlines the methodological strengths and limitations of the participatory action research process in the municipalities of the GAMA, and reflect on the applicability of the WasteAware indicators of the ISWM framework in benchmarking the solid waste management systems of emerging economies of Sub-Saharan Africa. The chapter provides suggestions on the practical implications of the current dissertation for future studies and practice. 
General Introduction 


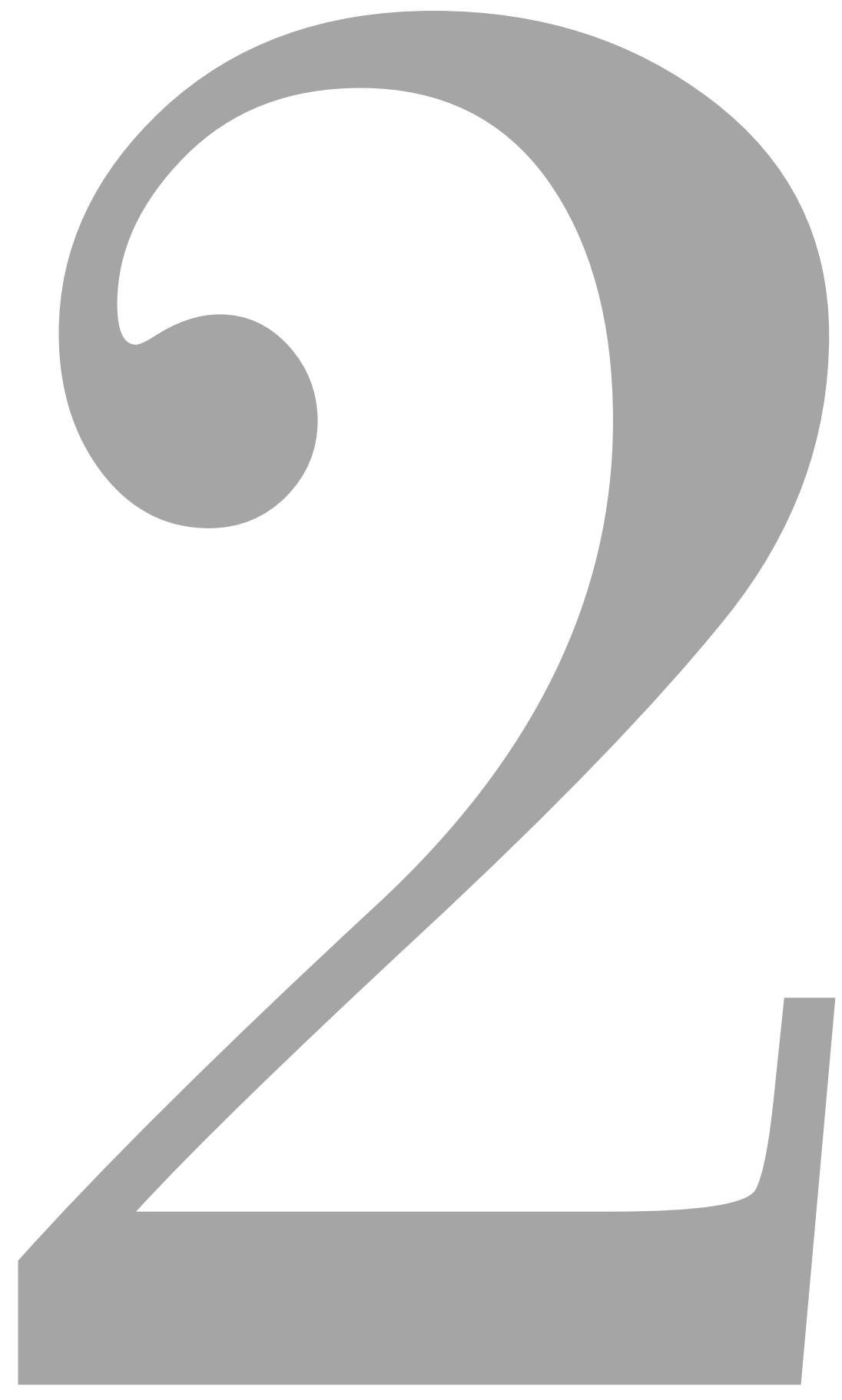




\section{Chapter 2}

\section{Assessment of the municipal solid waste management system in Accra, Ghana: A 'WasteAware' benchmark indicator approach}

This chapter has been published as:

Kwaku Oduro-Appiah, Anne Scheinberg, Anthony Mensah, Abraham Afful, Henry Kofi Boadu and Nanne de Vries (2017). Assessment of the municipal solid waste management system in Accra, Ghana: A 'WasteAware' benchmark indicator approach. Waste Management \& Research 35(11): 1149-1158 
Chapter 2

\begin{abstract}
This article assesses the performance of the city of Accra, Ghana, in municipal solid waste management as defined by the integrated sustainable waste management framework. The article reports on a participatory process to socialise the WasteAware benchmark indicators and apply them to an upgraded set of data and information. The process has engaged 24 key stakeholders for 9 months, to diagram the flow of materials and benchmark three physical components and three governance aspects of the city's municipal solid waste management system. The results indicate that Accra is well below some other lower middle-income cities regarding sustainable modernisation of solid waste services. Collection coverage and capture of $75 \%$ and $53 \%$, respectively, are a disappointing result, despite (or perhaps because of) 20 years of formal private sector involvement in service delivery. A total of $62 \%$ of municipal solid waste continues to be disposed of in controlled landfills and the reported recycling rate of $5 \%$ indicates both a lack of good measurement and a lack of interest in diverting waste from disposal. Drains, illegal dumps and beaches are choked with discarded bottles and plastic packaging. The quality of collection, disposal and recycling score between low and medium on the WasteAware indicators, and the scores for user inclusivity, financial sustainability and local institutional coherence are low. The analysis suggests that waste and recycling would improve through greater provider inclusivity, especially the recognition and integration of the informal sector, and interventions that respond to user needs for more inclusive decision-making.
\end{abstract}

\title{
Keywords
}

Assessment, integrated sustainable waste management, inclusive urban services, 'WasteAware' benchmark indicators, Accra, Ghana 


\section{Introduction}

Assessment of a city's municipal solid waste management (MSWM) system provides managing authorities and key stakeholders with an opportunity to re-evaluate and improve performance data to sustain service improvement and policy adjustment decisions for longer terms (Zurbrügg et al., 2014).

Assessment methods for solid waste management (SWM) systems are classified according to: the goal of the assessment; the object of investigation; and the sustainability domains to which the assessment applies (Allesch and Brunner, 2014). Notable methods include life cycle assessment, multi-criteria decision making, creating a participatory integrated sustainable waste management (ISWM) baseline and benchmarking. Benchmarking allows comparative assessment between cities; a baseline creates a monitoring floor and the others tend to be scenario-based and are employed to evaluate single solid waste streams and domains (Allesch and Brunner, 2014; Ilić and Nikolić, 2016).

The chronic lack of reliable data in lower middle-income cities like Accra undermines decision-making; and deprives professional staff of any clear basis for interventions to improve services (Oteng-Ababio et al., 2013; Zurbrügg et al., 2014). The literature is also replete with suggestions to the collection of essential data in developing countries, which would allow for the assessment of the performance of the MSWM systems and further support managers to make informed decisions on choice of appropriate treatment technologies (Asase et al., 2009; IJgosse et al., 2004; Oteng-Ababio et al., 2013).

The UN-Habitat publication, Solid Waste Management in the World's Cities, based on the concept of ISWM, used the comparison of 20 cities to create a methodology for capturing relevant baseline data, assessing their SWM systems, comparing their performance with other cities and using this information to take decisions to improve their SWM systems (Scheinberg et al., 2010b). This process produced the ISWM baseline methodology and the WasteAware benchmark indicators; and now more than 40 cities have been assessed using these tools (Soós et al., 2013; Wilson et al., 2012; Zabaleta and Rodić, 2015). The WasteAware ISWM indicator set remains unique in its evaluation of the quantitative and multi-attribute qualitative indicators of both physical components and governance aspects of MSWM, to facilitate the effective benchmarking of the performance of all cities across the world; in addition to promoting the development of a mass balance of the system (Wilson et al., 2015a).

The research for this article has added Accra, the capital city of Ghana, to the list of WasteAware benchmarks. The exercise in Accra has involved 24 key stakeholders in benchmarking the physical components and governance aspects of MSWM. Our 
objective has been to engage decision-makers and managers of MSW in Accra and to give them an experience of providing reliable data to compare their performance with other cities. The participatory process included development of a materials flow diagram of the city for stakeholders to concisely comprehend the current situation and prioritise relevant interventions. In response to the benchmarking, a group of stakeholders have worked together with key officials to elaborate recommendations for affordable and appropriate improvements.

\section{Accra, Ghana}

Accra, the capital city of Ghana, represented administratively by the Accra Metropolitan Assembly (AMA), is a coastal city with an area of $139 \mathrm{~km}^{2}$ (Ghana Statistical Services, 2014). The city, which is home to $1,936,836$ residents and an estimated 500,000 daily transients (World Bank and Accra Metropolitan Assembly, 2010), consists of 10 districts and serves as the economic hub of the rest of the country. The per-capita gross national income (GNI) is US\$1480, making Ghana a lower-middle-income country. Accra was recognised in 2012 as one of five African cities with high scores in environmental management at the UN climate change conference in South Africa.

\section{Methodology}

The methodology and guideline for the participatory assessment is based on the ISWM concept. ISWM provides a lens for understanding urban waste management as a combination of physical systems and governance aspects. ISWM is a participatory planning framework, to be distinguished from 'the other' 'IWM' (integrated waste management), a technical concept used to convey a system in which recycling and waste management are complementary management approaches (McDougall et al., 2008; Van de Klundert et al., 2001). In 2010, as part of the Habitat book process, the ISWM framework was simplified into two overlapping triangles (see Figure 2.1) and formed the basis for the WasteAware indicators, and these have been adopted as the benchmarking methodology for this study.

\section{ISWM: alliance building and assessment}

The methodology follows that of IJgosse et al. (2004). The assessment constituted the initial phase of a long-term initiative to formulate action plans to improve MSW performance in Accra. We selected Accra as a city with commitment to making informed decisions towards the development of locally responsive and appropriate interventions in MSWM. A plan was developed in a participatory process to build trust and create inter-group alliances. It involved presentations to the highest decision-making entities 
of the municipality. The active participation of the political and staff leadership resulted in the research being offered an office and a lead facilitator.

Some 37 representatives of 24 relevant stakeholders were divided, for purposes of the assessment, into three working groups: collection and financial sustainability; disposal, treatment and recycling; and policy and institutions. User and provider inclusivity functioned as cross-cutting indicators for all working groups. Working groups chose chairpersons, agreed on meeting times and venues, and developed a working plan to assess both the physical and governance aspects of the MSWM system in line with a checklist developed out of the detailed user manual to the WasteAware ISWM benchmark indicators (Wilson et al., 2015a).

The authors carefully identified and grouped stakeholders to ensure diversity, especially in the assessment of the governance aspects of the MSWM system. Several co-authors of this article, themselves stakeholders, provided terms of reference, training, and technical and financial assistance to the working groups, and interpreted the information extracted from the indicators. Working groups were not paid, but each member was granted an allowance of US $\$ 20$ per meeting. A performance-based monitoring and evaluation $(\mathrm{M} \& \mathrm{E})$ guide was developed to monitor progress and challenges, which were discussed on a monthly basis with all working groups and municipal officials. The municipality provided transport for field observations and mapping of treatment and disposal sites.

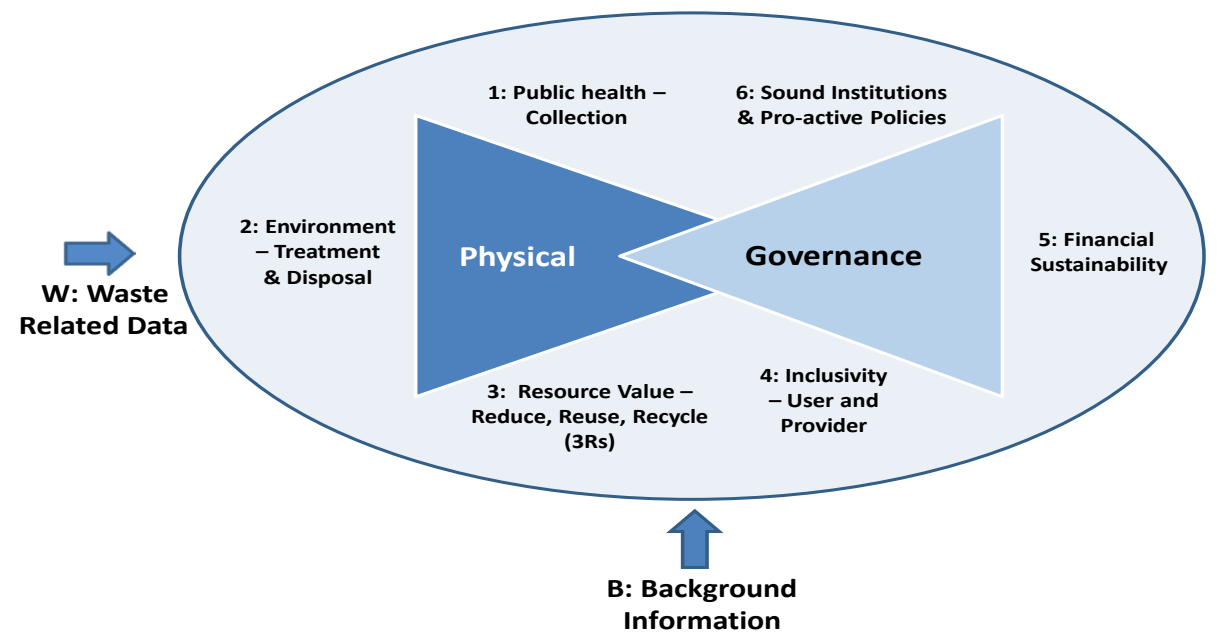

Figure 2.I: The simplified version of the ISWM framework (Wilson et al., 20I5a).

Reproduced with permission from authors. 


\section{WasteAware indicators: basis for participatory benchmarking}

The WasteAware ISWM indicators benchmark the adequacy of the physical components; and the inclusiveness and responsiveness of the governance aspects of a city's MSWM. They make an implicit claim that any sustainable, self-correcting and well-functioning system can only flourish when it is anchored in the two triangles of Figure 2.1. There are 12 composite indicators divided between the physical and governance aspects and weighted in a ratio of 7:5 respectively. Four benchmarks measure quantitative data and the others reflect service quality. Each qualitative indicator is multi-attribute and composite in nature, and defined by at least five sub-criteria. The indicator results are presented with traffic light symbolism, based on aggregate, computed or estimated scores. The colours red, red/orange, orange, orange/green and green reflect the performance of the MSWM system in each indicator, ranging respectively from low $(\mathrm{L})$ to high $(\mathrm{H})$.

\section{Supplementary field and laboratory analysis}

The first round of research showed convincingly that secondary data was not available. Gaps in data were filled through field and laboratory analysis of MSW of 120 households, institutions and commercial centres; validated in focus group discussions and interviews with consultants and retired practitioners. Assessment results were entered into the WasteAware automated excel indicator forms, which computes aggregate scores for each indicator (Wilson et al., 2015a).

\section{Results of the Research}

The summary results of the WasteAware benchmarking are provided in Table 2.1. The benchmarking exercise contextualises the performance of Accra in relation to lowermiddle-income countries in the 20 Habitat book reference cities (Wilson et al., 2012) and additional cities that have been benchmarked with the WasteAware indicators (Wilson et al., 2015a). This is intended to support authorities and stakeholders in understanding best practices from cities that have improved upon their systems in response to similar assessments.

The use of participatory research appraisal methods and the WasteAware benchmark indicator tool have empowered stakeholders of the realities and challenges ahead to improving the system. The overall system has been documented and analysed using a process flow diagram (PFD), which is presented in Figure 2.2. The meticulous and time-consuming process of collecting and triangulating data to develop the process flow diagram has created a new awareness among stakeholders of the need to monitor the system for effective planning. Per capita MSW of $0.71 \mathrm{~kg} \mathrm{~d}^{-1}$ from the study is comparable to the $0.72 \mathrm{~kg}$ for other metropolitan cities of Ghana (Miezah et al., 2015). MSW consists of four main categories of materials as in Table 2.1 . The $45 \%$ organic waste is lower than would be expected from literature, owing to high amounts of inert 
Table 2.I: WasteAware benchmark indicator results of Maputo, Mozambique; Accra, Ghana; and Lahore, Pakistan. ${ }^{a}$

\begin{tabular}{|c|c|c|c|c|c|c|}
\hline No. & Category & \multicolumn{2}{|l|}{ Indicator } & \multicolumn{3}{|l|}{ Results } \\
\hline \multicolumn{4}{|l|}{ City } & Maputo & Accra & Lahore \\
\hline \multicolumn{4}{|c|}{ Country } & Mozambique & Ghana & Pakistan \\
\hline \multicolumn{4}{|c|}{ Year of assessment } & 2013 & 2016 & 2014 \\
\hline \multicolumn{7}{|c|}{ Background information } \\
\hline \multirow[t]{2}{*}{ B1 } & \multirow[t]{2}{*}{ Income level } & \multicolumn{2}{|c|}{$\begin{array}{l}\text { World Bank income } \\
\text { category }\end{array}$} & Low & $\begin{array}{l}\text { Lower } \\
\text { middle }\end{array}$ & $\begin{array}{l}\text { Lower } \\
\text { middle }\end{array}$ \\
\hline & & \multicolumn{2}{|c|}{ GNI capita $^{-1}$} & $\$ 450$ & $\$ 1480$ & $\$, 1,140$ \\
\hline B2 & Population & \multicolumn{2}{|c|}{ City population } & $1,131,149$ & $1,936,836$ & $8,160,000$ \\
\hline B3 & Waste generation & \multicolumn{2}{|c|}{$\begin{array}{l}\text { MSW generation } \\
\text { (tonnes year }{ }^{-1} \text { ) }\end{array}$} & 508,000 & 631,506 & $1,916,000$ \\
\hline \multicolumn{4}{|c|}{ Key MSW-related data } & \multicolumn{3}{|c|}{$\begin{array}{l}4 \text { key fractions as \% of total MSW } \\
\text { generated }\end{array}$} \\
\hline \multirow{2}{*}{ W1 } & \multirow{2}{*}{ Waste capita ${ }^{-1}$ : } & \multirow{2}{*}{ MSW capita ${ }^{-1}$} & kg year $^{-1}$ & 316 & 259 & 219 \\
\hline & & & $\mathrm{kg} \mathrm{day}^{-1}$ & - & 0.71 & - \\
\hline W2 & Waste composition & & & & & \\
\hline W2.1 & Organic & $\begin{array}{l}\text { Organics (food } \\
\text { waste) }\end{array}$ & ind green & $65 \%$ & $45 \%$ & $65 \%$ \\
\hline W2.2 & Paper & Paper and card & oard & $8.5 \%$ & $4.6 \%$ & $2 \%$ \\
\hline W2.3 & Plastics & Plastics & & $8 \%$ & $13.7 \%$ & $12 \%$ \\
\hline W2.4 & Metals & Metals & & $2.5 \%$ & $1.7 \%$ & $0.1 \%$ \\
\hline W2.5 & MSW density & MSW density & & - & $592 \mathrm{kgm}^{-3}$ & - \\
\hline W2.6 & Moisture content & Moisture conte & & - & $31.5 \%$ & - \\
\hline \multicolumn{7}{|c|}{ Physical components } \\
\hline 1.1 & \multirow{3}{*}{$\begin{array}{l}\text { Public health -waste } \\
\text { collection }\end{array}$} & \multicolumn{2}{|c|}{ Waste collection coverage } & $\begin{array}{l}82 \% \\
(\mathrm{M}) \\
\end{array}$ & $\begin{array}{l}75 \% \\
(\mathrm{M})\end{array}$ & $\begin{array}{l}77 \% \\
(\mathrm{M})\end{array}$ \\
\hline 1.2 & & \multicolumn{2}{|c|}{$\begin{array}{l}\text { Waste captured by the } \\
\text { system }\end{array}$} & $\begin{array}{l}75 \% \\
(\mathrm{M}) \\
\end{array}$ & $\begin{array}{l}53 \% \\
(\mathrm{~L} / \mathrm{M})\end{array}$ & $\begin{array}{l}80 \% \\
(\mathrm{M})\end{array}$ \\
\hline $1 \mathrm{C}$ & & \multicolumn{2}{|c|}{ Quality of waste collection } & $\begin{array}{l}\mathrm{M} / \mathrm{H} \\
(63 \%)\end{array}$ & $\begin{array}{l}M \\
(42 \%)\end{array}$ & $\begin{array}{l}M \\
(58 \%)\end{array}$ \\
\hline 2 & \multirow{2}{*}{$\begin{array}{l}\text { Environmental con- } \\
\text { trol -waste treatment } \\
\text { and disposal }\end{array}$} & \multicolumn{2}{|c|}{$\begin{array}{l}\text { Controlled treatment and } \\
\text { disposal }\end{array}$} & $\begin{array}{l}0 \% \\
(\mathrm{~L})\end{array}$ & $\begin{array}{l}62 \% \\
(\mathrm{~L} / \mathrm{M})\end{array}$ & $\begin{array}{l}8 \% \\
(\mathrm{~L}) \\
\end{array}$ \\
\hline $2 \mathrm{E}$ & & \multicolumn{2}{|c|}{$\begin{array}{l}\text { Degree of environmental } \\
\text { protection in waste treat- } \\
\text { ment and disposal }\end{array}$} & $\begin{array}{l}\mathrm{L} / \mathrm{M} \\
(21 \%)\end{array}$ & $\begin{array}{l}M \\
(60 \%)\end{array}$ & $\begin{array}{l}\mathrm{L} / \mathrm{M} \\
(37 \%)\end{array}$ \\
\hline
\end{tabular}

Continue 
Continued

\begin{tabular}{|c|c|c|c|c|c|}
\hline No. & Category & Indicator & Results & & \\
\hline 3 & \multirow{2}{*}{$\begin{array}{l}\text { Resource manage- } \\
\text { ment }\end{array}$} & Recycling rate & $\begin{array}{l}<5 \% \\
(\mathrm{~L})\end{array}$ & $\begin{array}{l}5 \% \\
(\mathrm{~L})\end{array}$ & $\begin{array}{l}35 \% \\
(\mathrm{M})\end{array}$ \\
\hline $3 \mathrm{R}$ & & $\begin{array}{l}\text { Quality of the 3Rs- Reduce, } \\
\text { reuse, recycle-provision }\end{array}$ & $\begin{array}{l}\mathrm{L} / \mathrm{M} \\
29 \%\end{array}$ & $\begin{array}{l}\mathrm{L} / \mathrm{M} \\
(38 \%)\end{array}$ & $\begin{array}{l}\mathrm{L} \\
(17 \%)\end{array}$ \\
\hline \multicolumn{6}{|c|}{ Governance aspects } \\
\hline $4 \mathrm{U}$ & \multirow{2}{*}{ Inclusivity } & User inclusivity & $\begin{array}{l}M \\
(46 \%)\end{array}$ & $\begin{array}{l}\mathrm{L} / \mathrm{M} \\
(33 \%)\end{array}$ & $\begin{array}{l}\mathrm{L} / \mathrm{M} \\
(37 \%)\end{array}$ \\
\hline $4 \mathrm{P}$ & & Provider inclusivity & $\begin{array}{l}\text { M } \\
(60 \%)\end{array}$ & $\begin{array}{l}\mathrm{M} \\
(50 \%)\end{array}$ & $\begin{array}{l}\text { M } \\
(50 \%)\end{array}$ \\
\hline $5 \mathrm{~F}$ & $\begin{array}{l}\text { Financial sustaina- } \\
\text { bility }\end{array}$ & Financial sustainability & $\begin{array}{l}\mathrm{M} / \mathrm{H} \\
67 \%\end{array}$ & $\begin{array}{l}\mathrm{L} / \mathrm{M} \\
(38 \%)\end{array}$ & $\begin{array}{l}\mathrm{M} \\
(54 \%)\end{array}$ \\
\hline $6 \mathrm{~N}$ & \multirow{2}{*}{$\begin{array}{l}\text { Sound institutions, } \\
\text { proactive policies }\end{array}$} & $\begin{array}{l}\text { Adequacy of national SWM } \\
\text { framework }\end{array}$ & $\begin{array}{l}\mathrm{L} / \mathrm{M} \\
29 \%\end{array}$ & $\begin{array}{l}\text { M } \\
(50 \%)\end{array}$ & $\begin{array}{l}\mathrm{L} / \mathrm{M} \\
(29 \%)\end{array}$ \\
\hline $6 \mathrm{~L}$ & & $\begin{array}{l}\text { Local institutional cohe- } \\
\text { rence }\end{array}$ & $\begin{array}{l}M \\
58 \%\end{array}$ & $\begin{array}{l}\mathrm{L} / \mathrm{M} \\
(33 \%)\end{array}$ & $\begin{array}{l}\mathrm{M} / \mathrm{H} \\
(62 \%)\end{array}$ \\
\hline
\end{tabular}

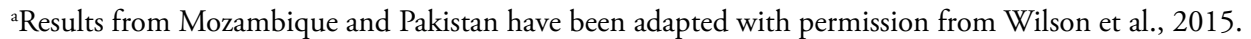
Legend: Performance levels in indicators and corresponding colour codes: low performance (L)-red; low/ medium performance (L/M)-red/orange; medium performance $(\mathrm{M})$-orange, medium/high performance $(\mathrm{M} / \mathrm{H})$-orange/green; and high performance $(\mathrm{H})$-green.

GNI: gross national income; MSW: municipal solid waste; SWM: solid waste management.

material swept from dirt floors in low-income areas of the city (Wilson et al., 2013). In the sections below, each benchmark and corresponding scores are presented and there is a description of the real-world facts 'behind' the scores.

\section{Benchmarking of the physical components}

\section{Waste collection benchmark}

The collection benchmark consists of two quantitative and one qualitative indicators. The quantitative indicators respectively measure: (1) the percentage of households with access to a reliable collection service; and (2) the proportion of the total MSW generated that is captured by the management system. The qualitative indicator determines the quality of collection based on six multi-attribute composite criteria.

\section{The facts behind the score}

Since 2011, collection in Accra has been franchised to eight formal service providers under an existing fee- and performance-based strategy, which responded to an earlier public private partnership agreement that was judged a failure, as the municipality and 


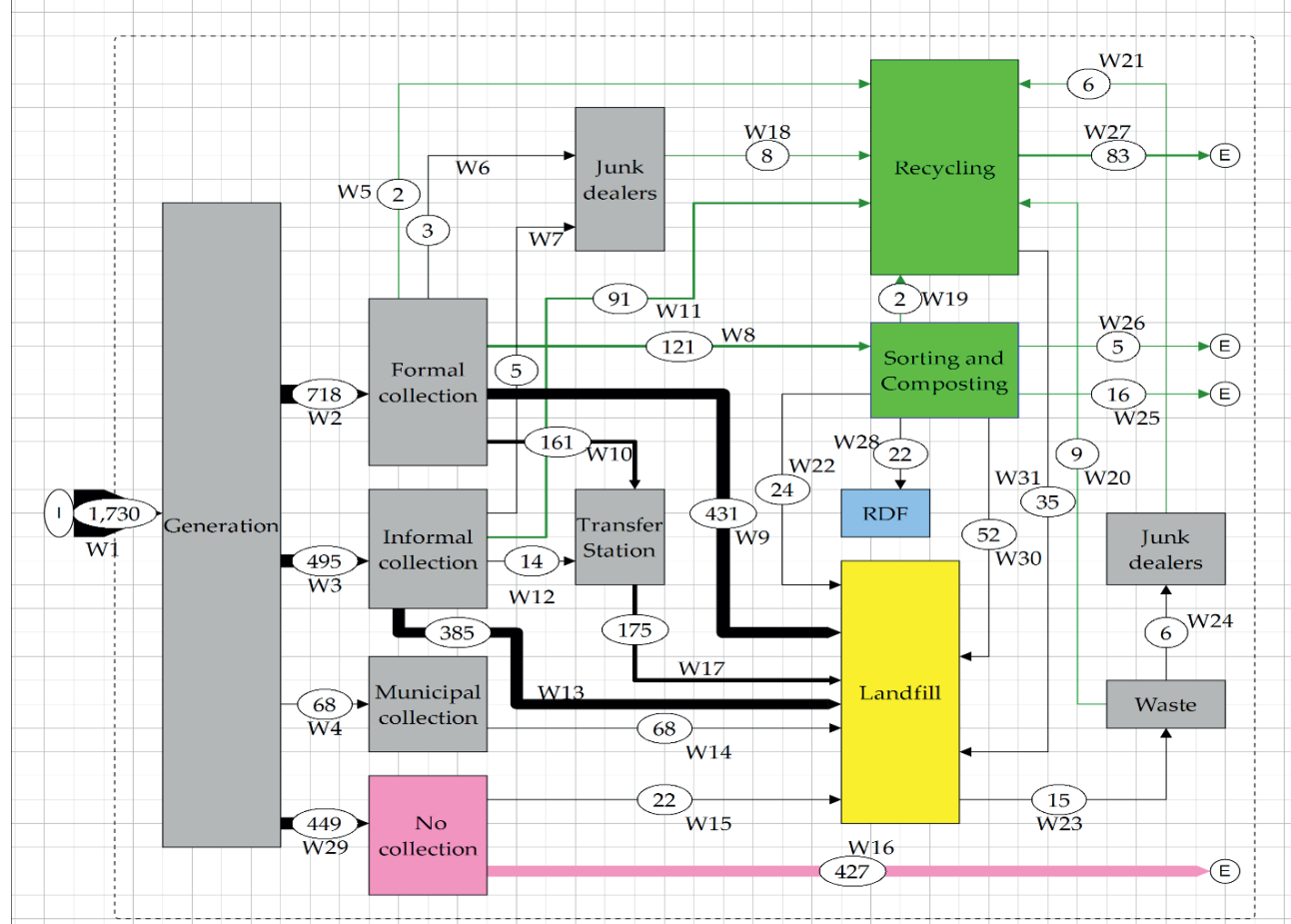

Figure 2.2: Process flow diagram of solid waste management in Accra.

Source: Based on computations and estimations of MSW in Accra using STAN 2.5( [Institute of Water Quality Resources and Waste Management - TU-Wien, Austria, 2016. Further details are in Table 2.2.
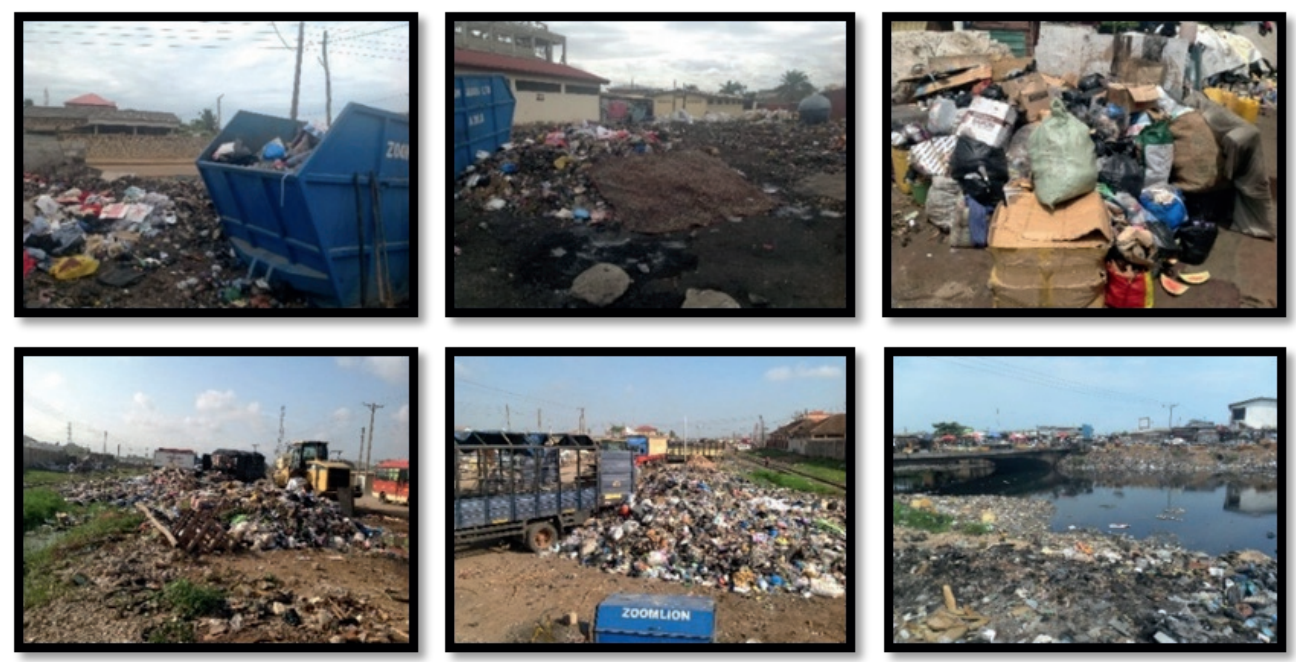

Figure 2.3: The quality of collection of MSW in Accra. Photos: Authors, 2016. 
Chapter 2

Table 2.2: Description of the various flows on the process flow diagram (PFD).

\section{Symbol Description}

W1 Daily MSW generated

W2 MSW collection by formal service providers

W3 MSW collection by informal sector

W4 MSW collection by the waste management department

W5 Recovered MSW by one formal service provider who promotes source separation

W6 Recyclable MSW sold to junk dealers by other formal service providers

W7 Recyclable MSW sold to junk dealers by informal collectors

W8 MSW collection to the Accra composting and recycling plant (ACARP)

W9 MSW collection to controlled landfills by formal service providers

W10 MSW collection by formal service providers to transfer station (Zoom Pak) for bulk transport to controlled landfills

W11 Recovered MSW by informal collectors to recycling industries

W12 MSW collection by informal collectors to transfer station

W13 MSW collection sent to a dumpsite by informal collectors

W14 MSW collection by the waste management department to controlled landfills

W15 Part of uncollected MSW, but collected once monthly in a clean-up exercise

W16 Uncollected MSW

W17 Total MSW collection through transfer stations

W18 Recyclable MSW sold to industries by junk dealers

W19 Recovered plastics after primary sorting at ACARP

W20 Recyclable MSW from landfill sites directly to industries by waste pickers

W21 Recyclable MSW from landfill sites to industries through junk dealers
Documentation of approach used for estimation

(Actual + transient population) multiplied by daily generation rate

$\mathrm{W} 5+\mathrm{W} 6+\mathrm{W} 8+\mathrm{W} 9+\mathrm{W} 10$

$\mathrm{W} 7+\mathrm{W} 11+\mathrm{W} 12+\mathrm{W} 13$

Average of daily records of the department

Average of daily records of the particular formal service provider, 2016

Estimated through interviews with the formal service providers

Estimated from junk dealers at the dumpsite

Average of daily records of ACARP, 2016

Average of daily records of controlled landfills, 2016

Average of daily Zoom Pak records, 2016

Estimated from informal collectors

Records of the formal service providers who transport it to controlled landfills.

Estimated after two weeks monitoring of site

Landfill records, W4

Average of collected amounts from January to July, 2016, divided by days involved

W29-W15

$\mathrm{W} 10+\mathrm{W} 12$

W6 + W7

Records of ACARP, 2016

Estimated from waste pickers on all landfill sites, W23-W24

W24

\section{Continue}




\section{Continued}

\begin{tabular}{|c|c|c|}
\hline Symbol & Description & $\begin{array}{l}\text { Documentation of approach used for } \\
\text { estimation }\end{array}$ \\
\hline W22 & $\begin{array}{l}\text { MSW residue to dumpsite after primary sorting } \\
\text { at ACARP }\end{array}$ & Records of ACARP, 2016 \\
\hline W23 & Recovered MSW by waste pickers from landfills & $\begin{array}{l}\text { Estimated from waste pickers on all } \\
\text { landfill sites }\end{array}$ \\
\hline W24 & $\begin{array}{l}\text { Recovered MSW from landfill sites sold to junk } \\
\text { dealers }\end{array}$ & W23-W20 \\
\hline W25 & MSW lost to the organic valorisation process. & Records of ACARP, 2016 \\
\hline W26 & Compost produced & Records of ACARP, 2016 \\
\hline W27 & Valuable material from recycling processes & $\begin{array}{l}\text { Estimated from recycling companies. } \\
70 \% \text { returns on value }\end{array}$ \\
\hline W28 & $\begin{array}{l}\text { Textiles recovered from MSW and stored as refuse } \\
\text { derived fuel on the premise of ACARP for future } \\
\text { market }\end{array}$ & Estimated from records of ACARP, 2016 \\
\hline W29 & Uncollected MSW & W1-W2-W3-W4 \\
\hline W30 & $\begin{array}{l}\text { Residues sent to dumpsite by ACARP after the } \\
\text { composting process }\end{array}$ & Estimated from records of ACARP, 2016 \\
\hline W31 & $\begin{array}{l}\text { Residues sent back to landfills by recycling indus- } \\
\text { tries }\end{array}$ & $\begin{array}{l}\text { Estimated from recycling companies. } \\
30 \% \text { rejects to landfills }\end{array}$ \\
\hline $\mathrm{E}$ & End of process & \\
\hline
\end{tabular}

MSW: Municipal solid waste; ACARP: Accra composting and recycling plant.

formal service providers failed to improve environmental conditions (Oduro-Kwarteng and van Dijk, 2013; Oteng-Ababio et al., 2013).

The formal service providers make use of two main collection systems: primary collection (door-to-door) using compaction collection vehicles in high- and middle-income areas; and communal container collection, using skip loaders mostly in low-income areas and markets. Primary collection frequency for a $240-\mathrm{L}$ bin is once a week, but that of the skips is dependent on when and as it is full.

The performance-based strategy aims: (1) to increase primary collection coverage to $100 \%$ through the private sector in a 5-year franchise agreement; and (2) to shift the responsibility for fee collection to these franchise-holders. Figure 2.2 shows the entire process flow.

Our results document that the performance-based strategy has significantly failed to increase formal collection coverage by the eight franchisees, and has had the perverse effect of stimulating an increase in informal service provider reach. Informal micro- 
collectors (about 350 in number) with motorised tricycles (1.1 tons) collect $28 \%$, or $385 \mathrm{t}$ (see Figure 2.2) of municipal solid waste, and dispose in a dumpsite developed out of a wetland by private individuals; a reason to the relatively low waste capture in the city.

The MSW department itself collects $68 \mathrm{t}$ from markets, parking lots and other public areas to compensate for non-compliance by formal service providers. Based on the total amount of waste generated and collected by the various stakeholders, the percentage of MSW uncollected is assumed by the stakeholders to amount to $26 \%$ (449 t) as shown in Figure 2.2, and that this waste ends up in drains, vacant plots, streets and beaches, or is burnt by residents.

\section{Waste treatment and disposal benchmark}

The WasteAware ISWM indicator for disposal assesses the total MSW sent for treatment or disposed of in an engineered or controlled facility, and the degree of environmental protection. The assessment score is $62 \%$ and of medium quality.

\section{The facts behind the score}

The city itself has never had a controlled landfill (Oteng-Ababio, 2010), and World Bank financing between 1998 and 2012 to support the construction of an engineered landfill failed owing to siting problems. Formal service providers dispose of waste in two controlled disposal facilities within a $45-\mathrm{km}$ radius of the city and one state-of-the-art composting plant. Both controlled disposal facilities charge a tipping fee of US\$6 per tonne, representing $50 \%$ of their explicit operating costs, and receive a $50 \%$ subsidy for the rest. Together they receive an estimated 606 tons of MSW from the city of Accra as shown in Figure 2.2. The Tema landfill was constructed in 2013 as a sanitary landfill, but is currently functioning at the level of a controlled facility and taking 400 tons per day above its design capacity of 500 tons per day. Both disposal facilities have working weigh-bridges that record the tonnes of MSW received. Informal service providers pay US $\$ 2$ to the city's dumpsite managers (and do not pass a weighbridge). Both controlled dumpsites will be full within 2 years, according to current estimates.

\section{Recycling and recovery benchmark}

The recycling benchmark assesses the rate of recycling and the quality of the 3Rs (reduce, reuse and recycle). The recycling rate at 5\% scores low, as shown in Table 2.1.

\section{The facts behind the score}

All recycling takes place in the private formal and informal sector, and all recyclables go to the commercial value chains. An umbrella organisation of plastic manufacturing companies in the city collects recyclable plastics from strategic markets and shopping 
malls. The programme, together with private informal collectors of paper and plastics, mostly from institutions, hotels and restaurants, account daily for 91 tons of recyclable material to paper and plastic recycling industries as shown in Figure 2.2. One formal service provider, Jekora Ventures, contributes 2 tons of paper and plastics to the recycling industry through an innovative source separation programme within his coverage area. Collection vehicle attendants and informal micro-collectors together retrieve approximately 8 tons of plastics and aluminium cans that are sold to junk dealers for onward delivery to recycling industries. Organised waste pickers from the two controlled landfills and the dumpsite together retrieve 15 tons of recyclable MSW to the industries as shown in Figure 2.2. Quality of materials is poor, as 30\% of all materials collected for recycling are rejected during processing and disposed at the Tema landfill.

The Accra recycling and 'windrow' composting plant - located at Adjen Kotoku, about $40 \mathrm{~km}$ North of Accra - operates under public-private partnership (PPP) arrangement and receives a government subsidy, comparable with that received for disposal sites. It has a design capacity of 600 tons per day, and is currently receiving and processing, on average, 300 tons of mixed MSW from Accra and its neighbouring municipalities. Accra's contribution to the plant, a state-of-the-art integrated recycling and windrow system, is 121 tons, of which only $4 \%$ is sold in $50 \mathrm{~kg}$ bags for US\$10 per bag, with a $67 \%$ government subsidy to stimulate beneficial use among estate developers and farmers. The other $96 \%$ of inputs evaporates or is lost as runoff, is diverted to recycling or is rejected during sorting or as post-process fines after mechanical screening.

\section{Results: Governance aspects}

\section{Inclusivity benchmark}

The user inclusivity indicator benchmarks the degree to which stakeholders can influence the city's decision-making processes and operations. Accra scores very low on user inclusivity. Provider inclusivity measures the degree to which service providers have access to economic and operational niches in solid waste and recycling. Accra performs relatively better on this indicator, with a medium score.

\section{The facts behind the score}

There is no equity of service between the income divides and areas. Even where there are legal or policy instruments that would allow system users to participate, these are not respected in practice. There are no stakeholder platforms nor do elected representatives care about what the users think about plans or performance. Not surprisingly, residents understand the city's top-down management of waste services as autocratic and insensitive to their preferences. One consequence is the low subscription rate for formal 
collection services, and the significant abandonment of the formal options for lowercost informal service provision with higher client friendliness.

Legal frameworks (Ghana Government, 1993) exist to support private sector participation, and $95 \%$ of MSW collection is by the private sector. These arrangements ignore the contribution and potential of informal service providers. Most formal PPP arrangements in MSW are between the central government and the private sector with no transparency to the users nor to the waste management department (WMD), and the official franchise agreements do not respond to user concerns. Enforcement by the municipality is irregular, and there are no sanctions for non-compliant service provision. Procurement laws (Ghana Government, 2003) are designed to promote open and transparent competition, but users suspect the process of corruption (Oteng-Ababio, 2010).

Official provider inclusivity is incomplete, as the entire informal service sector is held outside of the franchising system. This is paradoxical, since failures in service, transparency and affordability in the formal system have resulted in more than a third of households migrating to informal or semi-formal service providers (ISSPs), who currently collect more than a third of all MSW in Accra.

The benchmarking exercise has contributed to the growing awareness by city authorities and service beneficiaries of the value delivered by the ISSPs, and has perhaps created momentum towards a process to recognise and integrate their activities into the formal system in the near future. Despite this, the overall system guarantees a good balance of public and private sector interests by designing service contracts with clear objectives and relatively long durations.

\section{The facts behind the score}

Funding for solid waste is a shared responsibility between the municipality and service users. Users pay for collection services and the municipality theoretically subsidises disposal from the general fund, but often fails to pay on time - or at all. This failure to reimburse the providers, undermines the environmental and financial sustainability of the system.

Moreover, the full cost of MSWM in Accra is unknown. The available data since 2013 suggests that authorities spend more than $100 \%$ of the allocated budget as shown in Table 2.3; the yearly budgets are based on previous expenditures and do not pass the review of the waste management department. 
Table 2.3: Expenditures for MSW collected by the waste management department.

\begin{tabular}{llll}
\hline Year & Collection & \multicolumn{2}{c}{ \% increase } \\
\cline { 2 - 3 } & Budget (US\$) & Expenditure (US\$) & \\
\hline 2013 & $1,542,391.00$ & $3,291,048.67$ & $113 \%$ \\
2014 & $1,579,385.67$ & $3,384,389.67$ & $114 \%$ \\
2015 & $1,638,686.67$ & $3,555,823.00$ & $117 \%$ \\
\hline
\end{tabular}

Source: Accra Metropolitan Assembly, 2016.

A cross-subsidy scheme for once a week collection of a 240-L MSW storage container allows users in low-income areas to pay a subsidised monthly fee of US\$6, while users in middle- and high-income areas are paying US $\$ 20$ and US $\$ 35$, respectively. But even with subsidy, this is not affordable in practice, and as a result, users pay what they can, via side agreements with their service providers; alternatively, they migrate to less expensive, 'leaner, ISSPs. Commercial and institutional clients pay US $\$ 50$ for the same service.

\section{Sound institutions and proactive policies benchmark}

Good governance has proven to be more essential than investment or technology in creating and maintaining effective SWM systems, and this is the motivation for benchmarking institutions and policies (Bhuiyan, 2010; Wilson et al., 2015a). The two qualitative composite indicators used in this assessment focus on:

- the adequacy of a national framework regulating the implementation of legislations and policies on MSW and the human resource; and

- the organisational strength and coherence of the institutions managing the MSW system

The city's performance on these dimensions, as shown in Table 2.1, shows a strong need for improvement.

\section{The facts behind the score}

At the national level, there is no solid waste law, nor any waste management master plan nor is there any coherent legislative framework for environmental services (Asase et al., 2009). There is an environmental sanitation policy with accompanying strategy and investment plan (Ghana Government, 2010), but the environmental health and sanitation directorate, responsible for its coordination and implementation, is not wellresourced. The landfill and the monitoring of environmental sanitation services manuals developed in 2002 by the environmental protection agency (EPA) of Ghana are the only guidelines for SWM in Accra. The legal framework is fragmented (Asase et al., 2009), and articles relating to MSW are distributed in a variety of acts and codes. Each 
municipality has regulations on the procurement of services, service quality of providers, fixing of service charges and enforcement and sanctions, but these are neither transparent nor monitored, and in practice have little influence on service delivery on the ground.

There is comprehensive legislation within the EPA (a well-resourced agency), but commitment to enforcement is weak, especially when it relates to public sector departments and operations. Extended producer responsibility is not part of the SWM system of the city, although a proposed central government ban on plastics has created enough pressure that some packaging and consumer products companies are discussing product stewardship. Proposals for a national solid waste fund are stalled as a result of disagreements in ideas and approaches.

A significant amount of the planning, budgeting and implementation of SWM activities in Accra is the responsibility of the waste management department, but their jurisdiction does not extend to removal of widespread illegal or informal accumulations of waste, which are also not included in the budget. A variety of other administrative units remove heaps without approval, oversight, verification or basic knowledge of the department, but are invoiced to the waste management department, and approved and paid by the finance department. The Metropolitan Public Health Department (MPHD) has the responsibility of acting upon complaints of service users, sanctioning non-performing service providers and enforcing byelaws, but conflicts in bureaucratic claims between MPHD and the waste management department frustrate the efficient execution of such functions. The waste department is understaffed, and staff have little access to training or professional improvement.

\section{Conclusions and recommendations}

The WasteAware benchmarking exercise has illuminated many inadequacies in the physical and governance aspects of the MSWM system in Accra. Accra's performance is poorer than that of the low-income Maputo, and lower-middle-income Lahore, in all indicator sets with exception to environmental control, quality of the 3Rs and adequacy of the national SWM framework, but even these scores are low considering Ghana's economic strength. Despite the introduction of the fee- and performance-based MSW collection strategy in 2011, there is little movement towards the goal to increase formal coverage to $100 \%$. Total collection coverage stands at $75 \%$, well below corresponding scores for Maputo, Lahore and the $88 \%$ average for lower-middle-income countries of the Habitat Book reference cities (Wilson et al., 2015a; Wilson et al., 2012). The contribution of formal service providers to collection coverage has dropped from $60 \%$ (Oduro-Kwarteng and van Dijk, 2013) to 55\%, while informal collection coverage shows significant growth. Accra, like other cities in developing countries, relies heavily 
on land burial for waste treatment and disposal, but has neither any controlled nor any sanitary landfills. Dependency on neighbouring municipalities means that the system is weak at its core. Creating its own modernised and environmentally appropriate disposal is thus a priority.

The current situation has a strong involvement of formal private waste companies, to the extent that the private collectors operate largely without municipal supervision or enforcement. Their ability to do this is strengthened by the city's poor track record in paying for disposal and honouring payment obligations in the franchise agreements. The situation calls for a review of the mandate of the WMD to modernise and manage the system; and invest in staff capacity development in budget preparation, project management, communications, M\&E and enforcement. The environmental health and sanitation directorate, the environmental protection agency and the waste management department are institutionally in the most logical position to take charge of solid waste governance.

The process flow diagram will assist practitioners to comprehend the entire MSWM system. Although the current challenges are broad in scope, cooperation and support from both political and administrative leaders during the research process has provided the authors with some level of optimism. The use of working groups and the WasteAware benchmark indicators has set the path and example for future inclusion and involvement of relevant stakeholders in the assessment and decision-making process of the MSWM system. It is time for all stakeholders to make some clear choices and take decisions on a strategy to deliver a clean city. A SWOT (strengths, weaknesses, opportunities, threats) analysis alongside a risk assessment of the system, can be used to prepare staff and stakeholders to work together towards an ISWM approach to the development of interventions. The path to improvement in the performance of the physical components lies partly in the recognition, integration and regulation of the informal sector as important contributors to the system. It needs to be accompanied by the formation of a permanent stakeholder platform that anchors inclusivity in all processes of planning, implementation and M\&E.

The city's MSWM system requires a clear strategy. Regular and systematic appraisals, critical scrutiny of offers for projects and interventions - whether internally conceived or proposed by development partners - should be keyed to practical implementation and structural improvement that fit the strategy (Van de Klundert et al., 2001). The path to improvement requires strong political will and commitment (Wilson et al., 2013). Moving towards a more democratic control of operational institutions would be a step towards institutional anchoring, stabilising gains and improving the dynamics of good MSW governance (Marshall and Farahbakhsh, 2013). 


\section{Acknowledgements}

We are grateful to all stakeholders who participated in the assessment and acknowledge the municipality for granting us the permission for the research in the city.

\section{Declaration of conflicting interests}

The authors declared no potential conflicts of interest with respect to the research, authorship, and/or publication of this article.

\section{Funding}

The authors disclosed receipt of the following financial support for the research, authorship, and/or publication of this article: The corresponding author has received a grant for his $\mathrm{PhD}$ research in the framework of the NUFFIC project [grant number CF9419] from the Dutch government. 
Assessment of the municipal solid waste management system in Accra, Ghana 


$$
3
$$




\section{Chapter 3}

\section{Locally responsive intervention to improve municipal solid waste collection coverage in Accra, Ghana}

This chapter has been published as:

K. Oduro-Appiah*, A. Scheinberg, A. Mensah, V. Kotey, A. Afful, \& N. de Vries (2017). Locally responsive intervention to improve municipal solid waste collection in Accra, Ghana. In Proceedings of the 40th WEDC International Conference, Paper 2713, Loughborough, UK, 24th July, 2017. 


\title{
Chapter 3
}

\begin{abstract}
The paper reports on a process that engaged stakeholders to assess the strengths and weaknesses of the city of Accra's approach to raising solid waste collection coverage. Stakeholders, working with researchers, have made the evaluation using a combination of benchmark indicators, analysis of franchise agreements, process flow diagramming of collection trends, and statistical analysis of user answers to a survey. Informal services are growing while formal services are shrinking. A logistic regression model suggests that regular collection and affordable user charges significantly increases the levels of user satisfaction. The use of a participatory approach has led to an unusual alliance: formal service providers have agreed to work with informal providers as subcontractors and support them to formalise and increase collection coverage. The positive experience of participation leads the authors to advocate institutionalising the use of a participatory approach through stakeholder platforms to evaluate interventions and develop plans for service improvement.
\end{abstract}




\section{Introduction}

While scholars see gradual improvement in collection coverage in middle-income countries (Wilson et al., 2013), in sub-Saharan Africa, the average coverage remains below 88\%, especially in lower middle-income cities (Wilson et al., 2012). The tendency of local authorities to choose for private sector participation has more to do with the political difficulties involved in improving public sector operations, than in a genuine interest in what the private sector has to offer. Moreover, the authorities' focus on formal sector privatisation appears to be misplaced, when informal micro-enterprise service providers can do a better job at a lower cost (Coffey and Coad, 2010; Kirama and Mayo, 2016; Ishengoma, 2006).

What would it take large cities in lower middle-income countries to improve municipal solid waste (MSW) collection coverage and quality? What role can stakeholders take in planning, and how do systems users evaluate their collection service providers? When the formal sector is losing ground, while the informal sector contributes to improved collection coverage, how can stakeholders work together to recognise and institutionalise the informal sectors' role in improvement? These were leading questions in the investigation of strategies for improving the performance of the MSW system in Accra, the capital city of Ghana.

The city began with initiatives to improve collection coverage in 2011 through a feeand performance-based strategy. The strategy had two key aspects: first, to offer the private sector an opportunity to bid competitively to participate in a 5-year franchise agreement (Oduro-Appiah et al., 2013), and secondly, to shift the responsibility for payment collection for services to these same franchise-holders. The municipality has retained for itself certain control functions, such as responsibility to: set the user charges; improve legislation, regulation and enforcement; and support the providers to deliver an efficient service, through monitoring and evaluation (Oteng-Ababio, 2010; OduroKwarteng and van Dijk, 2013).

This initiative, while promising, has over the past 20 years failed to raise coverage through formal channels. In the meantime, the informal micro-enterprise collection sector, is collecting more than a third of all MSW collected in the city, and their activity is responsible for the $25 \%$ increase in coverage recorded in the same five-year period since 2011. The literature also supports and documents the potential of informal service provision to sustainably improve MSW collection services (Andrianisa and Brou, 2016), through processes that integrate the informal sector into formal frameworks for waste collection and recycling (Velis et al., 2012; Scheinberg et al., 2016; Ishengoma, 2006; 


\section{Chapter 3}

Masood and Barlow, 2013). Positive aspects of working with micro-privatisation of informal and community enterprises, especially in African cities, include;

- affordable user charges set by informal service providers to ensure that they have enough clients;

- "lean" operations based on simple technologies, affordable equipment, and lower profit demands

- personalised services and anchoring in the community; and

- preference to invest in personnel than in technology

There are also disadvantages of relying on the informal service sector, including the fact that they may not (always) pay taxes, nor (normally) use permitted disposal facilities, nor operate in the formal financial sector. These disadvantages are important at system level, but they have not prevented users from working with informal providers, and in the process, the informal sector is meeting public sector goals to increase collection coverage in a case where the formal sector is making no progress.

Despite mounting evidence of the advantages of this form of inclusive private sector participation, waste managers and local government officials are reluctant to believe that this will improve their system. Nor do the traditional approaches to planning produce a blueprint for co-operation with micro-enterprises. If the situation is to improve in our cities, something has to change in this regard.

In support of improving the waste situation in Accra, this paper looks at the potential to identify affordable pathways to sustainable improvement of waste systems by shifting the approach in the direction of consultation and engagement with stakeholders, through Integrated Sustainable Waste Management (ISWM), and away from reliance on donors and international consultants (Wilson et al., 2013; IJgosse et al., 2004). The main technique used, has been to create a working group of relevant stakeholders to assess the current strategy and work on improvements to expand the eligibility for service provision to informal service providers. The focus is to encourage MSW practitioners in low- and lower middle-income countries to reconsider their dependency on misplaced technologies and formal service providers, and initiate locally responsive paths that creates ownership and empowers service beneficiaries and the informal sector to contribute to improvement in collection services. 


\section{Methodology}

The authors selected Accra as an example of a city with commitment to improving collection coverage, and a problem with the strategy that was selected in 2011. The working group assessed the system within a 25 -week period from March to August, 2016. The overall collection coverage and quality, in addition to the level of user and provider inclusivity, was assessed using the 'WasteAware' benchmark indicators (Wilson et al., 2015a). The operational efficiency of formal service providers and the municipality was further assessed by checking compliance with obligations in the franchise agreements, supplemented by consultations with the environmental service providers' association. The satisfaction of users, and their opinion in relation to both formal and informal service providers, was researched through administering a survey to a stratified random sample of 700 households, institutions, and commercial centres in three socio-economically stratified residential areas: high-income, middle-income and low-income. The results were validated through interviews with retired practitioners and some development partners to understand the history and current state of the solid waste system.

\section{Data analysis}

The survey data was cleaned of errors and descriptive and inference statistics were used to explore and interpret the findings. Quantitative and qualitative assessment scores were entered into the 'WasteAware' automated excel forms to compute aggregate scores (Wilson et al., 2015a) . Similar scores were provided by the formal service providers, the working group and the municipality towards the obligations of the franchise agreement. The responses to the questionnaires items were coded, categorised, entered and analysed by means of the statistical package for service solution software, version 23.0. Logistic regression was used to determine the factors that significantly influence service satisfaction (Field, 2013; Pallant, 2016). The dependent categorical variable was service satisfaction and the explanatory variables were the provision of free bins, avenues for complaint and redress, public education, knowledge of users in the determination of service charges, and regularity of user payment: a function of affordability and MSW collection reliability. A total of 302 of the 583 respondents were clients of the formal providers, and 269 respondents were clients of the informal providers.

\section{Results and discussion}

\section{'WasteAware' benchmark indicators}

The assessment result is shown in Table 3.1. The "traffic light" system of coding the results as red, orange and green, indicating respectively low $(\mathrm{L})$, medium $(\mathrm{M})$, and high $(\mathrm{H})$, 
Table 3.I: WasteAware' benchmark indicator results of Lahore, Pakistan; Accra, Ghana; and Guadalajara, Mexico.

Results from Pakistan and Mexico, taken with permission from Wilson et.al, 2015 is solely for comparison and comprehension purposes.

\begin{tabular}{|c|c|c|c|c|c|}
\hline No. & Category & Indicator & Results & & \\
\hline City & & & Lahore & Accra & Guadalajara \\
\hline Coun & try & & Pakistan & Ghana & Mexico \\
\hline \multirow[t]{2}{*}{ B1 } & \multirow[t]{2}{*}{ Income level } & $\begin{array}{l}\text { World Bank income } \\
\text { category }\end{array}$ & Lower-middle & Lower-middle & Upper-middle \\
\hline & & GNI capita $^{-1}$ & $\$ 1,140$ & $\$ 1,480$ & $\$ 9,640$ \\
\hline B2 & Population & City population & $8,160,000$ & $1,936,836$ & $4,664,924$ \\
\hline B3 & Waste generation & $\begin{array}{l}\text { MSW generation } \\
\text { (tonnes year }{ }^{-1} \text { ) }\end{array}$ & $1,1916,000$ & 631,506 & $2,000,000$ \\
\hline 1.1 & \multirow{3}{*}{$\begin{array}{l}\text { Public health -waste } \\
\text { collection }\end{array}$} & $\begin{array}{l}\text { Waste collection } \\
\text { coverage }\end{array}$ & $77 \%(\mathrm{M})$ & $75 \%(\mathrm{M})$ & $\begin{array}{l}95 \% \\
(\mathrm{M} / \mathrm{H}) \\
\end{array}$ \\
\hline 1.2 & & $\begin{array}{l}\text { Waste captured by the } \\
\text { system }\end{array}$ & $80 \%(\mathrm{M})$ & $\begin{array}{l}53 \% \\
(\mathrm{~L} / \mathrm{M}) \\
\end{array}$ & $\begin{array}{l}95 \% \\
(\mathrm{M} / \mathrm{H}) \\
\end{array}$ \\
\hline $1 \mathrm{C}$ & & $\begin{array}{l}\text { Quality of waste } \\
\text { collection }\end{array}$ & $\begin{array}{l}\text { M } \\
(58 \%) \\
\end{array}$ & $\begin{array}{l}M \\
(42 \%)\end{array}$ & $\begin{array}{l}\mathrm{M} \\
50 \% \\
\end{array}$ \\
\hline $4 \mathrm{U}$ & \multirow{2}{*}{ Inclusivity } & User inclusivity & $\begin{array}{l}\mathrm{L} / \mathrm{M} \\
(37 \%) \\
\end{array}$ & $\begin{array}{l}\mathrm{L} / \mathrm{M} \\
(33 \%) \\
\end{array}$ & $\begin{array}{l}\text { M } \\
(46 \%)\end{array}$ \\
\hline $4 \mathrm{P}$ & & Provider inclusivity & $\begin{array}{l}\text { M } \\
(50 \%)\end{array}$ & $\begin{array}{l}\text { M } \\
(50 \%)\end{array}$ & $\begin{array}{l}\mathrm{L} / \mathrm{M} \\
(40 \%)\end{array}$ \\
\hline
\end{tabular}

with intermediate scores as well (Wilson et al. 2015) is a reflection of the performance of the system in the indicators. For example, the number of households with access to reliable collection service (waste collection coverage) from both formal and informal service providers stands at $75 \%$, classified as moderate with an orange colour. The quality of collection (1C) measured by a six multi-attribute composite criteria (Wilson et al., 2015a) is classified as medium at $42 \%$. The contribution of formal service providers to collection coverage has dropped from $60 \%$ to $55.1 \%$ (Oduro-Kwarteng and van Dijk, 2013), while informal collection coverage shows robust growth.

Provider inclusivity is moderate. The informal providers' collects $38 \%$ of MSW in the city and, since 2011 , have been the sole contributors to a $25 \%$ increase in collection coverage. Almost half, or $47.1 \%$, of service users subscribe to informal services and $89.9 \%$ appreciate their contribution to the system, suggesting that recognition and integration into the formal system is occurring - but is currently limited to the point of view of the users (Alamgir et al., 2012; Lederer et al., 2015).

With the exception of provider inclusivity, Accra's performance in the benchmark indicators compares unfavourably to that of Lahore and Guadalajara, suggesting that the fee- and performance-based MSW privatisation strategy has been neither effective 
Table 3.2: Assessment scores on adherence to obligations of the agreement on the strategy.

\begin{tabular}{|c|c|c|c|}
\hline No. & Obligation & Score & Observations \\
\hline \multicolumn{4}{|c|}{ Contractor Obligations } \\
\hline 1 & Register all service beneficiaries & $50 \%$ & $\begin{array}{l}25 \% \text { of beneficiaries are with the informal service } \\
\text { providers. The rest are not covered. }\end{array}$ \\
\hline 2 & $\begin{array}{l}\text { Supply } 240 \text { litre bins to clients for } \\
\text { free. }\end{array}$ & $55 \%$ & $\begin{array}{l}\text { It is financially unsustainable to seven out of the } \\
\text { eight formal service providers and also found not } \\
\text { to significantly influence beneficiary satisfaction } \\
\text { (Table 3.3). }\end{array}$ \\
\hline 3 & Collect MSW 2 times a week & $0 \%$ & Once a week is the practice. \\
\hline 4 & Educate client on strategy & $32 \%$ & Education is neither planned nor organised. \\
\hline 5 & Maintain clean sanitary sites & $25 \%$ & $\begin{array}{l}\text { There is high incidence of littering at MSW collec- } \\
\text { tion sites. }\end{array}$ \\
\hline 6 & $\begin{array}{l}\text { Increase primary coverage and redu- } \\
\text { ce to zero, secondary coverage. }\end{array}$ & $70 \%$ & $\begin{array}{l}\text { Poor roads and housing arrangements, and unaf- } \\
\text { fordable charges are restricting factors. }\end{array}$ \\
\hline 7 & $\begin{array}{l}\text { Collect approved fees from all waste } \\
\text { generators. }\end{array}$ & $55 \%$ & $\begin{array}{l}\text { Cross-subsidised user charges of US } \$ 50 \text {, US } \$ 35 \text {, } \\
\text { US } \$ 20 \text {, and US } \$ 6 \text { per month for commercial, } \\
\text { high-, middle- and low-income clients respectively } \\
\text { are unaffordable. Service providers negotiate with } \\
\text { clients for a } 35-50 \% \text { rebate. }\end{array}$ \\
\hline 8 & $\begin{array}{l}\text { Respond to complaints from service } \\
\text { beneficiaries within } 24 \text { hours. }\end{array}$ & $40 \%$ & $\begin{array}{l}\text { Complaints are not properly recorded and monito- } \\
\text { red. Most providers do not have complaint desk. }\end{array}$ \\
\hline 9 & $\begin{array}{l}\text { Maintain at all times a functional } \\
\text { office within assigned area of work. }\end{array}$ & $75 \%$ & $\begin{array}{l}\text { Two of the providers do not have functional } \\
\text { offices. }\end{array}$ \\
\hline
\end{tabular}

\section{Municipal Obligations}

10 Inspect collection vehicles biennially.

11 Promulgate and enforce byelaws to prevent unauthorised MSW collectors.

12 Enforce byelaws to make MSW of generators available to formal service providers.

13 Educate public on MSWM policies 10\% and the collection strategy.

14 Assist providers to register clients $20 \%$ and validate same.

15 Ensure service providers have access 50\% at all times to disposal sites

16 Undertake monitoring to ensure $10 \%$ maximum performance.

17 Sanction service providers who do $0 \%$ not perform satisfactorily.
$20 \%$ Vehicles are not monitored until a failure in service delivery

$0 \% \quad$ No such laws have been promulgated. Informal collectors operate freely in franchised zones of formal providers.

0\% Service beneficiaries choose their providers without regard to byelaws.

Short-term education is often triggered by disasters such as cholera outbreaks and flooding of the city.

Support is occasionally provided by the public health department of the municipality.

The municipality relies on privately owned disposal sites and have limited control over the sites.

Monitoring of service is rarely done.

Recommendations are in reports, but there are no records of sanctioning of poorly performing providers since implementation of the strategy. 
nor efficient. User inclusivity (access of users to participate in planning, decision-making and feedback in relation to the solid waste system) is relatively low, as shown in Table 3.1. Among the possible explanations to the poor system performance, the authors give the most weight to: the ad hoc development of the collection strategy; the lack of user inclusivity; an unanticipated increase in service charges; and the failure of both city authorities and contractors in meeting the obligations set out in the franchise agreement.

\section{Franchise agreement}

The working groups' assessment of provider compliance with the franchise agreement is shown in Table 3.2. The formal providers are responsible for the initial nine obligations, the rest being the responsibility of the municipality. Both parties have failed to meet their obligations, with the municipality's performance being further from the goal. In terms of the system, the decision to require franchisees to collect twice a week was ad hoc, and is not supported by either research or practice. The obligation to provide free 240 litre bins to service beneficiaries has not been financially sustainable to service providers. Both parties proved unable either to educate users or to respond effectively to complaints of service beneficiaries towards increased cooperation and coverage. Further service improvements as a result of better communication can be expected in the future, if the municipal authorities are willing to institutionalise a stakeholder platform to support solid waste activities (IJgosse et al., 2004). A stakeholder platform provides a natural path to improve governance and develop capacities of involved officials and staff in relation to communication, advocacy, project management and, monitoring and evaluation (Herat, 2015; IJgosse et al., 2004).

\section{Beneficiary survey}

The full model with all predictors was statistically significant, $\chi^{2}(5, \mathrm{~N}=223)=11.38$, $\mathrm{p}<0.05$ and was able to distinguish between respondents who were satisfied and those who were not satisfied. The model explained between $50 \%$ and $70 \%$ of the variance in satisfaction and correctly classified $70.4 \%$ of all cases (Pallant, 2016). A total of $41.3 \%$ of respondents were from the low income areas, with $39.5 \%$ and $19.2 \%$ from the middleand high-income areas respectively. A total of $45 \%$ of respondents from middle-income areas subscribe to formal service provision; with $56.9 \%$ of subscribers to informal collection service residing in low-income areas. Only user payment regularity, a function of collection service reliability and user charge affordability (Kassim and Ali, 2006) made a unique statistically significant contribution to the model at an odds ratio of 3.01 as shown in Table 3.3. Respondents who paid regularly to the service providers were three times more satisfied with the performance of the providers than those who were not regular in their payment, controlling all other factors in the model. This suggests that the cross-subsidy to users in low-income areas has a perverse result, and that measures to increase affordability could actually work to bring down subscription and coverage rates 
in these areas, alongside the contribution of poor road networks to the low subscription level. Affordability and higher frequency of collection clearly contribute to the relatively high subscription levels to informal service provision in middle-income areas. We find a weak, positive, but significant correlation $(\rho=0.287, \mathrm{n}=583, \mathrm{p}<0.001)$ between respondents' socio-economic divide and subscription to the type of service.

Table 3.3: Logistic regression estimates of service beneficiary satisfaction to formal service providers of the MSW collection strategy in Accra, Ghana.

\begin{tabular}{|c|c|c|c|c|c|c|c|c|}
\hline & \multirow{2}{*}{ B } & \multirow{2}{*}{ S.E. } & \multirow{2}{*}{ Wald } & \multirow{2}{*}{ df } & \multirow{2}{*}{$\mathbf{p}$} & \multirow{2}{*}{$\begin{array}{l}\text { Odds } \\
\text { Ratio }\end{array}$} & \multicolumn{2}{|c|}{ 95\% C.I } \\
\hline & & & & & & & Lower & Upper \\
\hline Free bin provision & -0.38 & 0.30 & 1.57 & 1 & 0.21 & 0.69 & 0.38 & 1.24 \\
\hline Avenue for complaint and redress & -0.24 & 0.31 & .59 & 1 & 0.44 & 0.79 & 0.43 & 1.44 \\
\hline Payment regularity & 1.10 & 0.47 & 5.41 & 1 & .02 & 3.01 & 1.19 & 7.60 \\
\hline Education on strategy & 0.24 & 0.45 & 0.29 & 1 & 0.59 & 1.27 & 0.53 & 3.08 \\
\hline $\begin{array}{l}\text { Knowledge of determinants of user } \\
\text { charges }\end{array}$ & 1.28 & 1.08 & 1.42 & 1 & 0.23 & 3.6 & 0.44 & 29.76 \\
\hline Constant & 0.04 & 0.49 & 0.01 & 1 & 0.94 & 1.04 & & \\
\hline
\end{tabular}

\section{Lessons Learnt}

- The participatory determination of user charges based upon an affordable, transparent, and fair cost recovery model, represent the highest single determinant to promote understanding and cooperation between the service beneficiaries and providers towards an improvement in collection coverage.

- The use of a participatory approach in the assessment of the strategy has provided the single most important platform for the relevant stakeholders of the collection process to understand each other, which has led to an unusual alliance: formal service providers have willingly agreed and are working with informal providers as subcontractors and legalised entities to increase collection coverage.

- The formal service providers have further shown commitment to improving collection coverage by providing motorised tricycles on hire purchase to their informal counterparts and subcontractors to increase their efficiency and turnover.

\section{Conclusion}

Municipal authorities and other stakeholders have been able to explore the factors that affect the performance of the existing waste collection strategy in Accra. The outcome of the research has been used to support the development of a new 5-year franchise agreement between the parties aiming towards collection coverage improvements. Recovery and recycling targets have been set over the next five years, and strategies 


\section{Chapter 3}

to improve waste collection in markets and public areas appear to be achievable. The municipality seems poised to listen to the service users and work with them to monitor the activities of the service providers. The process has produced a robust commitment by all stakeholders to promote informal integration and to secure recognition for the significant numbers of informal service providers through their relationship with the formal providers. As part of a broader commitment to improve the waste management system of the city, the research team has being working together with the municipality to form a stakeholder platform and develop an action plan to guide the integration of the informal waste sector into the formal waste management system. 
Locally responsive intervention to improve municipal solid waste collection coverage 


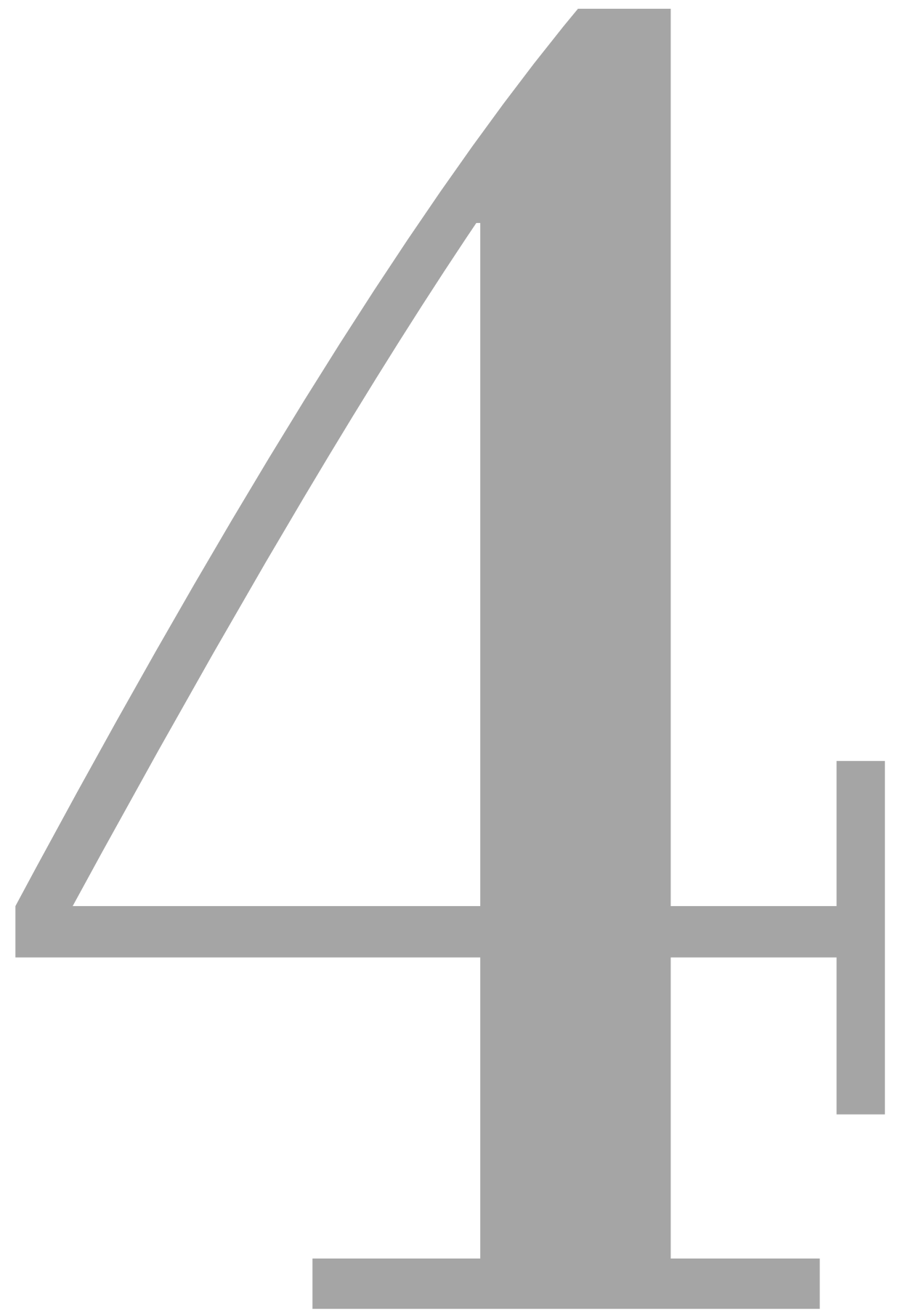




\section{Chapter 4}

\section{Working with the informal service chain}

as a locally appropriate strategy for sustainable modernisation of municipal solid waste management systems in lower-middle income cities: Lesson from Accra, Ghana

This chapter has been published as:

Kwaku Oduro-Appiah, Abraham Afful, Victor Neequaye Kotey and Nanne de Vries (2019). Working with the informal service chain as a locally appropriate strategy for sustainable modernisation of municipal solid waste management systems in lower-middle income cities: Lesson from Accra, Ghana. Resources 8 (12): $1-16$ 


\begin{abstract}
Twenty years of formal private sector participation in solid waste management in Ghana has failed to deliver an increase in collection coverage and recycling rates. This article shares lessons and experiences from Accra, Ghana, a middle-income city where researchers and municipal solid waste managers have collaborated to modernise the municipal solid waste management system by working together to develop a locally appropriate response to the informal waste service sector. Stakeholders have used inclusive decision-making and participatory research methods to bring formal service providers to work in partnership with their informal counterparts to improve collection and recycling. The WasteAware benchmark indicator framework has been used to assess and compare the improvements in the physical and governance aspects of the municipal solid waste management system, supplemented by statistical analysis of responses to a survey on the socio-economic contribution of the informal service providers in the city. Within two years of their inclusion, the number of informal service providers has increased by 71 percent, from 350 to 600, creating new livelihoods and contributing to poverty reduction. The informal service providers have been able to increase collection coverage from $75 \%$ to $90 \%$, waste capture from $53 \%$ to $90 \%$, and recycling rates from $5 \%$ to $18 \%$, saving the municipality US $\$ 5,460,000.00$ in annual operational costs. The results have influenced the decision-makers to move towards structural integration of the informal service providers into the formal waste service system. The shift towards practical, locally responsive interventions in Accra provides a positive example of sustainable waste management modernization, and key lessons for cities in similar economies.
\end{abstract}

Keywords: informal service providers; inclusive urban services; participatory planning; municipal solid waste management; modernization; emerging economies; Accra; Ghana 


\section{Introduction}

Despite the progress in high-income counties in modernising municipal solid waste management (MSWM) in the last three decades, the same cannot be said of emerging economies, especially in Sub-Saharan Africa. In Western Europe and North America, a combination of technological innovation, collaboration between academia and industry, and political and social commitment has contributed to strategies that deliver sustainable, equitable and resource-efficient MSWM, characterised by a near $100 \%$ collection coverage, state-of-the-art disposal, and moderately high recycling rates (Asase et al., 2009; Marshall and Farahbakhsh, 2013).

In contrast, the MSWM system of most middle-income economies is characterised by low to moderate levels of collection coverage with significant amounts of uncollected waste on illegal dumps and beaches (Guerrero et al., 2013; Oduro-Appiah et al., 2017a). The solid waste generated by households on poor urban settlements is rarely collected, even though the waste collection service consumes more than $50 \%$ of municipal budgets (Coffey and Coad, 2010). Rather than building on what is working and exploring truly local solutions, municipal authorities and national politicians tend to choose donorfinanced and technology- and capital-intensive management models modelled on MSWM in the developed worlds, as a path to system improvement (Ali, 2010; OtengAbabio et al., 2013). Such approaches may appear to represent a rapid solution but are seldom sustainable (Marshall and Farahbakhsh, 2013; Oteng-Ababio et al., 2013).

For this reason, decision-makers in countries like Ghana tend to dismiss opportunities to recognise, integrate and support informal waste collectors (referred to here as informal service providers (ISPs), to distinguish them from informal waste pickers or recyclers, who are valorising recyclables) into their formal systems (Oteng-Ababio, 2012; OtengAbabio et al., 2013). Interventions geared at recognition and formalisation of the informal waste sector (IWS) have been proven to increase collection coverage, raise recycling rates and create employment opportunities for the urban poor, many of whom are unable to find employment in the formal system (Medina, 2005; Silva de Souza Lima and Mancini, 2017; Wilson et al., 2009).

The joint United Nations Human Settlement Programme (UN-Habitat) and United Nations Environment Programme (UNEP) sustainable cities program in Dar es Salaam, Tanzania, supported by the International Labour Organisation (ILO), served as one of the first innovative micro-privatization models in Sub-Saharan Africa which institutionalised, organised and monitored the integration of ISPs to promote poverty eradication and improve waste collection (Halla and Majani, 1999; Ishengoma and Lyimo, 2002; Van de Klundert and Muller, 1998). 
Although ISPs often do not pay taxes nor work in the formal financial sectors of a city; they offer their clients personalised services, simple technologies, and affordable user charges, most of which are lacking in the formal waste collection systems found in lower middle-income cities. Despite their local knowledge, healthy price-value relationship and broad acceptability to system users, authorities charged with managing municipal solid waste (MSW) have been reluctant to recognise the ISPs as an integral and valuable part of the system (Oteng-Ababio, 2012). At best, their contribution is considered a nuisance, unhygienic and crime-related; even though they do a better job than their formal counterparts (Velis et al., 2012).

Why are municipal authorities so reluctant? Research interests, technical capacity, commitment, stakeholder inclusivity and an understanding of the local politics and waste system dynamics are widely understood to be paramount to delivering an integrated sustainable waste management (ISWM) system (Oteng-Ababio et al., 2017; Scheinberg et al., 2010b; Wilson et al., 2013), but city authorities in emerging economies tend to focus more on donor investment (Marino et al., 2018; Marshall and Farahbakhsh, 2013). This article presents the lessons and achievements in ISWM, of a collaborative working group of researchers, politicians, MSW managers and service providers; who have developed and implemented locally appropriate interventions to increase MSW collection coverage and recycling rates in Accra. The work is based on the hypothesis that ISWM improves the chances of sustainable and positive outcomes, by promoting structural co-operation between researchers, municipalities and relevant stakeholders. Such collaborations raise capacities to assess the MSWM system in a participatory and transparent manner, and facilitate co-operation at all levels.

The concrete objective of the ISWM assessment was to support city authorities to collect relevant data, transparently assess their systems, identify challenges, correct and encourage each other, and to explore the potential improvements that simple technologies and locally responsive interventions can bring about. The current paper represents one aspect of the collaborative approach to socialise the assessment of the socio-economic contribution of the ISPs, as part of a deliberate strategy to create a pathway and prepare the formal authorities to organise and integrate them into the formal MSWM system. This paper has a secondary objective to share lessons and experiences of the collaborative process of intervention development and implementation.

Following the introduction, this paper has five additional parts. Section two provides an overview of the definition and the theoretical framework that governs the informal waste sector. Section three summarises the history of the evolution of formal and informal MSW collection in Accra. This is followed by the interventions that were designed and implemented in the framework of action research; the methods that were adopted 
to assess the socio-economic contribution of the ISPs to the MSWM system; and the framework that was used to map system improvements, all in section four. Section five discusses the intervention outcomes and the related contributions to MSWM system modernization. The lessons learnt along with new interventions for a continuous improvement strategy in MSWM service delivery form part of the sixth section.

\section{Theoretical framework, the politics of the informal waste sector}

The informal solid waste sector (IWS) consists of private individuals, groups and microenterprises who are involved in solid waste collection, recovery and recycling but without the express support or recognition of the formal waste managers, putting them at risk of being considered to be in violation or in competition to formal contracting processes (Scheinberg et al., 2010a). The IWS, a segment of the wider informal economy in developing countries, has been growing since the 1990s, partly due to the limitations in the creation of formal jobs, and partly due to the mismatch between the capacities and skills of the sector and the requirements and expectations of the formal sector (Chen, 2012). Based on their modes of operation, the IWS is classified into two distinct groups: informal recyclers (IRs) in the value chain (recycling industry) and informal service providers (ISPs) in the service chain (formal solid waste management system) (Scheinberg et al., 2010a).

The policy debates about the informal economy and by extension the IWS have been governed by four main theories for decades: dualist, voluntarist, structuralist, and legalist (Chen, 2012). A recent addition is the co-production theory upon which this study is based. The dualist perspective considers the emergence and upsurge in IWS activities in developing countries as a consequence of limited economic growth and the lack of formal employment creation. According to the dualist school of thought, IWS activity is deliberately chosen as the sustainable and inevitable option by the marginalised in society because of a lack of skills and capacities to compete for formal employment. According to the dualist, IWS activities, which become more pronounced during times of economic crisis; are detrimental to the economic growth of a country, with the consequence that the focus of the policy should be to criminalise or eliminate the IWS and create more formal jobs. The MSW collection privatization concepts of the World Bank and the micro-privatization models of the ILO from the beginning of 1990s, especially in Sub-Saharan Africa, are seen as products of the dualist school of thought (Katusiimeh et al., 2013; Navarrete-Hernandez and Navarrete-Hernandez, 2018).

The voluntarist approach frames the informal economy as belonging to one end of the labor continuum in which IWS actors deliberately seek to work within the informal economy as free riders: they have a base from which to make gains but avoid taxes and 
regulations. Voluntarists vilify the IWS and use pejorative language to describe them as tax evaders that create unfair competition for their formal counterparts. They thus argue for all informal enterprises and individuals to be under formal regulatory control as a means for society to increase its tax base (Navarrete-Hernandez and NavarreteHernandez, 2018).

The structuralist, in contrast to the dualist, believes that informality arises at a particular developmental stage of capitalism. According to this view, the informal economy is subordinate to the formal economy (Chen et al., 2004), and is working for formal institutions. Structuralists see the informal sector as an integral part of the formal economy; they understand that informality drives competition between formal enterprises through direct and indirect linkages in provision of low cost inputs, materials, and services. The informal supply chain picking recyclables from dumpsites and selling them at low prices to formal recycling companies is considered by structuralists as proving the validity of their points of view. The linkage is considered exploitative to the informal sector since the formal enterprises are believed to set the rules for the transactions, which enables them to increase profit margins to the disadvantage of the waste pickers. Structuralists promote the organisation of informal sector entrepreneurs - almost always referred to as "workers", into solidarity unions and cooperatives to strengthen the informal economy to negotiate for recognition, the right to work, better working conditions and better prices for their goods and services (Birkbeck, 1978). The vision of the structuralists corresponds most closely to the situation in Latin America, while in other emerging economies the local realities contradict this position.

The legalist school of thought posits that the informal economy comes into being in response to hostile legal and labor requirements and obstacles to formalisation such as registering of a business, registration for income, value added tax (VAT) and other taxes, the need for licenses or permits, legal conditions for hiring employees, requirements for workers insurance, complying with legal and labor laws, etc. Legalists tend to favor interventions which aim to introduce simplified bureaucratic procedures to encourage informal enterprises to legalise their operations (De Soto, 2000).

The scholarly literature on the IWS to the MSWM system in developing countries has revolved around the role and contribution of the informal value chains, and has to a large extent embraced the dualist and the structuralist schools of thought (Wilson et al., 2006; Rockson et al., 2013). This paper, in contrast, takes as its point of departure, the theory of co-production, which in turn is linked with the use of combinations of state and non-state actors in public service delivery (Voorberg et al., 2015; Howlett et al., 2017). Co-production advocates the use of formal-informal linkages as effective answers 
to the failures of the kinds of state-based and privatised models of service provision (Meagher, 2013) found in the MSWM systems of many cities in emerging economies.

A complex mix of factors including weak governance, lack of political will, moderate capacities in both the private and public sectors, exacerbated by rigid financing and budgeting systems, has contributed to the failure of the privatization and public private participation (PPP) management models in most developing countries. The result is a gap between user economic and social demand for waste services on the one hand, and informal providers offering these services to a system which rejects them as illegitimate (Navarrete-Hernandez and Navarrete-Hernandez, 2018).

This was the baseline situation at the time the initiative behind this paper began, in 2015. The ISPs in Accra were contributing to the city's ability to meet performance targets, at a time when formal service providers were failing, creating a situation that was favorable for the development of new compromises that would allow the informal entrepreneurs to unleash their full potential and contribute to system modernisation and sustainability (Medina, 2007).

The co-production literature also emphasises the coordination that is possible through formal-informal linkages and multi-stakeholders arrangements to bridge institutional and resource gaps (Meagher, 2013). The use of a team of researchers, politicians, solid waste managers and other relevant stakeholders to develop and implement the interventions within this study was deliberately designed to enable synergies that will continuously and systematically build the capacities of municipal officials and also encourage local authorities to lead the process of recognising, integrating and organising the ISPs as part of the MSWM system of the city to improve their efficiency.

\section{Evolution of solid waste collection service delivery in Accra}

Solid waste collection service delivery in Accra until 1999 was publicly managed (Oteng-Ababio, 2010; Obirih-Opareh and Post, 2002). Prior to that time, the system was based on a network of secondary collection sites where residents were allowed to discharge their waste. Each site had at least one communal container-initially drawn by mules and later hoisted by skips-that was transported to municipal dumpsites for disposal (Owusu-Sekyere et al., 2015). Due to the lack of access routes in low-income areas, service was limited mostly to high- and middle-income areas. The cost of the service was largely borne by the central government with more than $80 \%$ of residents and commercial enterprises, mostly within middle- to low-income areas enjoying free services (Oduro-Kwarteng and van Dijk, 2013). Residents of high-income areas, who 
benefited from house-to-house collection services offered by ISPs paid privately and directly to the service providers.

\section{Public private partnership and the evolution of the formal system}

In 1999, local authorities in Accra were confronted with inflows of persons from rural-urban migration and high population growth. These, in addition to low revenue collection, undermined the autonomy of the system. Local and national authorities were neither politically nor administratively able (nor willing) to raise revenue sufficient to sustain the MSWM system. Rather than taking political risks, they took the path of choice of many decision-makers in emerging economy cities to enter into formal public-private partnerships (PPP); ostensibly with the objective to increase collection efficiency and coverage, but in practice to avoid taking responsibility for raising fees (Oteng-Ababio, 2010), as well as to comply with donor recommendations. Whatever the real reason for the PPP policy, it did not arise from any observable interest in what the private sector had to offer (Awortwi, 2004), and so it was not surprising that the "PPP arrangement" failed. It did not improve collection coverage in densely populated areas nor fix the problems with revenue collection. As a result, the municipality incurred a debt to private solid waste contractors of US $\$ 8,400,000.00$ (Oteng-Ababio, 2010) for collection and disposal charges between 2000 and 2007. The resultant legal and political unrest pushed decision-makers to rethink the role of the private sector providers and service users in the city (Oduro-Appiah et al., 2013).

In 2008, in the course of the World Bank's Second Urban Environmental Sanitation Project (World Bank, 2004), city authorities took the initiative to introduce the "polluter pays principle" with the aim to shift the cost of MSW collection to system users. The polluter pays principle ultimately led to the introduction of the fee- and performancebased MSW collection strategy in 2011 (Oduro-Appiah et al., 2013). The performancebased strategy had three major features:

- to offer the formal private sector the opportunity to bid competitively to participate in a five-year franchise agreement;

- to increase collection coverage, and

- to assign the responsibility of service fee collection to the franchise-holders

The city acting on behalf of the public retained for itself some regulatory and monitoring responsibilities:

- to set user charges;

- to enforce obligations, and

- to have the right to abrogate contracts for non-performance 
Despite the expected improvements, the system was in a downward spiral, and five years after the implementation of the strategy, coverage under formal service provision chains had dropped from 60\% to 55\% (Oduro-Kwarteng and van Dijk, 2013). During the same period, ISPs increased their client base and by 2016 were collecting more than a third of all MSW generated in the city, such that their activities had increased the overall collection coverage to 75\% (Oduro-Appiah et al., 2017a).

\section{Evolution of informal service provision in Accra}

The activities of the informal MSW service providers, working in parallel to the formal system, were first documented in the literature in 2002 (Obirih-Opareh and Post, 2002). These activities continued during the period of the PPPs, with its emphasis on formal private sector participation in service delivery (Boadi and Kuitunen, 2003). In this, Accra is not unique: there are many examples of micro-enterprises in the informal sector providing or supplementing formal service delivery, especially in emerging economies (Tilaye and Van Dijk, 2014; Kassim and Ali, 2006; Andrianisa and Brou, 2016; Katusiimeh et al., 2013). ISPs are not, unfortunately, a solution to all of Accra's MSWM problems: the reach and effectiveness of micro-service providers is constrained by limitations in financial management capacity, professional skills, ability to mobilise investment in vehicles, and other problems faced by bottom-of-the-pyramid entrepreneurs.

Despite such limitations, in Accra, the current generation of ISPs has evolved from cart-pushers to motorised tricycle operators (Figure 4.1). They work primarily in lowincome areas, and have experienced significant growth in the last 20 years. ISPs, partially in support of their own interests, have been the main advocates of equitable MSW collection. Their reliable and friendly services have given users a sharp contrast with unreliable and costly formal waste collection. Lean operations, affordable user charges and simple technologies have allowed this sector to essentially whip their formal sector competitors. However, their operations are not perfect: they have been criticised for disposing of the collected waste in heaps or semi-formal dumping sites, rather than paying to discharge it at formal disposal facilities. They collect fees directly from the users and are reported not to pay taxes on this income (Oduro-Appiah et al., 2017b).

The implementation of the fee- and performance-based MSW collection strategy in 2011 had both a positive and a negative impact on the ISPs. It brought their activities to the attention of city officials and donors, but the nature of the franchise agreements between the municipality and formal service providers gave the formal sector a nominal monopoly, in effect criminalising ISP operations and meaning that ISPs could no longer work within the zonal monopolies of their formal counterparts. Their activities were thus confined to the (less profitable) slums and low income areas of the city, where 

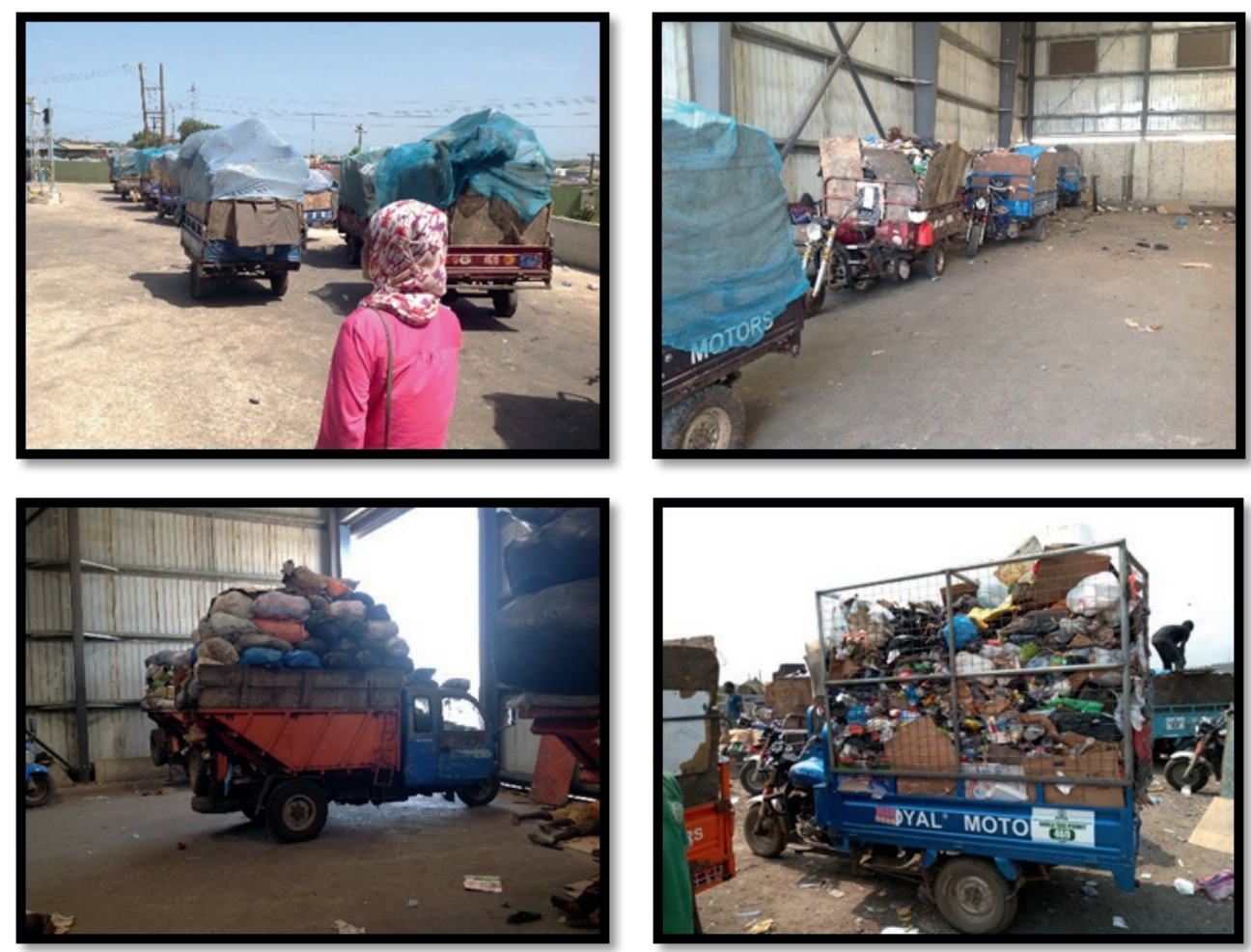

Figure 4.I: Motorised tricycles in a queue to dispose collected municipal solid waste (MSW) at one of the bulk transport stations (Zoom Pak) in Accra.

Photos: The authors, 2018.

the formal providers had failed to increase collection coverage. In 2014, the ISPs were formally recognised by the environmental service providers association, an association of formal MSW collectors. Partly as a result of this, between 2013 and 2016, the number of ISP units grew from 52 to 350 members. They are currently registered under the Ghana "Bola" Taxi Union with chapters in each of the ten recognised zones of the city (Figure 4.2), and were found in 2016 to be providing as much as $28 \%$ of waste collection in the city (Oduro-Appiah et al., 2017a) .

Despite the documented benefits of informal service provision coupled with the existence of frameworks for their integration into the formal system (Velis et al., 2012; Scheinberg and Simpson, 2015; Serrona et al., 2014; Masood and Barlow, 2013), those charged with MSWM in the city have been reluctant to integrate and regulate their activities. During a participatory assessment of the MSWM system in Accra, stakeholders identified two perverse effects of the inaction of local authorities on the ISPs. First, the market and survival orientation of the informal business has pushed collectors to set their user charges too low, creating "unfair" competition with their formal counterparts whose earning models depend on economies of scale. Secondly, the lack of recognition 


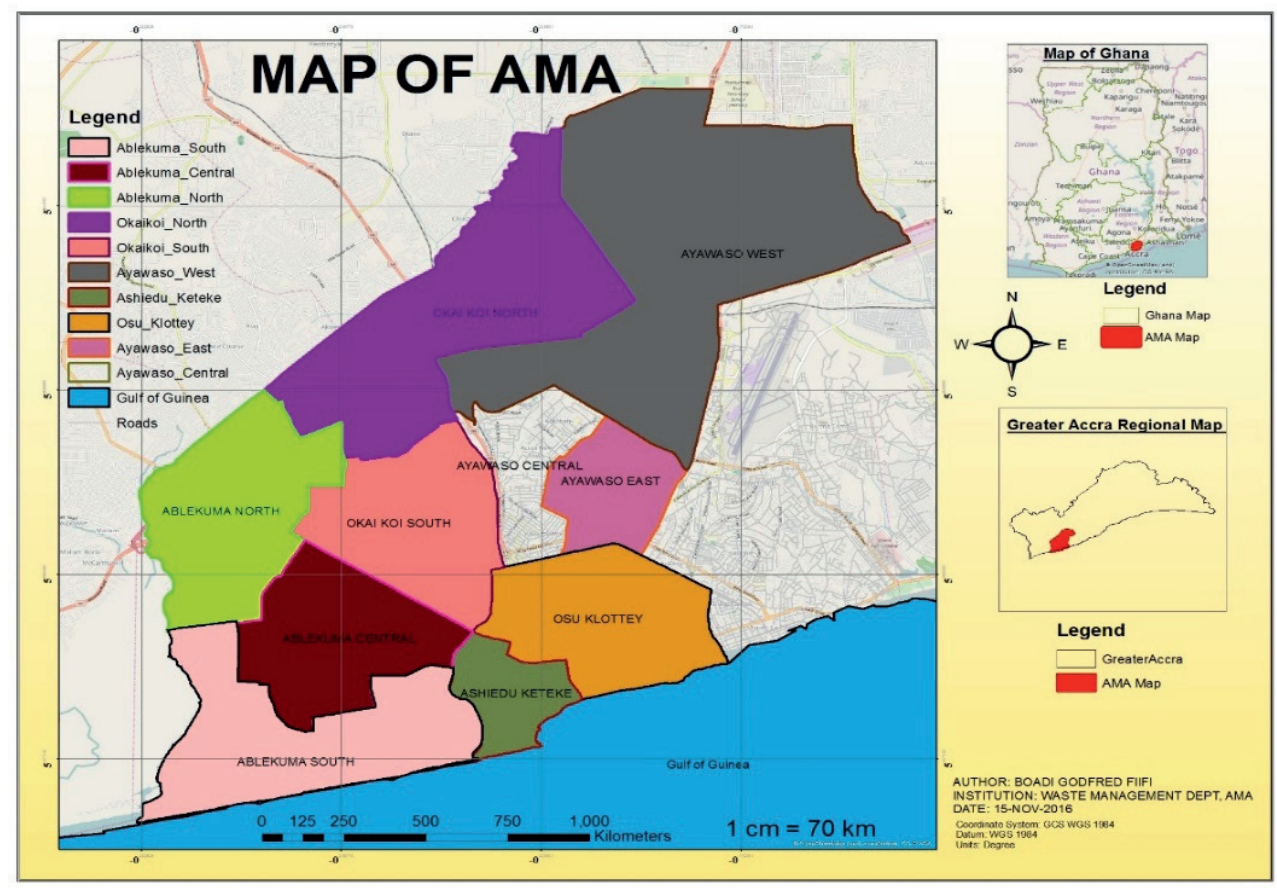

Figure 4.2: Formal collection zones of the Accra metropolitan assembly (AMA).

Source: Waste management department of the AMA, 2016. Six new district assemblies have been carved out of the 10 zones of the AMA by a legislative instrument since March 2018 but all are still being nurtured by the AMA until 2019.

has created data gaps in the MSWM system since their activities are largely unreported and therefore unaccounted for (Linzner and Lange, 2013). Through a participatory review of the fee- and performance-based MSW collection strategy, working groups decided to develop and implement inclusive and participatory interventions to improve the physical components and also harmonise the MSWM service delivery field (OduroAppiah et al., 2017b).

\section{Materials and methods}

\section{Action research and intervention development}

This article reports on three years of participatory action research with the objective to understand the problems in the MSWM system and work in a participative way to modernise MSWM delivery in Accra. In this process, a working group of researchers, stakeholders and staff of the municipality have:

1. assessed the physical components and governance aspects of the MSWM system in line with the concept of ISWM (Oduro-Appiah et al., 2017a); 
2. reviewed an existing collection strategy and developed a new five-year fee- and performance-based MSW collection franchise agreement that supports ISPs to work as legalised entities within franchised monopolies of formal service providers to increase collection coverage (Oduro-Appiah et al., 2017b);

3. negotiated with formal service providers to support their informal counterparts with motorised tricycles at hire purchase to increase their efficiency and turnover (Oduro-Appiah et al., 2017b);

4. recommended and developed an action plan for the integration of the ISPs as a locally appropriate and sustainable path to improve the physical indicators of collection, disposal and resource value (Oduro-Appiah et al., 2017a);

5. recommended and supported the closure of unofficial dumpsites patronised by 350 ISPs and stimulated subsequent construction of two bulk transport stations to improve the cost and time efficiency of waste transfer activities (Government of Ghana, 2017).

\section{Survey and registration of informal service providers}

The survey and registration of the ISPs were carried out for fourteen consecutive weeks between May and August 2018 from 8:00 a.m. to 5:30 p.m. at the transfer stations (bulk transport stations) where the ISPs dispose of collected waste. Data was collected using a structured questionnaire (see supplementary material, Tables S1 and S2) administered by 12 members of the working group, two of which were representatives of the association of ISPs. The consent and participation of the ISPs to the process were sought through their leaders and also through national print and broadcast media (Citinews, 2018; Dodoo, 2018). All 600 ISPs were registered and provided with identification stickers for their tricycles. A total of 234 out of these 600 participants were randomly selected for the interview. Participants were asked for the source of acquisition of their equipment (tricycles), maintenance schedules, durability and breakdown frequencies in addition to the daily amounts paid for equipment usage to enable the municipality to comprehend their working environments and challenges. The economic contribution of the ISPs to the system was estimated by computing the average amount of waste brought to the sites by each operator, the money raised per day vis-a-vis the expenditures on fuel, disposal and maintenance. The health and work safety of participants were assessed by soliciting the routines on the acquisition and use of safety gears. Level of education, marital status, evidence of valid driving license, road worthiness of equipment and participants' registration to national health insurance and pension schemes were asked to enable the municipality to formulate realistic plans towards their education and support. The earnings of participants were analysed in line with their dependents to determine ways 
through which they can be supported to increase their turnover. Each respondent was allowed to share work-related challenges and their expectation of support from the city. Quantitative data was validated after the survey through face-to-face interviews with two operations managers of the bulk transport stations where the ISPs are mandated to dispose of their waste, using the standardised semi-structured interview guide (see supplementary material, Table S3). The responses to the survey were coded manually, entered, and analysed by means of the statistical package for social scientists (SPSS), version 24.0. Descriptive statistics were used to explore and interpret the findings. The registration data, however, was entered into a Microsoft access database for use by the municipality.

\section{WasteAware indicators: basis for benchmarking}

The WasteAware benchmark indicators and the immediate incubator: the $2010 \mathrm{UN}$ Habitat publication 'Solid Waste Management in the World's Cities' (Scheinberg et al., 2010b) have become a model framework that supports cities to assess the performance of their MSWM system with other cities (Wilson et al., 2015a). The indicators have proved versatile and responsive to the global community's need for an all-inclusive quantitative and multi-attribute qualitative assessment tool (Cervantes et al., 2018; Wilson et al., 2015a); and since 2010, it has been used to assess and compare the MSWM of more than 40 cities (Wilson et al., 2015a).

Based on the concept of integrated sustainable waste management (ISWM), the indicators evaluate a city's MSWM system on two overlapping components: the physical systems and the governance aspects. The physical systems and their 'hardware' refer to collection as a measure of public health; treatment and disposal based on transfer, processing, landfilling, and incineration as a measure of environmental protection; and resource management, referring to reduction, re-use and recycling and organic waste valorization as a measure of resource value. Operational openings for user and provider inclusivity, financial sustainability, and sound institutions and proactive policies form the backbone of the governance "software" aspects. The accompanying traffic light symbolism is an indication of the performance of the city's MSWM system in each indicator; where red, orange, and green signify low, medium and high performances respectively.

The outcome of the action research interventions and the contribution of the ISPs to collection coverage and recycling throughout the period were documented and entered into the automated Microsoft Excel sheets of the WasteAware benchmark indicators to compute aggregate scores and assess improvements in the physical components and governance aspects of the city's MSWM system (Wilson et al., 2015a). The WasteAware indicators were chosen to benchmark the improvements in the MSWM system of Accra because of its global applicability across all income levels, broad usage and coverage, and 
the existence of a detailed user manual and automated Excel sheets to guide users in its application (Cervantes et al., 2018; Wilson et al., 2015a).

In the following sections, we present the interventions' outcomes and how they have affected the physical and governance aspects of the city's MSWM system. Particular emphasis is put on the cost of the services to the municipality, the system users and the ISPs. Lessons learnt are also discussed.

\section{Intervention outcomes and system modernisation}

\section{Benchmarking the improvements in the municipal solid waste management system}

The authors, with support from local authorities, implemented locally responsive interventions that focused on the inclusion of informal service providers. In the process, the number of ISPs in Accra increased from 350 in 2016 to 600 in 2018 (Oduro-Appiah et al., 2017a). The increase is attributable to three factors:

1. the agreement of the formal service providers to support and allow informal counterparts to work in their franchised zones;

2. the persistent inefficiencies in the formal service delivery of the city, and

3. the inability or unwillingness of the informal collectors to find alternative sources of livelihood

Within two years of intervention implementation, the ISPs daily contribution to MSW collection increased from 385 tons (Oduro-Appiah et al., 2017a) to 720 tons, and their overall contribution to MSW collection improved from $28 \%$ in 2016 to $47 \%$ in 2018 (Table 4.1). Paradoxically, the contribution of formal service providers dropped in percentage points from 55\% in 2016 to $48 \%$ in 2018 (Table 4.1). The performance and improvement in the MSWM system of the city throughout the intervention period (2016-2018) is shown in Table 4.2. The quantitative physical indicators of collection, environmental protection, and resource recovery are represented by the numbers 1.1 and 1.2, 2 and 3 respectively. The number and letter combinations of $1 \mathrm{C}, 2 \mathrm{E}$, and $3 \mathrm{R}$ are representative of the qualitative physical indicators. The combinations $4 \mathrm{U}$ and $4 \mathrm{P}, 5 \mathrm{~F}$, and $(6 \mathrm{~N}$ and $6 \mathrm{~L})$ represent the 'qualitative governance indicators of user and provider inclusivity, financial sustainability, and sound institutions and proactive policies respectively. The performance of the city in the indicators is represented as Low $(\mathrm{L})$, Low/Medium (L/M), Medium (M), Medium/High (M/H) and High (H); depicted by the colors Red, Red/Orange, Orange, Orange/Green, and Green, respectively. Selected 
Table 4.I: Daily collection amounts (tons) of MSW in Accra (AMA) between 2016 and 2018.

\begin{tabular}{lllll}
\hline Year & FSPs (tons) & ISPs (tons) & WMD (tons) & Total (tons) \\
\hline 2016 & 718 & 385 & 68 & 1171 \\
2017 & 682 & 600 & 70 & 1352 \\
2018 & 734 & 720 & 81 & 1535 \\
Percentage increase & $2 \%$ & $87 \%$ & $19 \%$ & $31 \%$ \\
Percentage contribution & $48 \%$ & $47 \%$ & $5 \%$ & \\
\hline
\end{tabular}

Source: The authors, 2018: Legend: AMA: Accra metropolitan assembly; FSPs: Formal service providers; ISPs: Informal service provider; WMD: Waste management department.

background and waste-related information of the city are represented by the letters B1 through $\mathrm{B} 3$ and $\mathrm{W} 1$, respectively.

At least partly due to the increased activity of the ISPs, the documented rate of collection coverage (1.1) increased from $75 \%$ to $90 \%$ (Table 4.2). Since 2017 , the city has closed all known unofficial dumpsites and the private sector has been empowered to construct two new bulk transport facilities of a daily capacity of 1800 tons to receive MSW from the ISPs (Government of Ghana, 2017). Consequently, the volume of waste captured (1.2) for controlled disposal (2) and valorization increased significantly from 2016 figures (Table 4.2). The quality of disposal expressed by the indicator $2 \mathrm{E}$ (Table 4.2) did not increase significantly throughout the period, but the closure of the dumpsites provides a greater opportunity to improve health in the communities where they were located. The ISPs, the informal waste pickers and recyclers, and the municipality contributed to somewhat higher recycling rates (3) —an increase from 5\% in 2016 to $18 \%$ in 2018 through recovery and diversion of valuable materials from disposal to valorisation. However, the quality of recycling performance (3R) remains low since a significant part of the recovered materials is not separated at source but picked from the landfill after they have been contaminated with food waste.

Despite a lack of robust participation by system users $(4 \mathrm{U})$ in decision-making, provider inclusivity (4P) has improved significantly as a result of efforts by the municipality and formal service providers to recognise the ISPs and bring them into the formal MSWM system (Table 4.2). There has also been some marginal gain in the financial sustainability indicator due to the construction of the two transfer (bulk transport) stations and attempts to recover the full cost of disposal through a declining subsidy scheme in a new franchise agreement (Oduro-Appiah et al., 2017b). Moreover, activity-based budgeting is slowly becoming more common, so that the total cost of MSWM will be clear in the near future. There has been improved cooperation among municipalities to build adequate disposal capacity in the region and the national government has established a 


\section{Chapter 4}

Table 4.2: WasteAware benchmark indicators of MSWM in Accra before and after intervention implementation.

\begin{tabular}{|c|c|c|c|c|c|}
\hline \multicolumn{2}{|c|}{ No. Category } & Indicator & \multicolumn{3}{|l|}{ Results } \\
\hline \multicolumn{3}{|c|}{ City/Country } & \multicolumn{3}{|c|}{ Accra/Ghana } \\
\hline Year & of assessment & & 2016 & 2017 & 2018 \\
\hline \multicolumn{6}{|c|}{ Background information } \\
\hline \multirow{2}{*}{$\mathrm{B} 1$} & \multirow{2}{*}{ Income level } & WB income category & \multicolumn{3}{|c|}{ Lower middle } \\
\hline & & GNI capita ${ }^{-1}$ & $\$ 1390$ & $\$ 1490$ & - \\
\hline \multirow{2}{*}{$\mathrm{B} 2$} & \multirow{2}{*}{ Population } & City population & $1,936,836$ & $1,983,320$ & $2,030,919$ \\
\hline & & Transient population & 500,000 & & \\
\hline B3 & Waste generation & MSW generation (tons year ${ }^{-1}$ ) & 631,506 & 643,552 & 655,888 \\
\hline \multicolumn{6}{|c|}{ Key MSW-related data } \\
\hline & Waste capita $^{-1}$ & MSW capita ${ }^{-1}$ & \multicolumn{3}{|l|}{259} \\
\hline
\end{tabular}

\section{Physical components}

\begin{tabular}{|c|c|c|c|c|c|}
\hline 1.1 & \multirow{3}{*}{$\begin{array}{l}\text { Public health- } \\
\text { waste collection }\end{array}$} & Waste collection coverage & $\begin{array}{l}75 \% \\
(\mathrm{M})\end{array}$ & $\begin{array}{l}81 \% \\
(\mathrm{M})\end{array}$ & $\begin{array}{l}90 \% \\
(\mathrm{M} / \mathrm{H})\end{array}$ \\
\hline 1.2 & & Waste captured by the system & $\begin{array}{l}53 \% \\
(\mathrm{~L} / \mathrm{M})\end{array}$ & $\begin{array}{l}77 \% \\
(\mathrm{M})\end{array}$ & $\begin{array}{l}90 \% \\
(\mathrm{M} / \mathrm{H})\end{array}$ \\
\hline $1 \mathrm{C}$ & & Quality of waste collection & $\begin{array}{l}\mathrm{M} \\
(42 \%)\end{array}$ & $\begin{array}{l}\mathrm{M} \\
(58 \%)\end{array}$ & $\begin{array}{l}\mathrm{M} / \mathrm{H} \\
(63 \%)\end{array}$ \\
\hline 2 & \multirow{2}{*}{$\begin{array}{l}\text { Environmental } \\
\text { control—waste } \\
\text { treatment and } \\
\text { disposal }\end{array}$} & $\begin{array}{l}\text { Controlled treatment and } \\
\text { disposal }\end{array}$ & $\begin{array}{l}62 \% \\
(\mathrm{~L} / \mathrm{M}) \\
\end{array}$ & $\begin{array}{l}77 \% \\
(\mathrm{M})\end{array}$ & $\begin{array}{l}87 \% \\
(\mathrm{M} / \mathrm{H})\end{array}$ \\
\hline $2 \mathrm{E}$ & & $\begin{array}{l}\text { Degree of environmental } \\
\text { protection in waste treatment } \\
\text { and disposal }\end{array}$ & $\begin{array}{l}M \\
(60 \%)\end{array}$ & $\begin{array}{l}M \\
(60 \%)\end{array}$ & $\begin{array}{l}\mathrm{M} / \mathrm{H} \\
(65 \%)\end{array}$ \\
\hline 3 & \multirow{2}{*}{$\begin{array}{l}\text { Resource } \\
\text { management }\end{array}$} & Recycling rate & $\begin{array}{l}5 \% \\
(\mathrm{~L}) \\
\end{array}$ & $\begin{array}{l}10 \% \\
(\mathrm{~L} / \mathrm{M})\end{array}$ & $\begin{array}{l}18 \% \\
(\mathrm{~L} / \mathrm{M}) \\
\end{array}$ \\
\hline $3 \mathrm{R}$ & & $\begin{array}{l}\text { Quality of the 3Rs-Reduce, } \\
\text { reuse, recycle-provision }\end{array}$ & $\begin{array}{l}\mathrm{L} / \mathrm{M} \\
(38 \%) \\
\end{array}$ & $\begin{array}{l}\text { M } \\
(42 \%) \\
\end{array}$ & $\begin{array}{l}\text { M } \\
(46 \%) \\
\end{array}$ \\
\hline \multicolumn{6}{|c|}{ Governance aspects } \\
\hline $4 \mathrm{U}$ & \multirow{2}{*}{ Inclusivity } & User inclusivity & $\begin{array}{l}\mathrm{L} / \mathrm{M} \\
(33 \%) \\
\end{array}$ & $\begin{array}{l}\mathrm{L} / \mathrm{M} \\
(38 \%)\end{array}$ & $\begin{array}{l}\mathrm{M} \\
(46 \%)\end{array}$ \\
\hline $4 \mathrm{P}$ & & Provider inclusivity & $\begin{array}{l}\mathrm{M} \\
(50 \%)\end{array}$ & $\begin{array}{l}\text { M } \\
(60 \%)\end{array}$ & $\begin{array}{l}\mathrm{M} / \mathrm{H} \\
(75 \%)\end{array}$ \\
\hline $5 \mathrm{~F}$ & $\begin{array}{l}\text { Financial sustaina- } \\
\text { bility }\end{array}$ & Financial sustainability & $\begin{array}{l}\mathrm{L} / \mathrm{M} \\
38 \% \\
\end{array}$ & $\begin{array}{l}\text { M } \\
(42 \%)\end{array}$ & $\begin{array}{l}\text { M } \\
(50 \%)\end{array}$ \\
\hline $6 \mathrm{~N}$ & \multirow{2}{*}{$\begin{array}{l}\text { Sound institutions, } \\
\text { proactive policies }\end{array}$} & $\begin{array}{l}\text { Adequacy of national SWM } \\
\text { framework }\end{array}$ & $\begin{array}{l}\mathrm{M} \\
50 \%\end{array}$ & $\begin{array}{l}\mathrm{M} \\
(50 \%)\end{array}$ & $\begin{array}{l}\mathrm{M} \\
(54 \%)\end{array}$ \\
\hline $6 \mathrm{~L}$ & & Local institutional coherence & $\begin{array}{l}\mathrm{L} / \mathrm{M} \\
33 \% \\
\end{array}$ & $\begin{array}{l}\mathrm{L} / \mathrm{M} \\
(38 \%)\end{array}$ & $\begin{array}{l}\mathrm{M} \\
(42 \%)\end{array}$ \\
\hline
\end{tabular}

Source: The authors, 2018. Legend: Performance levels in physical and governance indicators and corresponding colour codes: low performance (L)-red; low/medium performance (L/M)-red/orange; medium performance $(\mathrm{M})$-orange, medium/high performance $(\mathrm{M} / \mathrm{H})$-orange/green; and high performance $(\mathrm{H})$ green. GNI: gross national income; MSW: municipal solid waste; WB: World Bank. 
new ministry dedicated to sanitation, waste management and water resources and when these are fully functioning, there should be a significant improvement in the institutional and policy indicators $(6 \mathrm{~N}$ and $6 \mathrm{~L})$.

\section{Financial sustainability}

The full cost of MSWM in Accra is not known but the available data between 2013 and 2017 suggests that the city has been spending more than $100 \%$ of previous budgets (Oduro-Appiah et al., 2017a) for each of those years. This might be partly due to the absence of a systematic program of implementation and the lack of activity-based budgeting procedures. Having privatised MSW collection services, the municipality's financial commitment to MSWM is through subsidies in disposal and supplemental collection actions — such as liquidating illegal dumps - that serve to compensate for nonperforming aspects of the formal system. Until 2016, the full cost of disposal was borne by the municipality. As part of measures to attain financial sustainability, the working group and the municipality developed and are implementing an intervention related to the new five-year franchise agreement that serves to shift the full cost of collection and disposal to users in a declining subsidy arrangement.

The MSWM system currently uses a cross-subsidization approach to subsidise service user charges for low-income users. Currently, resident-users living in high-income neighborhoods pay their formal concessionaire US $\$ 20.00$ for four-times-a-month collection of a 240-L bin of co-mingled MSW. Middle- and low-income counterparts officially pay US\$12.00 and US\$4.00 respectively, to their formal providers. In practice, they pay what they can through semi-formal arrangements with their formal service providers, who accept the partial payments as being fair, considering the chronic inefficiencies in the formal service delivery system (Oduro-Appiah et al., 2017b).

Informal service providers fill in the gaps and offer reliable service, negotiable fees, and personalised services. Collection frequencies of 10 times a month among the ISPs are not uncommon, and each tricycle full of MSW (1.2 tons) collects from an average of 100 households per round trip. Two round trips per day is the practice but delays in offloading at the bulk transport stations have reduced it to one round trip-this, of course, affects their turnover. On average, collectors realise US\$35.00 with a full tricycle of MSW, with a daily turnover of US\$15.00. The rest constitutes daily expenses on disposal charges, fuel, maintenance and depreciation. Service users pay, on average, US\$4.00 for a 240-L bin of MSW collected by the ISPs. The 600 ISPs through their contribution are improving upon the living standards of 3000 dependents and are saving the city US\$3,120,000.00 in annual collection and disposal cost. 


\section{Lessons learnt and new interventions for system sustainability}

After more than three decades of MSW challenges, and nearly 20 years of interventions through formal private sector participation, the research team was facing a poorly performing system at the beginning of their intervention. Collection coverage along formal service provision was dropping, and had declined from $60 \%$ in 2011 to $55 \%$ in 2016 (Oduro-Appiah et al., 2017a), a rate lower than the 88\% average for WasteAware benchmarking of lower-middle income cities (Wilson et al., 2012). The city was facing inadequate public and environmental health and perennial outbreaks of cholera and flooding (Asumadu-Sarkodie et al., 2015). A participatory benchmarking exercise in 2016 - using the WasteAware benchmark indicators - was seen as an initial step to establish a baseline and analyse system performance (Oduro-Appiah et al., 2017a). Instead, it turned out to be an engine of positive change, confirming the observation that the peculiar dynamics of the MSWM system in cities of developing countries call for a different approach towards modernisation. Training and assistance that support municipal staff to map their own MSWM challenges and elaborate ideas towards responsive and affordable solutions works better than having consultants make decisions in a politico-social vacuum (Herat, 2015; Ali, 2010). In place of complex technologies promising quick fixes, which have proved to be unsustainable (Ali, 2010; Oteng-Ababio et al., 2013), an innovative collaboration between academia and municipal authorities has shown itself to be a working and effective tool for change: the authors in collaboration with system stakeholders have taken only three years to shift the thinking of municipal staff and decision-makers from technology- and capital-intensive models of MSWM modernisation to identify what works for the city.

A basic lesson of this article is that participatory research appraisal (PRA) of the MSWM systems of cities in developing and emerging economies, conducted in accordance with the ISWM concept and in collaboration with research institutions and or academia, has the potential to stimulate locally appropriate interventions that succeed in modernising the system. The primary goal advanced by ISWM is that there are no fixed solutions to MSWM, but modernisation has to be developed and tailored to local needs and conditions to preserve what is working and improve what is failing after a critical assessment of the physical and governance aspects of the system (Wilson et al., 2013).

Accra's commitment to embrace such collaborative efforts at almost no cost to the city has led to the systematic improvement in the physical and governance indicators since they were first measured in 2016 (Table 4.2). The collaborative research team has enjoyed support from different political regimes and is continuously working to develop new interventions to address and improve the MSWM system. The working group has drawn action plans to integrate the ISPs into the formal system, with the aim to regulate 
their activities and also reduce urban poverty. The focus also is to seek support for them to increase collection coverage and recycling rates further.

Despite the significance of PRA as a sustainable methodology, most emerging economies fail to involve all relevant stakeholders during the planning of MSWM systems (Alamgir et al., 2012), creating major gaps in ownership and the implementation of plans and interventions (IJgosse et al., 2004). Accra adopted PRA methods to bring together relevant stakeholders as working groups to assess and plan interventions together. The system opened itself to transparency and accountability, which has provided opportunities for trust, understanding and cooperation among stakeholders. A positive outcome which has set a chain reaction for the integration of the ISPs and the improvement of the physical systems of the city's MSWM system has been the unusual agreement in 2016 in which formal service providers engaged their informal counterparts to further support them with loan schemes through high purchase of motorised tricycles to increase collection coverage and turnover (Oduro-Appiah et al., 2017b). In addition, the participatory process has contributed significantly to the generation of reliable data for future planning purposes. Currently, the authors, the municipality and service users are leading the process of forming the city's first ever stakeholder platform in MSWM to develop modalities to sustain the integration of the informal sector into the formal system.

The collaboration has also yielded positive but marginal improvement in the governance aspects of the city's MSWM system. Working groups have kept faith to support and improve the system through continuous and participatory development of locally appropriate interventions. The city has shown further commitment to the process by implementing the outcome and recommendations of the process.

In Accra, the resource recovery rate is driven solely by the informal sector and has been poor (Oduro-Appiah et al., 2017a) compared to other emerging economies (Wilson et al., 2013; Wilson et al., 2012). Subsidy schemes, especially those related to landfilling, indirectly contribute to low scores in two-ways: first, they prevent service providers from leading the initiative of diversion of recyclables from disposal and separation of waste at source, measures that would eventually lead to higher valorisation amounts. Secondly, full cost accounting of MSWM is not achieved, coupled with the fact that the municipality is unable to sustain such subsidies. We have developed a declining subsidy scheme since 2016 to shift the full cost of collection, transportation and disposal to system users as a sustainable measure to eventually suspend subsidies and promote fullcost recovery in the city's MSWM system. 
A bigger challenge in policy formulation, regulation and monitoring for MSWM in Accra has been the overlap of responsibilities among ministries and departments, a practice which has created huge gaps in policy implementation and enforcement. Fortunately, the political commitment in the establishment of the new ministry of Sanitation and Water Resources in 2017 and the engagement of stakeholders in planning and implementation of interventions are targeted at addressing such issues. Although yet to be experimented, we recommend the movement of the ministry towards the establishment of democratic MSWM departments towards good governance.

\section{Conclusions}

In Accra, Ghana, there has been significant improvement in the physical and governance indicators of MSWM after researchers and municipal staff deliberately developed interventions to involve informal waste collectors in service delivery. Within two years of engaging the informal service providers (ISPs), collection coverage increased by $20 \%$, waste capture by $70 \%$, recycling rates by $260 \%$, and the municipality is making substantial savings in annual collection and dumping cost. The apparent improvement underscores the importance of collaboration, cooperation and commitment among researchers, politicians and local authorities in identifying what works for lower-income cities of the world, especially in Sub-Saharan Africa. In addition to developing and implementing new and locally appropriate interventions towards system improvement, the collaboration has led to capacity building of municipal staff in MSWM assessment, intervention development, advocacy, and monitoring and evaluation. The process has established the potential of the informal waste sector to fill the gaps created by their formal counterparts in service delivery. The process has provided the opportunity for the generation of new and relevant data for future planning purposes. Even before their integration into the formal system, the increase in the number of ISPs throughout the intervention period serves a significant contribution to urban poverty reduction. The working group is still developing policy initiatives to improve further the governance indicators of financial sustainability and sound policies and proactive institutions. Although progress on the two governance indicators has been slow and expected, the authors are optimistic to see systematic improvements because of the continuous support and commitment of local and national authorities towards the process. The ministry, the municipality and the researchers need to intensify efforts geared to developing action plans to formally recognise, regulate and support the ISPs in the formal MSWM system of the city. It is essential for cities with similar peculiarities and dynamics to Accra to find a practical guide to modernizing their own systems. 


\section{Supplementary materials}

The following are available online at www.mdpi.com/xxx/s1, Table S1: The survey questionnaire used to assess the socio-economic contribution of the informal service providers in Accra; Table S2: The questionnaire used to register the informal service providers in Accra; Table S3: The semi-structured interview guide used to collect data from the facility (bulk transport stations) operations managers to validate data from the survey. 


$$
5
$$




\section{Chapter 5}

\section{The contribution of participatory}

engagement strategies to reliable data gathering and inclusive policies in developing countries: Municipal solid waste management data in the greater Accra metropolitan area of Ghana

This chapter has been submitted as:

Kwaku Oduro-Appiah, Anne Scheinberg, Abraham Afful, and Nanne de Vries (submitted). The contribution of participatory engagement strategies to reliable data gathering and inclusive policies in developing countries: Municipal solid waste management data in the greater Accra metropolitan area of Ghana. 


\title{
Chapter 5
}

\begin{abstract}
The absence of participatory engagement strategies in the collection of solid waste management data in most developing countries affects reliability and deprives professional staff and local authorities of any clear basis for system modernisation. This article addresses these challenges in the greater Accra metropolitan area of Ghana, by using participatory action research and systems analysis approaches, to engage a working group of relevant stakeholders to map material flows, assess socio-economic contributions, and chart a sustainable pathway towards informal waste sector integration. The data collected were analysed statistically and the result is a seemingly simple statement: 1618 informal service providers and 646 informal recycling entrepreneurs are collecting 1370 tonnes per day, which is equivalent to $46 \%$ of municipal solid waste. In total they are recovering 85,653 tonnes of recyclables annually; achieving a 6.4\% recycling rate, and saving the municipalities an estimated US\$20 million in annual solid waste operations costs. Despite the critical mass of pointers to the benefits of this activity, integration of the informal sector remain a complex issue; and the fear of losing access to clients and materials remain a challenge to the sector. In response to the assessment, the working group has worked together with municipal officials and the related policy institution to elaborate recommendations for integration of the informal waste sector. The assessment suggests that the next step for decision-makers is to institutionalise inclusive waste and recycling policies, and to continue to collaborate with stakeholders to support the informal waste sector to sustain reliable data flows and to unleash their full potential as valued contributors to urban waste management.
\end{abstract}

Keywords: Data, Developing countries, Ghana, Inclusive waste management policies, Informal waste recycling, Integration. 
The contribution of participatory engagement strategies to reliable data gathering

\section{Introduction}

This article reports on how a participatory engagement strategy has proved useful in an attempt to close the municipal solid waste (MSW) and recycling data gaps in the Greater Accra Metropolitan Area of Ghana ("the GAMA"), as part of prerequisites for the development of action plans and inclusive governance policies towards working with the informal waste sector in both the service and value chains.

The Informal Waste Sector (IWS) refer to private individuals and micro-enterprises who are involved in solid waste management and recycling activities, but are not necessarily acknowledged and supported by the formal waste authorities (Scheinberg et al., 2010a). They are categorised into two: informal recyclables collectors (IRCs) working within the value chain and informal service providers (ISPs) working within the service chain.

In most cities and regions in emerging economies; this sector is responsible for almost all of the recycling that occurs (Wilson et al., 2013; Scheinberg et al., 2010b). In Ghana, ISPs have been widely reported to offer user-friendly and reliable services at affordable rates to their waste collection clients (Oduro-Appiah et al., 2017b; Oduro-Appiah et al., 2019), while informal recyclables collectors (IRCs) are the main extractors of valuable recyclables (Oteng-Ababio, 2012; Rockson et al., 2013). Through their activities, IRCs supply secondary (recycled) materials to intermediate processors and end-user manufacturing industries. The activities of the IWS contribute to support their families, to savings in municipal budgets, to extension of useful landfill life, to achieving the requirements of the SDGs (Valencia, 2019), to energy benefits and to subsequent $\mathrm{CO}_{2}$ footprint reduction (Linzner and Lange, 2013; Ayodele et al., 2018).

Reliable data and inclusive governance are considered essential components of a wellfunctioning solid waste management (SWM) system (World Bank Group, 2018). Data on the performance and contribution of the IWS supports local authorities in policy making, planning of MSWM systems, and provides a baseline upon which support systems for the IWS can be designed (Linzner and Lange, 2013; UNEP, 2018; Soós et al., 2017). But almost by definition, there is little reliable data and information in informal operations, especially where their operations are defined as belonging to the "grey economy." The performance of informal recycling and re-use is therefore usually absent in statistics on recycling rates, and the number of informal entrepreneurs and workers in the service and value chains does not appear in official registers of professions or occupations. And while the informal sector is a real factor in what happens on the ground in cities, its existence and functioning are seldom part of decision-making. Could the lack of participatory engagement methodologies for collecting reliable data 
and the absence of information on the activities and socio-economic contribution of the ISPs and IRCs be contributing factors?

As the Sustainable Development Goals (SDGs) become more important, finding modalities for working with the micro private waste sector in developing countries assumes a higher priority (Velis, 2018; Valencia, 2019).

Understanding what recyclables and organics have value - specifically what can be valorised and marketed to the value chains - requires more accurate information than can be found in "the usual data sources," which often consist of 10- to 20-year-old desktop studies that estimate the waste by counting the discharges of vehicles at formal dumpsites. To plan for the circular economy, a completely different approach is needed, that engages a range of stakeholders in measuring, evaluating, and estimating various solid waste and recycling factors (Diaz, 2017). In Ghana, a multi-year initiative between researchers and the municipality of Accra, has shown how inclusive and participatory processes can make a real contribution to improving information and data in public waste management organisations (Oduro-Appiah et al., 2019).

The research to this article has engaged a 14-member working group of researchers, informal waste actors, development planners, waste managers and policy makers for 11 months to use the participatory action research method to comprehensively map the material flow, assess the contributions of informal actors to the overall MSWM system within all the 25 lower middle-income municipalities of the GAMA, and recommend the actions likely to lead to a successful integration of the informal waste and recycling sector. Participatory Action Research (PAR) is a research approach that supports stakeholders to collaborate and collectively work together towards a common goal (McIntyre, 2007). It opens up governance and planning processes to both professionals and non-professionals; empowering them in the process to form, articulate and own their opinions towards reliable data gathering, inclusive intervention development and decision-making (IJgosse et al., 2004).

Strategically, this process of documentation is important because it provides a platform for modelling, valuating, and communicating the positive contributions of informal entrepreneurial activity in the service- and value-chains, which in turn informs policy and practice in institutionalising the system.

Following the introduction, this article has been organised further into five sections: Section two provides an overview of the informal waste sector and the relationships between participatory engagement strategies, reliable data on the IWS, and inclusive waste management governance in developing countries. This is followed by a brief 
description of the study area, the greater Accra Metropolitan Area of Ghana. The methodological interventions for a systems analysis approach to facts-based data collection, and the strategic results of the assessment of the roles and contributions of the informal waste sector form section four. Sections five concludes the paper with discussions on how integration of the IWS can sustain reliable data flows for planning purposes; with recommendations on a pathway likely to drive decision-makers commitment towards ideal integration processes within the GAMA and other similar cities in developing economies.

\section{The informal waste sector, data and information gathering, participatory action research and inclusive solid waste management and recycling in developing countries}

Despite best efforts and the strong support of development partners and international financial institutions to modernise waste systems in lower middle-income countries, the neo-liberal promise of formal private sector participation (conceived and promoted as an antidote to inefficient public services) has proved disappointing in the waste sector (Achankeng, 2003; Obirih-Opareh and Post, 2002). The wisdom and much of the scholarly literature ascribes weak governance characterised by limited financial resources; low cost recovery mechanisms, low technical and human resource capacities; and the absence of strategic plans and regulatory frameworks for such failures (Leal Filho et al., 2016; Mmereki et al., 2016; Asase et al., 2009; Guerrero et al., 2013; Oduro-Appiah et al., 2020; Oduro-Kwarteng and van Dijk, 2013). This lack of well-functioning, robust formal waste management and recycling systems has created opportunities for a large and growing informal waste sector to supplement services and fill gaps; creating significant numbers of livelihoods in the process.

Collecting baseline solid waste data from the IWS in developing countries is no easy task. Unlike their formal counterparts, they lack the requisite capacity and may remain under no obligation to record, document and report their activities (Linzner and Lange, 2013). Where they willingly provide data, their desire to work as free riders raises doubts about the authenticity and reliability of such data. Municipal authorities in most lower middle-income countries like Ghana, are thus confronting challenges to build, maintain, and institutionalise inclusive MSWM and recycling systems (Oteng-Ababio et al., 2017; Oteng-Ababio et al., 2013). The lack of basic MSW data and information, that is the basis for planning and developing appropriate interventions and support systems towards inclusive system modernisation is lacking (UNEP, 2018). Even where there appears to be information, its usefulness and reliability is limited in a number of (predictable) ways (Scheinberg et al., 2010b): 
1. The information has been collected by external consultants working under time pressure for donors or development banks, and is therefore likely to consist only of the most obvious and available information on formal activities.

2. It is based on and extrapolated from global or regional data sets that have not been validated in the field, and therefore are likely to miss key locally relevant factors and site-specific information.

3. It is in most cases more than 10 years old.

4. It has mostly been gathered in relation to planning a facility, and is likely to be inflated for a number of institutional reasons, such as the fear of not building sufficient capacity or to capture the maximum amount of donor funding for the project.

The research for this article has used the Participatory Action Research (PAR) method to improve data collection and inclusive governance in the GAMA. The PAR is considered suitable for research work that is committed to co-develop interventions and programs with people rather than the conventional research approach that engage consultants and experts to develop solutions for people (McIntyre, 2007; Chambers, 1994; Chambers, 1992; Van de Klundert et al., 2001). McIntyre (2007, 1), identifies four main underlying tenets of the PAR process "(a) the collective commitment to investigate an issue or a problem, (b) a desire to engage in self- and collective reflection to gain clarity about the issue under investigation, (c) a joint decision to engage in individual and/or collective action that leads to a useful solution that benefits the people involved, and (d) the building of alliances between researchers and participants in the planning, implementation, and dissemination of the research process"

We adopted the PAR approach based on three main reasons:

1. the experience of the authors and their colleagues with the MSWM system of the GAMA and the resulting realisation that the conventional systems for data collection, system assessment and intervention development have for far too long failed to provide validated and reliable data to support planning and inclusive decision-making

2. the availability and "open source" framework of the integrated sustainable waste management (ISWM) concept for system modernisation to which participatory processes are considered central to allow managing authorities to open governance and planning to both professionals and non-professionals 
3. the unique desire and understanding of the authors to collaborate with municipalities to: strengthen capacities, close existing data gaps in IWS operations, and chart a plausible path for IWS integration into the formal MSWM system

The PRA approach promotes cooperation and transparency among stakeholders, empower and build capacities of working group members in addition to creating a wide ownership of results (IJgosse et al., 2004). The process lends itself to a better understanding of the concerns of the target group (the IWS) and a higher probability of developing locally appropriate and systematic interventions towards inclusive waste management systems.

In the GAMA, the working group chose PRA as the engagement strategy to assess the contributions of the ISPs and IRCs with the objectives to build consensus on what works and to identify challenges and opportunities to drive decision-makers' commitment at charting a sustainable pathway towards inclusive MSWM systems. The choice to use PRA was and remains above all a practical one: conventional data sources are simply inadequate to support this kind of co-operative process and achieve useful and affordable results.

\section{The greater Accra metropolitan area}

The Greater Accra Metropolitan Area ("the GAMA") lies along the South-Eastern coast of Ghana and covers an area of $1453.53 \mathrm{~km}^{2}$. It consists of 25 municipalities (Figure 5.1) and it is home to the capital city (Accra) and the industrial hub (Tema) of the country. The GAMA is home to an estimated 4.6 million residents and contributes to about $25 \%$ of the gross national income of Ghana (Government of Ghana, 2017). It is considered as the 11th largest metropolitan area in Africa and generates an estimated 3293 metric tonnes of MSW daily. With the exception of the two metropolitan cities of Accra and Tema $(0.71 \mathrm{~kg})$, the daily average per capita MSW generation is estimated at $0.50 \mathrm{~kg}$. Biodegradable waste including grass cuttings (45-61\%), plastics (14\%), paper and cardboard (5\%) and metals (2-5\%) form the four major constituents of MSW (Miezah et al., 2015; Oduro-Appiah et al., 2017a). Formal separation of MSW is nonexistent although a few individuals separate glass bottles and high density polyethylene pouches used for water packaging at the household level to sell to itinerant buyers. We selected the GAMA because it represents the largest (about 90\%) hub of IWS activities within the country. 


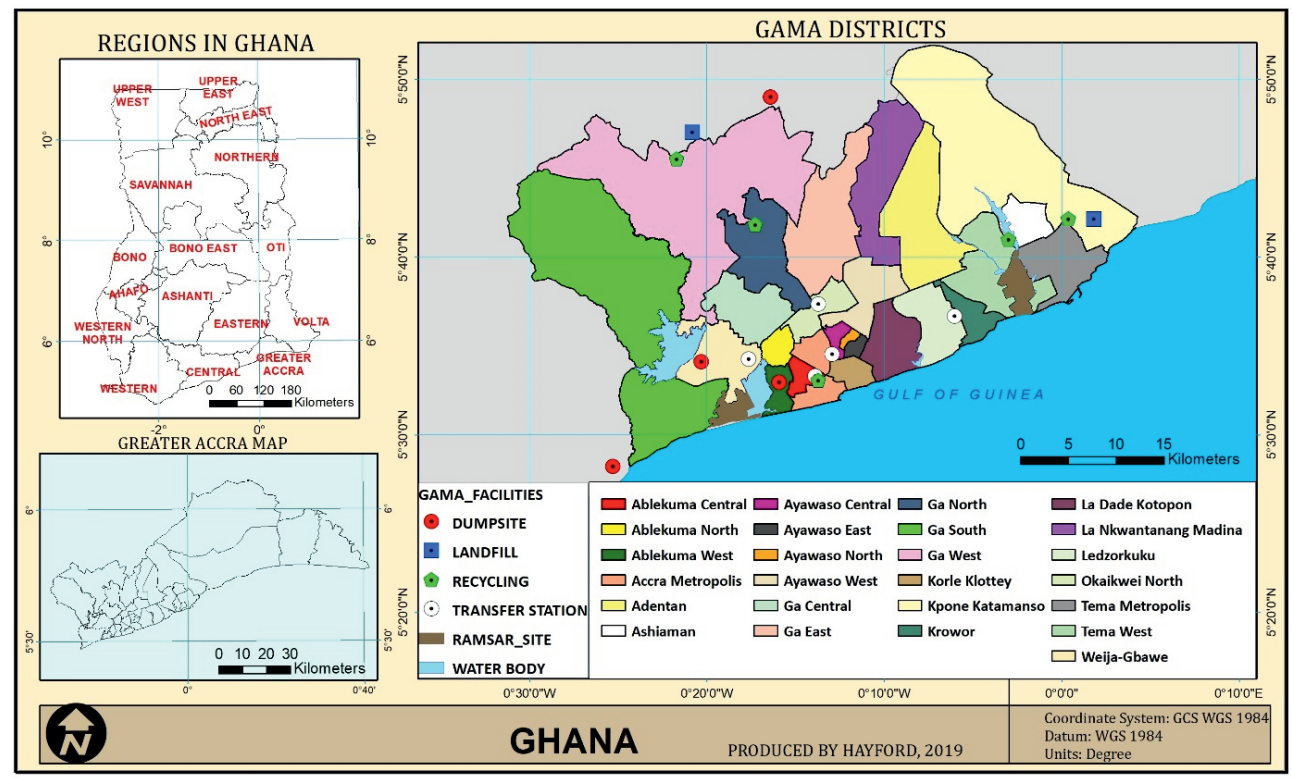

Figure 5.I: The Greater Accra Metropolitan Area showing the 25 municipalities and MSWM facilities.

Source: The authors, 2019.

\section{Key methodological interventions and strategic results}

The research to this article has used a participatory engagement strategy (the PAR) to identify and mobilise relevant stakeholders together to collect verifiable, real time practical data on the informal waste sector and assess their socio-economic contributions to the MSWM system of the GAMA. The objective was to allow these stakeholders to:

- freely articulate their opinions and perceptions of the IWS

- gain a comprehensive understanding of the activities, contributions and challenges of the IWS

- promote trust and transparency towards reliable data and information gathering

- build competencies and further improve upon inclusive decision-making

The main data collection approach of the working group includes a combination of structured surveys and semi-structured interviews, discussions, field observations and measurements, and mapping of material paths. Unlike the conventional method of data collection, the point of departure in the use of PAR was that, the target group of study (the IWS) were the protagonists in control of a process that actively engaged them in data collection and decision-making, rather than objects for study and passive recipients of information (IJgosse et al., 2004). The working group, which had a reasonable representation of the IWS collectively developed a checklist of questions and survey 
instruments to meet the data requirements. The Cochran's formula was used to estimate the sample size (234 for the waste pickers and 320 for the ISPs) for the study (Cochran, 1977). But the dynamics and complexities of the activities of the IWS, especially with the waste pickers, called for a careful approach to the use of these conventional sample sizes. Based on the varied nature of material quantities collected and salvaged, and the wide dispersal of the IWS within the GAMA, the working group came to the conclusion to increase the sample size of the waste pickers and the ISPS to 330 and 700 respectively. In addition to this, all informal waste sector actors were counted. The IBM statistical package for social scientists, version 24 and the subSTance flow ANalysis (STAN) software, version 2.6, were used for data analysis and the drawing of waste flow diagrams. In the following sub sections, the specific instruments used to collect the various data and the results obtained are discussed.

\section{Census of the informal waste and recycling sector within the GAMA}

The census data of the ISPs and the IRCs (waste pickers, buyers and junk dealers) were collected using face-to-face questionnaires. This was followed by a random sample survey covering 330 out of 600 waste pickers, 35 out of 46 buyers and junk dealers, and 700 out of 1618 ISPs. The questionnaire administration was done by 12 members of the working group in six different languages including English and French. Snowball research sampling approaches allowed researchers to reach the junk dealers who operated outside of the traditional processing locations. The questionnaires were pretested earlier on 40 people to test validity and reliability. The questions were limited to name, sex, age, marital status, household size, contact address, highest education level and registration or otherwise to national health insurance and pension schemes. The working group had to visit all bulk transport, final disposal and processing sites for six consecutive weeks to engage with the informal operators, create a rapport, build alliances, and assure the ISPs and the IRCs of confidentiality. This was necessary to pave way for mutual trust and understanding towards reliable data. The responses to the survey were coded manually, entered, and analysed by means of the statistical package for social sciences (SPSS), version 24.0. Descriptive statistical tools were used to explore and interpret the findings.

\section{Results of the census}

The census results are shown in Table 5.1. The total number of IRCs within the GAMA is 646 . The $15 \%$ female workforce of the waste pickers represents a slight increase when compared with the $90 \%$ male and 10\% females reported earlier (Rockson et al., 2013). With an average household size of four, the waste pickers are composed of $53 \%$ Ghanaians, 35\% Nigeriens, 9\% Nigerians and 3\% Togolese; confirming the involvement of immigrants in waste salvaging for survival purposes (Gerdes and Gunsilius, 2010). The ISPs, 1618 in number (Table 5.2), however, are predominantly Ghanaians (93\%) with only $7 \%$ from the neighbouring countries. Unlike the IRCs and partly because of 
Table 5.I: Demographic characteristics of the IWS within the GAMA.

\begin{tabular}{llllll}
\hline & & ISPs & IRCs & & \\
\hline \multirow{4}{*}{ Sex } & & $(\mathbf{n}=\mathbf{7 0 0})$ & $\begin{array}{l}\text { Pickers } \\
(\mathbf{n}=\mathbf{3 3 0})\end{array}$ & $\begin{array}{l}\text { Buyers } \\
(\mathbf{n}=\mathbf{2 4})\end{array}$ & $\begin{array}{l}\text { Junk Dealers } \\
(\mathbf{n}=\mathbf{1 1})\end{array}$ \\
\hline \multirow{4}{*}{ Age } & Category & $\%$ & $\%$ & $\%$ & $\%$ \\
\hline & Male & 99 & 85 & 98 & 100 \\
& Female & 1 & 15 & 2 & 0 \\
\hline \multirow{5}{*}{ Education } & $<18$ & 4 & 3 & 0 & 0 \\
& $18-27$ & 45 & 43 & 12 & 15 \\
& $28-37$ & 36 & 32 & 52 & 38 \\
& $38-47$ & 12 & 14 & 28 & 32 \\
& $48-57$ & 3 & 6 & 8 & 15 \\
& $>57$ & 1 & 3 & 0 & 0 \\
\hline \multirow{4}{*}{ Nationality } & None & 42 & 52 & 9 & 8 \\
& Primary & 20 & 33 & 66 & 77 \\
& Secondary & 37 & 14 & 22 & 15 \\
& Tertiary & 1 & 1 & 3 & 0 \\
\hline & Ghanaian & 93 & 53 & 54 & 77 \\
& Nigerien & 5 & 35 & 42 & 23 \\
& Nigerians & 2 & 9 & 4 & 0 \\
& Togolese & 0 & 3 & 0 & 0 \\
\hline
\end{tabular}

Source: The authors, 2019.

societal perceptions, only four females (1\%) are involved in informal MSW collection. A significant number (more than 75\%) of both the IRCs and ISPs are youth between 18 years and 37 years with no formal education; putting them at extremely low odds to formal employment opportunities. The $1 \%$ of respondents with tertiary education are mostly from deprived regions of the country who join the sector during vacations to raise funds to support their education.

\section{Developing data and information on the activities and material balance of the informal waste sector}

The material and process flow diagrams (Figure 5.2 and Figure 5.3) are based on data from structured interviews and questionnaire administration among the randomly selected ISPs and IRCs and validated amongst managers of MSWM and recycling facilities, in combination with observations, photos (which did not include identifiable individuals), and mapping. The questions focused on the types and quantities of valuable materials picked separately by the IRCs and collected as part of MSW by the ISPs. It also included the disposal and processing paths of the collected and recovered materials. Additional 
The contribution of participatory engagement strategies to reliable data gathering

Table 5.2: The number of informal service providers (ISPs) collecting MSW from within the GAMA.

\begin{tabular}{|c|c|c|c|c|c|}
\hline No. & Municipalities & $\begin{array}{l}\text { Area } \\
\left(\mathbf{K m}^{2}\right)\end{array}$ & Population & $\begin{array}{l}\text { No. of } \\
\text { ISPs }\end{array}$ & MSWM facilities \\
\hline 1 & Accra Metropolis & 23.50 & 568,172 & 150 & $\begin{array}{l}\text { Integrated Recycling and Composting } \\
\text { Plant } \\
\text { Korle Klottey Ecological Rehabilitati- } \\
\text { on Project (KLERP) Transfer Station }\end{array}$ \\
\hline 2 & Ablekuma West & 12.47 & & 48 & \\
\hline 3 & Ablekuma North & 10.77 & 246,838 & 251 & \\
\hline 4 & Ablekuma Central & 9.10 & 336,088 & 59 & \\
\hline 5 & Ayawaso East & 3.71 & \multirow{2}{*}{230,538} & 45 & \\
\hline 6 & Ayawaso North & 2.13 & & 35 & \\
\hline 7 & Ayawaso West & 35.19 & 88,918 & 11 & \\
\hline 8 & Ayawaso Central & 6.04 & 178,478 & 121 & Kokomlemle Mini Transfer Station \\
\hline 9 & Okaikwei North & 20.86 & 285,903 & 85 & Zoom Pak Transfer Station, Achimota \\
\hline 10 & Korle Klottey & 11.88 & 152,733 & 29 & \\
\hline 11 & Ga Central & 41.33 & 141,070 & 25 & \\
\hline 12 & Ga East & 82.89 & 179,107 & 100 & \\
\hline 13 & Ga West & 247.40 & \multirow[t]{2}{*}{268,557} & 45 & $\begin{array}{l}\text { Accra Compost and Recycling Plant } \\
\text { (ACARP) }\end{array}$ \\
\hline 14 & Ga North & 58.29 & & 40 & City Waste Recycling \\
\hline 15 & Ga South & 262.55 & \multirow[b]{2}{*}{521,162} & 43 & \\
\hline 16 & Weija-Gbawe & 43.46 & & 28 & $\begin{array}{l}\text { Weija Dumpsite } \\
\text { Tidy-Up Mini Transfer Station }\end{array}$ \\
\hline 17 & Ledzokuku & 37.05 & \multirow{2}{*}{275,239} & 33 & Zoom Pak Transfer Station, Teshie \\
\hline 18 & Krowor & 18.38 & & 55 & \\
\hline 19 & La Dade-Kotopon & 35.97 & 221,284 & 62 & \\
\hline 20 & $\begin{array}{l}\text { La Nkwantanang } \\
\text { Madina }\end{array}$ & 67.80 & 134,837 & 135 & \\
\hline 21 & Adentan & 82.24 & 93,158 & 50 & \\
\hline 22 & Tema Metropolis & 42.31 & \multirow{2}{*}{353,086} & 4 & Safi Sana Recycling Plant \\
\hline 23 & Tema West & 51.63 & & 11 & \\
\hline 24 & Ashaiman & 20.29 & 231,096 & 151 & \\
\hline \multirow[t]{2}{*}{25} & Kpone Katamanso & 226.27 & 132,070 & 22 & $\begin{array}{l}\text { Kpone Landfill } \\
\text { Blowplast Recycling Ltd. }\end{array}$ \\
\hline & Total & 1453.51 & $4,638,334$ & 1,618 & \\
\hline
\end{tabular}

Source: The authors, 2019. 


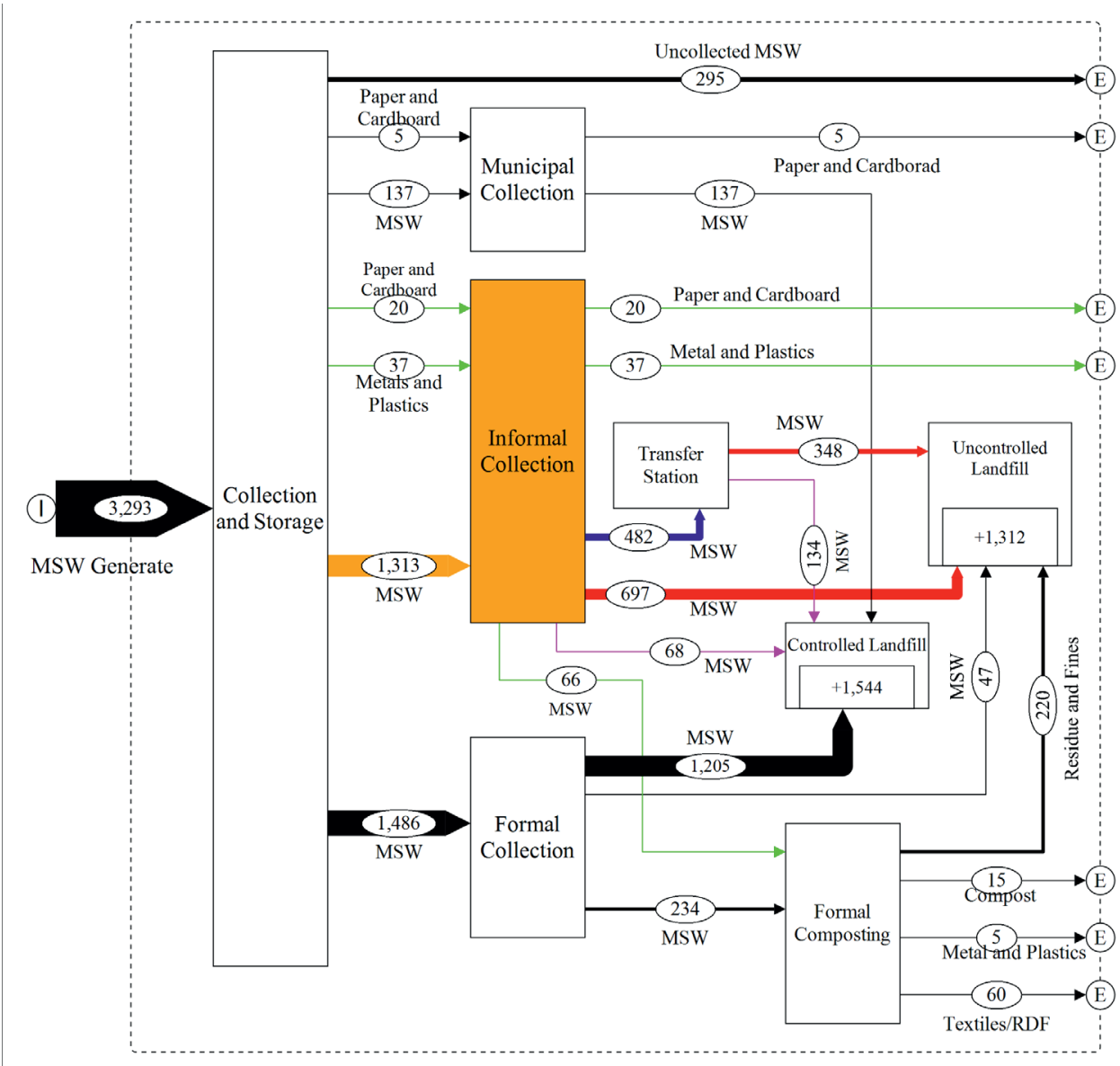

Daily MSW collection and disposal, the GAMA, 2019

Figure 5.2: Sankey-type material flow diagram for MSW collection and disposal within the GAMA, Ghana. The contribution of the ISPs is depicted in colour, other than black. The thickness of the flow corresponds to the weight of the waste (tonnes per day).

Source: The authors, 2019. Developed using STAN 2.6C (Institute for Water Quality Resources and Waste Management, TU-Wien, Austria).

Legend: ISPs: Informal Service Providers; MSW: Municipal Solid Waste; RDF: Refuse Derived Fuels.

Colour Legend: Orange: MSW collected by the ISPs; Green: Recovered materials and MSW for recycling and valorisation; Red: MSW to uncontrolled landfills; Blue: MSW to landfills via transfer stations; Magenta: MSW to controlled landfills.

questions addressed working schedules and specific challenges. Data collected were validated among managers of MSWM and recycling facilities.

The survey began with trust-building actions, including a series of meetings between the working group and the ISPs and IRCs. The working group presented themselves to answer and clarify pertinent questions, assure confidentiality of economic-related data 
and information, and agree to a work plan and to respect a checklist of do's and don'ts of the ISPs and the IRCs. To validate quantitative information, materials collected by the IRCs and the ISPs were weighed at the end of each week for four consecutive weeks - with the permission of, and in the presence of the waste picker, the buyer and two members of the working group. The data collected per ISP and IRC were analysed and averages were computed for the total number of ISPs, waste pickers, buyers and junk dealers. The computed tonnages were then used to estimate the informal recycling rate within the GAMA as a percentage of the total MSW generated. A process and material flow diagram was developed by tracking the flow and quantities of recovered waste streams within the value chain.

\section{Results: activities and material balance of the informal service providers}

The material flow diagram of the ISPs (Figure 5.2) is intended to assist stakeholders and decision-makers to understand the linkages between informal and formal activities within the service-chain (Scheinberg et al., 2011). Through healthy price-value relationships and reliable services, the ISPs have attracted a large customer base and are collecting daily, an average of 1370 metric tonnes (46\%) of all collected MSW within the GAMA. Whilst they recover 37 tonnes of metals and plastics daily for sale to junk dealers, intermediate buyers operating as micro-enterprises collect 20 tonnes of paper mostly from institutions and commercial centres to sell to paper recycling industries. Depending on proximity, the ISPs dispose all collected MSW directly or via designated bulk transport stations to landfills and dumpsites. Two round trips per day is the norm for each operator, but delays at the disposal sites (deliberately created as a countermeasure to compel municipalities to pay debts owed to the management of the landfills) has reduced it to one; greatly affecting their turnovers. A significant number of the ISPs work six days a week with average collection frequencies of three times per week per client.

\section{Results: activities and material balance of the informal recyclable collectors}

The flow of materials of the IRCs is shown in Figure 5.3. Preferred materials of the IRCs are:

- Polyethylene Terephthalate (PET)

- High-Density Polyethylene (HDPE)

- Low-Density Polyethylene (LDPE)

- Polypropylene (PP)

- Ferrous metals

- Non-ferrous metals, mostly Aluminium and Copper 


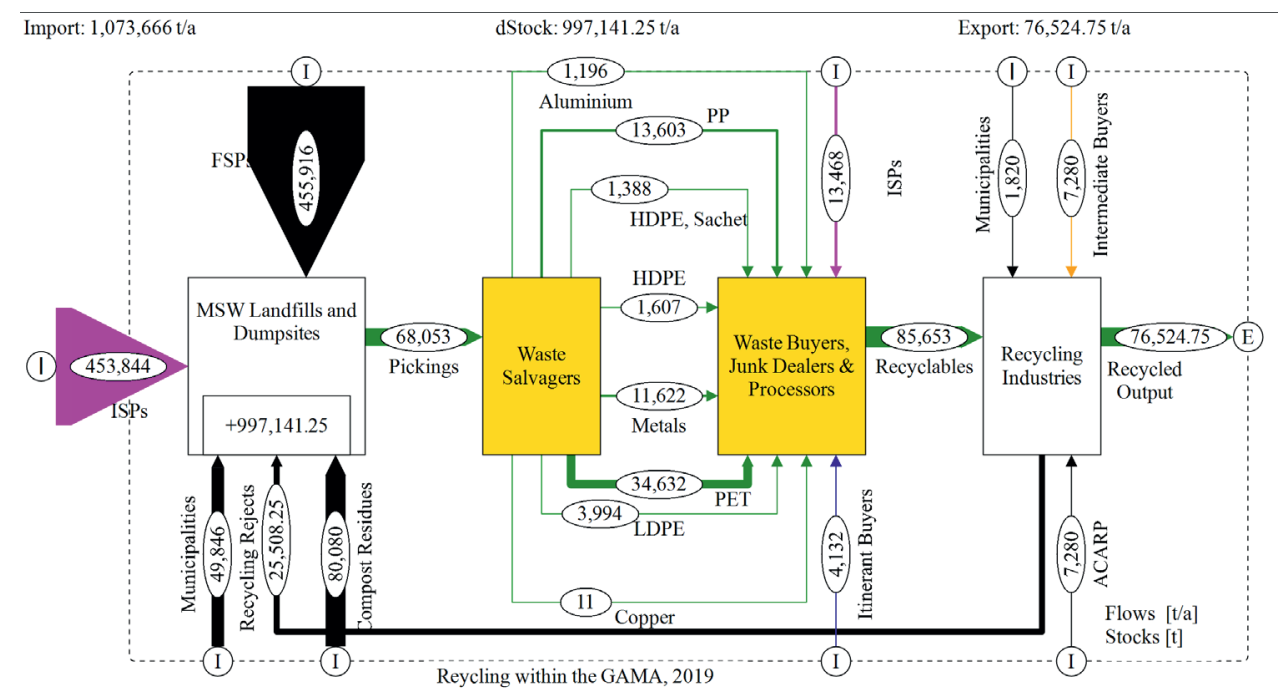

Figure 5.3: Process flow diagram for MSW recycling within the GAMA, Ghana. The thickness of the flow corresponds to the weight of the waste (tonnes per year). The contribution of the informal waste and recycling sector are in colour, other than black.

Source: The authors, 2019.

Legend: ACARP: Accra Composting and Recycling Plant; FSPs: Formal Service Providers; HDPE: High-Density Polyethylene; ISPs: Informal Service Providers; LDPE: Low-Density Polyethylene; MSW: Municipal Solid Waste. PET: Polyethylene Terephthalate; PP: Polypropylene.

Colour Legend: Magenta: ISPs contribution; Green: Recovered materials for recycling; Gold: Intermediate buyers contribution to recycling; Blue: Itinerant buyers contribution to recycling.

The number of waste pickers, the quantities of the various MSW components they recover and the amount per tonne at which the recovered materials are sold to intermediate buyers and junk dealers are shown in Table 5.3. Most waste pickers pick more than one stream of recyclables; the minimum being three per collector. The 600 waste pickers, who constitute the base of the network, recover 68,053 tonnes $(6.4 \%)$ of the total annual MSW (1,065,194.25 tonnes) arriving at the landfills and dumpsites (Figure 5.3). Depending on storage space, type of recovered waste stream and the requirements of local buyers, most pickers accumulate their waste for at least a week before selling.

The ISPs recover 13,468 tonnes (3\%) of the waste collected and this together with the contributions of itinerant buyers are sold to junk dealers and intermediate processors for further processing. Together with the contribution of some selected municipalities, the Accra Composting and Recycling Plant (ACARP) and the intermediate buyers, the annual quantity (102,033 tonnes) of materials recovered for recycling amounts to $8.5 \%$ of the total MSW generated (1,198,652 tonnes) within the GAMA. 
The contribution of participatory engagement strategies to reliable data gathering

Table 5.3: Average quantities and selling prices of MSW streams recovered weekly by the waste pickers.

\begin{tabular}{llllll}
\hline Waste Stream & $\begin{array}{l}\text { No. of } \\
\text { waste } \\
\text { pickers }\end{array}$ & $\begin{array}{l}\text { Average recovery/per- } \\
\text { son/week } \mathbf{K g})\end{array}$ & $\begin{array}{l}\text { Total reco- } \\
\text { very/week } \\
\mathbf{( K g )}\end{array}$ & $\begin{array}{l}\text { Price/tonne } \\
\text { US\$ }\end{array}$ & $\begin{array}{l}\text { Total price/ } \\
\text { tonne } \\
\text { US } \$\end{array}$ \\
\hline PET & 333 & 2000 & 666000 & 120.00 & $79,920.00$ \\
HDPE & 515 & 60 & 30900 & 240.00 & $7,416.00$ \\
HDPE, (Pouches) & 178 & 150 & 26700 & 160.00 & $4,272.00$ \\
LDPE & 128 & 600 & 76,800 & 260.00 & $19,968.00$ \\
PP & 327 & 800 & 261600 & 200.00 & 52,320 \\
Metal & 447 & 500 & 223500 & 140.00 & $31,290.00$ \\
Copper & 72 & 3 & 216 & 3400.00 & 734.40 \\
Aluminium & 460 & 50 & 23000 & 240.00 & 5.520 .00 \\
Total & & 4163 & 1308716 & & $201,440.40$ \\
\hline
\end{tabular}

Source: The authors, 2019; US\$1.00= GHC5.00.

Legend: IRCs: Informal recyclable collectors; PET: Polyethylene Terephthalate; HDPE: High-Density Polyethylene; LDPE: Low-Density Polyethylene; PP: Polypropylene

With an estimated recycling efficiency rate of $75 \%$, only $76,524.75$ tonnes of the total recovered materials are recycled into useful products; bringing the actual recycling rate within the GAMA to $6.4 \%$. The rest are returned to landfills as rejects. Of the 600 waste pickers identified, only 250, mostly Ghanaians, on the Kpone landfill site are well organised with a well-structured leadership hierarchy; partly because of strict rules from the management of the controlled landfill and partly due to the effort of Women in Informal Employment Globalizing and Organizing (WIEGO), who provide support through education and demonstration of best practices.

\section{The socio-economic contribution of the informal service providers and the informal recyclers}

The activities of the informal solid waste sector supports livelihoods of most urban poor in addition to creating social and indirect economic benefits to the cities they work in (Scheinberg et al., 2010a).

The economic benefits of the activities of the ISPs to the municipalities within the GAMA has been estimated based on their cost of operation and turnover (Table 5.4). Relevant data was obtained as part of the interviews and the day-to-day field monitoring processes of the activities of the ISPs and the IRCs. In relation to the ISPs, the working group made an inventory of the source of their equipment (motorized tricycles), maintenance schedules, breakdown frequencies, in addition to the daily amounts paid for equipment usage. Their economic contribution to the system was estimated by computing the 
average frequency and average quantity of waste brought to the sites by each operator, the amount raised per day minus the expenditures on fuel, disposal, maintenance and depreciation. The economic contribution of the IRCs was estimated by computing the economic value of the void space saved from their activities; in addition to computing the tonnages and related prices of the various waste streams recovered, weighed and sold to local buyers and junk dealers.

Service users pay a relatively lower average cost of US $\$ 8.00$ for three times a week MSW collection by the ISPs, compared to US $\$ 12.00$ for once a week collection by formal service providers. This in addition to service reliability and client friendliness justifies the relatively strong preference of clients to the services of the ISPs. On average, an ISP realises US $\$ 40.00$ upon collecting a full tricycle (1.2 tonnes) of MSW from 100 households (Table 5.4). Out of this, US\$22.00 is spent on fuel, maintenance and servicing of equipment parts, disposal, and depreciation for operators who own the tricycles or as daily returns to the individuals who rent out the tricycles. The rest, US $\$ 18.00$, is considered as turnover, which provides livelihood to household members.

The ISPs indirectly contribute to saving the municipalities an amount of US\$20,192,640.00 (Table 5.4) annually in MSW collection and disposal cost. If not for the three times collection frequency per week and reliable services, the US $\$ 40.00$ collection and disposal cost for a 1.2 tonne of MSW by the ISPs would have been higher than the estimated average of US $\$ 30.00$ per tonne of MSW collected and disposed in lower middle-income countries (Kaza et al., 2018; Coffey and Coad, 2010). In reality, the ISPs are offering quality services at a highly reduced cost to the municipalities. For example, the municipality of Accra, in 2015, is reported to have collected 21216 tonnes of MSW at approximately US\$3.6 million minus labour cost (Oduro-Appiah et al., 2017a). The ISPs would have collected the same at just $13 \%$ of the cost based on the computations of Table 5.4 .

Table 5.4: Estimated cost of service provision by the informal service providers within the GAMA.

\begin{tabular}{lllll}
\hline Item No. & Expenses Category & No. of ISPs & \multicolumn{2}{l}{ Cost of Service Provision in US\$ } \\
\hline & & & Daily & Annually \\
\hline 1 & Fuel & 1618 & 4.00 & $2,019,264.00$ \\
2 & Maintenance Cost & & 2.00 & $1,009,632.00$ \\
3 & Disposal Cost & 6.00 & $3,028,896.00$ \\
4 & Depreciation/Returns & & 10.00 & $5,048,160.00$ \\
5 & Average Turnover & & 18.00 & $9,086,688.00$ \\
& Total & & $\mathbf{4 0 . 0 0}$ & $\mathbf{2 0 , 1 9 2 , 6 4 0 . 0 0}$ \\
\hline
\end{tabular}


Each waste picker earn averagely US $\$ 300.00$ per month and collectively, these microentrepreneurs sustain 2400 dependants. Although lower than their ISP counterparts, this amounts to a daily turnover of US $\$ 12.50$ (which is still 6 times higher than Ghana's minimum wage of US\$2.00). Local buyers and junk dealers earn on average US\$ 400.00 and US $\$ 1000.00$ per month respectively. Each of 195 workers (mostly women) employed by the junk dealers to wash, cut, dry and pre-process recovered materials earn an average of US $\$ 4.00$ a day. The IRCs and the ISPs contribute to save the GAMA $387,902 \mathrm{~m}^{3}$ of void space and US\$856,530.00 in annual landfill operational expenses (Abledu and Amfo-Otu, 2018; Kusi et al., 2016).

\section{Sustaining reliable data flows and inclusive governance within the GAMA and Sub-Saharan Africa through IWS integration}

The IWS within the GAMA contribute to $84 \%$ of recycling compared to the formal sector. This in addition to their economic contribution to useful landfill life extension and savings in MSW operational expenditures provides strong evidence for their integration into the formal solid waste management system. But local authorities and decision-makers of MSWM in most lower-middle income cities of Sub-Saharan Africa seem not to recognise such form of inclusive private sector participation to be beneficial to the cause of MSWM modernisation (Oteng-Ababio et al., 2017; Sandhu et al., 2017).

Neither the existence of analytical and recycling frameworks (Velis et al., 2012; Scheinberg and Simpson, 2015; Fei et al., 2016), examples of best practices of the International Labour Organization (ILO) towards informal inclusiveness and integration in East Africa (Ishengoma and Toole, 2003), nor recent attempts by WIEGO and other Non-Governmental Organisations (NGO's) to strengthen informal recyclable collectors (Ezeah et al., 2013), have been able to drive commitment of local and national authorities towards IWS inclusiveness across Sub-Saharan Africa (UNEP, 2018). With the exception of South Africa, Uganda, Kenya, Tanzania, and Madagascar (Godfrey and Oelofse, 2017; Aparcana, 2017; Andrianisa et al., 2018), where the scholarly literature provides evidence of policy development and practical attempts at integration for the IWS in selected cities, all other Sub-Saharan Africa countries, including Ghana, have yet to demonstrate commitment both at policy and legislative levels towards informal waste sector integration (Oteng-Ababio et al., 2017; Ayodele et al., 2018). This apparent lack of recognition for the contribution of the IWS does not only prevent them from unleashing their full potential towards MSW system modernisation in the region, but leaves them also in constant fear of losing their means of employment and survival at any time. 
However, the participatory approach to this article and recent projects in Accra have made a convincing case that collaboration and structural cooperation between researchers, municipalities and other relevant stakeholders can prove a good approach to close apparent gaps in MSW data and drive decision-makers commitment towards inclusive governance and MSW system modernisation within the GAMA (OduroAppiah et al., 2019; Oduro-Appiah et al., 2017a). Integration of the IWS may not only open up opportunities for local government support, but will provide the necessary path to sustain reliable MSW data flows for continuous planning and inclusive decisionmaking.

The municipalities within the GAMA stands further to benefit immensely from the experiences of Latin American and Asian cities like Brazil, Columbia, Chile, Mexico, Peru, China, India, Indonesia, Bangladesh and the Philippines; where policies and legal frameworks towards formalisation and integration of the informal waste sector have been translated into successful organising, often of co-operatives, sometimes business associations or waste picker unions (Medina, 2000; Silva de Souza Lima and Mancini, 2017; Paul et al., 2012). Modest success in organising, combined with some form of external impulse and donor support, suggest that integration is a win-win and sustainable MSWM delivery system.

\section{Recommendation for informal sector integration within the GAMA}

Recommending a pathway for integration of the IWS within the GAMA and other Sub-Saharan regions to address the outlined challenges and sustain reliable MSW data flows is necessary but requires cautiousness. A one-fits-all solution may definitely not be the way to go. Based on the experiences and the findings of this study, we support the continuous collaboration and participatory development of action plans based on building on what works for each particular location. Nonetheless, the process within the GAMA and best practices of other developing cities (especially in Latin America) suggest that any attempt at successful integration should be municipality and local government driven with the support of academia, research institutions and NGO's; but also maintaining private actors' value-chain control (Navarrete-Hernandez and Navarrete-Hernandez, 2018; Oduro-Appiah et al., 2019; Scheinberg, 2012).

We recommend the following steps towards the integration of the IWS within the GAMA.

1. Engagement of the sector through registration of active IWS members.

2. Organisation of new and strengthening of existing IWS associations. 
3. Provision of training and capacity building support.

4. Development of a stakeholder platform with significant representation of the IWS sector actors.

5. Assigning of low-income service zones (where the formal service providers are known to be failing in service delivery) to the IWS in future franchise agreements.

6. Provision of unhindered access to MSW to the IWS from within their working zones and on the landfill sites to enable them continue with their collection services and value-chain recovery activities.

7. Continuous gathering of data and monitoring of the activities of the sector to drive advocacy and societal support towards the enactment of policies for their integration.

A careful balance between the repercussions of an integrated IWS with the full potential to maximize collection coverage and recycling rates, and the probable legal and economic effects on the existing formal service providers needs further research and deliberations to prevent conflicts, promote cooperation and harmonise user fees where necessary (Gerdes and Gunsilius, 2010). The potential possibilities of creating markets for recyclables, improving the bargaining power and working conditions of the IRCs and tapping the experiences of the ISPs and IRCs towards household and central MSW separation systems, (Scheinberg, 2012) should remain subjects of research interest to be introduced systematically after trust and some significant measure of system sustainability has been achieved.

\section{Conclusion}

Contrary to the conventional approach to data gathering, especially with regards to the informal waste sector in developing countries, this study has made the case that structural cooperation and stakeholder consultation, based on inclusive planning and participatory action research methods, create a reliable pathway to baseline data and information gathering for inclusive decision making.

The process has provided evidence to support the significant role and socio-economic contribution of the ISPs and IRCs to the MSWM system within the GAMA, Ghana. The detailed process and material flow diagrams provide a comprehensive overview of the movement of materials handled by the ISPs and the IRCs and is intended for 


\section{Chapter 5}

stakeholders to identify points of entry for support provision and development of locally appropriate action plans towards a sustainable integration process within the GAMA.

The informal waste and recycling sector within the GAMA is contributing to substantial savings for the 25 municipalities in MSWM operation costs in addition to increasing the useful life of the region's scarce landfills. Despite their efforts, the sector still lacks official recognition and has been facing difficulties with occupational safety and health, harassment and a related threat of being refused to continue with their choice of employment (Boampong and Tachie, 2017). The challenge for the municipalities is to optimise the benefits that the informal sector provides, through positive engagement, support and integration into the formal waste economy (Diaz, 2017).

The working group with support from the municipalities and the new ministry of Sanitation and Water Resources has come to appreciate the partnership linkages in addition to the need to mobilise various types of capital, among them human-, financial-, social-, physical-, and public infrastructure capital, in order to ensure sustainable integration (Sembiring and Nitivattananon, 2010). The working group members are cooperating with other stakeholders to develop the action plans and policies which will be systematically implemented to engage, register, organise, and integrate the informal waste sector as part of a comprehensive programme that seeks to modernise and sustain the MSWM and recycling systems in the 25 municipalities. Although the content of the information gathered will differ in other developing countries, the methodology, the process flows and the process recommendations and their capacity to leverage locally responsive informal waste and recycling sector integration will likely result in closing of data gaps and integration of the sector in similar developing economies. 
The contribution of participatory engagement strategies to reliable data gathering 


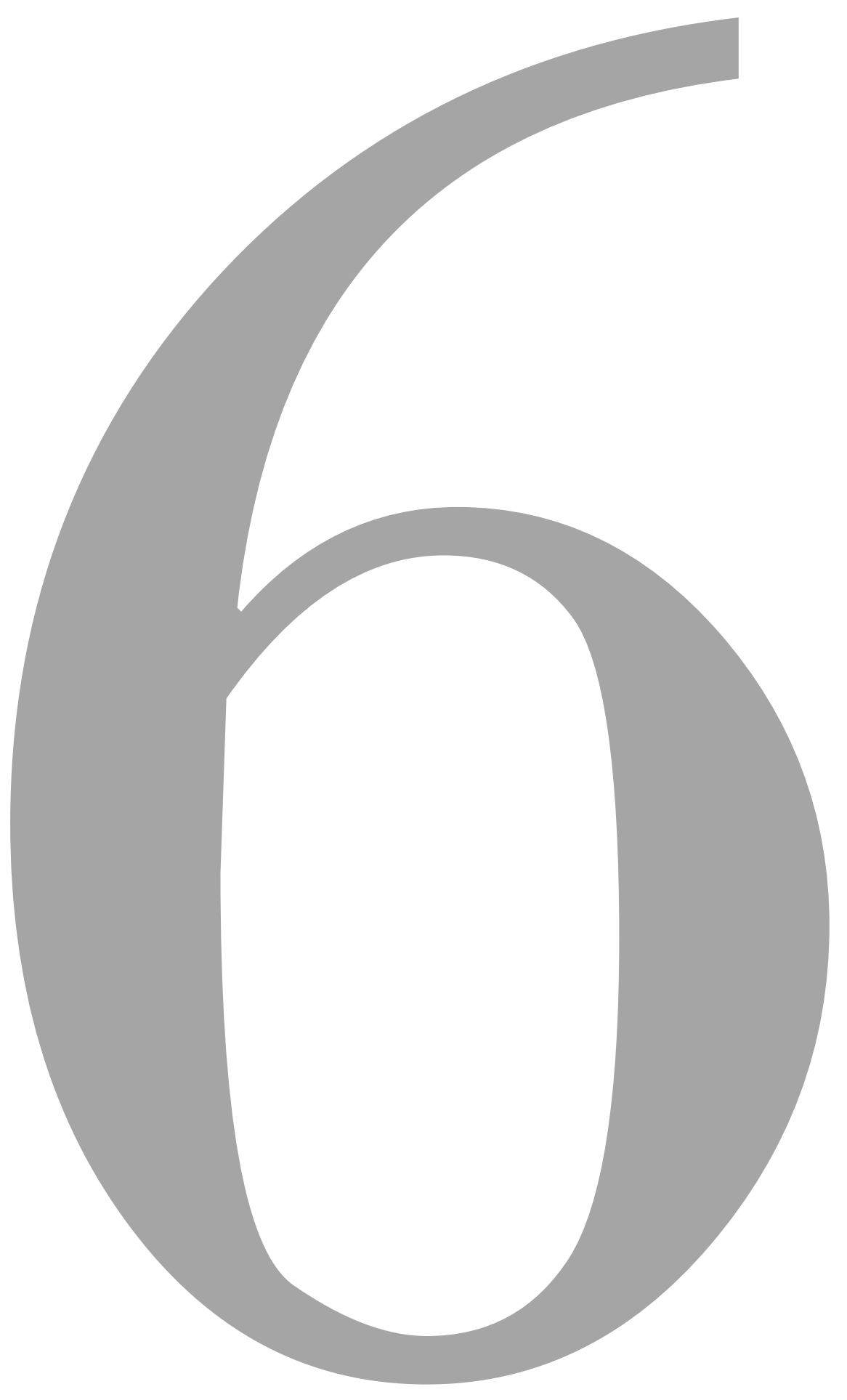




\section{Chapter 6}

\section{Existing realities and sustainable pathways for solid waste management in Ghana}

This chapter has been published as:

Kwaku Oduro-Appiah, Anne Scheinberg, Kodwo Miezah, Anthony Mensah and Nanne de Vries (2020). Existing realities and sustainable pathways for solid waste management in Ghana. In A. Pariatamby, F. Shahul Hamid \& M. S. Bhatti (Eds.), Sustainable waste management challenges in developing countries (115143) Hershey, Pennsylvania (PA), USA. 


\begin{abstract}
The demands of the circular economy and the sustainable development goals call for a critical appraisal of the solid waste management systems of developing economies to divert decision-making towards the development of sustainable strategies and support systems for purposes of modernisation. This chapter uses a combination of literature review, network queries to key experts within municipalities, and the authors' experiences and outputs of an ongoing collaborative research to evaluate and present the realities of solid waste management and recycling in Ghana. The goal is to chart a locally appropriate and sustainable pathway to drive system improvement. The analysis and evidence suggest that structural and coordinated cooperation between researchers of higher educational and research institutions and municipal authorities creates an enabling platform to build human resource capacities, to bridge data gaps, to identify what works, and to drive decision-makers' commitment towards the development of realistic action plans and continuous policy strategies.
\end{abstract}

Keywords: Municipal solid waste, E-waste, Solid waste, Coordination, Cooperation, Participation, Higher educational institutions, Integrated sustainable waste management, Modernisation, Developing countries, Ghana 


\section{Introduction}

This chapter presents the existing realities of solid waste management (SWM) and recycling in Ghana and proposes an evidence-based and locally appropriate pathway to inform sustainable system modernisation. The authors have elaborated an assessment of the physical components and governance aspects of the solid waste management (SWM) system seen through the frame of Integrated Sustainable Waste Management (ISWM). Moreover, the authors have relied on data and research outputs of an ongoing collaborative and participatory research project with selected municipalities within the country that seeks to develop action plans and interventions to modernise the SWM system (Miezah et al., 2015; Oduro-Appiah et al., 2019; Oduro-Appiah et al., 2017a).

Consistent with an ISWM methodology, the authors have analysed the physical system using materials flow diagramming based in part on the WasteAware benchmark approach (Wilson et al., 2015a) for the six metropolitan cities of the country. WasteAware is increasingly seen as a tool both to assess the physical systems and the governance aspects of the SWM systems of cities and to allow comparability of urban waste systems across countries, regions, and similar income levels. The goal is to aid readers and stakeholders to comprehensively visualise the realities and performance of the SWM system on the ground, and open up the opportunity for stakeholders to contribute to planning.

Although there is a robust literature on the SWM system in cities of Ghana (Boadi and Kuitunen, 2003; Oduro-Kwarteng and van Dijk, 2013; Oteng-Ababio et al., 2017), this chapter seeks, for the first time, to integrate many aspects, and address municipal solid waste (MSW), agricultural and biomass utilisation, biomedical solid waste, waste of electrical and electronic equipment (WEEE), industrial solid waste, and construction and demolition waste. Secondly, the authors of this chapter have relied on the ideas of a working group on system modernisation, that is, involving practitioners in the discussion and the choices made. The objective is twofold:

- to provide a quick and easy reference resource for academia, research institutions, policy makers, solid waste managers, non-governmental organisations (NGO's) and the international community; to support them to identify points of entry for the development of sustainable interventions and support systems for the country's SWM system

- to create a participatory basis for advocacy and policy development purposes amongst policy-makers 


\section{Background}

Increasing population growth, rapid urbanisation, technological advancement and the apparent rise in living standards in the $21^{\text {st }}$ century have led to an unprecedented consumption of natural resources and a subsequent increase in the quantities and diversity of solid waste (SW) generated across the globe (Kaza et al., 2018). In developed and highly industrialised countries, this increase in waste generation has been associated with a range of political and environmental crises, which in turn stimulated the development of a set of integrated waste management and recycling policies and practices to promote public health, environmental control and efficient resource management which have become recognised as good practice in high-income countries in Europe, Oceania, Asia and North America (Marshall and Farahbakhsh, 2013). Ideally, the result of applying governance and financial tools will work to create virtuous circles of self-correction and continuous improvement (Scheinberg, 2011).

Importing these Integrated Waste Management (IWM) tools and approaches to upgrade waste systems in developing and transition economies has generally failed. The boundary conditions that have made sub-systems of IWM (such as internalising the environmental costs by charging fees for disposal of mixed waste; and diverting materials from land disposal through municipally sponsored waste prevention, recycling, composting, or energy recovery) thrive in developed countries are not present in the current SWM systems in (African) emerging economies. More often than not, the SWM systems of developing countries are characterised by a variable political commitment and a lack (or absence) of clearly defined strategies to deliver an efficient service and charge its real cost price (Bundhoo, 2018; Ezeah and Roberts, 2012; Guerrero et al., 2013). As a result, despite multiple attempts to transfer the wealth of information, approaches, and best practices developed and institutionalised in the global North, cities in Ghana (and other cities in lower middle-income countries) are caught in a downward spiral of overcapitalisation of technology without the fiscal systems to raise revenues and pay operating costs. Transfer of technology has thus partly contributed to a persistent inability to create sustainable systems or achieve balanced national policies that protect environmental and public health (Diaz, 2017).

The point of departure for this chapter is to acknowledge that Ghana, like other developing countries, is faced with numerous challenges in solid waste management (SWM) and recycling systems (Guerrero et al., 2013; Oteng-Ababio et al., 2013). More than 60 years after independence from colonial rule, the country continues to suffer from both an absence of clear policies and an uneven political commitment towards SWM (Asase et al., 2009; Oduro-Appiah et al., 2017a). Despite the continual investment in personal and institutional capacity development, those charged with the management of solid waste have neither been able to generate the necessary baseline data for planning 
purposes; nor to create the enabling conditions for support from academia and research institutions towards the development and implementation of locally appropriate strategies. Technology transfer and murky Private Public Partnerships (PPP) have been accepted as the path of least resistance to address challenges. The international loans and Extended Producer Responsibility (EPR) funds have been grabbed and used for modernising landfills and constructing state-of-the-art composting and recycling plants, even when the solid waste characteristics, handling conditions and market forces do not support the application of such technological approaches. Analysis of the solid waste landscape in Ghanaian cities continues to document a basic lack of appropriate strategies or support systems that could stimulate sustainable system modernisation (Government of Ghana, 2017).

The SWM system of the country has thus evolved through a series of external pressures, developments, policies, and ad hoc interventions. The result for Ghanaian cities is a mix of weak policies and regulatory frameworks, partial collection coverage, low recovery and recycling rates dependent on informal recycling enterprises, under-regulated private sector participation, and the total unavailability of environmentally appropriate disposal facilities. The results can be widely perceived in the prevalence open-burning of MSW, industrial solid waste, and WEEE with its attendant health- and environmental-related burdens (Tue et al., 2016; Feldt et al., 2014; Oduro-Appiah et al., 2017a).

Moreover, the six Ghanaian cities profiled are carrying heavy financial burdens related to overambitious technology choices, and paying (or defaulting on payment) for systems that do not support them to meet their own performance standards. In this situation, there is little convincing reason for residents to comply with rules or change their environmental behaviours. In short the prevailing situation is chaotic, inadequate, and a health hazard.

One measurable consequence of the existing situation has been poor public and individual health (Boadi and Kuitunen, 2005). Sanitation related diseases constitute more than $70 \%$ of the health problems reported at outpatient health facilities in the country with persistent seasonal epidemic outbreaks of cholera (Government of Ghana, 2010). Solid waste in drains and gutters and along beaches has been a major cause of floods with its attendant annual loss of lives and property (Asumadu-Sarkodie et al., 2015; Gaisie et al., 2019). The visibility of solid waste all over the place further interferes with the tourism potential of the country.

In the quest to modernise the SWM system, municipal authorities in Ghana have tended to place excessive confidence in the ideas and commitment of international financial institutions and development partners. Rather than taking control of the situation, 
authorities allow the panic associated with a series of (real or media) crises to guide their choice for quick fixes, which further contribute to the vicious circle of capitalising unsustainable technologies and infrastructure whose operating costs are not affordable. The resulting models and master plans fail to address local waste conditions and realities (Oteng-Ababio et al., 2013).

Ghana continues, therefore, to witness a confusing proliferation and overlap of SWM intervention projects leaving in its path a cycle of perpetual dependency on short-term projects from development partners and international organisations. Unfortunately, there is no evidence that this has translated to improved system performance, but it does appear to have diminished the institutional space for public and private-sector specialists to chart a locally responsive, holistic and long-term pathway towards system modernisation. If circular economy policies and the Sustainable Development Goals (SDGs) goals are to be achieved, sustainable responses to the aforementioned challenges have to be built in this regard.

\section{Overview of Ghana}

Ghana is a lower-middle income republic along the West African Coast with a gross national income (GNI) per capita of US $\$ 1880.00$ (World Bank, 2019). It is bounded by Ivory Coast to the West, Togo to the East, Burkina Faso to the North and the Gulf of Guinea to the South (Figure 6.1). It comprises 16 administrative regions, 260 Metropolitan, Municipal and District Assemblies (MMDAs), and covers an area of $238,539 \mathrm{~km}^{2}$. Ghana is home to an estimated 30,280,811 inhabitants (Ghana Statistical Services, 2019). The daily average per capita municipal solid waste (MSW) and health care waste generation rates are $0.47 \mathrm{~kg}$ and $1.2 \mathrm{~kg}$ respectively (Miezah et al., 2015; Asante et al., 2014). The four largest household waste composition categories in Ghana are biodegradable waste (61\%), plastic (14\%), paper (5\%) and metals (2\%) (Miezah et al., 2015). Ghana was the first country in Sub-Saharan Africa to gain independence from British colonial rule.

\section{Status of solid waste management and recycling in Ghana}

Solid waste management in Ghana is presented here in relation to the three key physical components (collection, treatment and controlled disposal, and the 3Rs (Reduce, Reuse and Recycle)) and the three governance aspects (stakeholder inclusivity, financial sustainability, and sound institutions with proactive policies) of the ISWM concept (Wilson et al., 2013). The ISWM framework allows for a comprehensive assessment of the system elements, the stakeholders, and the governance aspects required to deliver a well-functioning solid waste and recycling system in a city (Schübeler et al., 1996). For 


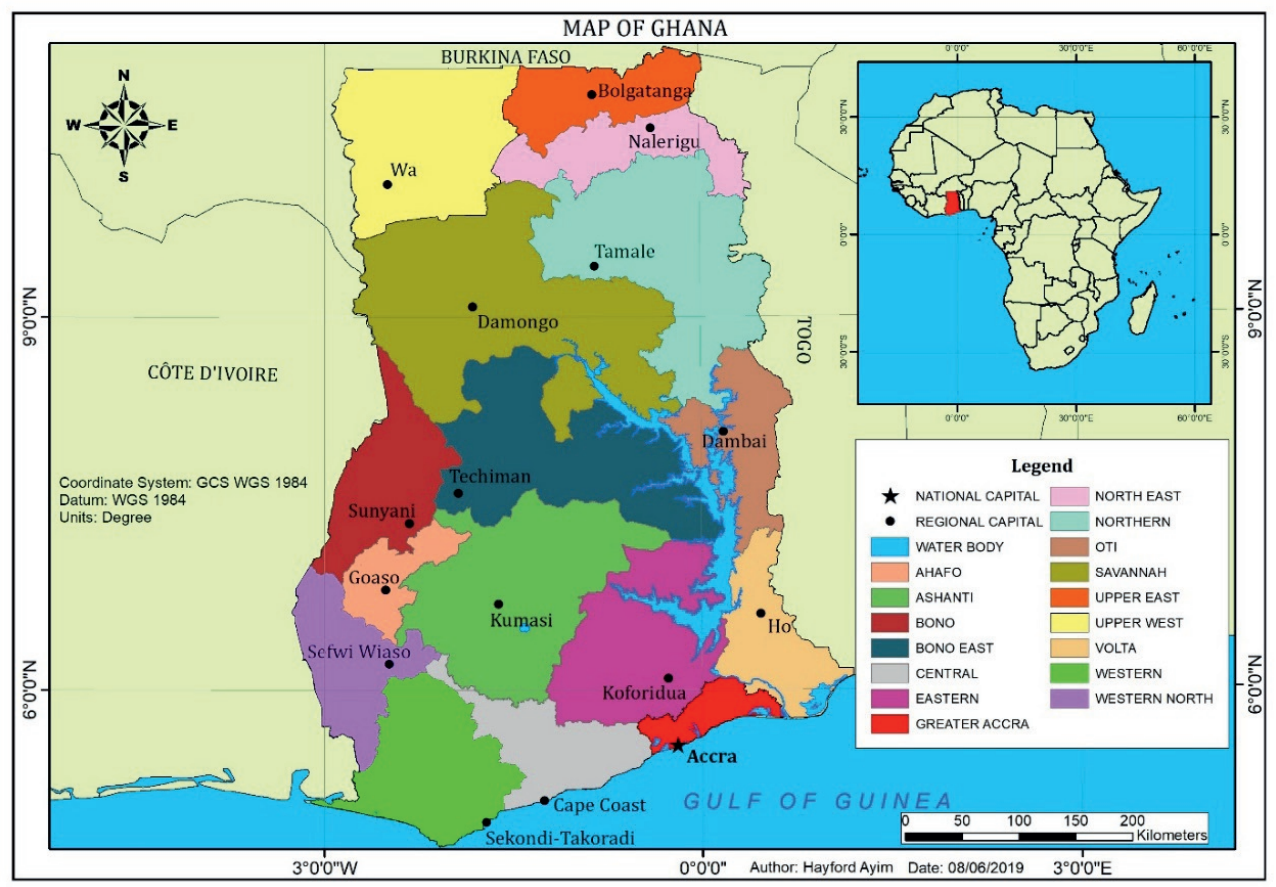

Figure 6.I: Map of Ghana showing the regions and boundaries to neighbouring countries.

Source: The authors, 2019.

this chapter, the authors are extrapolating from six cities (Accra, Cape Coast, Kumasi, Sekondi-Takoradi, Tamale and Tema) to benchmark the entire country's MSW system performance; using the WasteAware benchmark indicators.

First elaborated in the 2010 publication "Solid Waste Management in the World's Cities", global ideals of good practice such as universal collection coverage, controlled disposal, resource efficiency, activity-based budgeting, service provider and user inclusivity, and sound institutions and proactive policies constitute the basis for the indicators (Scheinberg et al., 2010b). The indicators (which come with automated excel sheets to compute scores) have proved useful and responded to the robust demand for a unified, freely available and real-time diagnostic tool. They are increasingly utilised by consultants and public authorities to assess SWM systems, identify strengths and weaknesses, and to make informed decisions for improvement. Since their introduction, more than 45 cities have been assessed using the indicators (Wilson et al., 2015a; Kabera et al., 2019).

The performance of the six metropolitan cities in the physical components and the governance aspects of MSW including detailed background and waste related data is shown in Table 6.1. The quantitative physical indicators of collection coverage and 


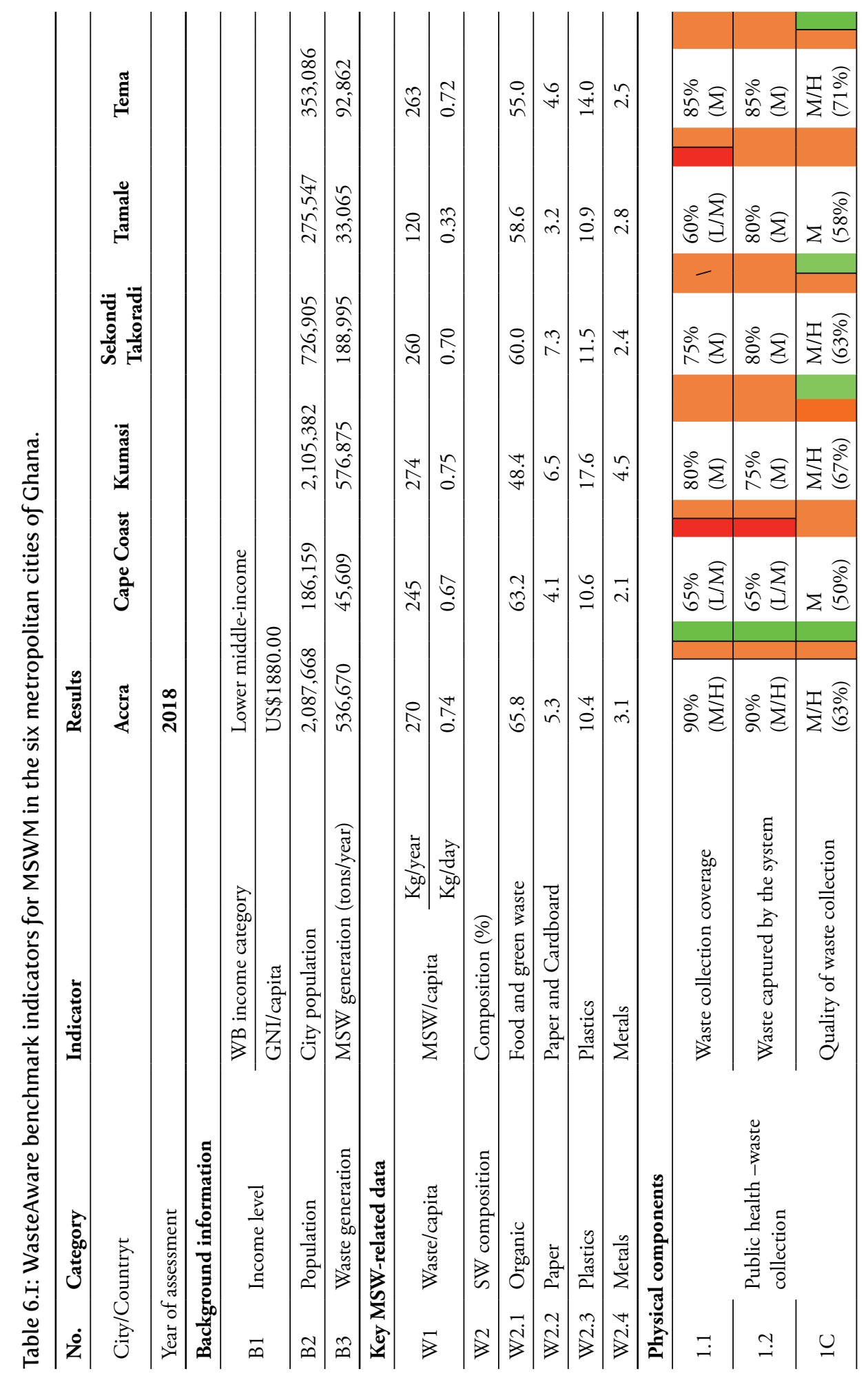




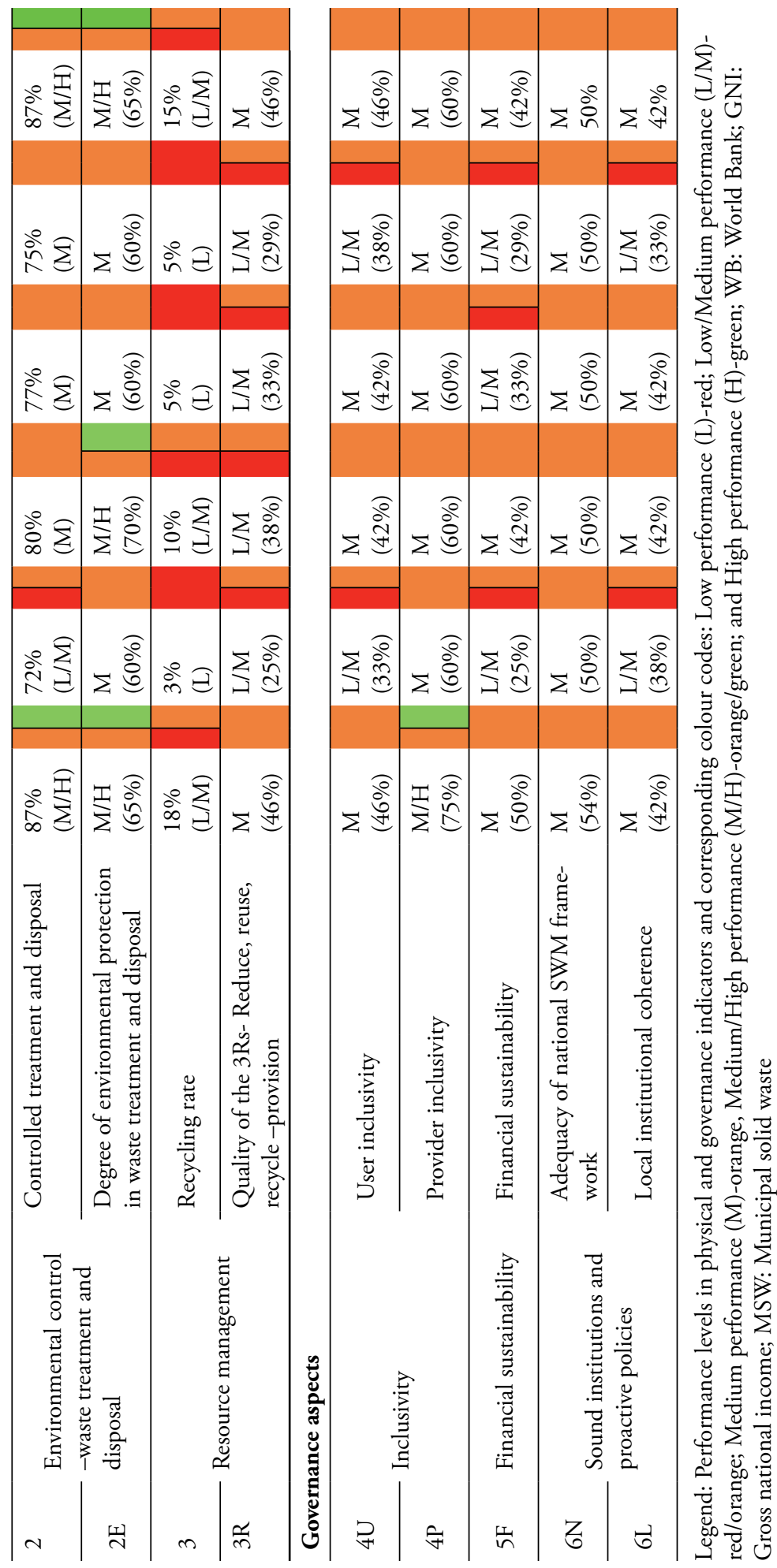


waste capture, controlled treatment and disposal, and resource recovery are represented by the numbers (1.1 and 1.2), 2 and 3 respectively. The corresponding qualitative physical indicators are represented by the number and letter combinations of $1 \mathrm{C}, 2 \mathrm{E}$, and $3 \mathrm{R}$ respectively. The combinations ( $4 \mathrm{U}$ and $4 \mathrm{P}), 5 \mathrm{~F}$, and $(6 \mathrm{~N}$ and $6 \mathrm{~L})$ represent the 'qualitative governance indicators of user and provider inclusivity, financial sustainability, and sound institutions and proactive policies' respectively. The colours "go, go slow, stop" symbolism of traffic lights to create a system of scoring of the performance of the cities in the indicators, where red, orange and green denotes low $(\mathrm{L})$, medium $(\mathrm{M})$ and high $(\mathrm{H})$ performances respectively. The letters B1, B2, B3 and W1 and W2 represent relevant background and waste-related information of the cities such as income level, population, total annual MSW generation rate, per capita annual generation rate and MSW composition respectively.

In the following sections, the status of MSW systems in the six cities, in relation to the indicators are discussed. The institutional and policy indicator is however discussed later in addition to the other forms of solid waste for the sake of brevity and organisation.

\section{Collection of municipal solid waste}

In spite of 20 years of official franchising of MSW collection services to formal service providers, average collection coverage in the country stands at $60 \%$. Informal service providers (ISPs) have partially filled the gap to push collection coverage to an average of $75 \%$ within metropolitan and urban centres (Government of Ghana, 2017); and in Accra, the capital city, locally responsive interventions targeted at providing a response to the informal service sector since 2016 has led to a coverage of $90 \%$ (Oduro-Appiah et al., 2019). At a national per capita generation rate of $0.47 \mathrm{~kg} /$ day (Miezah et al., 2015), the total daily average MSW generation rate stands at 14,232 tons (Figure 6.2). An estimated $75 \%$ of all generated MSW is collected, with the rest ending up on beaches, in drains, on vacant plots, or in unofficial dumpsites; and where there are no other options, it may be burned in households. The respective population, per capita and annual MSW generation rates, and the four major MSW compositions of the six metropolitan cities, are provided in Table 6.1.

Two main MSW collection systems exist in Ghana: house-to-house collection by formal companies on the one hand, and combined house to house collection, street sweeping, and related services (including some separate collection) provided by the ISPs. However, in most rural and urban areas (outside of central business districts and high-income neighborhoods), skip containers $\left(12 \mathrm{~m}^{3}\right)$ are provided at key intersections and other convenient points within communities to allow for secondary collection by formal service providers. Informal actors alone contribute to an average MSW collection rate of $40 \%$ in the six metropolitan cities of the country (Oduro-Appiah et al., 2019). 


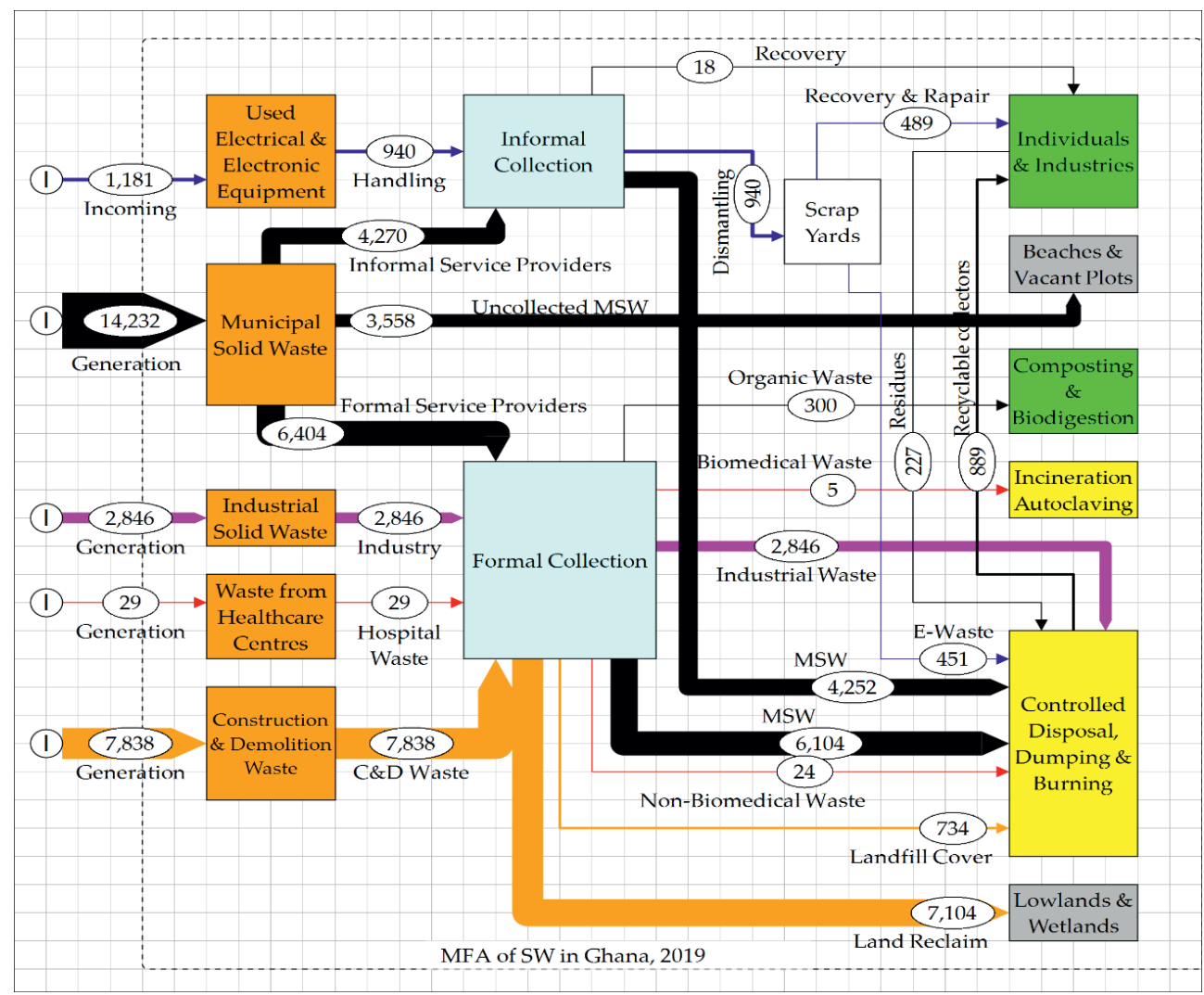

Figure 6.2: Sankey-type material flow diagram for solid waste collection, disposal and recycling in Ghana. The thickness of the flow corresponds to the weight of the waste (tons per day).

Source: The authors, 2019. Developed using STAN 2.6@ (Institute for Water Quality Resources and Waste Management, TU-Wien, Austria).

Legend: C\&D: Construction and demolition waste; E-Waste: Waste of electrical and electronic equipment (WEEE); MSW: Municipal solid waste.

Colour Legend, Flowlines: Black: MSW; Blue: WEEE; Magenta: Industrial solid waste; Orange: Construction and demolition waste; Red: Healthcare-related waste.

\section{Disposal of municipal solid waste}

Landfilling and dumping remain the largest and inevitably preferred MSW disposal methods in Ghana. There are four engineered landfills with leachate collection systems and 172 official dumpsites in the country (Environmental Protection Agency, 2017). With the exception of 300 tons of organic materials valourised in two state-of-theart composting and recycling plants, one windrow composting and two faecal sludge digestion plants in the Greater Accra Region, all collected MSW is disposed of in landfills and dumpsites. There is little use, in Ghanaian cities, of the globally accepted good landfill management practices such as daily cover, compaction, leachate collection and treatment, and even perimeter fencing and passage of all incoming vehicles over a 

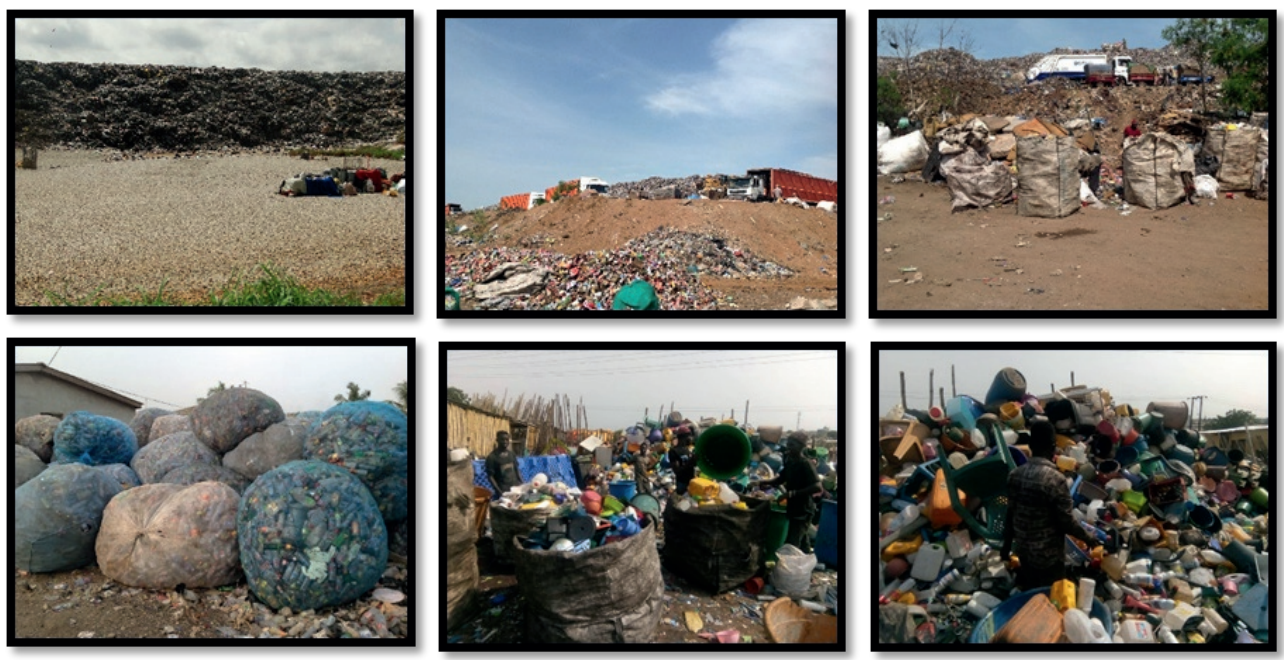

Figure 6.3: Disposal patterns and informal waste recovery and recycling activities within Ghana.

Photos: The Authors, 2019.

weigh bridge (see Figure 6.3). This in addition to poor management has contributed to the deterioration of all four engineered landfill sites within the metropolitan cities to controlled landfill sites; a reason for the low to moderate environmental control score for the six cities (Table 6.1).

Although all the engineered landfills have gas collection systems in place, there are no records of landfill gas emission measurements to support the development of a climate change action plan for the cities; nor are there any future post-closure energy recovery plans. Currently, most landfills and disposal sites have exceeded their design capacities, leaving the cities and towns in a precarious situation with regards to disposal of MSW (Government of Ghana, 2017). Years of poor governance and a lack of system user inclusivity in planning of MSWM facilities have denied the capital city, Accra, of a planned engineered landfill under the erstwhile Urban Environmental Sanitation Project (Oteng-Ababio, 2011a; Oteng-Ababio, 2014); compelling city authorities to rely on landfills within neighbouring municipalities.

\section{Recovery and recycling of municipal solid waste}

Apart from the publicly funded but privately managed Accra Composting and Recycling Plant (ACARP), the recently commissioned Integrated Recycling and Composting Plant (IRECOP), the Ga Mashie Aerobic Composting Plant, the JVL Fortifer Compost Plant, and the Safi Sana biogas digester, which together process only $18 \%$ of the daily input of 300 tons of organic waste (Figure 6.2), all recovery and recycling activities within the country take place in the private informal service and value chains. The 
combined MSW recycling rate in Ghana is estimated at $8.6 \%$ with the informal sector contribution at $6.2 \%$ (Oduro-Appiah et al., 2020a), which is classified as low on the WasteAware indicators but is at least based on some real evidence-based information (Table 6.1). However, the real solid waste recycling rate is probably higher, since this rate calculation does not include the recovery of metals and e-waste taking place at the Old Fadama Scrap Yard.

The 3Rs (reduce, reuse and recycle) are not supported by laws or policies, although there is some activity at the Government level to change this. There is no formal MSW segregation at source at the household and institutional levels in Ghana (OduroAppiah and Aggrey, 2013); the exception is a private formal collection company, Jekora Ventures, which encourages its clients within a municipality to separate biodegradable solid waste from recyclables and other fractions found in MSW before collection. This means that a significant amount of recyclable material travels as mixed MSW to formal and informal disposal sites (see Figure 6.2). In larger cities, much of this material is recovered by waste pickers on the disposal sites and sold to recycling companies via junk dealers and processors. These together with the absence of policies to integrate and support the waste pickers explains the relatively low to moderate scores in the quality of recycling (Table 6.1).

The market value of recyclables `inspires some householders to separate plastics for sale to itinerant buyers. The Greater Accra Region, which harbours both the capital city, Accra, and the industrial hub of the country, Tema, accounts for $90 \%$ (Government of Ghana, 2017) of all the recycling industries and activities in Ghana. High production costs and erratic energy supplies have drastically reduced investments into the recycling sector since 2012. The recycling efficiency of industries in Ghana stands at 75\%; meaning that $25 \%$ (227 tons) (see Figure 6.2) of MSW recovered are returned as residues to landfills and dumpsites.

\section{Level of user and provider inclusivity in municipal solid waste}

Service users - the households and businesses whose waste is removed for disposal — are seldom involved in the planning or implementation of MSWM decisions and programs in the six cities. Four of the six municipalities lack a stakeholder's platform, further denying system users of transparency and improved MSWM governance (Alamgir et al., 2012). There is little equity in service provision — poorer clients have a lower level of service and are seldom listened to (even if they take the time to complain). Most users within the urban and peri-urban centres pay a fee (directly to the service provider) for solid waste collection services, but they are not normally consulted, nor invited to participate in determining, either the level of service or the price for the level in their area. Although sanctioned by law, public review of MSWM budgets is seldom implemented 
in Ghana cities, earning them a low score on user inclusivity. What is missing is the type of participatory research, appraisal, monitoring and feedback that serve to stimulate the feeling of ownership that leads to compliance with norms and other forms of good solid waste behaviour. It is therefore not surprising that littering, illegal dumping, resistance to pay user charges and the prevalence of the Not In My Backyard (NIMBY) syndrome towards the construction of waste treatment and disposal facilities within the country are recurrent issues. Formal service providers are known to be moderately involved in MSW decision-making (Table 6.1) but this mild commitment to participation (provider inclusivity) does not apply to any of the informal waste and recycling service providers. Still, formal service providers do have a platform that relates to all MSW tendering processes, with clear guidelines and franchise agreements provided to support them in their service delivery.

\section{Municipal solid waste management funding and financing}

Solid waste financing remains a major challenge to national and local authorities. Loans and grants from development partners and donor agencies constitute the major source of capital funding, and user pay systems are underdeveloped, and, where they exist, the revenues seldom cover the costs. Tax revenues from municipalities, supplemented by user fees, theoretically cover budgeted operation and maintenance costs for collection services, especially in urban centres of the country, but this does not "reach" incidental or irregular expenses such as clearing away illegal dumpsites, even when such activities are technically part of the collection service. Subsidy schemes for landfill operations are politically popular, but they hide the true cost of the service from users, so that there is no incentive to divert recyclables from disposal, nor any perceived financial advantage for waste prevention. The result is that waste disposal is chronically underpriced, leaving the local and national government in a vicious cycle of debt to service providers and landfill operators (Oduro-Appiah et al., 2019). The absence of a MSWM strategy, political hesitation to charge the full cost for disposal, and the lack of activity-based budgeting means that the total cost of MSWM within the country has not been known since independence.

\section{Agricultural biomass and utilisation, waste-to-energy}

Residual biomass from economic activities is an important source of fuel for renewable energy and sustainable development and its use is expected to increase in the future. At the present time, it is estimated that biomass residues contributes as much as $64 \%$ of primary source of energy supply in Ghana (Kemausuor et al., 2014). Several forms of biomass can be identified in Ghana and they include: forest residues; wood processing residues; agricultural residues deriving from the cultivation from sugar cane, maize, oil palm, coconut, rice, cocoa, sorghum, millet, grasses; manures and slaughterhouse 
wastes from domestic livestock; urban waste including municipal solid waste, food waste, and sewage sludge (Duku et al., 2011; Kemausuor et al., 2014; Präger et al., 2019). Kemausour et al. (2014) determined the technical potential of biomass residues in Ghana as $96 \mathrm{PJ}$ in $2700 \mathrm{Mm}^{3}$ of biogas or $52 \mathrm{PJ}$ in $2300 \mathrm{ML}$ of cellulosic ethanol and this can replace more than a quarter of wood fuel use, a major source of deforestation in Ghana.

The challenge to sustainable use of biomass residues in Ghana lies in the mapping of these resources, and the organisation of logistics, transport, and financing systems. This is the case despite successful examples of conversion of biomass from pit latrine emptying into biogas. There is no specific policy nor incentive defining biomass; the rules for classifying and distinguishing between harvesting biomass or collecting residual biomass are not clear; and there are few guidelines for its utilization in Ghana. Even though the Ghana Energy Commission strives to gain maximal use of biomass as the main renewable source of energy (10\% renewable energy use by 2020), there is much to be done if these goals will be met, and there are basic challenges still to be addressed.

\section{Solid waste from healthcare centres}

In Ghana biomedical waste is generated by over 8,318 healthcare centres (Government of Ghana, 2018). The type of wastes generated depends on the status and activities of the healthcare centres, but legally, all waste from the healthcare system is classified as either biomedical or non-biomedical. The biomedical wastes from laboratories, pharmacies, surgical theatres, delivery rooms, etc. are defined to include pathogenic wastes, infectious waste, pharmaceutical wastes, laboratory waste, and other materials which may have health consequences. The daily waste generation from health care activities stands at 29 tonnes (Figure 6.2), and this has been estimated from the per capita biomedical waste generation rate of $1.2 \mathrm{~kg}$ per bed per day (Asante et al., 2014) and the 23,829 beds occupied per day within the country (Government of Ghana, 2018).

\section{Storage and collection of biomedical waste}

Per regulation (based on accepted good practice,) biomedical waste should be comprehensively separated at the point of generation into appropriately coded containers and directed to proper treatment and disposal centres. This currently occurs only in a few metropolitan and larger health care institutions. Notwithstanding, sharps and pathogenic wastes are generally separated in most hospitals. Other biomedical wastes are normally not separated, but stored and collected together with MSW. With the exception of hospitals within some tertiary institutions which collect their wastes, all other healthcare centres within urban areas have agreements with formal waste collection companies for collection and disposal. More often than not, biomedical 
waste is transported in ordinary MSW waste skip containers and compaction trucks for treatment and disposal at landfills.

\section{Treatment and disposal of biomedical waste}

An estimated five tons of biomedical waste is treated daily via incineration and autoclaving (Figure 6.2). The rest, estimated on average to be 24 tons of both pathogenic and infectious wastes, is mixed with non-biomedical waste from hospitals and disposed of on municipal landfills and dumpsites. Larger and older healthcare centres in the regions make use of brick-lined incinerators for the burning of infectious and pathological waste, but this is done without temperature monitoring and without treatment of flue gases. In the capital city, Accra, there is a privately managed autoclave facility situated on the premises of one of the MSW bulk transport stations for the treatment of biomedical waste. Designed for a capacity of 1.2 tons per hour (230 tons per month), the facility has been increasing its client base and treatment capacity, and had increased from 15 healthcare centres and $300 \mathrm{~kg}$ per month to 110 centres and 10.2 tons per month by mid-2019. Biomedical waste received at the facility is autoclaved at temperatures ranging between $121^{\circ} \mathrm{C}$ and $131^{\circ} \mathrm{C}$. This renders it inert and enables shredding to reduce the volume by $70 \%$, as well as making it safe for land disposal. The cost of treatment for a kilogram of biomedical waste is US $\$ 1.2$, which is deemed unsustainable considering the fact that most public and private healthcare centres in the country are only able to pay for services through a national health insurance policy which is constrained by financial difficulties and delayed payments. The autoclave facility provides training to clients to ensure effective segregation of waste streams and also makes use of specialised vans with freezing compartments for the collection and transportation of biomedical waste to the treatment centre. The lack of enforcement of the regulation on biomedical waste disposal further affects the rate at which medical centres subscribe to appropriate facilities. In place of facing sanctions for improper management of their wastes, managers of healthcare facilities remain free to choose less expensive, non-specialised management of their wastes — at poorly functioning landfills — in the normal municipal waste system.

\section{Management of waste of electric and electronic equipment (WEEE)}

Ghana and especially the Old Fadama dumpsite in Agbogbloshie (a slum area within the capital city, Accra) has achieved worldwide notoriety (Oteng-Ababio, 2018) and a great deal of "disaster tourism" for claimed abuses in labour, human rights, and environmental aspects of the dismantling, recycling, and disposal of end-of-life electronics. There is a great deal of written information and many unverified claims about what is happening at the site, and these create a climate of scandal and confuse real information on the economic activities in the technology and recycling sectors. 
The scholarly literature alone since 2010 is replete with more than 50 articles on e-waste in Ghana with major themes ranging from assessment (Amoyaw-Osei et al., 2011; Caravanos et al., 2013; Atiemo et al., 2012), public health impacts and environmental burdens (Feldt et al., 2014; Tue et al., 2019; Huang et al., 2014; Amuzu, 2018), occupational health and safety (Caravanos et al., 2011; Burns et al., 2019), socioeconomic contributions, (Daum et al., 2017; Grant and Oteng-Ababio, 2012) to policy initiatives (Atiemo et al., 2018; Manhart et al., 2014). The gloomy e-waste picture in the literature on Ghana and especially on Agbogbloshie as a dumping ground for the e-waste from the global North has however been recently contested (Davis et al., 2019; Akese and Little, 2018). The handlers and recyclers of e-waste in Ghana are predominantly value chain actors, many of whom are Muslim young men from Northern tribes around Tamale, who come to the cities and begin with recycling activities as a form of livelihood.

Because of the large amount of negative publicity and contested numbers, this Chapter will not go into much detail on the management of e-waste in Ghana, but will attempt to orient the reader to some basics about the recycling activities at Agbogbloshie/Old Fadama.

Old Fadama is the name given to several areas which are behind the Agbogbloshie onion market, which is the site of a great deal of economic activity based on the value of metal scrap, especially ferrous scrap from automobiles, and non-ferrous scrap derived from waste from electrical and electronic equipment (WEEE), otherwise known as e-waste. Old Fadama and two adjacent areas in Agbogbloshie, one called Galloway and the other called Mortuary Road, is an informal area where a great many valorisation activities take place. Most fall under the labels of recycling, repairing and disassembly. The goal of most of the activities is to recover materials for sale to the recycling value chains, ranging from components from electrical and electronic equipments to automobiles on the one side of the road, to the pre-processing of plastic and waste oils on the other (Lepawsky et al., 2015), personal observation of the first two authors.

What is not contested is that the original source of much of this material is used vehicles and devices (and some parts and components) which have been imported to Ghana by Ghanaian entrepreneurs who are in the business of wholesaling and retailing secondhand (working) equipment. These entrepreneurs choose to import used high-quality devices from Europe, North America and Asia because they have solid state components, are repairable, and have a longer useful life than new devices made for African markets. Export of devices from Europe is strictly controlled and all devices have to be complete and working. Import of all devices is controlled by the Ghana customs service on arrival, and non-working items are not allowed. 
The electronic equipments (laptops, mobile phones, cameras, television sets, central processing units, monitors, game consoles, DVD players, MP3 players, washing machines and microwaves) and other metal devices and vehicles at Agbogbloshie have been purchased by the scrap dealers and metal recyclers with premises there: materials do not come to the scrap area unless they have value. There is one exception, there is a small former legal dumpsite in the same area, and Accra authorities have not been successful in closing it, so a small amount of municipal solid waste is discharged at that specific dumpsite by small waste collection companies and especially by some informal service providers.

After a period of 10-30 years of use, at the end of useful life, these items or their parts reach Old Fadama and similar recycling areas in Kumasi in the Ashanti region (Atiemo et al., 2018). Devices and components are either repaired for sale and/or for reuse; dismantled, processed (often by hand) and sold to metal recycling firms, which may be local intermediaries or global firms via a chain of scrap dealers, middlemen and international firms (Daum et al., 2017). Wire which is PVC coated is sometimes burned with attendant public- and environmental health risks to adjacent settlements (Caravanos et al., 2011). Projections from reported estimates indicate that the e-waste reuse, recovery and recycling sector currently employs more than 16,000 informal sector actors and indirectly sustains the lives of more than 200,000 people; contributing a projected US\$500 million annually to Ghana’s economy. (Oteng-Ababio et al., 2014; Grant and Oteng-Ababio, 2012; Amoyaw-Osei et al., 2011).

\section{Collection, recycling and disposal of e-waste}

The Ghana technology sector is very active, and many second-hand devices are in use. Two systems of e-waste and valuable metal collection exist in Ghana: collection predominantly from electrical and electronic equipment retail and repair shops by scrap collectors, and limited collection from households, cooperative organizations and institutions by itinerant waste buyers (IWBs). While the scrap collectors, who work for the informal recyclers, often know their clients and move straight to their shops, the IWBs are known to travel for relatively longer distances within cities and peri-urban areas, using push carts to collect all sorts of metal and electronic equipment (Akese, 2014). Informal dump pickers (recyclers) also collect unknown amounts of WEEE and metals from the country's landfills and sell to junk dealers for processing at the scrap yards.

There is a lack (or absence) of public sector and institutional oversight of the activities of the informal e-waste sector in Ghana. Estimating the flow of Electrical and Electronic Equipment (EEE) in such circumstances becomes an arduous venture to undertake. Nonetheless, the authors have relied on the recommendations of the most extensive 
and participatory work so far on e-waste in Ghana (Amoyaw-Osei et al., 2011) to conservatively estimate the current flows. The total tonnage of used EEE reaching the various scrapyards, the fractions dismantled, repaired, recovered, assembled into "new" products for reuse and for sale to individuals and the industrial value chain; in addition to the e-waste disposed and burnt daily in Ghana are shown in Figure 6.2. An estimated total of 1181 tons of used electrical and electronic equipment per day reach the scrap yards and processing sites at Agbogbloshie, Pantang and Ashaiman; all within the greater Accra region, and Dagomba Line and Suame Magazine within the Ashanti Region. At an estimated repair and recovery rate of $52 \%$, the rest ( 451 tons) are disposed of at nearby dumpsites with some plastics being recovered and some burned (see Figure 6.2).

The advent of e-waste regulation policy has seen few formal companies showing interest in recycling. Both government agencies, especially the Environmental Protection Agency (EPA) and selected private companies are in the process of establishing collection and recycling systems to handle e-waste in Ghana. The government of Ghana in 2019 launched a "national integrated e-waste management plan" which is seeking to establish a facility at Agbogbloshie to create 22,000 self-sustaining jobs.

\section{Industrial solid waste and extended producer responsibilities}

There are no special collection, transportation, treatment and disposal systems for industrial solid waste in Ghana. Industrial solid waste is collected mostly by formal waste collection service providers and sent to MSW landfills and dumpsites, with some being disposed informally in nature or at unauthorised dumps and heaps. The authors' estimate of the daily generation rates of 2,846 tons (Figure 6.2) originates from publically available records documenting the operations of the country's landfills and dumpsites. There is, however, no specific nor separate regulation of documentation of disposal of the hazardous components of industrial waste, nor does this occur in special facilities or segregated cells.

Plastic importers and manufacturers under the umbrella of a plastics, beverage, and chemical industry plastic waste management program (that seeks to push back the central government's threat of banning plastics) contribute towards a SWM fund as part of an Extended Producer Responsibility system overseen by the Ministry of Environment, Science, Technology and Innovation (MESTI). The application of the fund however, for research, establishment of recycling plants and support of private recycling efforts to address the country's ever growing plastic waste challenges has been associated with managerial challenges and murky value-for-money Public Private Participation (PPP) recycling and composting arrangements. 


\section{Construction and demolition (C\&D) waste}

Construction and demolition (C\&D) debris is generated when new structures are built and existing structures are renovated or demolished. Sources of construction and demolition waste are homebuilders, commercial developers, highway and street contractors, site grading activities, demolishing, roofing, excavating companies among others (Prairie Village, 1998). In Ghana, major activities that generate C\&D waste include construction, demolition and renovation of buildings. Debris from C\&D wastes may include hazardous and non-hazardous materials. Non-hazardous substances may be wood, dry wall, plastics, roofing, bricks, glass, ceramic tiles, asphalt and metals. Hazardous materials from C\&D however include batteries, fluorescence light bulbs, paints, thermostat, lead coated surfaces, cleaning agents, among others. Ghana chronically lacks data on $\mathrm{C} \& \mathrm{D}$ waste. The estimate of $\mathrm{C} \& \mathrm{D}$ waste generation rate on the mass flow diagram in Figure 6.2 is generated based on recommendations of the scholarly literature on developing countries (Lu et al., 2011; Al Masha'an and Mahrous, 1999; Kartam et al., 2004). The daily C\&D generation rate in Ghana is estimated at 7838 tons which amounts to $30 \%$ of all SW generated in the country (Al Masha'an and Mahrous, 1999; Kartam et al., 2004). The predominant fractions of C\&D waste after demolitions of buildings are: $70 \%$ concrete; $15 \%$ wood and $4 \%$ iron. However, during construction of buildings, there are wastages leading to losses such as $36 \%$ concrete, $10 \%$ reinforcement materials, $14 \%$ bricks and blocks, $18 \%$ form works and $22 \%$ tiles (Awuah, 2017).

\section{Storage, collection and management of C\&D waste}

Waste from construction activities is generally used as filling material, often on site and without regulation or permitting. In contrast, demolition wastes are normally gathered in heaps for onward collection. The normal practice has been collection for disposal to reclaim excavated lands and to fill lowlands. Most developers in urban areas where land for construction is scarce illegally use C\&D waste and soil to fill wetlands; a practice which contributes to the incidence of flooding in Ghanaian cities. The author's assessment of landfill records shows that $9.3 \%$ (734 tons) of C\&D waste ends up daily on municipal landfills and dumpsites (Figure 6.2). In case of natural or man-made disasters, heavy earth-moving equipment is employed to clear debris into heaps for transport to landfill sites. There is no known C\&D waste recycling company in Ghana. Metal components of demolition waste are sold to informal scrap dealers for recycling. Another popular option for managing $\mathrm{C} \& \mathrm{D}$ waste is reuse of the waste in new buildings or construction works. Metal parts, floor tiles, roofing materials, block or bricks are often reused. Alternative practices are the use of inert aggregate wastes for gravelling road surfaces, as base materials for building foundations, for filling of trenches, and for pothole patches. 


\section{Policy, institutional and legal framework for solid waste management in Ghana}

Sound policies translated into strong legislative and regulatory frameworks coupled with pro-active institutions form the backbone of effective SWM systems (Rodić and Wilson, 2017). The MSWM system of Ghana is not driven by an integrated and sustainable strategy (Asase et al., 2009; Government of Ghana, 2017). In Ghana, as in most places in the world, significant progress in legislative reform and/or system upgrading and modernisation are triggered by crisis management of disasters and disease outbreaks (Asumadu-Sarkodie et al., 2015).

Ghana is also not alone in that its solid waste operations are the responsibility of a fragmented institutional and bureaucratic landscape. Three separate ministries are responsible for solid waste management (SWM) in Ghana. The Ministry of Environment, Science, Technology and Innovation (MESTI) formulates policies and develops plans and strategies for management of industrial waste; WEEE and all hazardous waste. The Ministry of Health $(\mathrm{MoH})$ develops policy and guidelines for the regulation of biomedical waste and a newly created Ministry of Sanitation and Water Resources (MSWR) is in charge of policy formulation and strategy development in MSW and $\mathrm{C} \& \mathrm{D}$ waste. Amongst the three, the MESTI is relatively well resourced in terms of sufficiency of human resource.

As part of efforts towards decentralization, waste management and environmental health departments within the Metropolitan, Municipal and District Assemblies (MMDAs) are the implementing agencies for MSW policies and strategies. At the national level, there is no national strategic municipal solid waste management plan. There is a policy on environmental sanitation with supporting strategic and investment plans, but the absence of a comprehensive legislative framework and a sustained funding source has hampered its operational usefulness to the waste system. The municipalities, the governance institutions tasked with the implementation of the policies for waste management, are under-resourced and over-committed. Cities and towns have limited budgetary authority and too little trained staff, but the core problem is lack of political commitment and space to develop long-term strategic plans. Nor are the waste management departments granted the requisite autonomy to seek research support nor supported to take politically difficult but economically and environmentally sustainable decisions for system modernisation. The new ministry for Sanitation and Water Resources shows some promise, having recently bucked this trend by showing an appreciable level of commitment to develop new waste policies and master plans, and a willingness and capacity to open decision-making to involve relevant stakeholders. It has 
commenced the strengthening of capacities of waste management personnel as initial steps towards a continuous and sustained MSWM strategy.

The MSW system is managed with a limited number of acts and guidelines, which are also scattered in different documents within different departments. There is no specific regulation on C\&D waste but the Ghana Building Code and the Local Government Authority Act have some statements that seek to provide a guide for $\mathrm{C} \& \mathrm{D}$ regulation.

Ghana is a signatory to two international regulatory frameworks on the control of transboundary movement of hazardous waste and disposal, namely: the Basel and the Bamako Conventions (Amoyaw-Osei et al., 2011). The country has since 2016 ratified a hazardous and electronic waste control and management act, Act 917 (2016), that seeks to regulate the control, management and disposal of hazardous waste, in addition to the establishment of an EPR system to provide the necessary finance for the sustainable management of WEEE accompanied by public education (Daum et al., 2017; Manhart et al., 2014). Act 917 (2016) classifies hazardous waste to include an ambitious list of various waste materials namely: biomedical wastes, industrial wastes, agrochemical wastes, laboratory wastes from research and academic institutions, photographic chemical wastes, flammable solids, oxidizing wastes, poisonous wastes, corrosive wastes, and toxic wastes among others.

Act 917 (2016) also provides the necessary directives for the handling of hazardous waste in addition to prohibiting importation, exportation, transportation, selling, purchasing, and trading of hazardous waste and WEEE in the country. Those contravening the directives are required to pay fines and/or even serve jail terms but enforcement has little relationship to what happens on the ground (Daum et al., 2017). The permitting system does not work, with the result that the informal recycling of non-ferrous metals coming from e-waste is largely an unpermitted activity. Although Act 917 (2016) stipulates that manufacturers, distributors and wholesalers of electrical and electronic equipment should take back used or discarded devices from their customers, this process is far from universal (Daum et al., 2017; Manhart et al., 2014).

Biomedical waste management in Ghana is regulated by the Ghana Health Service with the Ministry of Health Policy and Guidelines for Healthcare Institutions (2006). The guidelines require hospitals to use appropriate treatment options to handle biomedical waste. The generators are required to separate waste at source for collection to treatment centres, and use the correctly coded bins for storage of waste. However, there is no compliance to the regulation. The Healthcare Facility Regulation Authority (HEFRA) does not have the required capacity to enforce the regulation. They are however, faced by numerous challenges including human capacity and reliable funding sources. 


\section{Realities and sustainable pathways for system modernisation}

The scholarly literature is replete with various recommendations of potential strategies to modernise the SWM of developing countries (Marshall and Farahbakhsh, 2013; Guerrero et al., 2013). Notably, most of these recommendations partly or wholly fall under the Integrated Waste Management (IWM) and the Integrated Sustainable Waste Management (ISWM) concepts which, for more than two decades, have gained prominence in the solid waste management systems of low and middle-income countries (McDougall et al., 2008; Scheinberg et al., 2010b; Daskalopoulos et al., 1998; Schübeler et al., 1996).

The IWM concept evolved in the 1980s in early adopter high-income countries in Western Europe, North America, Oceania, and high-income Asia. It advances a systems approach to solid waste management in which the system elements (storage, collection, transportation, recovery, recycling, treatment and disposal) are considered in a holistic manner with the ultimate goal of achieving environmental effectiveness, economic sustainability and social acceptability (White et al., 2012). In a developing country context, an IWM strategy systematically recommends the:

- separation at source of biodegradable kitchen and garden waste from all other waste to promote composting and anaerobic digestion for potential treatment and energy recovery options

- further separation of the non-biodegradable streams at designated central sorting points to support recycling and alternative treatment options

- collection and transportation of the separated waste for treatment and disposal

- gradual shift from use of dumpsites to controlled and sanitary landfill sites for solid waste disposal purposes

The concept further advocates for all beneficiaries (local government, businesses, individuals, etc.) to equitably contribute towards the payment and financial sustainability of the system.

The ISWM framework (developed in relation to low- and middle-income countries and emerging economies), however envisions a city's SWM system as the intersection of two overlapping triangles (Wilson et al., 2015a): the physical components and the governance aspects. The edges of the physical triangle comprise of collection, controlled treatment and disposal, and resource recovery as drivers of public health, environmental control, and resource management respectively. The extent to which users and providers of the physical services are involved in decision-making, the budgeting processes adopted to achieve financial sustainability, and the proactive policies and sound institutions put 
in place to support the delivery of a well-functioning SWM system form the edges of the governance triangle. Attention to these approaches is not well-established in the cities in lower middle-income Ghana and other developing countries of Sub-Saharan Africa (Asase et al., 2009; Oteng-Ababio et al., 2013; Henry et al., 2006). While the literature based especially on the ISWM concept suggests that there are structural improvements in collection (Wilson et al., 2013), Ghana and other developing countries are experiencing recurring challenges in all the physical indicators and the governance aspects of SWM, and especially in relation to modernising disposal and making a policy commitment to diversion of recyclables (Grant and Oteng-Ababio, 2019; Oduro-Appiah et al., 2017a).

A review of the scholarship on SWM in Ghana and similar developing economies, enriched by the authors' experience with working with the selected municipalities in Ghana, suggests that the appearance of recurrent themes in relation to the seemingly endless challenges of SWM is a structural characteristic of these systems. At the top of the hierarchy of these challenges are the:

- political unwillingness of decision-makers to take structural measures for improvement, complicated by the tendency to wait for crises and then to look for overnight solutions to fix the system (Oteng-Ababio et al., 2013; Ali, 2010)

- absence of a consistent and realistic strategic policy and regulatory framework for implementation of waste management system improvements (Guerrero et al., 2013)

- vulnerability of political authorities to accept "donations" of unsustainable technologies from developed countries without knowing what operating costs they are committing to, and in general without analysing their usefulness given the characteristics and composition of local solid waste streams (Ali, 2010; OtengAbabio et al., 2013)

- lack (or absence) of commitment to charge for the real cost of SWM (even when there is evidence of users' ability to pay) to effectively fund the system, and the related overdependence on donor financial support for both capital and recurrent investments (Ali, 2010)

- financial constraints and underfunded infrastructure (Ezeah and Roberts, 2012)

- chronic lack of data to plan and develop locally appropriate and long-term interventions (Oduro-Appiah et al., 2017a; UNEP, 2018)

- lack of sustained research into locally responsive treatment options (Guerrero et al., 2013; Marshall and Farahbakhsh, 2013)

- weak and limited human resource capacity, especially in the SWM and sanitation sectors (Bundhoo, 2018; Wilson et al., 2013) 
It is clear, that these observations and the evidence from the WasteAware benchmark indicators (Table 6.1) show that governance, administrative and institutional constraints prevail as recurring nemesis to sustainable SWM systems delivery in Ghana and other developing countries (Wilson, 2007; Wilson et al., 2013; Tot et al., 2017). Finding an evidence-based path to addressing these governance-related challenges is an urgent priority, and one which is highly relevant to Ghana (Wilson et al., 2017).

The authors' experience with working with the largest private sector actor in solid waste management in Ghana, along with supporting the waste management departments (WMDs) of selected municipalities within the country, suggests that coordinated and participatory cooperation and collaboration of research institutions and Higher Educational Institutions (HEIs) with municipalities of Ghana has a high potential to stimulate improvements in both solid waste governance and service delivery (OduroAppiah et al., 2019).

The authors, as researchers, since 2016, have (through participatory and action research methods) been working with the Accra Metropolitan Assembly (AMA) and recently with the Greater Accra Metropolitan Area (GAMA)-an agglomeration of 25 municipalitiesto systematically:

- close reliable SWM data gaps

- assess the SWM systems

- identify the mix of operator models that suits the system

- prioritise and develop participatory and locally responsive interventions

- create ownership of interventions and empower staff for effective implementation

- provide the platform for successful execution and scale-up of donor supported SWM projects

- win the trust and commitment of decision makers for improved governance and locally appropriate solutions

- make available through peer-reviewed publications sustainable entry points for support of national and international stakeholders,

- draw relevant stakeholders together to support the development of a locally appropriate long-term strategy for system modernisation and sustainability

In the process, staff and professional capacities are being strengthened and systematic paths for informal waste sector recognition have been agreed upon (Oduro-Appiah et al., 2019). This has opened the opportunity for support from a not-for-profit international organisation for further research towards informal waste sector integration and the development of a climate change action plan for the GAMA. 
Along such a path of cooperation and sustained research, Ghana would not be unique: there is a great deal of scholarship and evidence that shows that higher educational and research institutions can be and have been key and central contributors to the continuous improvement of strategies for delivering sustainable, equitable and resourceefficient SWM systems in developed economies (Asase et al., 2009; Leal Filho et al., 2019c; Marshall and Farahbakhsh, 2013). The authors have deliberately refrained from reiterating the sequence of conventional recommendations that seek to provide direct answers to the physical and governance aspects of the numerous SWM challenges in Ghana. Along that path, there is no paucity in the scholarly literature (Oteng-Ababio et al., 2017; Wilson et al., 2009); the evidence however, is that such recommendations have neither been adhered to by decision-makers nor have they led to sustained modernisation of the country's SWM system.

The dynamics of the SWM system of Ghana and other developing countries, and the evidence available show that a coordinated pathway of participatory cooperation from universities and research institutions along the lines of sustained research, data management, implementation support and monitoring and evaluation, especially in the waste- and sanitation-related SDGs, will bridge the existing gap in which academia, industry and local municipalities operate in isolation to a sustainable pathway in which the scholarship and know-how of academia and research institutions would become more relevant and practicable to compliment the efforts of development partners and NGO's towards SWM system modernisation (Leal Filho et al., 2019c).

A sustainable future for ISWM in Ghana will include, at a minimum, the following features:

- the right mix of public and private (formal and informal) actor involvement in service delivery (Wilson et al., 2017; Cossu et al., 2019)

- the right mix of locally appropriate and sustainable treatment and recycling technologies (Grossule and Lavagnolo, 2018)

- the charging of realistic cost for service provision, treatment and disposal

- the establishment of a capable, strong and transparent client base working within realistic and flexible policy and regulatory frameworks (Soós et al., 2017)

- the integration of all relevant stakeholders intervention projects and support

Participatory development of objective- and research-oriented SWM strategic plans which takes into account the aforementioned, provides a huge potential to modernise and deliver a sustainable SWM system (Wilson et al., 2017; Soós et al., 2017), rather than the prevailing situation where foreign strategies are adopted for use without reference to the goals, conditions and characteristics of the solid waste for which such 
strategies were developed. The existing dynamics and the evidence available in Ghana and similar developing economies in Sub-Saharan African show that higher educational institutions (HEIs) and research institutions would have to provide leadership to initiate the cooperation and collaboration link; partly because of their position as the bastion of knowledge and their inherent capability to undertake applied research, and partly because of their social responsibility to help society to modernise and sustain the SWM systems and the related SDGs (Leal Filho et al., 2019a; Leal Filho et al., 2019b).

Higher educational and research institutions also may be able to host and keep the institutional memory of municipalities to forestall the too frequent shift and abandoning of policies, often associated with changes in government in Ghana and in most developing countries.

\section{Case studies}

\section{Integrated and improved municipal solid waste collection within the greater Accra metropolitan area}

Waste collection coverage has improved in the Greater Accra Metropolitan Area (GAMA), consisting of 25 municipalities, including the capital city, Accra, and the industrial hub of the country, Tema, (Oduro-Appiah et al., 2019). The successful modernisation is partly due to the participatory and research-driven development of a locally appropriate strategy (Oduro-Appiah et al., 2017b) that recognises and further unleashes the contribution of informal service providers (ISPs) and legalises their important role in solid waste collection service delivery. Substantial credit is also due to the willingness of a key private waste management contractor (Zoom Pak) to construct two state-of-the-art bulk transport stations with a combined capacity of 2400 tons to receive the collected waste of the ISPs. This strategy (Oduro-Appiah et al., 2017b), which sought to improve MSW collection by including providers of informal services, was itself informed by an earlier research project (Oduro-Appiah et al., 2017a) that brought researchers to collaborate with municipalities, government agencies and other relevant stakeholders to assess the MSWM system, identify strengths and system failures and together develop and implement locally appropriate interventions to drive system modernisation.

Throughout a four year period of such cooperation and strategy development, the working group of researchers, municipal officials and informal sector representatives has witnessed a positive change both in the intended modernisation of collection coverage, and also in improved recyclables capture, improved disposal, improved service provider inclusivity and improved tolerance between both the formal and informal service providers. The ISPs now work alongside the formal waste collection companies and 
sometimes serve as backup collectors, especially in poor communities. The commitment and support from municipal decision-makers has also improved and the narrative of the ISPs has moved from neglect to recognition with an ongoing development of action plans towards integration (Oduro-Appiah et al., 2020a). The Accra Metropolitan Assembly in 2018 registered all 720 ISPs within its boundaries as part of efforts towards their integration and also as a best practice to the other municipalities. There are about 1618 ISPs within the GAMA contributing to the collection of 1320 tons (45\%) of all MSW collected within the area; and their activities alone saves the 25 municipalities of US\$20 million in annual MSW operations cost (Oduro-Appiah et al., 2020a). The ISPs now have access to improved and affordable tricycles for MSW collection and travel shorter distances to disposal sites.

Prior to this strategy, MSW collection coverage along the formal channels was $60 \%$. The ISPs had contributed to an overall coverage of $75 \%$ but were in the habit of illegally dumping collected waste along roadsides, bushes, vacant plots and on unofficial dumpsites. While the strategy has been successful, there still remain challenges with respect to service user fee harmonisation and training of the ISPs to promote further quality of the collection service. Moreover, much more advocacy needs to be undertaken to solicit the support of all the formal service providers. Issues of apparent delays and random increase in disposal cost at the bulk transport stations would need further attention to support the ISPs to increase their turnover and also prevent them from abandoning the facilities for environmentally unsustainable disposal methods.

\section{The Accra composting and recycling plant (ACARP)}

The Accra Composting and Recycling Plant (ACARP) is one of the only two stateof-the art Mechanical and Biological Treatment (MBT) facilities in the country. The ACARP has been in operation since 2012, with the goal and promise of producing high value compost for application by peri-urban farmers within the Akuapim South Municipality and its environs. Despite some positive attributes, such as the fact that the plant recovers plastics, metals, textiles and contributes towards youth employment in the country, the investment in this plant, which is not designed for local circumstances, represents to the authors a textbook example of overcapitalisation. First and foremost, the plant was designed for a shift capacity of 600 tons but has since been operating at only half its capacity despite the fact that the GAMA generates 3293 tons of MSW. The concept of MSW segregation to readily make available biodegradable waste to the plant and for improved compost has not been implemented yet. Perhaps the market for the compost was not found to be viable even before project commencement since the government of Ghana subsidises $67 \%$ of the cost of US $\$ 7.00$ for a $50 \mathrm{~kg}$ finished compost as an incentive to attract local farmers. Subsidiary formal service providers whose services are paid for by the clients and service users dispose collected MSW at no 
cost at the plant. As of 2016, the operations of the plant was reported to cost the central government US $\$ 320,000.00$ per month under a PPP arrangement. Perhaps the PPP arrangement might be the platform that sustains the plant instead of a resource recovery drive. Paradoxically, a similar plant with almost similar goals and arrangement has been commissioned in 2019.

\section{Conclusion}

Modernising the solid waste system in Ghana has been a major challenge, and will remain so for many years to come. This chapter has shared with the reader the realities of SWM in Ghana and further discussed the nexus between system failures and success. The authors have used participatory and action research methods to assess the SWM system and have recommended locally appropriate and evidence-based paths that have the potential to stimulate modernisation. The underlying hypothesis is that participation and consultation between researchers and public officials in Ghanaian cities creates a higher probability towards improvement in both the physical aspects and the governance components of solid waste. When researchers in both higher education and research institutions collaborate with local authorities to support policies driven by the concerns of public health, environmental control, and resource recovery; they are able to introduce improvements in existing management approaches in a systematic way, rather than waiting for modernisation by crisis management, and triggered by disasters. Acting upon the hypothesis has proven that such a path opens up for trust, transparency, and commitment; three key ethical and governance factors virtually absent in the SWM system of most developing countries. The existing cooperation has been supporting capacity building of municipal SWM staff to close data gaps and develop locally responsive strategies for implementation; two factors that are chronically lacking in the SWM system of Ghana. The WasteAware indicators and the mass flow diagram are intended to support stakeholders to comprehensively understand the performance and the various waste flows of the system; to enable them to determine points of entry for support. While the path recommended may not be able to solve all the complex challenges of SWM in Ghana overnight, it has the potential to systematically improve and sustain the system for future generations. 


\section{Additional readings}

1. Akese, G. A., \& Little, P. C. (2018). Electronic Waste and the Environmental Justice Challenge in Agbogbloshie. Environmental Justice, 11(2), 77-83.

2. Amoyaw-Osei, Y., Agyekum, O. O., Pwamang, J. A., Mueller, E., Fasko, R., \& Schluep, M. (2011). Ghana e-waste country assessment. SBC e-waste Africa Project. Available online: http://www.basel.int/portals/4/basel\%20convention/docs/ewaste/ e-wasteassessmentghana.pdf (accessed on 10th June 2019).

3. Cossu, R., Grossule, V., \& Lavagnolo, M. C. (2019). Sustainable low cost waste management: learning from airlines. Detritus, 6, 1-3.

4. Daum, K., Stoler, J., \& Grant, R. (2017). Toward a more sustainable trajectory for E-waste Policy: A review of a decade of E-waste research in Accra, Ghana. International Journal of Environmental Research and Public Health, 14(2), 135.

5. Davis, J.-M., Akese, G., \& Garb, Y. (2019). Beyond the pollution haven hypothesis: Where and why do e-waste hubs emerge and what does this mean for policies and interventions? Geoforum, 98, 36-45.

6. Government of Ghana. (2017). Enhancing urban resilience in the Greater Accra Metropolitan Area. Global Practice on Social, Urban, Rural and Resilience, The World Bank Group, Washington DC, USA. Retrieved from http://documents.worldbank. org/curated/en/949241495793834492/Enhancing-urban-resilience-in-theGreater-Accra-Metropolitan-Area:

7. Guerrero, L. A., Maas, G., \& Hogland, W. (2013). Solid waste management challenges for cities in developing countries. Waste Management, 33(1), 220-232.

8. Kaza, S., Yao, L. C., Bhada-Tata, P., \& Van Woerden, F. (2018) What a Waste 2.0: A Global Snapshot of Solid Waste Management to 2050. Urban Development Series. Washington, DC: World Bank. The World Bank.

9. Leal Filho, W., Vargas, V. R., Salvia, A. L., Brandli, L. L., Pallant, E., Klavins, M., .. . Conticelli, E. (2019). The role of higher education institutions in sustainability initiatives at the local level. Journal of Cleaner Production, 233, 1004-1015.

10. Oteng-Ababio, M., Arguello, J. E. M., \& Gabbay, O. (2013). Solid waste management in African cities: Sorting the facts from the fads in Accra, Ghana. Habitat International, 39, 96-104.

11. Wilson, D. C., Rodic, L., Cowing, M. J., Velis, C. A., Whiteman, A. D., Scheinberg, A. ... Oelz, B. (2015). 'WasteAware' benchmark indicators for integrated sustainable waste management in cities. Waste Management, 35, 329-342

12. http://www.retroworks.net/good_point_recycling\%2010\%20Points.htm; also

13. http://www.retroworks.net/contactus/goodpointideasblog.php

14. https://nl.snew.eu

15. https://www.google.com/search?client=safari\&rls=en \&q=world +reuse+repair + and + recycling+association \&ie $=U T F-8 \&$ oe $=U T F-8$ 


\section{Key terms and definitions}

Collection Coverage: The percentage of total households or waste generating units in a city that has access to a regular service of waste collection and street sweeping, irrespective of whether it is provided by formal or informal service providers.

Controlled Landfill Site: A landfill site which enjoys some appreciable level of waste compaction, waste covering if even irregularly and also some level of leachate containment and treatment.

Formal Service Providers: Private companies who have official franchise agreements with municipalities and use different categories of solid related vehicles (skips, compactor trucks etc.) to collect MSW from household, institutions and light industries to disposal and recycling centres.

Informal Service Provider (ISP): An individual entrepreneur or enterprise which provides a service — in this case of waste collection or street sweeping — which is paid by the clients but which is not planned, authorised, supervised, paid, or acknowledged by the formal authorities to be part of the official waste system. Specifically, the term ISP is designed to distinguish the waste collection informal sector, which is providing the service of removal of waste, from the recycling informal sector, which is extracting materials that have value and valorising them by trading them to the recycling industry.

Municipal Solid Waste (MSW): MSW in the Ghanaian context of SWM is defined to include household solid waste, institutional waste, commercial waste, waste from light industries, and construction and demolition $(\mathrm{C} \& \mathrm{D})$ waste.

Waste captured: The percentage of waste generated that is actually handled completely by the waste management and recycling system. It includes all waste material collected and delivered to official treatment, recycling and disposal facilities. Any waste that is lost through illegal burning, burying or dumping in unofficial locations within a city or country is excluded in the estimation or computation of waste capture. 


$$
7
$$




\section{Chapter 7}

\section{General Discussion}




\section{Introduction}

Assessing the performance of municipalities in solid waste management and understanding what works and what requires repair serves as an essential step towards system planning. It also provides a baseline to support researchers, professional staff and relevant stakeholders to prioritise, develop and implement locally responsive interventions. Where interventions are designed in a participative way to recognise and unleash the full potential of the informal waste sector, they potentially promote inclusive governance and support the efforts of the formal waste actors to stimulate the modernisation of solid waste management systems. Despite the level of effort required to do participation right, this approach has been found to be true for selected municipalities in Ghana, and is an urgent necessity for the attainment of the circular economy and the sustainable development goals (SDGs) in developing countries. The primary aim of the work reported in this dissertation was to understand how inclusive processes can improve the functioning of the solid waste management (SWM) system of the 25 municipalities within the greater Accra metropolitan area, and to inform the elaborations of interventions that move towards a development pathway that can stimulate modernisation and system sustainability. To achieve this, the author of this thesis adopted a participatory action research approach that brought relevant stakeholders (researchers, decision-makers, solid waste managers, private waste management actors, the informal waste sector representatives and SWM service beneficiaries) together as members of working groups. This chapter summarises and discusses the main findings of the five studies described in this thesis. It also discusses the strengths, limitation, and practical implication of the studies to inform future research patterns; and reflects on the applicability of the ISWM WasteAware indicator framework in lower-middle income cities of emerging economies. The chapter will end with a general conclusion.

\section{Main findings}

\section{Performance of the municipal solid waste system (MSWM) of Accra, Ghana}

Chapter 2 has made the case that assessing the performance of the solid waste management system of a city through participatory action research methods is a sustainable first step towards modernisation. Apart from allowing stakeholders to freely articulate their opinions and perceptions of the system, it allows for a comprehensive understanding of what is working and what is failing; providing stakeholders of a true picture of system performance and the opportunity to develop and prioritise locally appropriate interventions to improve what is functioning poorly and fix what is broken. 
The performance assessment and benchmarking exercise on both the physical components (collection, treatment and disposal, and recycling) and governance aspects (user and provider inclusivity, financial sustainability, and sound institutions and proactive policies) of the city's solid waste management system was undertaken by working groups of stakeholders in 2016, using the integrated sustainable waste management (WasteAware) analytical framework as a lens. The central research question was: How is the city of Accra performing in the physical and governance indicators of municipal solid waste management, and what was working and what required fixing? A process flow diagram of the municipal solid waste management (MSWM) system was developed to allow stakeholders to visualise and understand the flow of materials through process steps in the service chain (solid waste system) and the value chains (the recycling industry and the agricultural/food system).

The results of the benchmarking exercise showed that Accra was performing poorly in all the quantitative and qualitative indicators compared to similar lower middle-income cities across the world (Scheinberg et al., 2010b; Wilson et al., 2012; Wilson et al., 2015a). The findings also confirmed the problems with decision-making in planning, in the context of a chronic lack of current, verifiable, validated solid waste related data. There was also a serious communication gap: paying clients of waste collection and active and passive users of the street sweeping services were rarely consulted in planning and decision-making; neither were they provided with opportunities for education in pro-environmental behaviours. The city lacked a stakeholder platform and there was not even a working action plan for efficient solid waste management. The system was not cost-effective, it was only affordable for a few of the higher-income households and businesses; there was no attention to cost recovery; and the finances were not in order. The true cost of solid waste management had not been known for several years and activity-based budgeting was not a common (or known) practice. There were formal budgets but they didn't always include all activities.

The working groups, supported by the framework of the WasteAware Indicators, worked together to set priorities. They identified the lack of solid waste management plans and legislative frameworks, the absence of inclusive governance strategies, weak institutions, and weak human resource capacities, as the core factors affecting the poor performance of the city in collection coverage, controlled disposal and recycling.

These findings are supported by earlier research on developing countries in which governance and administrative issues have been observed to be major contributors to system failure (Ali, 2010; Asase et al., 2009; Bhuiyan, 2010; Bundhoo, 2018; Ezeah and Roberts, 2012; Guerrero et al., 2013; Henry et al., 2006; Tot et al., 2017; Wilson et al., 2012; Wilson et al., 2013). The difference in Accra was that, the working group, 
after nine months of field visits, meetings and discussions, came to these conclusions themselves, based on their increasing understanding of the mix and extent of governance issues affecting system modernisation. They further ranked these problems in terms of urgency, importance and ease of fixing.

The group initiated measures to win the commitment of decision-makers to systematically develop and implement locally appropriate interventions to fix what was broken. Based on the findings of the assessment and the process flow diagram, the working group recommended as first and foremost, the development of an intervention to improve provider inclusivity through the recognition and the involvement of the informal solid waste collection service sector to further unleash their full potential towards improved collection coverage.

\section{Locally appropriate intervention to improve municipal solid waste collection coverage in Accra}

Chapter 3 has brought insight into the methods and processes adopted by the working group to get formal service providers (the holders of the collection services franchises) to create administrative and operational space to enable their informal counterparts to contribute meaningfully towards residential waste collection in the city, thereby raising coverage levels. The chapter posed the research question: How can the informal waste collectors (informal service providers) have the institutional and financial support of formal authorities to contribute to an increase in solid waste collection coverage in Accra, against the backdrop that their activities are not sanctioned by law and considered illegal?

To do this, the working group (researchers, key solid waste management officials, formal service providers and informal service providers) evaluated the performance of the formal service providers to collection coverage based on the obligations of an existing fee- and performance-based municipal solid waste collection franchise agreement between them and the city; and conducted a user satisfaction survey on the service delivery of the formal providers. The hypothesis was that: if recognition, support and some administrative and legal freedom were granted the informal service providers (ISPs), it would potentially empower them to contribute significantly to an improvement in collection coverage.

The findings of the evaluation indicated that the formal service providers were losing service clients to the informal service providers at an alarming rate, and that the users were choosing for higher service levels, more personal contact, and better value for their money. More than $60 \%$ of service users stated that they were dissatisfied with the services of the formal providers. Neither the municipality nor the formal providers were adhering to the obligations of the franchise agreements. Monitoring of service provision 
was very poor and there were no feedback loops to stimulate either communication or improvement of formal performance. The study arrived at various reasons for the poor performance of the providers: weak oversight responsibilities and monitoring of the activities of the providers by the city, challenges related to the fixing of service fees and affordability, and political interference in the implementation of sanctions to nonperforming service providers. The working group re-imagined the collection service as a mixed system, and this framing allowed them to design a path for cooperation and understanding between the officially recognised formal MSW collection companies and the informal waste collectors to shore up collection coverage. An unusual agreement between the municipality and the formal service providers was achieved in which the formal service providers agreed to work with their informal counterparts as subcontractors and also support them with equipments (tricycles) on hire purchase to increase collection coverage.

This agreement led to the drafting, signing and implementation of a new 5-year (20162021) franchise agreement between the municipality and the formal service providers in which the informal service providers for the first time in the history of solid waste management in Ghana, received some significant mention in official documents. In this, the city of Accra is not unique, there are examples of such agreements in the scholarly literature of informal waste collectors supplementing formal service delivery in cities of Sub-Saharan Africa (Andrianisa and Brou, 2016; Halla and Majani, 1999; Ishengoma and Lyimo, 2002; Ishengoma and Toole, 2003; Kassim and Ali, 2006; Katusiimeh et al., 2013; Tilaye and Van Dijk, 2014; Van de Klundert and Muller, 1998). What is different, innovative and unusual about the Accra situation is that these agreements were arrived despite the absence of official recognition of the informal service providers, the refusal to assign specific zones to them, and the fact that the formal private collectors had agreed to financially help them acquire equipment for their work. This agreement which later became the most relevant step towards system modernisation underpins the benefits of participatory research appraisal to promoting transparency and mutual understanding, creating ownership, empowering actors towards the selection and implementation of locally responsive sustainable alternatives for system upgrading (IJgosse et al., 2004; Van de Klundert et al., 2001); something the conventional topdown and the technologically-oriented approach of solving the solid waste management challenges of cities of developing economies have continually failed to achieve. The process did also set new but realistic 5-year recycling targets between the parties of the franchise agreement to increase recycling rates.

\section{Lessons learnt from working with the informal service chain in Accra}

Chapter $\mathbf{4}$ has shown quite conclusively, the potential to make gains in the physical components and governance aspects of the city's municipal solid waste management 
system, as a result of developing interventions around the informal solid waste service sector. The research question here was: Will evidence-based indicators of municipal solid waste management (MSWM), demonstrate significant improvement in the physical and governance aspects, at the close of a process where stakeholders have deliberately developed and implemented together locally appropriate interventions focused on the informal solid waste sector for a period of two and half years?

The objective of the chapter was to evaluate the apparent improvements made by the municipality in collection coverage, controlled disposal, improved working conditions, higher recycling rates and enhanced provider inclusivity. The focus was on benchmarking the changes that had occurred during the two and half years following official recognition and participation of the informal service providers as useful contributors to the city's municipal solid waste collection service delivery system. The research team adopted participatory research appraisal methods and the ISWM framework to benchmark the perceived improvements in both the physical and governance indicators.

The findings showed a significant improvement in collection coverage (75\% to 90\%). The inclusion of the informal service providers and an intervention to close all unofficial dumpsites in the city attracted private investments in the construction of two bulk solid waste transport stations (Zoom Pak and KLERP) with a daily capacity of 2400 tons, specifically for use by informal service providers to dispose of collected waste. This led to an improvement in the physical indicators of waste capture (53\% to $90 \%)$ and also improved controlled disposal (62\% to $87 \%)$. The inclusion of recycling targets within the new franchise agreement also contributed to an improvement in recycling rates $(5 \%$ to $18 \%$ ) along informal channels.

The working group was able to further win the commitment of decision-makers to officially register all known informal service providers (their numbers had increased from 350 to 720 ) within the city and emboss their tricycles with approved municipal stickers as initial processes towards their integration into the municipal solid waste management system of the city. This apparently led to a modest but measurable increase in the governance indicators of user inclusivity (35\% to 46\%) and provider inclusivity ( $50 \%$ to $75 \%$ ). Although not a focus of the interventions, there was a reported modest improvement in the indicator 'sound institutions and proactive policies'. The findings in this study are consistent with best practices and experiences in Latin America and Asia where the recognition and inclusion of the informal micro-service sector in the solid waste management system has led to considerable improvements in the physical components of the system and the service levels (Agamuthu, 2010; Medina, 2005). 


\section{Closing reliable data gaps, building capacities, promoting inclusive governance, and mapping a pathway for informal waste sector integration through participatory processes}

Chapter $\mathbf{5}$ addressed the persistent challenge of managing city waste in a participatory way in Ghana. The research question to this study was: How can the informal serviceand value-chain actors within the 25 municipalities of the greater Accra Metropolitan area be stimulated to collect reliable evidence-based socio-economic data from their activities, and how can such data be legitimised and used to influence decision-making towards informal waste sector integration into the formal waste management system? Inclusivity works to remedy the absence of participatory action research processes, the lack of reliable data especially on informal waste activity, and the difficulty of mapping a pathway for integration of both the informal service- and value-chain actors into the formal solid waste management system. The initial objective of this study was to assess the contribution of the informal service providers towards the municipal solid waste system to make a case for their integration. Local government interests and the use of participatory action research methods led to the widening of the study scope from the capital city to include all 25 municipalities within the greater Accra area, and the inclusion of the informal value-chain actors in the integration process.

The approach has been used for the collection of verifiable, real-time practical data on the informal waste sector and also provided evidence on their socio-economic contribution to the system. The findings also provide relevant stakeholders with intricate process flow diagrams of the various solid waste materials handled by the informal waste sector in addition to estimates of the recycling rate in the greater Accra metropolitan area (GAMA) of the country. The informal waste sector within the GAMA contributes to $46 \%$ of the daily municipal solid waste collection in addition to saving the municipalities US $\$ 20$ million in annual operations cost. They contribute $6.4 \%$ of the estimated $8.5 \%$ municipal solid waste recycling rate. The study comprehensively charts a potential pathway of engagement, organisation, training, capacity building, participation and monitoring as part of the integration of the sector to further unleash their full potential as significant contributors to solid waste modernisation in the region and other developing economies.

The findings also lend credence to the fact that participatory engagement processes that bring together relevant and concerned stakeholders has the potential to close reliable data gaps, promote understanding and transparency, build competencies and further improve inclusive governance systems in the solid waste management of cities of developing countries (Ragossnig and Tunesi, 2018; Alamgir et al., 2012). 


\section{Existing realities and sustainable pathways for solid waste management in Ghana}

Chapter 6 continues the meta-level methodological analysis based on participatory processes. It discusses the realities of the solid waste management system of the country and highlights the nexus between apparent success and system failures. The research question was: What are the points of intersection between system failure and success in solid waste management in Ghana, and how can lessons learnt and evidence gathered in the previous studies be used to map a potential pathway to stimulate solid waste modernisation in Ghana? Unlike the other four studies where the focus and scope was on municipal solid waste management within the capital city and the greater Accra region, this study encompasses all aspects of solid waste (e-waste, healthcare waste, construction and demolition waste, industrial solid waste, agricultural biomass and municipal solid waste) in Ghana. The objective was to allow researchers, local authorities, development partners and other relevant stakeholders have an in-depth understanding of the solid waste management system of the country to support them in finding an entry point towards continuous intervention development and support. The ISWM framework was used to benchmark the municipal solid waste management system of six metropolitan cities (Accra, Cape Coast, Kumasi, Sekondi-Takoradi, Tamale and Tema) as a representation of the existing realities, and clearly outlined the process flow diagram of all solid waste within the country.

The findings of this study confirm that Ghana faces a complex challenge with modernising and improving solid waste management. The governance system is weak and this affects delivery in the physical components. International influence continues to create a confusing overlap of intervention projects denying system handlers the space and time to develop locally appropriate solutions. Instead of a long-term solid waste management strategic plan with accompanying legislative framework and regulations, the solid waste system is run on short-term projects which are rarely scaled up. There is a lack of oversight responsibilities in most of the waste sector, neither is enforcement of regulations and bye-laws complied with. Those charged with monitoring and evaluation of service contracts rarely do their jobs and where evidence of non-performance abounds, political interference prevents the implementation of sanctions.

The comprehensive flow diagram developed shows that a significant amount of waste goes uncollected in the country, and for this there are no quick fixes; nor does technology transfer hold any promise. There are some specific issues to be dealt with in locally appropriate ways, in relation to the need for unique treatment systems for industrial solid waste, hospital waste, agricultural waste and construction and demolition waste. The country relies heavily on uncontrolled dumpsites for final disposal of almost all forms of waste, and some alternative processing and more diversion from disposal could lighten 
this burden. The study finds the informal e-waste technology sector as contributing significantly to the socio-economic development of the country and creating livelihoods through their repair, reuse and recycling activities. Most importantly, the chapter has used the evidence of the outcome of the participatory action research process of the previous studies in this thesis to chart a potential pathway for modernisation of the country's solid waste management system.

\section{Methodological strengths and limitations}

Working on participation in the $21^{\text {st }}$ century is no easy task. The strength of the work reported on in this dissertation is that we relied on a well-defined and tested analytical framework (the integrated sustainable waste management framework) and participatory action research processes to bring relevant stakeholders together to transparently assess their solid waste management system and map locally appropriate interventions to improve upon what was failing and preserve what was working. Using the framework and the participatory approach for the assessment and evaluation of the system add value to the study because they allowed for the: (1) formation, articulation and ownership of stakeholders positions and opinions, (2) gathering of relevant baseline data to inform decision-making and (3) interpretation of data in a similar way before and after implementation of interventions.

The use of action research, participatory processes and stakeholder working groups (researchers, municipal staff, gender representatives, service users, development planners, policy makers, and the informal and formal waste actors as working groups) have lent themselves to reliable data collection, building of competencies and capacities, ownership of locally developed interventions, empowering of municipal managers towards intervention implementation, evaluation and monitoring; and a reduction in the amount of validation exercises. The processes have further promoted inclusive governance and self-belief. These approaches, having worked for the greater Accra metropolitan area, serve as a best practice for other cities in Ghana and SubSaharan Africa towards the development of locally appropriate interventions that can be implemented to stimulate modernisation of their solid waste management systems. There are always time and organisational challenges in bringing stakeholders together for such an exercise, but permitting the municipalities to lead and coordinate affairs promotes greater stakeholder participation and understanding. Most importantly, creating a cooperative and an open attitude that allows all stakeholders to freely express their opinions of the system during discussions and especially upon problem recognition are fundamental to the coherence and sustainability of the working group. 
Despite the commitment to inclusive governance reported in this dissertation, the participatory action research approach was not always able to anchor or stabilise improvement in all the governance aspects of the system. Notably, our team cannot document very much improvement in the WasteAware scoring of the governance indicators of financial sustainability, sound institutions and proactive policies. Although the reported-upon participatory measures have led to modest improvements in institutional capacities and professional competencies, the researchers and working group were not able to specifically "reach" into the financial aspects of governance, and so cannot report on the impacts of interventions, neither to address financial sustainability, nor to sound institutions and proactive policies.

The failure of the working group to develop interventions to improve participatory governance on the ground, was partially due to time factor. To support and anchor the continuous commitment of municipal officials, to engage with stakeholders on the one hand, and to invest in fostering and empowering stakeholders to elevate their levels of engagement with public officials and processes, require time. A much longer term time horizon and commitment, with cooperation and consultation with stakeholders outside of the walls of City Hall are longer-term investments that are necessary to achieve significant improvement in proactive policies and financial sustainability. We ultimately envision that improvement in the parameters measured, by these two governance indicators might first commence with the development of a stakeholder's platform, to co-create the city's solid waste management action plan and contribute to a national solid waste strategic plan in which specific objectives, goals, and realistic targets are set (Ragossnig and Tunesi, 2018). This must be followed by an analysis of the existing legal frameworks with an understanding amongst stakeholders at introducing modifications where necessary (Tunesi and Gorelick, 2018).

Researchers and stakeholders would have to come together to navigate the difficult but necessary step of selecting locally appropriate technological scenarios for the various components of the solid waste in addition to comparing their environmental and risk impacts (Cheng et al., 2002). A full cost accounting of the existing system and the various scenarios based on activity based budgeting procedures appear to be useful strategies to prepare stakeholders for the adoption, implementation and monitoring of the city's action plan and the national strategy. These activities would preferably be coordinated and led by the policy institutions with jurisdiction and/or oversight responsibilities in relation to solid waste management systems, in close collaboration with the municipalities, service beneficiaries and relevant stakeholders like academia and research institutions. 
The dynamics of developing country cities call for significant emphasis to be laid on coordinated cooperation between researchers and municipalities and or local governments, both to build a critical mass of social capital supporting changes, and to reduce the risk of time delays and intervention implementation and in subsequent research towards intervention development and preparation of action plans. A memorandum of understanding $(\mathrm{MoU})$ between the parties (municipalities and research institutions) might be critical, within a developing country context, to safeguard research continuity and underpin probable implementation and evaluation of interventions.

The work reported on in this dissertation was carried out just in such an environment of transparency, fairness and strong commitment of working groups towards system modernisation, without necessarily signing a MoU between the parties though one was drafted for such a cause. It is important to note that to reap maximum benefits, there must be a commitment of adequate time and resources to the process, because it can be time consuming and costly. In Accra, the research team with leadership support from the municipalities was able to assemble committed stakeholders who put the solid waste modernisation process ahead of compensation. Nonetheless, a working group member was paid at least US\$10.00 each for transport per weekly meetings and per site visits. Each study within the thesis took an average of nine months to be completed.

The use of the same working group of stakeholders throughout the process, the commitment and support of the political and administrative leaderships of the municipalities to implement the locally appropriate interventions of the group, and the relative success achieved after evaluation of implemented interventions provides a convincing proof of the validity of the ISWM framework and the collaborative processes to system modernisation. The scholarly literature is replete with examples of how such collaborative processes and commitment of city authorities has led to locally appropriate modernisation and relative sustainability in SWM systems in cities. The processes that has led to modernisation in SWM in the greater Accra Metropolitan area are viable and stands a strong chance of working well and improving the prospects of sustainable solid waste management for other cities and municipalities across the developing world.

\section{Reflections on the WasteAware benchmark indicators for emerging economies}

The WasteAware indicators were chosen as the methodological framework for this dissertation because of its free availability, its global applicability across all GNI levels,, broad usage and coverage and the existence of a detailed user manual and an automated Microsoft Excel sheet to guide benchmarking agents on its usage and implementation (Cervantes et al., 2018; Wilson et al., 2015). 
But the extensive use of the WasteAware benchmark indicators both as a tool of research and as an object of reflective investigation in emerging municipalities in Ghana has provided insights and some methodological challenges to allow for the questioning of the indicators implicit claim that "green light" values for physical and governance features delineate good practice and a well-functioning service chain.

Our investigations and reflections allow for questioning of the indicators in three areas, namely:

1. How well does the approach with WasteAware benchmarking to both physical and governance solid waste systems apply in emerging economy cities?

2. To what extent does WasteAware benchmarking of governance aspects need to be adjusted to conditions in emerging cities to accommodate roles and attitudes of the formal keepers of information, and what insights can be drawn from this in relation to political culture?

3. To what extent does the resource management composite indicator needs to be adjusted to adequately benchmark and evaluate the performance of the value chain in cities where formal and informal forms of resource recovery co-exist?

\section{The performance of WasteAware in benchmarking physical and governance systems}

WasteAware benchmark indicators rely heavily on the use of existing and reliable data to assess system performance (Wilson et al., 2015a). Reliable data however is chronically lacking in most lower-middle-income cities (UNEP, 2018). This may render the usage, applicability and interpretation of the outcome of indicators questionable. In most developing economies, especially of Sub-Saharan Africa, waste quantities and collection statistics are available when the local authority either operates the service or regulates the private sector or PPP arrangements via a contract or a concession. In a city like Accra where there is direct contracting between households and independent formal or informal collectors, city institutions may lack the resources to allow them to calculate the composite indicators necessary to fill in the WasteAware forms.

Benchmarking of disposal facilities - even open dumps - is also relatively reliable as long as there is some form of supervision and control at the gate - and if there are not, the indicators produce a "red light" purely for that reason alone. One additional point worth highlighting is that in these cities and most emerging economies, collection and disposal data are seldom independent variables, since the amount of collected waste is registered only (if at all) when it enters the gate of an authorised facility (and when it is removed 
from the disposal facility by informal recyclers it is normally not registered at all). The effort to develop data on uncollected waste or household prevention, re-use, recycling, and other management activities such as backyard burial or burning, will usually be lacking, and if, like in Accra, the disposal facilities do not always have a working weighbridge, even the level of accuracy in relation to basic waste quantity is open to question. Most of the available data in Accra on the physical indicators was limited to landfill records, which gives a very basic set of data, as the systems for tracking exist but are incomplete, due to frequent breakdown of weighbridges or their computer registration systems. Estimates of volumes disposed via a truck count are not triangulated with truck capacity or performance.

In Accra, the researchers opted to carry out original research to virtually create the necessary primary MSW data for assessing and benchmarking, but this is expensive and time-consuming, and is seldom possible in developing country cities. The research shows that even for the two most basic physical indicators (collection coverage and controlled disposal), original data collection will be necessary, increasing the cost and duration of the benchmarking exercise and creating problems for comparability among cities. A related issue arises in Accra, where ISPs (informal service providers) are collecting significant percentages of household waste, - but are not obligated to or do not have the capacity and interest to keep records (Linzner and Lange, 2013); and may even refuse to open up and share data if available - so that the concept of collection coverage as defined by the indicators may be too limited. Benchmarking agents may be forced to report on what the city's formal service chain institutions do or control, and this does not always include the full range of what is actually happening within the city.

Even when formal data systems are in place, their main tracking system is usually the weigh bridge at the landfill, and all material that enters is recorded as solid waste. There is also no registration of materials that are removed from the disposal site by informal waste pickers, and estimating the performance of landfill-based recycling would require direct observation and measurement, which is seldom allowed.

\section{WasteAware benchmarking of governance in relation to political culture}

The WasteAware system depends on four basic meta-criteria: 1) the underlying data and information is available; 2) the performance data includes the contributions and performance of private and informal actors in the value chains as well as the service chain; 3) benchmarking agents have timely access to officials, staff and consultants who are able and willing to provide requested data and information; and 4) the benchmarking agent is able (and permitted) to triangulate and verify the data through a range of concrete and time-bound actions in the city itself, such as meetings and/or interviews with officials, photo-documentation, site visits and the like. Thus, even in Western 
democracies, scoring of the governance system relies on subjective observations, and an open discussion to interpret the findings (Scheinberg et al., 2011; Whiteman et al., 2001; Wilson, 2007).

These meta-conditions were somehow lacking in all the municipalities of the GAMA, due to a lack of time or knowledge in how to track basic data and system performance, the overstretched capacity of municipal staff, and a tendency towards closed political culture and fear of criticism from 'outsiders.' Accra partially meets these criteria and would have presumably scored in the "green" zone, as key officials, politicians and staff participated in the process and openly shared information.

The benchmarking of Accra raises the interesting issue of whether contracts between municipal authorities and private service chain operators also have provisions for sharing of raw data, rather than officially processed data and information. In this case the officially processed data is limited to the volume of waste collected and transported for disposal. It is not clear whether this is audited regularly, or that the information is collected once, and then the volumes are replicated without checking. In any case there is no methodology for recording uncollected waste, which could be produced by tracking clean-ups of wastes on beaches, in drains and on vacant plots. The private disposal company collects sufficient information to support their operations and there is no contractual obligation to share this, especially with external researchers. This creates an unusual situation, and would produce "orange" lights on the WasteAware table, indicating lack of transparency, rather than poor performance. The use of participatory action research and collection of primary data worked relatively well to reduce this effect in Accra. The experience with the municipalities however offer insights that including a fourth WasteAware governance indicator might be important - and that is the availability of accurate and verifiable data and information and the presence of procedures that allow access to it (see Figure 7.1).

Commitment from city authorities has always been an important ingredient for sustainable MSWM but it is also a necessary condition to be able to benchmark governance (Wilson et al., 2013). In Accra, the participatory process of benchmarking and its empirical results created a commitment itself. Selected representatives of working groups, researchers and MSWM staff have since 2016 identified and implemented locally appropriate interventions to improve upon and sustain the MSWM system (Oduro-Appiah et al., 2017b).

\section{Benchmarking with the resource management composite indicator in the existence of formal and informal material recovery}

Benchmarking and comparison of resource management using WasteAware is possible when service chain institutions have taken charge of recycling and are actively working on diversion systems to divert recyclables and organics from disposal to valorisation. In 


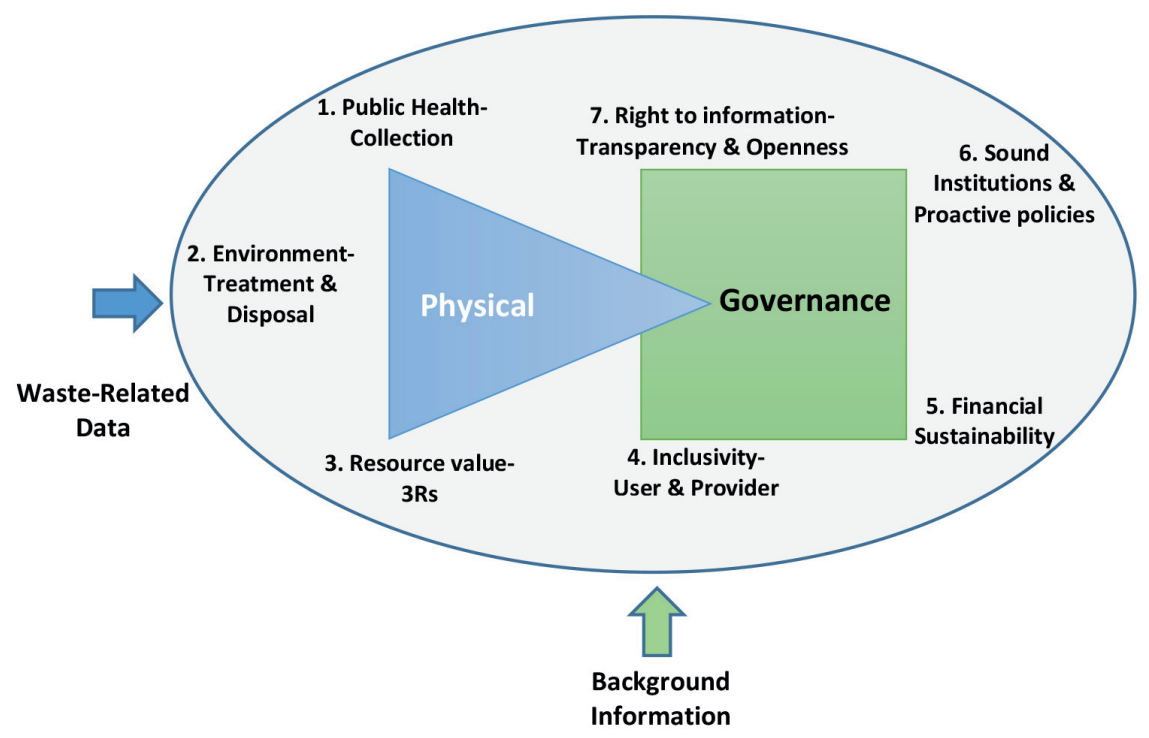

Figure 7.I: The recommended and modified version of the ISWM framework.

The Authors, 2019.

these municipalities of the GAMA and most emerging economies, it is outside of the competence and experience of the local authorities.

Macro-level data is available at country level and from industry trade associations, but extrapolating it to city level is tricky, in part because it is based on a set of producer and value chain definitions, and these are different from those used in the WasteAware process. Neither is there data on landfill picking, as none of municipalities measure either diversion from disposal, nor amounts recycled, yet another signal that the service chain is not involved in recycling. Informal collectors in all municipalities sell to private value chain institutions and enterprises who partially keep records and seldom share them. The formal recycling industry has a culture of secrecy, and private recycling companies are reluctant to disclose information about their operations or quantities traded.

Thus, between the fact that the performance of the informal recovery systems is seldom recorded, and that records on the formal systems for recycling - if they exist and function — is incomplete, the level of reliability of the resource management indicator is highly questionable, even when there is inclusivity and recognition of informal recycling. For instance, in Accra, the researchers initially had to personally observe the activities of informal recycling collectors at an illegal dumping site to determine their numbers and estimate their total collection tonnage and coverage, and to visit almost all known recycling points and industries to collect data on materials that are brought in by the informal waste sector (Oduro-Appiah et al., 2017a). 
This research suggests that indicator 3 , resource management, remains inadequate in addressing the characteristics of the value chain in emerging economies, where only limited or no levels of recycling could be monitored in the service chain and the means to measure recycling activities in the value chain are lacking. Thus, the calculations based on Indicator 3 are likely to be estimations based on incomplete information and unclear definitions - something that was clearly the case in the Habitat book research in Varna, Nairobi, and other middle-income-country cities (Scheinberg et al., 2010b).

\section{Recommendations for including the considerations of emerging economies}

The analysis of the six metropolitan cities of Ghana supports the proposal that the WasteAware Indicators be adapted to the needs and institutional circumstances in cities in the emerging economy context, first in order to meet the growing demand for workable benchmarking tools, and secondly because it is urgent for such cities to improve inclusive resource management approaches and support sustainable finance and inclusive governance. The research to this dissertation have identified three main areas to adapt.

\section{Governance aspects: a tetrahedron instead of a triangle}

Transparency and accessibility of information represent core boundary conditions that do or do not allow the WasteAware approach to produce meaningful and comparable results. The first recommendation that the governance triangle become a tetrahedron (Figure 7.1), with the fourth indicator representing transparency and openness to information. The specific method, details and scoring system for assessing these remains to be fully developed, but we recommend the following relevant sub-indicators (Table 7.1), based on experience and lessons learnt from the municipalities of the greater Accra region of Ghana to be considered.

\section{Resource management: Indicator 3 in need of therapy}

The second conclusion to be drawn from this exercise is that a resource management indicator that looks only or primarily at service chain municipal recycling, is not sufficient for studying emerging economies. This is a more complex and challenging issue to address, for three reasons.

- First, the functioning of the value chain can in practice never be benchmarked from "existing information," and original field work is necessary, in part because most WasteAware benchmarking agents - like their municipal or national clients - are both focused and specialised in the service chain. As the Accra research team proved, primary field work (to create original and reliable data) is key to being 
Table 7.I: Proposed sub-indicators for recommended governance addition to the WasteAware indicators.

\begin{tabular}{llll}
\hline No. & Criterion & Description & Scoring range \\
\hline 7 I.1 & $\begin{array}{l}\text { Right to (Freedom } \\
\text { of) information act }\end{array}$ & $\begin{array}{l}\text { Evidence of existence and implementation } \\
\text { of a right to (freedom of) information act } \\
\text { within the benchmarking city }\end{array}$ & $\begin{array}{l}0,5,10,15,20 \\
\text { Evidence of and degree } \\
\text { of implementation }\end{array}$ \\
7 I.2 & $\begin{array}{l}\text { Information transpa- } \\
\text { rency and accessibility }\end{array}$ & $\begin{array}{l}\text { Ease to which benchmarking-related infor- } \\
\text { mation is accessible to benchmarking agent/ } \\
\text { lead facilitator/working group }\end{array}$ & $\begin{array}{l}0,5,10,15,20 \\
\text { Ease of accessibility }\end{array}$ \\
7 I.3 & $\begin{array}{l}\text { Participation and } \\
\text { support of munici- } \\
\text { pality }\end{array}$ & $\begin{array}{l}\text { Extent to which the municipality of the } \\
\text { benchmarking city is involved and supports } \\
\text { the benchmarking process }\end{array}$ & $\begin{array}{l}\text { Level of participation } \\
\text { and support }\end{array}$ \\
7 I.4 & $\begin{array}{l}\text { Control of infor- } \\
\text { mal waste data and } \\
\text { records }\end{array}$ & $\begin{array}{l}\text { Degree to which the MSW managers have } \\
\text { control over informal waste service and value } \\
\text { chain information and data }\end{array}$ & $\begin{array}{l}0,5,10,15,20 \\
\text { Degree of informal data } \\
\text { control }\end{array}$ \\
& $\begin{array}{l}\text { Participation/coo- } \\
\text { peration of MSWM } \\
\text { stakeholders }\end{array}$ & $\begin{array}{l}\text { Extent to which the stakeholders of MSWM } \\
\text { participates and or cooperates to participate, } \\
\text { share and validate relevant information to } \\
\text { the benchmarking process }\end{array}$ & $\begin{array}{l}0,5,10,15,20 \\
\text { Degree of participation }\end{array}$ \\
\hline
\end{tabular}

able to "include the contribution from the 'informal' recycling sector" credibly. Methods such as interviews, participant observation and scrap industry records go well beyond the normal instructions for WasteAware.

- Secondly, there is little understanding on the informal sector and what these microenterprises actually do with the materials, or that the key indicator for valorisation of a particular type of material is a transaction proving that they have value and have been sold. In terms of recycling rates, this means that when an answer is given, it is seldom reliable and requires verification, triangulation and modelling of informal performance. (Scheinberg et al., 2010b; Ramusch et al., 2015).

- Moreover, in cities in emerging economies, stakeholders having relevant information on recovery and valorisation, such as extended producer responsibility (EPR) compliance organisations (PROs for packaging), are likely to be in conflict or competition with the informal recycling sector, and so any numbers irrespective of which "side" they come from - are of questionable value (Ramusch et al., 2015; Scheinberg et al., 2016). Thus, this research reveals the challenge and urgency of developing a working benchmarking approach for resource management in emerging economies. 


\section{Third round of advancement in ISWM indicators among the community of practice}

In addition to the two substantive adaptations - a governance tetrahedron and a radical revision of the resource management indicator, the research reported here challenges the community of practice once again to go further in the development of practical and locally appropriate situated strategies and to organise sustainable finance and inclusive governance in the contexts where forms of service delivery is heterogeneous, and the municipal sphere of influence does little with recycling or resource management. The recommendation is, in effect, to embark on a "third round" of advancement, of the indicators; the "first round" of further development in the Habitat book process, and the "second round" centred around scholars in the community of practice and strengthened by independent benchmarking of more than 50 cities as projects of MSc or $\mathrm{PhD}$ students or in relation to consulting projects (Velis et al., 2012; Wilson et al., 2015a; Wilson et al., 2013; Scheinberg et al., 2010a; Oduro-Appiah et al., 2017a).

A "third round" that acknowledges the difference and increasing geopolitical importance of emerging economies may likely broaden the applicability of the WasteAware system and stimulate a new research, benchmarking, and improved practice. Such a radical change in how we understand and apply the WasteAware indicators is urgent to ensure their continuous relevance and usefulness in analysing cities and supporting sustainable system transformation.

\section{Recommendations for future research}

There still remain questions for the research community in solid waste management within the GAMA and the country. Notable amongst them include: (1) how to develop an action plan to initiate processes towards the integration and sustainability of the operations of the informal waste sector; (2) how to develop appropriate and long term interventions towards activity-based budgeting and financial sustainability; (3) how to develop interventions for sound institutions and proactive policies; (4) how to develop a locally appropriate and national strategic plan; (5) how the existing solid waste working agreements, bye-laws and their related changes could be sustained; and (6) how the various development partner supported projects within the solid waste sector could be coordinated to continuously support system modernisation?

We recommend the continual cooperation between researchers and municipalities in addition to the soliciting of financial support and small grants from corporate organisations, non-governmental organisations and the beneficiary municipalities towards similar research studies and participatory processes. We estimate that an integrated sustainable waste management (ISWM) process in a city can cost as much 
as US\$40,000.00 to complete (IJgosse et al., 2004), excluding the cost of external consultants. The research for this thesis has so far spent US\$25,000.00 of which US $\$ 16,500.00$ has been from the funding agency ${ }^{1}$. However, the development of an action plan for the city is yet to be undertaken.

Moreover, ISWM implementation is reported to work best where the municipality or the city initiates the process (IJgosse et al., 2004). The research in this dissertation had the researchers as initiators; and this construction takes an appreciable amount of time to convince authorities to be on board, but provides continuity and extrinsic motivation and may bring with it a greater potential of achieving concrete and tangible intervention implementation. Arranging for M.Sc. and $\mathrm{PhD}$ candidates to coordinate the process for a period of at least four years might likely be an alternative path to reducing the risk involved in coupling stakeholders to practical interventions.

Working with municipalities and cities in developing countries, especially in Sub-Saharan African can be politically difficult, academically frustrating and socially challenging, but where modernisation and sustainability of the system brings about immense public health and environmental benefits in addition to creating and strengthening livelihoods for a large informal sector, the difficulty and challenges can be perceived as the transaction cost associated with giving stakeholders the incentive to make difficult but potentially sustainable modernisation choices.

\section{General Conclusion}

Increasing population, urbanisation and the resulting increase in solid waste generation is of great concern in cities of emerging economies such as Ghana. This concern has grown in proportion both to the related natural resources depletion and climate change, and also because of the continuous public health and environmental burdens as a result of the chronic failure of institutions in such cities to adopt sustainable approaches to modernise their solid waste management systems.

Despite various attempts and support from development partners, cities like Accra, Ghana, have for more than four decades been struggling to increase solid waste collection coverage, improve disposal systems, and divert recyclables from disposal. Solid waste governance systems have more often than not been characterised by weak institutions, lack of realistic policy and legal frameworks; and the absence of inclusive governance and financial sustainability principles. Finding locally appropriate pathways towards

\footnotetext{
1 This amount excludes costs to conferences to share the outcomes and lessons learnt. And of course it does not include any of the academic costs of the $\mathrm{PhD}$ study associated with this dissertation, such as tuition, travel to and residence during periods at University abroad, cost of $\mathrm{PhD}$ advising, cost of publications and the like.
} 
the modernisation of the solid waste system of such cities is a necessity and of urgent importance.

The objective of this dissertation was to identify and test methods to engage key public sector holders in finding real solutions and mobilising local resources and ideas, which will be sustainable over a long term. The findings reported in this thesis contribute to a body of ISWM research that strengthen capacities and promotes inclusive governance for comprehensive insight into the nexus between failure and success in the solid waste management system of Ghanaian cities. This research strongly supports the claim that locally appropriate interventions developed and implemented through coordinated participatory action research approaches can lead to locally appropriate system modernisation and continuous improvement on the road towards sustainability. After four and a half years of cooperative and participative work between researchers and the municipalities within the greater Accra metropolitan area (GAMA) of Ghana, reliable data gaps especially in the informal waste sector has been closed and competencies have grown. Physical indicators of solid waste management (SWM) have significantly improved; governance indicators have improved modestly but measurably; livelihoods have been created and strengthened; and the commitment of local authorities and decision-makers has been won. The results have been a systematic improvement in inclusive solid waste management governance and systems thinking (IJgosse et al., 2004; Lederer et al., 2015; Alamgir et al., 2012; Ragossnig and Tunesi, 2018).

The most important conclusion drawn from the activities and interventions forming the basis for this dissertation is that coordinated cooperation between higher educational or research institutions, municipalities and relevant stakeholders has a higher potential to close chronic and reliable data gaps; to strengthen human resource capacities and competencies; to promote inclusive governance; to develop locally appropriate interventions and create ownership of same, to empower municipalities to implement, monitor and evaluate developed interventions towards the modernisation of solid waste management systems in Ghana and similar developing countries.

The commitment of these stakeholders as working groups using participatory action research processes seems an appropriate method to create transparency, accountability and trust during assessments and implementation of interventions. Above all the timely presentation and sharing of results becomes an advocacy tool to further win the commitment of decision-makers towards a continuous system improvement and sustainability; and an entry point for support from development partners. The evidence alluded by the outcomes of this work and the recommendations both in the methodological approach and the framework can serve to support similar cities and economies to begin processes towards the modernisation of their waste systems. 


\section{References}

Abledu ES and Amfo-Otu R. (2018) Contribution of Informal Sector Recycling Workers to Sustainable Landfill Management: The Case of Kpone Landfill Site in the Greater Accra region. PUCG Applied Research Journal 4: 1-11.

Achankeng E. (2003) Globalization, urbanization and municipal solid waste management in Africa. Proceedings of the 26th annual conference of African Studies Association of Australasia and the Pacific.

Addae S. (1996) History of Western medicine in Ghana 1880-1960: Durham Academic Press.

Agamuthu P. (2010) The role of informal sector for sustainable waste management. Waste Management and Research 28: 671-672.

Akese GA. (2014) Price realization for electronic waste (e-waste) in Accra, Ghana. Memorial University of Newfoundland.

Akese GA and Little PC. (2018) Electronic Waste and the Environmental Justice Challenge in Agbogbloshie. Environmental Justice 11: 77-83.

Al Masha'an M and Mahrous F. (1999) Environmental Strategy for Managing the Kuwait's Solid Wastes until 2020. Proceedings of Arab and Middle East International Conference and Fair on Solid Waste Management, Cairo. 8-6.

Alamgir M, Bidlingmaier W and Cossu R. (2012) Successful waste management strategies in developing countries require meaningful involvement of the concerned stakeholders. Waste Management 32: 2007-2008.

Ali A. (2010) Wasting time on solid waste in developing countries. Waste Management 30: 1437-1438.

Ali M, Geng Y, Robins D, et al. (2019) Improvement of waste management practices in a fast expanding sub-megacity in Pakistan, on the basis of qualitative and quantitative indicators. Waste Management 85: 253-263.

Allesch A and Brunner PH. (2014) Assessment methods for solid waste management: A literature review. Waste Management and Research 32: 461-473.

Amoyaw-Osei Y, Agyekum OO, Pwamang JA, et al. (2011) Ghana e-waste country assessment.

Amuzu D. (2018) Environmental injustice of informal e-waste recycling in Agbogbloshie-Accra: urban political ecology perspective. Local Environment 23: 603-618.

Andrianisa HA and Brou YO. (2016) Role and importance of informal collectors in the municipal waste pre-collection system in Abidjan, Côte d'Ivoire. Habitat International 53: 265-273.

Andrianisa HA, Randriatsiferana FM, Rakotoson SL, et al. (2018) Socio-economic integration of the informal recycling sector through an NGO intervention at the Andralanitra dumpsite in Antananarivo, Madagascar. Waste Management and Research 36: 86-96.

Aparcana S. (2017) Approaches to formalization of the informal waste sector into municipal solid waste management systems in low-and middle-income countries: Review of barriers and success factors. Waste Management 61: 593-607.

Asante B, Yanful E and Yaokumah B. (2014) Healthcare Waste Management; Its Impact: A Case Study Of The Greater Accra Region, Ghana. International Journal Of Scientific and Technology Research 3. 
Asase M, Yanful EK, Mensah M, et al. (2009) Comparison of municipal solid waste management systems in Canada and Ghana: A case study of the cities of London, Ontario, and Kumasi, Ghana. Waste Management 29: 2779-2786.

Asomani-Boateng R and Haight M. (1998) Assessment of municipal solid waste management practices in Accra, Ghana. Journal of Environmental Systems 26.

Asumadu-Sarkodie S, Owusu PA and Rufangura P. (2015) Impact analysis of flood in Accra, Ghana. Advances in Applied Science Research 6: 53-78.

Atiemo S, Faabeluon L, Manhart A, et al. (2018) Baseline Assessment of E-Waste Management in Ghana.

Atiemo SM, Ofosu FG, Aboh I, et al. (2012) Assessing the heavy metals contamination of surface dust from waste electrical and electronic equipment (e-waste) recycling site in Accra, Ghana. Res J Environ Earth Sci 4: 605-611.

Awortwi N. (2004) Getting the fundamentals wrong: woes of public-private partnerships in solid waste collection in three Ghanaian cities. Public Administration and Development 24: 213-224.

Awuah HK. (2017) Waste reduction strategies on construction projects: the case of Accra metropolis. Academic Press.

Ayodele T, Alao M and Ogunjuyigbe A. (2018) Recyclable resources from municipal solid waste: Assessment of its energy, economic and environmental benefits in Nigeria. Resources, Conservation and Recycling 134: $165-173$.

Bhuiyan SH. (2010) A crisis in governance: Urban solid waste management in Bangladesh. Habitat International 34: 125-133.

Birkbeck C. (1978) Self-employed proletarians in an informal factory: the case of Cali's garbage dump. World Development 6: 1173-1185.

Boadi KO and Kuitunen M. (2003) Municipal solid waste management in the Accra Metropolitan Area, Ghana. Environmentalist 23: 211-218.

Boadi KO and Kuitunen M. (2005) Environmental and health impacts of household solid waste handling and disposal practices in third world cities: the case of the Accra Metropolitan Area, Ghana. Journal of Environmental Health 68.

Boampong O and Tachie BY. (2017) Implications of Private Participation in Solid Waste Manangement for collective organization in Accra, Ghana. In: Webster E, Britwum AO and Bhowmik S (eds) Crossing the Divide:Precarious work and the future of labour. South Africa: Univrsity of Kwazulu-Natal Press.

Bundhoo ZM. (2018) Solid waste management in least developed countries: current status and challenges faced. Journal of Material Cycles and Waste Management: 1-11.

Burns KN, Sayler SK and Neitzel RL. (2019) Stress, health, noise exposures, and injuries among electronic waste recycling workers in Ghana. Journal of Occupational Medicine and Toxicology 14: 1.

Caravanos J, Clarke EE, Fuller R, et al. (2011) Assessing worker and environmental chemical exposure risks at an e-waste recycling and disposal site in Accra, Ghana. Journal of Health and Pollution 1: 16-25.

Caravanos J, Clarke EE, Osei CS, et al. (2013) Exploratory health assessment of chemical exposures at e-waste recycling and scrapyard facility in Ghana. Journal of Health and Pollution 3: 11-22.

Cervantes DET, Martínez AL, Hernández MC, et al. (2018) Using indicators as a tool to evaluate municipal solid waste management: A critical review. Waste Management 80: 51-63. 
Chambers R. (1992) Rural apprasial: rapid, relaxed and participatory: Institute of Development Studies (UK).

Chambers R. (1994) Participatory rural appraisal (PRA): Analysis of experience. World Development 22: 1253-1268.

Chen MA. (2012) The informal economy: Definitions, theories and policies, WIEGO working Paper; WIEGO: Manchester, UK.

Chen MA, Vanek J and Carr M. (2004) Mainstreaming informal employment and gender in poverty reduction: $A$ handbook for policy-makers and other stakeholders: Commonwealth Secretariat.

Cheng S, Chan CW and Huang GH. (2002) Using multiple criteria decision analysis for supporting decisions of solid waste management. Journal of Environmental Science and Health, Part A 37: 975990.

Citinews. (2018) AMA registers 472 Borla Taxi Operators. Available at: https://citinewsroom. com/2018/07/22/ama-registers-472-borla-taxi-operators/.

Cochran WG. (1977) Sampling Techniques: John Wiley \& Sons.

Coffey M and Coad A. (2010) Collection of municipal solid waste in developing countries: UN-Habitat, United Nations Human Settlements Programme: Nairobi, Kenya.

Cohen B. (2006) Urbanization in developing countries: Current trends, future projections, and key challenges for sustainability. Technology in Society 28: 63-80.

Cossu R, Grossule V and Lavagnolo MC. (2019) Sustainable low cost waste management: learning from airlines. Detritus 6: 1-3.

Daskalopoulos E, Badr O and Probert S. (1998) An integrated approach to municipal solid waste management. Resources, Conservation and Recycling 24: 33-50.

Daum K, Stoler J and Grant R. (2017) Toward a more sustainable trajectory for E-waste Policy: A review of a decade of E-waste research in Accra, Ghana. International Journal of Environmental Research and Public Health 14: 135.

Davis J-M, Akese G and Garb Y. (2019) Beyond the pollution haven hypothesis: Where and why do e-waste hubs emerge and what does this mean for policies and interventions? Geoforum 98: 36-45.

De Soto H. (2000) The mystery of capital: Why capitalism triumphs in the West and fails everywhere else: Basic Civitas Books.

Diaz LF. (2017) Waste management in developing countries and the circular economy. SAGE Publications Sage UK: London, England.

Dodoo SO. (2018) Registration of "Borla Taxis" in Accra begins July 4. Available at: http://www. ghananewsagency.org/social/registration-of-borla-taxis-in-accra-begins-july-4-134800.

Duku MH, Gu S and Hagan EB. (2011) A comprehensive review of biomass resources and biofuels potential in Ghana. Renewable and Sustainable Energy Reviews 15: 404-415.

Environmental Protection Agency. (2017) Ghana State of the Environment (2016) Report, Environmental Protection Agency, Ministry of Environment, Science, Technology and Innovation, Accra. http:// www.epa.gov.gh/epa/publications/state-environment-report.

Ezeah C, Fazakerley JA and Roberts CL. (2013) Emerging trends in informal sector recycling in developing and transition countries. Waste Management 33: 2509-2519. 
Ezeah C and Roberts CL. (2012) Analysis of barriers and success factors affecting the adoption of sustainable management of municipal solid waste in Nigeria. Journal of Environmental Management 103: 9-14.

Fei F, Qu L, Wen Z, et al. (2016) How to integrate the informal recycling system into municipal solid waste management in developing countries: Based on a China's case in Suzhou urban area. Resources, Conservation and Recycling 110: 74-86.

Feldt T, Fobil JN, Wittsiepe J, et al. (2014) High levels of PAH-metabolites in urine of e-waste recycling workers from Agbogbloshie, Ghana. Science of the Total Environment 466: 369-376.

Field A. (2013) Discovering statistics using IBM SPSS statistics: Sage.

Gaisie E, Kim HM and Han SS. (2019) Accra towards a city-region: Devolution, spatial development and urban challenges. Cities 95: 102398.

Gerdes P and Gunsilius E. (2010) The waste experts: Enabling conditions for informal sector integration in solid waste management: Lessons learned from Brazil, Egypt and India. Vol. 1.: Eschborn: GTZ.

Ghana Government. (2003) Public Procurement Act, Act 663. Accra, Ghana.

Ghana Government. (2010) Environmental Sanitation Policy. Accra: Ministry of Local Government and Rural Development.

Ghana Statistical Services. (2014) 2010 Population Census, District Analytical Report, Accra Metropolitan Assembly, Accra, Ghana.

Ghana Statistical Services. (2019) Ghana Population and Housing Census: Projection_Districts_2015_2020. Available at: http://www.statsghana.gov.gh/.

Godfrey L and Oelofse S. (2017) Historical review of waste management and recycling in South Africa. Resources 6: 57.

Government of Ghana. (2010) National Environmental Sanitation Strategic Action Plan., 143.

Government of Ghana. (2017) Enhancing urban resilience in the Greater Accra Metropolitan Area. Washington DC, USA.

Government of Ghana. (2018) The Health Sector in Ghana: Facts and Figures. https://www. ghanahealthservice.org/.

Grant R and Oteng-Ababio M. (2012) Mapping the invisible and real" African” economy: urban e-waste circuitry. Urban Geography 33: 1-21.

Grant R and Oteng-Ababio M. (2019) Electronic-Waste Circuitry and Value Creation in Accra, Ghana. Value Chains in Sub-Saharan Africa. Springer, 115-131.

Grossule V and Lavagnolo MC. (2018) From 3R to 3S: An appropriate strategy for developing countries. Detritus 4: 1-3.

Guerrero LA, Maas G and Hogland W. (2013) Solid waste management challenges for cities in developing countries. Waste Management 33: 220-232.

Halla F and Majani B. (1999) Innovative ways for solid waste management in Dar-Es-Salaam: Toward stakeholder partnerships. Habitat International 23: 351-361.

Henry RK, Yongsheng Z and Jun D. (2006) Municipal solid waste management challenges in developing countries-Kenyan case study. Waste Management 26: 92-100.

Herat S. (2015) Waste management training and capacity building for local authorities in developing countries. Waste Management and Research 33: 1-2. 
Howlett M, Kekez A and Poocharoen O-O. (2017) Understanding co-production as a policy tool: Integrating new public governance and comparative policy theory. Journal of Comparative Policy Analysis: Research and Practice 19: 487-501.

Huang J, Nkrumah PN, Anim DO, et al. (2014) E-waste disposal effects on the aquatic environment: Accra, Ghana. Reviews of Environmental Contamination and Toxicology. Springer, 19-34.

IJgosse J, Anschütz J and Scheinberg A. (2004) Putting integrated sustainable waste management into practice: using the ISWM assessment methodology as applied in the UWEP Plus programme (2001-2003). The Netherlands: Waste. Gouda, The Netherlands: WASTE.

Ilić M and Nikolić M. (2016) Waste management benchmarking: A case study of Serbia. Habitat International 53: 453-460.

Ishengoma A. (2006) Employment creation in municipal service delivery in Eastern Africa: Improving living conditions and providing jobs for the poor 2003-2005. Programme Report of the combined programmatic initiatives of ILO-Small Enterprise Development (PPP), ILO-Employment-Intensive Investment Programme, ILO/ASIST-Africa, ILO Sub Regional Office, Addis Ababa, ILO-IPEC Tanzania. Geneva, Switzerland. International Labor Organization (ILO). Dar es Salaam, Tanzania.

Ishengoma A and Lyimo T. (2002) The Dar es Salaam experience to reduce poverty-promoting employment through urban services. World Urban Forum. Nairobi, Kenya, 4th May 2002.

Ishengoma A and Toole K. (2003) Jobs and services that work for the poor; Promoting Decent Work in municipal service enterprises in East Africa; the Dar es Salaam Project and the informal economy. Knowledge-sharing workshop organized by INTEGRATION. ITC Turin Italy.

Kabera T, Wilson DC and Nishimwe H. (2019) Benchmarking performance of solid waste management and recycling systems in East Africa: Comparing Kigali Rwanda with other major cities. Waste Management and Research 37: 58-72.

Kartam N, Al-Mutairi N, Al-Ghusain I, et al. (2004) Environmental management of construction and demolition waste in Kuwait. Waste Management 24: 1049-1059.

Kassim SM and Ali M. (2006) Solid waste collection by the private sector: Households' perspectiveFindings from a study in Dar es Salaam city, Tanzania. Habitat International 30: 769-780.

Katusiimeh MW, Burger K and Mol AP. (2013) Informal waste collection and its co-existence with the formal waste sector: the case of Kampala, Uganda. Habitat International 38: 1-9.

Kaza S, Yao LC, Bhada-Tata P, et al. (2018) What a Waste 2.0: A Global Snapshot of Solid Waste Management to 2050. Urban Development Series. Washington, DC: World Bank. The World Bank.

Kemausuor F, Kamp A, Thomsen ST, et al. (2014) Assessment of biomass residue availability and bioenergy yields in Ghana. Resources, Conservation and Recycling 86: 28-37.

Kirama A and Mayo AW. (2016) Challenges and prospects of private sector participation in solid waste management in Dar es Salaam City, Tanzania. Habitat International 53: 195-205.

Kusi E, Nyarko AK, Boamah LA, et al. (2016) Landfills: Investigating Its Operational Practices in Ghana. International Journal of Energy and Environmental Science 1: 19-28.

Leal Filho W, Brandli L, Moora H, et al. (2016) Benchmarking approaches and methods in the field of urban waste management. Journal of Cleaner Production 112: 4377-4386. 
Leal Filho W, Doni F, Vargas VR, et al. (2019a) The integration of social responsibility and sustainability in practice: Exploring attitudes and practices in Higher Education Institutions. Journal of Cleaner Production 220: 152-166.

Leal Filho W, Shiel C, Paço A, et al. (2019b) Sustainable Development Goals and sustainability teaching at universities: Falling behind or getting ahead of the pack? Journal of Cleaner Production 232: 285-294.

Leal Filho W, Vargas VR, Salvia AL, et al. (2019c) The role of higher education institutions in sustainability initiatives at the local level. Journal of Cleaner Production 233: 1004-1015.

Lederer J, Ongatai A, Odeda D, et al. (2015) The generation of stakeholder's knowledge for solid waste management planning through action research: A case study from Busia, Uganda. Habitat International 50: 99-109.

Lepawsky J, Akese G, Billah M, et al. (2015) Composing urban orders from rubbish electronics: Cityness and the site multiple. International Journal of Urban and Regional Research 39: 185-199.

Linzner R and Lange U. (2013) Role and size of informal sector in waste management-a review. Proceedings of the Institution of Civil Engineers-Waste and Resource Management 166: 69-83.

Louis GE. (2004) A historical context of municipal solid waste management in the United States. Waste Management and Research 22: 306-322.

Lu W, Yuan H, Li J, et al. (2011) An empirical investigation of construction and demolition waste generation rates in Shenzhen city, South China. Waste Management 31: 680-687.

Manhart A, Meinel J and Walgenbach S. (2014) Legal and institutional requirements for e-waste recycling in Ghana: Workpackage 3.5of the Bo2W project. Available at: http://www.oeko/de/oekodoc/2142/2014695-en.pdf.

Marino AL, Chaves GdLD and dos Santos Junior JL. (2018) Do Brazilian municipalities have the technical capacity to implement solid waste management at the local level? Journal of Cleaner Production 188: 378-386.

Marshall RE and Farahbakhsh K. (2013) Systems approaches to integrated solid waste management in developing countries. Waste Management 33: 988-1003.

Masood M and Barlow C. (2013) Framework for integration of informal waste management sector with the formal sector in Pakistan. Waste Management and Research 31: 93-105.

McDougall FR, White PR, Franke M, et al. (2008) Integrated solid waste management: a life cycle inventory: John Wiley \& Sons.

McIntyre A. (2007) Participatory action research: Sage Publications.

Meagher K. (2013) Unlocking the informal economy: A literature review on linkages between formal and informal economies in developing countries. Work. ePap 27.

Medina M. (2000) Scavenger cooperatives in Asia and Latin America. Resources, Conservation and Recycling 31: 51-69.

Medina M. (2005) Serving the unserved: informal refuse collection in Mexico. Waste Management and Research 23: 390-390.

Medina M. (2007) The world's scavengers: salvaging for sustainable consumption and production: Rowman Altamira. 
Mensah A, Cofie O and Montangero A. (2003) Lessons from a pilot co-composting plant in Kumasi, Ghana. 29th WEDC Inernational Conference. Abuja, Nigeria.

Meyer G. (2019) Waste-recycling as a livelihood in the informal sector. The example of refuse collectors in Cairo. Egypte/Monde arabe: 61-76.

Miezah K, Obiri-Danso K, Kádár Z, et al. (2015) Municipal solid waste characterization and quantification as a measure towards effective waste management in Ghana. Waste Management 46: 15-27.

Mills-Tettey R. (2013) Urban Housing and Sanitation: Our Habitat, Our Health: Being Inaugural Lecture Presented as a Fellow of the Ghana Academy of Arts and Sciences on 5th June 2008: Ghana Academy of Arts and Sciences.

Mmereki D, Baldwin A and Li B. (2016) A comparative analysis of solid waste management in developed, developing and lesser developed countries. Environmental Technology Reviews 5: 120-141.

Navarrete-Hernandez P and Navarrete-Hernandez N. (2018) Unleashing Waste-Pickers' Potential: Supporting Recycling Cooperatives in Santiago de Chile. World Development 101: 293-310.

Obirih-Opareh N and Post J. (2002) Quality assessment of public and private modes of solid waste collection in Accra, Ghana. Habitat International 26: 95-112.

Oduro-Appiah K, Afful A, Kotey V, et al. (2019) Working with the Informal Service Chain as a Locally Appropriate Strategy for Sustainable Modernization of Municipal Solid Waste Management Systems in Lower-Middle Income Cities: Lessons from Accra, Ghana. Resources 8: 12.

Oduro-Appiah K and Aggrey BE. (2013) Determinants of source separation of municipal solid waste in developing countries: The case of Ghana. Journal of Sustainable Development in Africa 15: 47-60.

Oduro-Appiah K, Aidoo DO and Sarbah G. (2013) Fee-based solid waste collection in economically developing countries: The case of Accra metropolis. International Journal of Development and Sustainability 2: 629-639.

Oduro-Appiah K, Scheinberg A, Afful A, et al. (2020a) The contribution of participatory engegement strategies to reliable data gathering and inclusive policy in developing countries: Municipal solid waste management data in the greater Accra metropolitan area of Ghana. In Press.

Oduro-Appiah K, Scheinberg A, Mensah A, et al. (2017a) Assessment of the municipal solid waste management system in Accra, Ghana: A" Wasteaware' benchmark indicator approach. Waste Management and Research 35: 1149-1158.

Oduro-Appiah K, Scheinberg A, Mensah A, et al. (2017b) Locally responsive intervention to improve municipal solid waste collection coverage in Accra, Ghana. 40th WEDC International Conference. Loughborough, UK.

Oduro-Appiah K, Scheinberg A, Miezah K, et al. (2020b) Existing Realities and Sustainable Pathways for Solid Waste Management in Ghana. In: Pariatamby A, Hamid FS and Bhatti MS (ed) Sustainable Waste Management Challenges in Developing Countries. USA: IGI Global, 115-143.

Oduro-Kwarteng S and van Dijk MP. (2013) The effect of increased private sector involvement in solid waste collection in five cities in Ghana. Waste Management and Research 31: 81-92.

Oteng-Ababio M. (2010) Private sector involvement in solid waste management in the Greater Accra Metropolitan Area in Ghana. Waste Management and Research 28: 322-329.

Oteng-Ababio M. (2011a) Beyond technical details: The stalled Kwabenya engineered sanitary landfill project in Accra, Ghana. Geografisk Tidsskrift-Danish Journal of Geography 111: 169-179. 
Oteng-Ababio M. (2011b) Missing links in solid waste management in the Greater Accra Metropolitan Area in Ghana. GeoJournal 76: 551-560.

Oteng-Ababio M. (2012) The role of the informal sector in Solid Waste Management in the GAMA, Ghana: Challenges and Opportunities. Tijdschrift voor Economische en Sociale Geografie 103: $412-$ 425 .

Oteng-Ababio M. (2014) "Guilty with explanation": rethinking the destiny of landfills in a Millennium City in Ghana. Management of Environmental Quality: An International Journal 25: 200-215.

Oteng-Ababio M. (2018) Crossing conceptual boundaries: re-envisioning coordination and collaboration among women for sustainable livelihoods in Ghana. Local Environment 23: 316-334.

Oteng-Ababio M, Amankwaa EF and Chama MA. (2014) The local contours of scavenging for e-waste and higher-valued constituent parts in Accra, Ghana. Habitat International 43: 163-171.

Oteng-Ababio M, Arguello JEM and Gabbay O. (2013) Solid waste management in African cities: Sorting the facts from the fads in Accra, Ghana. Habitat International 39: 96-104.

Oteng-Ababio M, Owusu-Sekyere E and Amoah ST. (2017) Thinking globally, acting locally: Formalizing informal solid waste management practices in Ghana. Journal of Developing Societies 33: 75-98.

Owusu-Sekyere E, Bagah DA and Quansah JYD. (2015) The urban solid waste management conundrum in Ghana: Will it ever end? World Environment 5: 52-62.

Pallant J. (2016) SPSS Survival Manual: A Step by Step Guide to Data Analysis Using IBM SPSS, 6th Edn Crows Nest. NSW: Allen \&Unwin.

Paul JG, Arce-Jaque J, Ravena N, et al. (2012) Integration of the informal sector into municipal solid waste management in the Philippines-What does it need? Waste Management 32: 2018-2028.

Präger F, Paczkowski S, Sailer G, et al. (2019) Biomass sources for a sustainable energy supply in Ghana-A case study for Sunyani. Renewable and Sustainable Energy Reviews 107: 413-424.

Prairie Village K. (1998) Characterization of building-related construction and demolition debris in the United States. The US Environmental Protection Agency Municipal and Industrial Solid Waste Division Office of Solid Waste.

Ragossnig A and Tunesi S. (2018) Succeeding in involving decision-makers in solid waste management planning by setting appropriate goals and providing a structured planning method. Waste Management and Research 36: 924-933.

Ramusch R, Pertl A, Scherhaufer S, et al. (2015) Modelling informally collected quantities of bulky waste and reusable items in Austria. Waste Management 44: 3-14.

Rockson GN, Kemausuor F, Seassey R, et al. (2013) Activities of scavengers and itinerant buyers in Greater Accra, Ghana. Habitat International 39: 148-155.

Rodić L and Wilson DC. (2017) Resolving governance issues to achieve priority sustainable development goals related to solid waste management in developing countries. Sustainability 9: 404.

Sandhu K, Burton P and Dedekorkut-Howes A. (2017) Between hype and veracity; privatization of municipal solid waste management and its impacts on the informal waste sector. Waste Management 59: 545-556.

Scheinberg A. (2003) The proof of the pudding: urban recycling in North America as a process of ecological modernisation. Environmental Politics 12: 49-75. 
Scheinberg A. (2011) Value added: modes of sustainable recycling in the modernisation of waste management systems. PhD Thesis. Wageningen University.

Scheinberg A. (2012) Informal sector integration and high performance recycling: Evidence from 20 cities. Women in Informal Employment Globalizing and Organizing (WIEGO), Manchester 23.

Scheinberg A, Nesić J, Savain R, et al. (2016) From collision to collaboration-Integrating informal recyclers and re-use operators in Europe: A review. Waste Management and Research 34: 820-839.

Scheinberg A and Simpson MH. (2015) A tale of five cities: Using recycling frameworks to analyse inclusive recycling performance. Waste Management and Research 33: 975-985.

Scheinberg A, Simpson MH, Gupt Y, et al. (2010a) Economic aspects of the informal sector in solid waste management; WASTE, SKAT, and city partners for GTZ (Deutsche Gesellschaft furTechnische Zusammenarbeit) and CWG (Collaborative Working Group on Solid Waste Management in Lowand middle-Income Countries) Eschborn, Germany.

Scheinberg A, Spies S, Simpson MH, et al. (2011) Assessing urban recycling in low-and middle-income countries: Building on modernised mixtures. Habitat International 35: 188-198.

Scheinberg A, Wilson DC and Rodić L. (2010b) Solid waste management in the world's cities. UN-Habitat's State of Water and Sanitation in the World's Cities Series. Newcastle-onTyne, UK: Earthscan.

Schübeler P, Wehrle K and Christen J. (1996) Conceptual framework for municipal solid waste management in low-income countries: SKAT (Swiss Center for Development Cooperation), St. Gallen, Switzerland.

Sembiring E and Nitivattananon V. (2010) Sustainable solid waste management toward an inclusive society: Integration of the informal sector. Resources, Conservation and Recycling 54: 802-809.

Serrona KRB, Yu J, Aguinaldo E, et al. (2014) Developing a monitoring and evaluation framework to integrate and formalize the informal waste and recycling sector: The case of the Philippine National Framework Plan. Waste Management and Research 32: 882-895.

Silva de Souza Lima N and Mancini SD. (2017) Integration of informal recycling sector in Brazil and the case of Sorocaba City. Waste Management and Research 35: 721-729.

Soós R, Whiteman AD, Wilson DC, et al. (2017) Operator models for delivering municipal solid waste management services in developing countries: Part B: Decision support. Waste Management and Research 35: 842-862.

Soós R, Whiteman AD, Wilson DC, et al. (2013) Operator Models. Respecting Diversity: Concepts for Sustainable Waste Management. Eschorn: (Deutshe Gesellchaft fúr Zusammenarbeit) GIZ GmbH.: GIZ.

Tilaye M and Van Dijk MP. (2014) Private sector participation in solid waste collection in Addis Ababa (Ethiopia) by involving micro-enterprises. Waste Management and Research 32: 79-87.

Tot B, Vujić G, Srđević Z, et al. (2017) Group assessment of key indicators of sustainable waste management in developing countries. Waste Management and Research 35: 913-922.

Tue NM, Goto A, Takahashi S, et al. (2016) Release of chlorinated, brominated and mixed halogenated dioxin-related compounds to soils from open burning of e-waste in Agbogbloshie (Accra, Ghana). Journal of Hazardous Materials 302: 151-157.

Tue NM, Matsushita T, Goto A, et al. (2019) Complex Mixtures of Brominated/Chlorinated Diphenyl Ethers and Dibenzofurans in Soils from the Agbogbloshie e-Waste Site (Ghana): Occurrence, Formation, and Exposure Implications. Environmental Science \& Technology 53: 3010-3017. 
Tunesi S and Gorelick J. (2018) Solutions design for solid waste management: A guidebook to an effective method for low and middle-income countries and cities.

UNEP. (2018) Africa Waste Management Outlook. United Nations Environment Programme, Nairobi, Kenya. Available at: http://hdl.handle.net/20.500.11822/25514.

Valencia M. (2019) Informal Recycling Sector (IRS), Contribution to the Achievement of the SDGs, and a Circular Economy. In: Filho WL (ed) Responsible Consumption and Production, Encyclopedia of the UN Sustainable Development Goals. Switzerland: Springer Nature.

Van de Klundert A, Anschütz J and Scheinberg A. (2001) Integrated sustainable waste management: the concept. Tools for decision-makers. experiences from the urban waste expertise programme (19952001). Integrated sustainable waste management: the concept. Tools for decision-makers. experiences from the urban waste expertise programme (1995-2001). WASTE.

Van de Klundert A and Muller M. (1998) Community based waste collection and small scale enterprise development in waste recycling in Dar es Salaam. WASTE, The Netherlands.

Velis CA. (2017) Waste pickers in Global South: Informal recycling sector in a circular economy era. Waste Management and Research 35: 329-331.

Velis CA. (2018) No circular economy if current systemic failures are not addressed. Waste Management and Research 36: 757-759.

Velis CA, Wilson DC and Cheeseman CR. (2009) 19th century London dust-yards: A case study in closedloop resource efficiency. Waste Management 29: 1282-1290.

Velis CA, Wilson DC, Rocca O, et al. (2012) An analytical framework and tool ('InteRa') for integrating the informal recycling sector in waste and resource management systems in developing countries. Waste Management and Research 30: 43-66.

Voorberg WH, Bekkers VJ and Tummers LG. (2015) A systematic review of co-creation and co-production: Embarking on the social innovation journey. Public Management Review 17: 1333-1357.

White P, Dranke M and Hindle P. (2012) Integrated solid waste management: a lifecycle inventory: Springer Science and Business Media.

Whiteman AD, Smith P and Wilson DC. (2001) Waste management: an indicator of urban governance. Proceedings of UN-Habitat Global Conference on Urban Development. New York.

Wilson DC. (2007) Development drivers for waste management. Waste Management and Research 25: 198207.

Wilson DC, Araba AO, Chinwah K, et al. (2009) Building recycling rates through the informal sector. Waste Management 29: 629-635.

Wilson DC, Kanjogera JB, Soós R, et al. (2017) Operator models for delivering municipal solid waste management services in developing countries. Part A: The evidence base. Waste Management and Research 35: 820-841.

Wilson DC, Rodić L, Cowing MJ, et al. (2015a) 'Wasteaware' benchmark indicators for integrated sustainable waste management in cities. Waste Management 35: 329-342.

Wilson DC, Rodić L, Modak P, et al. (2015b) Global waste management outlook: UNEP.

Wilson DC, Rodić L, Scheinberg A, et al. (2012) Comparative analysis of solid waste management in 20 cities. Waste Management and Research 30: 237-254. 
Wilson DC, Velis CA and Cheeseman CR. (2006) Role of informal sector recycling in waste management in developing countries. Habitat International 30: 797-808.

Wilson DC, Velis CA and Rodić L. (2013) Integrated sustainable waste management in developing countries. Proceedings of the Institution of Civil Engineers-Waste and Resource Management 166: 5268.

Wilson DC, Whiteman AD and Tormin A. (2001) Strategic Planning Guide for Municipal Solid Waste Management, Washington: World Bank.

World Bank. (2004) Ghana-Second Urban Environmental Project, Project Appraisal document.

World Bank. (2019) GNI per capita, Atlas methods (current US\$). Available at: https://data.worldbank.org/ indicator/ny.gnp.pcap.cd.

World Bank and Accra Metropolitan Assembly. (2010) City of Accra, Ghana: Consultative Citizen's Report Card. Washington DC: World Bank.

World Bank Group. (2018) Municipal Solid Waste Management: A Roadmap for Reform for Policy Makers, Washington, DC. Available at: https://openknowledge.worldbank.org/handle/10986/30434.

Worrell WA and Vesilind PA. (2011) Solid waste engineering: Cengage Learning.

Zabaleta I and Rodić L. (2015) Recovery of essential nutrients from municipal solid waste-Impact of waste management infrastructure and governance aspects. Waste Management 44: 178-187.

Zurbrügg C, Caniato M and Vaccari M. (2014) How assessment methods can support solid waste management in developing countries—a critical review. Sustainability 6: 545-570. 


\section{Valorisation Addendum}

The present dissertation describes how participatory action research processes and coordinated cooperation between researchers, municipalities and relevant stakeholders can lead to the development and implementation of locally appropriate interventions towards solid waste modernisation in cities of developing countries. This section provides an overview of the scientific and societal impacts of the work presented in this thesis. This will be discussed in terms of the relevance of the main findings, the target group, the products and implications for future results.

\section{Relevance}

Solid waste management has become an essential responsibility of city mayors and national governments across nations and continents. It is considered as an indicator of good governance (Whiteman et al., 2001). Simply put, where there is good governance, solid waste is managed sustainably to protect public health, promote environmental friendliness and conserve resources. Perhaps the opposite holds true that no one takes the government of a city seriously when their solid waste is all over the place. Today, at a time when most developed country cities have transformed their solid waste management system into a combination of environmentally controlled sinks and facilitated resource management, most cities in developing economies are still grappling with poor environmental control, moderate collection coverage and low recycling rates.

While projections of higher population growth and urbanisation stare these cities in the face (Cohen, 2006; Kaza et al., 2018), transfer of unsustainable technologies, weak technical capacities, weak governance systems and international interferences (Marshall and Farahbakhsh, 2013; Cossu et al., 2019) are gradually diminishing the institutional space within which professional staff and decision-makers can explore real local solutions to their solid waste management challenges. Cities like Accra, Ghana in Sub-Saharan Africa are facing a chronic lack (or absence) of data for system planning, nor is there any evidence of the conventional top-down approach of information gathering closing reliable data gaps (UNEP, 2018).

Addressing these challenges are necessary and urgent; for this reason, moving away from technologically-oriented and top-down approaches which have proven a failure for more than three decades to participatory action research-oriented and locally appropriate options is worth trying. 
The findings and positive outcomes in the physical components and the governance aspects of Accra's solid waste management have proved to be a game-changer in the local context, and could improve the prospects for sustainable solid waste modernisation across lower and middle-income cities of developing countries in Africa and other continents. The positive outcomes are as a result of a deliberate, coordinated, and orchestrated cooperation of researchers, municipalities and decision-makers at developing, implementing and evaluating locally responsive interventions to modernise the city's municipal solid waste management system.

\section{Scientific Relevance and Products}

This dissertation follows and documents research based upon an innovative methodological approach which is rarely used in the solid waste management system of lower-middle income countries. The findings show that the use of participatory action research methods, based on the integrated sustainable waste management analytical framework and stakeholder working groups (first institutionalised in the ERM-UK World Bank Strategic Planning Guide (Wilson et al., 2001) can significantly improve results. The resulting process, comprising co-operation between researchers, solid waste managers, informal waste sector actors and other relevant stakeholders, can serve to:

- assess systems and create a baseline (Chapter 2);

- develop, prioritise, implement and evaluate locally appropriate interventions (Chapters 3 and 4);

- replace the current poor solid waste management systems (Chapter 2) with modernised alternatives (Chapter 4);

- close chronic and predictable data gaps, strengthen competencies and capacities, empower stakeholders, improve inclusive governance, and win decision-makers commitment towards the attainment of the SDGs and the circular economy (chapter 5), and

- create an entry point for development partners and not-for-profit organisations to intervene and support the solid waste management systems of Ghana and other developing countries in ways which are locally appropriate, and acknowledge and respect the parts of the system that are already working (Chapter 6).

The outcome of the processes documented in this dissertation can be attributed to the commitment of a working group of stakeholders who were guided to transparently assess the existing solid waste management system and develop locally appropriate interventions to implement them and evaluate their responsiveness to system modernisation. 
The changes and relative success achieved through their efforts can be seen in the following innovative results, also covered in this dissertation, including but not limited to:

- The engagement of the informal service providers to improve upon municipal solid waste collection coverage and strengthen livelihoods;

- the drafting and implementation of a new five-year (2016-2021) fee- and performance-based municipal solid waste collection franchise agreement between the municipality and the formal solid waste service providers;

- the closing of all known unapproved dumpsites within the city of Accra to prevent illegal dumping of solid waste by the informal waste collectors;

- the facilitation for the subsequent construction of two bulk transport stations to receive the collected waste of the informal waste collectors;

- the registration of all known informal service providers in Accra and embossment of their tricycles as initial processes towards their integration into the formal solid waste management system; and

- the closing of data gaps and estimation of the socio-economic contribution of informal value-chain activities in the management of both municipal solid waste and waste of electrical and electronic equipment

The commitment and willingness of the working group to make amendments where necessary made the implementation of interventions locally appropriate and cheaper than normal.

\section{Socio-economic relevance and dissemination of results}

The author of this dissertation and his collaborators have designed most of the interventions for system modernisation documented here based on the concept of inclusive governance. This has led to an improvement in the frequency and consistency with which service users and service providers are involved in planning and decision making. Moreover, most of the interventions had the informal service providers as the focus and this has been of tremendous benefit to the sector and to their service clients and value chain customers. The dynamics of the informal waste and recycling sector has shifted from rejection to recognition and the working group is still developing an action plan for their eventual integration into the municipal solid waste management system of the city of Accra and the other 24 municipalities.

The active participation of the informal waste sector in the implementation of the studies documented in this dissertation has shown to be saving the 25 municipalities within the greater Accra region US\$20 million in annual operational expenses. The registration of 
the informal service providers and the recording of same on a Microsoft Access database in Accra has been a best example to the other neighbouring municipalities in their efforts towards organising of the informal waste sector within their jurisdictions.

The dissemination of the methodological approaches and findings through seminars, conferences and publication in peer-reviewed journals and edited books has contributed to the winning of a small grant from the C40 Climate Leadership Group, a not-forprofit organisation, to support the working group to carry out a municipal solid waste characterisation and landfill emissions measurement study; under the project theme: "Empowering Cities with Data" towards the development of a climate change action policy for the city of Accra. The characterization study, which commenced in July 2019 and is expected to end in June 2020 is geared towards further closing of data gaps and the development of a climate change action plan for the city of Accra. The author of this dissertation and his collaborators are in touch with Women In Employment Globalising and Organising (WIEGO) to assist them identify a possible point for entry towards the support and training of the informal waste sector as part of the integration process.

Most importantly, the studies in this dissertation has contributed to the city of Accra being a recipient of the 2019 C40 Cities Bloomberg Philanthropies Award organised in New York on $11^{\text {th }}$ October 2019. Accra received an award on citizen's engagement and the project was on informal waste collection expansion and livelihood creation (Chapters 3 and 4 of this dissertation). 


\section{Summary}

Increasing population, urbanisation and the resulting increase in solid waste generation is of great concern in cities of emerging economies such as Ghana. This concern has grown in proportion both to the related natural resources depletion and climate change occasioned by the chronic failure of institutions in such cities to adopt sustainable approaches to modernise their solid waste management systems.

Despite various attempts and support from development partners, cities like Accra, Ghana, have for more than four decades been struggling to increase solid waste collection coverage, improve disposal systems, and divert recyclables from disposal. Solid waste governance systems have more often than not be characterised by weak institutions, lack of realistic policy and legal frameworks; and the absence of inclusive governance and financial sustainability principles. Finding locally appropriate pathways towards the modernisation of the solid waste system of such cities is a necessity and of urgent importance.

The field studies and participatory action research approaches reported in this thesis are based on four and a half years of consultation with relevant stakeholders to deliver an improved solid waste management system, upgrade physical system elements and modernise governance aspects to be more open and inclusive. The main goal of the research presented in this thesis has been to understand the Ghana SWM system and chart a potential pathway for sustainable modernisation that is rooted in local circumstances and jointly created by multiple actors. Stakeholders acting as working groups have assessed the solid waste management system, developed, prioritised, implemented and evaluated locally appropriate interventions using the integrated sustainable waste management analytical framework as a lens to modernise the system.

In Chapter 1, the solid waste management system operating in the city of Accra at the time of writing, is briefly compared with city solid waste management in other developing country cities, to bring out some of the challenges faced by these cities as reported by the scholarly literature. The drivers and history of solid waste management, especially in the developed countries of Europe and North America, are also presented. This is followed by the chronology of events in solid waste management in Ghana before, during, and after British colonial rule. A comprehensive description of the research objective and approach including an overview of the participatory action research method adopted for this dissertation is then outlined. A brief outline of the analytical framework (Integrated Sustainable Waste Management) used and a narrative/linkage of the various studies/ chapters follow. Finally, the connection is made to the goals, rationale, and the research 
questions behind each of the studies within this dissertation. The chapter ends with an outline of the various studies.

Chapter 2 describes the performance assessment of the municipal solid waste management system as seen through the lens of the integrated sustainable waste management (ISWM) framework. This assessment of Accra's performance in the physical components (collection treatment and controlled disposal, and resource management) and the governance aspects (user and provider inclusiveness, financial sustainability, and sound institutions and pro-active policy) of municipal solid waste management was undertaken by 24 relevant stakeholders divided into three working groups that met and worked together for a period of nine months. Each working group was composed of a mix of researchers, waste managers, local government officials, environmental protection agency representatives, development planners, service beneficiaries, gender groups, NGOs, academics, informal waste sector actors and private solid waste company representatives. Each working group had one physical and one governance indicator to assess against the backdrop of a checklist developed in relation to the requirements of the analytical framework.

Accra was found to be performing at a low to moderate level in most of the indicators. The use of the working groups and the participatory action research approach was useful in promoting transparency, fairness, ownership of results and a better understanding of what was working within the system and what needed fixing. It also proved successful in subsequent studies and also in practice by creating local support to facilitate locally appropriate intervention development, implementation and evaluation. This approach has been successful in Accra, Ghana, and would be suitable for other cities and regions of developing economies, especially of Sub-Saharan Africa.

Chapter 3 presents the results of an intervention developed by the working group to increase collection coverage in Accra by supplementing failing formal systems with the entrepreneurs working in informal channels. This was necessary after the initial assessment showed that collection coverage along formal channels was only $60 \%$. The working group had planned initially to seek improvements through interventions in the formal system, but this was seen as less appropriate after the group evaluated the performance of the formal service providers based on an existing fee- and performancebased franchise agreement between them and the municipality of Accra. The formal service providers had failed in many of their obligations, a key reason for the working group to focus interventions on supporting and incorporating the informal service providers. The challenge for the working group was how to involve a sector that had no official recognition, no contract with the city, and whose activity was considered illegal and perceived as a nuisance. 
The working group, which had both representation of the formal and informal service providers as members, took difficult decisions that challenged the hegemony of existing agreements, and convinced the formal service providers to retain their informal counterparts/competitors as sub-contractors, in addition to supporting them with tricycles on hire purchase for at least two years to help increase solid waste collection coverage especially in low income areas of their service zones. This was an unusual intervention, but faced with poor performance and also with a survey results which pointed to service user dissatisfaction with the formal contractors, the working group found themselves forced to develop new compromises. They developed a framework that called for the involvement and support of the informal entrepreneurs to further unleash their full potential towards collection coverage improvement in the city. Low and lowermiddle income cities and municipalities can learn lessons from such interventions, not only to promote public health but also to strengthen livelihoods for the large informal waste sector depending on the opportunities at the margins of the formal system, to make a living.

Chapter $\mathbf{4}$ discusses results of attempts aimed to further push for the official recognition of the informal service providers, by assessing their socio-economic contribution and also evaluating system improvements two and half years after their inclusion in the solid waste service delivery of the city of Accra. The aim was to collect data and evidence to: (1) evaluate the system to measure whether their inclusion had brought about significant improvement in the physical and governance indicators, and (2) further support informal service provider integration into the formal solid waste management system. The working group used the WasteAware benchmark indicators of the integrated sustainable waste management (ISWM) framework as the lens to evaluate the improvements. The working group further used interviews, questionnaire administration, field visits, and focus group discussions to collect information to estimate the socio-economic contribution of the informal service chain actors.

The results of this assessment were clear and dramatic. There has been significant improvement in all the three physical components and marginal improvement in the governance indicators. These findings confirmed the importance of inclusive governance and a positive example of locally appropriate and sustainable waste management modernisation for low and lower-middle income cities of developing countries. Using these two pieces of evidence, the working group won the commitment of decision-makers to register all known informal service providers (720 in number and a more than $100 \%$ increase from earlier numbers), and emboss their tricycles with municipal identification stickers' at no cost to them as part of the initial processes for their integration. 
The study discussed in Chapter $\mathbf{5}$ also made use of participatory action research processes to close data gaps, promote inclusive governance and map appropriate pathways towards the integration of both the informal solid waste service- and value-chain actors, but now in all 25 municipalities of the greater Accra Metropolitan area. The working group included the informal value chains and the 25 municipalities as a pre-condition to further win the total commitment and support of decision-makers towards the integration of the informal sector. The working group appraised the activities and the socio-economic contribution of the informal waste sector in the 25 municipalities and mapped the process flow of solid waste collection, recovery and recycling by the sector. The group used the results as a basis to address the peculiar challenge of cities in developing countries, and to open a pathway towards the integration of the informal recycling sector. The positive findings of this study provide valuable lessons and an emerging best practice towards informal sector integration and inclusive governance for all developing country cities, especially towards the attainment of the sustainable development goals (SDGs) and the circular economy policy initiatives.

In chapter 6, the working group expanded the scope of the study from municipal solid waste and the 25 municipalities to include all types of solid waste and the country as a whole. The aim was to discuss the realities of solid waste management as currently existing in Ghana and further use the experiences and positive examples of the working group, the participatory action research approach, and the findings of the previous four studies as a basis to recommend a pathway that has the potential to address the numerous challenges of solid waste management in Ghana.

The working group has used a combination of literature review, participatory assessments of the six metropolitan cities of the country, and the outputs of the four year study to discuss the nexus of system failure and relative success in the management of e-waste, industrial solid waste, construction and demolition waste, agricultural waste, waste from healthcare centres and municipal solid waste. The chapter describes the policy, legal and institutional challenges of SWM in the country and argues that a pathway of coordinated cooperation between academia, research institutions and municipalities situated on the integrated sustainable waste management concept and participatory action research stands the higher chance towards system modernisation and sustainability.

Finally, chapter 7 of this thesis presents the most important findings from the studies undertaken, and puts them in a broader perspective. The chapter also presents methodological strengths and limitations of the dissertation and provides recommendations for future research especially relating to potential challenges in the usage of participatory action research processes within municipalities of developing countries, with an emphasis on English-speaking Sub-Saharan Africa. Most importantly 
the chapter discusses the perceived shortcomings of the applicability of the WasteAware indicator framework in benchmarking the solid waste of cities of emerging economies, and suggest modifications for consideration by the scientific community of practice.

The most important conclusion drawn from the activities and interventions forming the basis for this thesis is that coordinated cooperation between higher educational or research institutions, municipalities and relevant stakeholders has a higher potential to close chronic and reliable data gaps; to strengthen human resource capacities and competencies; to promote inclusive governance; to develop locally appropriate interventions and create ownership of same, to empower municipalities to implement, monitor and evaluate developed interventions towards the modernisation of solid waste management systems in Ghana and similar developing countries.

The commitment of the stakeholders as working groups using participatory action research processes seems an appropriate method to create transparency, accountability and trust during assessments and implementation of interventions. Above all the timely presentation and sharing of results becomes an advocacy tool to further win the commitment of decision-makers towards a continuous system improvement and sustainability; and an entry point for support from development partners. 


\section{Acknowledgements}

"As we express our gratitude, we must never forget that the highest form of appreciation is not to utter words, but to live by them". John F. Kennedy

During the process of writing this thesis, many people have contributed and supported me in various ways. This is the time to acknowledge and thank them for their support.

First my promoter, Nanne de Vries, the vice-dean of the Faculty of Health, Medicine and Life Sciences (FHML) of Maastricht University. I am grateful for your time, guidance, encouragement and support throughout this journey. You have contributed immensely to improve my research capabilities and writing skills within these years.

Anne Scheinberg, my daily supervisor, has been a bulwark to rely on for guidance, insight and support throughout these years. Anne, the circumstances in getting you on board to support the writing of this thesis, your constructive criticism and your desire to make me a better researcher would never be forgotten. I know without any prejudice, that it would have been difficult for me without you on board. I am and shall always be grateful to you.

Abraham Afful, my research assistant, made such a difficult choice to work with me even at the expense of other viable options. Together we have learnt a lot along this journey and there may be a lot more to do together.

Heinz G. M. Greijn and his former colleague Hennie, of the Maastricht University Centre for International Cooperation in Academic Development (MUNDO) facilitated the activities and processes under the Netherlands Organisation for International Cooperation in Higher Education (NUFFIC) Project (NICHE 194-204) that brought me to Maastricht University in the first place. Their commitment to work and Heinz's unique desire to facilitate all my travels both to Maastricht and to conferences abroad are still fresh in my mind. You always tried all you can to make me feel at home whenever I travelled to Maastricht. I cherish your support and hope you extend same to all people.

I received financial support from the NUFFIC for all the studies within this thesis to which I am grateful. I also appreciate the support of the University of Cape Coast whenever I was due to visit Maastricht.

Patricia, Kim, Leon, Sandra, Hannerieke; all of CAPHRI, Maastricht University. I call your support as "behind the scenes", but the eagerness with which you render these 
services and support systems is what makes the difference. You facilitated my work at the Department of Health Promotion and made me feel comfortable at the workplace. Thank you and please keep on doing what you know doing best.

To the head, lecturers, researchers and colleagues at the Department of Health Promotion, CAPHRI, Maastricht University, I wasn't always around during interaction programs, but your presence in your various offices working towards your varied goals and expectations motivated me to carry on with mine. Thank you all also for offering a hand of support when the need arose.

To my colleagues at the University of Cape Coast, thank you for your support and companionship throughout these years. The journey has been long and difficult, but it has been worth the travel.

Alfred Oko Vandepuije and Mohammed Nii Adjei Sowah, the former and current mayor of the city of Accra. Your approval, support and commitment to commence the studies and agree to the implementation of the findings in this dissertation is what has brought me this far. I look forward to working with you to continuously and systematically contribute to the modernisation of the solid waste management system of Accra. I am proud to be part of the success story of the city of Accra in cleanliness, citizen engagement and livelihood creation.

Anthony Mensah, the director of Sanitation at the Ministry of Sanitation and Water Resources; Solomon Noi and Victor Neequaye Kotey, the head and deputy head of the Waste Management Department of the Accra Metropolitan Assembly (AMA); Julius Azumah, the director of Administration at the AMA. It was you who bought into this idea of participatory action research and locally appropriate interventions. You championed its cause, facilitated the identification/invitation of stakeholders and the formation of working groups, and hosted this research at the Waste Management Department even until now. Your contribution may be the seed that grows to bridge the gap between academic research and industry in the field of solid waste management in Ghana. I hold you all in high esteem.

Immanuel Nartey Tokoli, the director of Jekora Ventures Limited, a private solid waste management company. Your corporate support and contribution to data collection in the first study made a big difference. Your workers are the few diligent ones I encountered in the cause of this thesis. Accept my thanksgiving and continue to support the working group to improve the system. 
John Bosco Avom, Tetteh Kemey and Lydia Bamfo, all of the informal waste sector in the greater Accra region of Ghana. You facilitated our working collaboration with the sector. Your immense contribution towards the activities of the working group will never be forgotten. You know we are not done yet, there is more to do towards the complete integration of the sector into the system. Your work, apart from creating livelihoods is critical to Ghana's attainment of the SDGs and the circular economy.

To Pastor Benjamin Odetola and the Church family in Maastricht, I shall ever be grateful to you for care and support. Your efforts contributed to making my stay a pleasant one in Maastricht. There is a reward for good deeds and the giver would bestow it in due time. Our friendship will definitely not end with the completion of this dissertation.

To the Church family back in Ghana, I am grateful for your prayers and show of support to the family I always left behind to travel to Maastricht.

Angenies Brandenburg of Van Heylerhoflaan 11 was my landlady for most parts of my stay in Maastricht. I am grateful to you for providing a place I call home away from home. Your interest in seeing my progression in the course of study is much appreciated.

To my parents, Samuel Oduro Brobbey and Comfort Frimpomaah, this dissertation is just one of the outcomes of your investment in my education. Your words of encouragement during the writing of the thesis still ring in my ears. To my brothers, sisters, nephews, nieces, cousins and their families, I appreciate your support and friendship. I hope the family will agree with me to dedicate Chapter 6 of this dissertation to the memory of my nephew, Joseph Okai Afrane.

To my wife, Gifty Oduro-Appiah, I don't know how to say it differently. Ethically it is wrong to add your name as a contributor to this dissertation, but between you and me, there is no doubt that you are a major contributor. I hope dedicating this thesis to you and our children: Frimpomaah, Konamah and Kofi may be a good rationale for the extent of your support. Help offered when one is in need is what really matters. You have really demonstrated your love throughout these years. I love you.

To the people who supported me in various ways but whose names have not been mentioned in here, please bear in mind that I am grateful.

Finally to the unseen God, whom I believe looks into the affairs of mankind on this earth, I am grateful for life, strength, good health, protection, guidance and travelling mercies throughout these years. Accept my thanksgiving and continue to sustain me in this life. 


\section{Curriculum Vitae}

Kwaku Oduro-Appiah was born on March 23, 1977 in Asonomaso in the Ashanti region of Ghana. After graduating from his ordinary and advanced secondary education (1989-1996) at Osei Kyeretwie Secondary School, he was offered the opportunity to study Geological Engineering (1997-2001) at the now Kwame Nkrumah University of Science and Technology (KNUST) for his bachelors. He graduated in 2001 with a major in Geotechnical Engineering.

During his national service in 2002 at the same University, He was offered admission to the University of Stuttgart (2003-2005) Germany to study WASTE (Air Pollution Control, Solid Waste and Wastewater Process Engineering). He graduated successfully and was awarded a Master of Science (M.Sc. WASTE) in March 2006.

He returned to Ghana to work with the Waste Management Department of the Accra Metropolitan Assembly (2006-2008) and was responsible for landfills and the Urban Environmental Sanitation Project (UESP). He contributed to the development of the first ever franchise agreement (Fee- and performance-based solid waste collection) between the Accra Metropolitan Assembly and the formal solid waste collection service providers.

He has since February 2008 being working as a lecturer of solid waste and wastewater management at the Department of Water and Sanitation of the University of Cape Coast (UCC). He was the coordinator of the Water and Sanitation Programme of the UCC from 2012 to 2015 and also the coordinator of the Netherlands Organisation for International Cooperation in Higher Education (NUFFIC) project (NICHE 194-204) between the University of Cape Coast and the Netherlands from 2014 to 2016.

In January 2015, He started his $\mathrm{PhD}$ Studies in Maastricht University, the Netherlands on split-site as part of the staff development component of the NUFFIC Project. The studies focused on locally appropriate interventions and evidence-based pathways for solid waste modernisation within Accra, Ghana. He is expected to defend his PhD Dissertation in 2020.

He is married to Gifty Oduro-Appiah with three children; Frimpomaah, Konamah and Kofi Oduro-Appiah. Kwaku Oduro-Appiah can be contacted though +233209333876 and koduro-appiah@ucc.edu.gh 


\section{Publication List}

\section{Publications presented in this thesis}

Kwaku Oduro-Appiah, Anne Scheinberg, Kodwo Miezah, Anthony Mensah and Nanne de Vries (2020). Existing realities and sustainable pathways for solid waste management in Ghana. In A. Pariatamby, F. Shahul Hamid \& M. S. Bhatti (Eds.), Sustainable waste management challenges in developing countries (115-143) Hershey, Pennsylvania (PA).

Kwaku Oduro-Appiah, Abraham Afful, Victor Neequaye Kotey and Nanne de Vries (2019). Working with the informal service chain as a locally appropriate strategy for sustainable modernisation of municipal solid waste management systems in lowermiddle income cities: Lesson from Accra, Ghana. Resources 8 (12): 1-16.

K. Oduro-Appiah, A. Scheinberg, A. Mensah, V. Kotey, A. Afful, \& N. de Vries (2017). Locally responsive intervention to improve municipal solid waste collection in Accra, Ghana. In Proceedings of the $40^{\text {th }}$ WEDC International Conference, Paper 2713, Loughborough, UK, $24^{\text {th }}$ July, 2017.

Kwaku Oduro-Appiah, Anne Scheinberg, Anthony Mensah, Abraham Afful, Henry Kofi Boadu and Nanne de Vries (2017). Assessment of the municipal solid waste management system in Accra, Ghana: A 'Wasteaware' benchmark indicator approach. Waste Management \& Research 35(11): 1149-1158.

Kwaku Oduro-Appiah, Anne Scheinberg, Abraham Afful, and Nanne de Vries (submitted). The contribution of participatory engagement strategies to reliable data gathering and inclusive policies in developing countries: Municipal solid waste management data in the greater Accra metropolitan area of Ghana.

\section{Other publications}

Kwaku Oduro-Appiah and Bernard Ebo Aggrey (2013). Determinants of source separation of municipal solid waste in developing countries: The case of Ghana. Journal of Sustainable Development in Africa, 15 (1520-5509), 47-60.

Kwaku Oduro-Appiah, Daniel Ohene Aidoo and Graham Sarbah (2013). Feebased solid waste collection in economically developing countries: The case of Accra metropolis. International Journal of Development and Sustainability, 2(2), 629-639. 
Kwaku Oduro-Appiah, Thomas Atteh Donkor and Kwame Agyei Ampim-Darko (2013). Sustainability of sanitary landfill management in Sub-Saharan Africa: The case of Ghana metropolis. International Journal of Development and Sustainability, 2(3), 1937-1952. 


\section{Abbreviations}

ACARP Accra Compost and Recycling Plant

AMA Accra Metropolitan Assembly

EPA Environmental Protection Agency

EPR Extended Producer Responsibility

GAMA Greater Accra Metropolitan Assembly

ILO International Labour Organisation

ISPs Informal Service Providers

IRCs Informal Recyclable Collectors

IRECOP Integrated Recycling and Composting Plants

ISWM Integrated Sustainable Waste Management

IWM Integrated Waste Management

IWS Informal Waste Sector

MBT Mechanical Biological Plant

MESTI Ministry of Environment, Science, Technology and Innovation

MMDAs Metropolitan, Municipal and District Assemblies

$\mathrm{MoH} \quad$ Ministry of Health

MSW Municipal Solid Waste

MSWM Municipal Solid Waste Management

NGO Non-Governmental Organisation

PAR Participatory Action Research

PFD Process Flow Diagram

PPP Public-Private Participation

PRA Participatory Research Appraisal

PSP Private Sector Participation

SDGs Sustainable Development Goals

SW Solid Waste

SWM Solid Waste Management

SWOT Strengths Weaknesses, Opportunities and Threats

UNEP United Nations Environment Programme

UN-Habitat United Nation Human Settlement Programme

WB World Bank

WEEE Waste of Electric and Electronic Equipment

WIEGO Women in Informal Employment Globalising and Organising

WMD Waste Management Department 



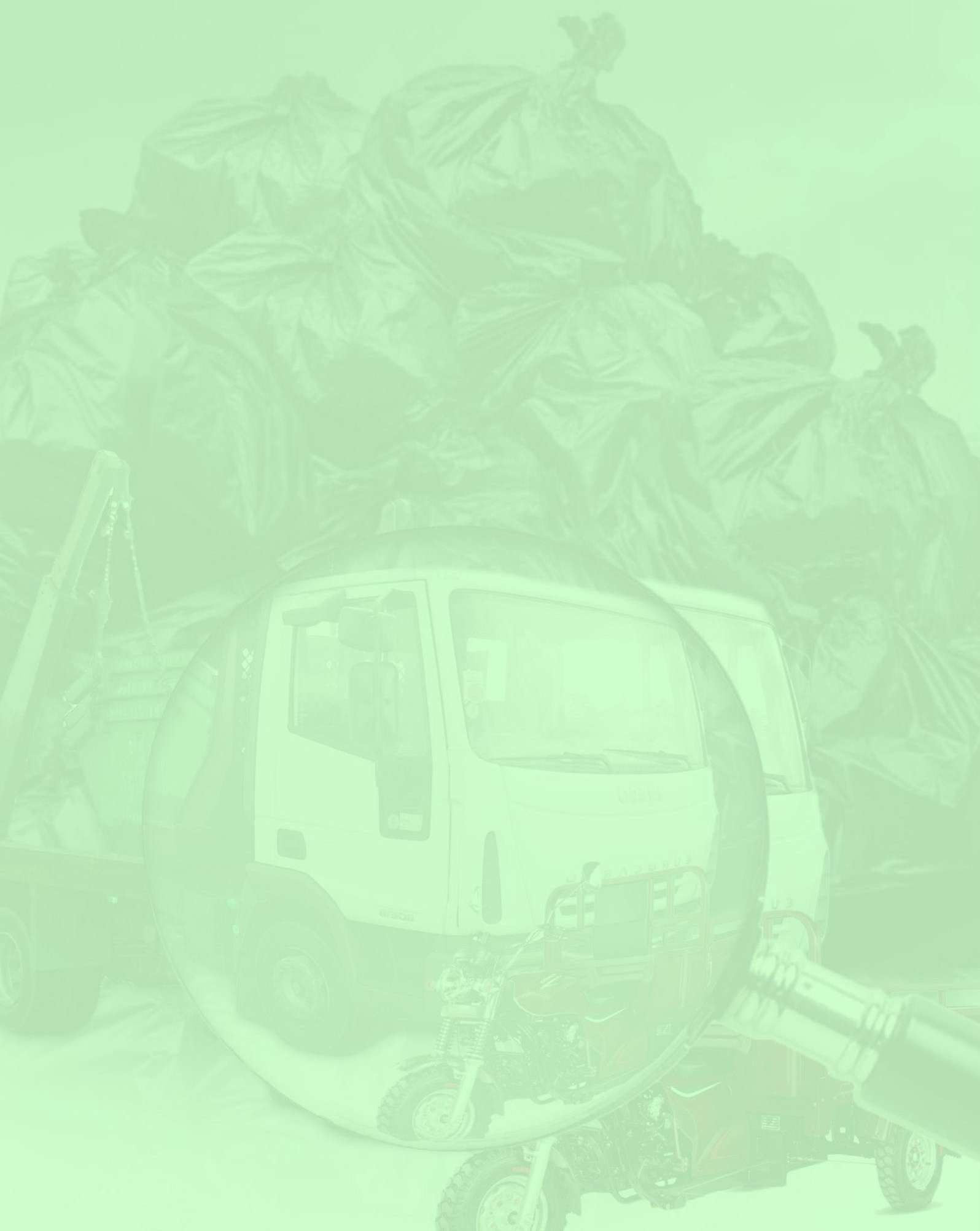

